\title{
Stanley Milgram's Obedience to Authority Experiments: Towards an Understanding of their Relevance in Explaining Aspects of the Nazi Holocaust
}

By Nestar John Charles Russell

A thesis submitted to the Victoria University of Wellington in fulfilment of the requirements for the degree of Doctor of Philosophy in Public Policy. 
Although the most common interpretation of Milgram's findings is that participants did not wish to harm the learner, the motives generated in this paradigm may well have been more mixed or ambivalent in many participants. Unfortunately, the manner in which people actually regard the act of punishing others when they make mistakes ... has been virtually ignored in discussions of the obedience research. However... harming is a widely accepted form of child discipline ... . Most people are hardly unequivocally opposed to the use of physical punishment under absolutely any circumstances. That a majority approve the use of capital punishment in this country [the United States] might serve as another illustration-Miller (2004, pp. 198-199).

... if humanity can survive the violence of our age, [our descendants] might consider us as late barbarians-Elias (1991, pp. 146-147). 


\section{Abstract}

Two leading Holocaust historians, Yehuda Bauer and Christopher Browning, have in recent years independently asked how so many ordinary Germans (most of whom in the 1930s had been moderately anti-Semitic) could become by the early 1940s willing murderers of Jews. Social psychologist, Stanley Milgram, had years before been interested in finding answers to similar questions, and to that end in the early 1960s carried out his widely debated "Obedience to Authority" (OTA) experiments at Yale University. Drawing on previously unpublished material from Milgram's personal archive at Yale, this thesis investigates how Milgram developed his research idea to the point where, by the time he ran his first official experiment, he was able to convert the majority of his ordinary subjects into torturers of other people. It is argued that Milgram's experiments were in themselves structured as a bureaucratic microcosm, and say less about obedience to authority, per se, than about the ways in which people in an organisational context resolve a pressing moral dilemma. The thesis uses insights gained from Milgram's experimental innovations to assist in answering the question posed by Bauer and by Browning, focusing on the Nazis' progressive development of mass killing methods, from 1941 to 1944, during Operation Barbarossa and Operation Reinhard. It is shown how these methods were designed to diminish perpetrators' perceptual stimulation, in order to make the "undoable" increasingly "doable", in ways that were later reflected in Milgram's development of his own experimental methodology. 


\section{Acknowledgements}

The completion of this thesis owes more than a great deal to the belief and scholarly influence of my primary academic supervisor Professor Bob Gregory. Bob is what I-and many other students — consider to be a "real academic": an independent thinker not afraid to take big risks on the not-so-impressive end of the potential $\mathrm{PhD}$ candidate spectrum. Bob's intellectual stamp is, of course, throughout the thesis. But it is most obvious in Chapter Nine, which extends into his specialist academic area of inquiry-the potentially destructive bureaucratic process. This chapter explores ideas and raises issues that, before meeting Bob, had never crossed my mind. I could easily go on in praise of Bob but, as modest as he is, I fear he'd tell me to settle down and to also "get off that high donkey". Thanks Bob.

I am also greatly indebted to my secondary supervisor, Holocaust historian Dr Simone Gigliotti of the History Programme, Victoria University of Wellington, who provided much needed advice in regard to this complex research area. Because Milgram's legacy dominates the thesis, there was little room left in which to explore the Holocaust. Therefore, I was unable to go into the kind of detail Simone would have preferred. But Simone directed me to the most obvious weaknesses and gaps in my use of this literature, and her insights and careful guidance have been invaluable.

The following were, in a variety of ways, of great help to me in the production of this thesis: Graeme Whimp, Dr Sara McFall, Margaret Nixon, Gina Perry, Professor Thomas Blass, Dr Sarah Anderson, Dr Judy Whitcombe, Jovian Parry, Doug Dixon, Dr Anna McKenzie, Katherine Hodge, Professor José Brunner, Sebastian Glende, Craig Elvidge, Tanja Rother, Dr Anne Phillips, and Dr Gabrielle Maxwell.

I would also like to thank the following people: Amanda Lynn, Dawn Yeabsley, Dr Chris Eichbaum, Lyne Todd, Maria Modig, Diane Kaplan (and her staff at Yale University), Professor Terry Stokes, Professor Gary Hawke, Dr Amanda Wolf, Dr Eva Beuselinck, Professor Omer Bartov, Professor Robert van Krieken, Jean-Christopher Somers, Barbara Gillespie, Francine McGee, Siamah Kaullychurn, Jessie Williams, Dr Trevor Bradley, Dr Douglas Lush, Wayne Pihema, Murdoch Stephens, Garoon Pongsart, Dr Mark Thornton, 
Robin O’Neal, Chris Boorman, Nick Sygrove, Rachael James, Craig Mills, Sally-Anne Bennett, Maureen Revell, Brenda Collver, Stephen Eames, Dee Jones, Zoe Lawton; Michelle Walmsley, and Jane Snaider.

Finally, thanks to Stacey, Gareth, Nick, Jason, Marty, and Lisa for the welcomed distractions and my family, Mum, Dad, Kelly, and Shelena, all of whom offered support when needed.

All responsibility for the content of this thesis rests with the author.

All correspondence to: nestar.russell@gmail.com 


\section{Table of Contents}

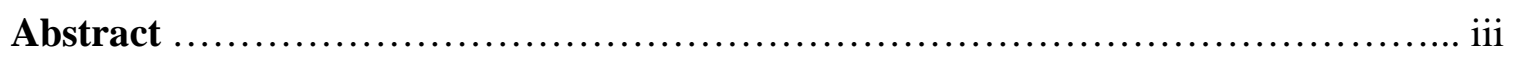

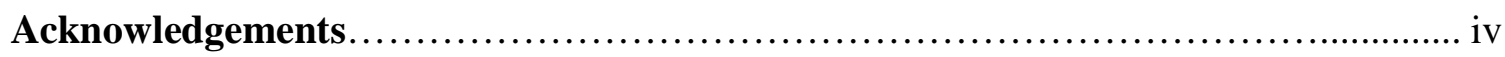

Table of Contents................................................................

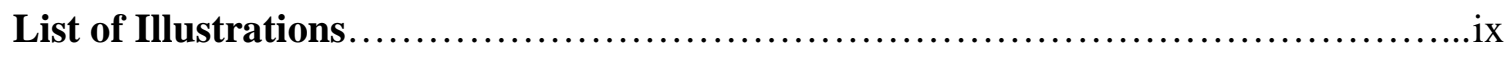

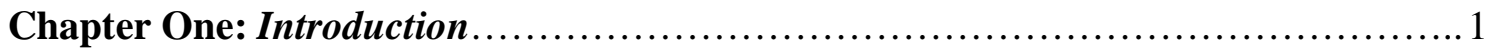

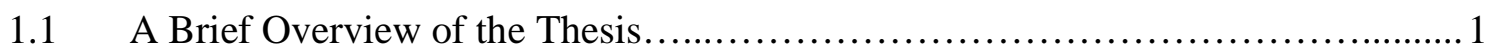

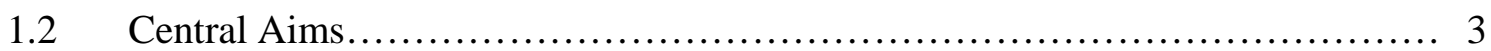

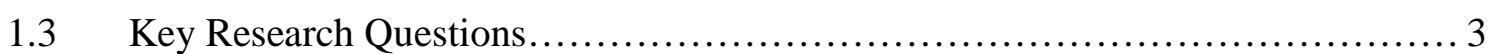

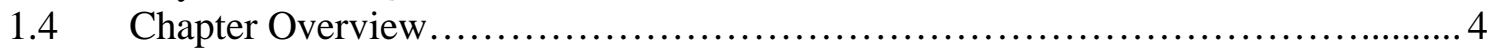

Chapter Two: Methodological Approach...................................... 6

2.1 The Author's Journey into the PhD Candidacy.................................... 6

2.2 Research Strategy and Sources of Data........................................ 8

2.3 Approach to Data-Collection................................................ 10

2.4 Data Analysis: Documentary Analysis and Case Studies............................. 11

Chapter Three: The Problem of "Ordinary Monsters" and the Holocaust-a

Review of the Literature ............................................................ 15

3.1 The Holocaust: a Brief Overview.......................................... 15

3.2 Introduction to the Problem of "Ordinary Monsters" ........................... 16

3.3 Stanley Milgram and the Obedience to Authority Experiments...................... 17

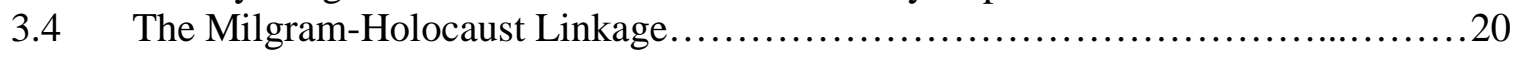

Chapter Four: The Development of Milgram's Obedience to Authority

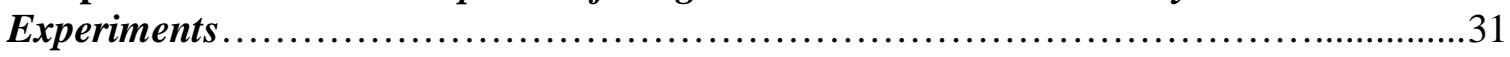

4.1 Stanley Milgram: Beginnings and Early Influences............................ 31

4.2 Harvard University and the Influence of Solomon Asch................................... 34

4.3 Milgram's PhD Thesis..................................................... 36

4.4 Milgram's Experience at Princeton: the Invention of the OTA

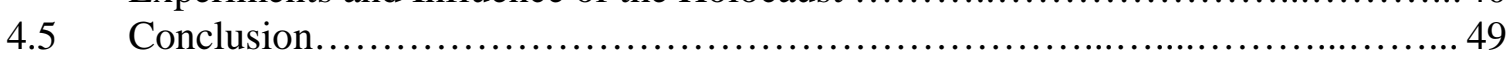

Chapter Five: How Milgram Induced Most Ordinary Subjects to Complete

the Obedience to Authority Experiments. 
$5.1 \quad$ The First Obedience to Authority Research Proposal............................50

5.2 First Pilot Study: the Winter Pre-tests 1960-61 ................................. 55

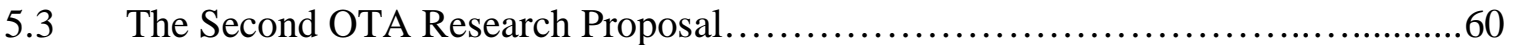

5.4 Second Pilot Series: Summer Pre-tests 1961 ............................................66 66

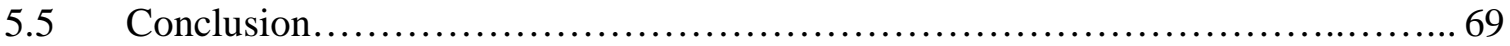

Chapter Six: The Obedience to Authority Research Programme and

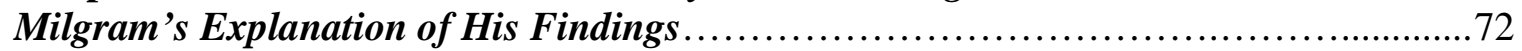

6.1 Further Variations and Controls: ad hoc Testing of Justifications...................75

6.2 Further Variations and Controls: Conditions Stimulated by Emerging

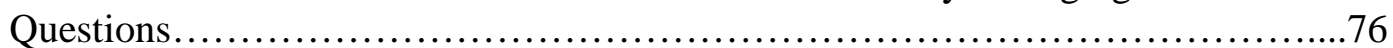

6.3 Further Variations and Controls: the Proximity of Authority Series.................... 80

6.4 The Role Permutations Series.............................................. 81

6.5 The Group Effects Series................................................. 83

6.6 Post-Experimental Contemplations on Theoretical Development.......................87

6.7 Milgram's (1974) Theory of Obedience.......................................... 91

6.8 Conclusion................................................................... 95

Chapter Seven: The Response of Academia to Milgram's Findings and

Explanation ....................................................................... 97

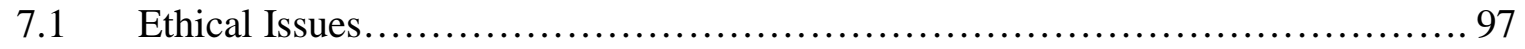

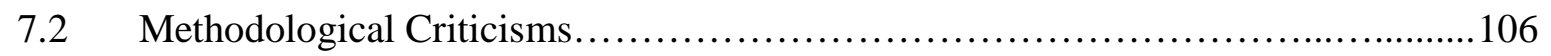

7.3 Generalisation: the Milgram-Holocaust Linkage.............................. 113

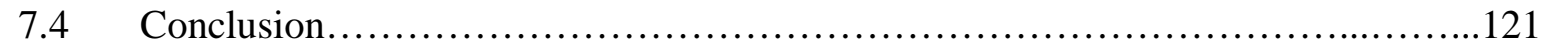

Chapter Eight: Rethinking Milgram's Theoretical Model: the State of Autonomous Denial (SAD).

8.1 Why Did Most Subjects Complete the Baseline Experiment?...................................123

8.2 Rethinking Milgram's Theoretical Model........................................ 132

8.3 Milgram's Web: the Gradual Seduction and Systematic Ensnarement

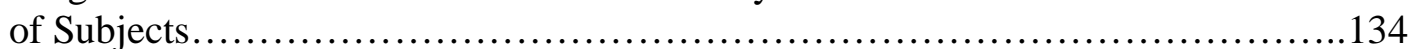

8.4 The Shift from the State of Autonomy to the SAD ..............................139

8.5 The Binding Factor of the Foot-in-the-Door Phenomenon Reducing Feelings of Responsibility..................................................... 140

8.6 The Supplied Strain Resolving Mechanism of Rationalising Away Feelings of Responsibility....

8.7 The Self-Invented Strain Resolving Mechanism of Blaming the Victim—the Just World Phenomenon—Lerner (1980)......................... 146

8.8 The Self-Invented Strain Resolving Mechanism of Blaming Military Service in Reducing Feelings of Responsibility................................... 146

8.9 The Self-Invented Strain Resolving Mechanism of Avoidance Behaviour in Reducing Feelings of Responsibility..............................150

8.10 The Self-Invented Strain Resolving Mechanism of Positive Self-Image in Reducing Feelings of Responsibility 
8.11 The Supplied Strain Resolving Mechanism of the Shock Generator: The

Most Powerful Mechanism Capable of Reducing Feelings of Responsibility....... 154

8.12 Conclusion.

Chapter Nine: Milgram's Obedience to Authority Experiments as an

Emergent Organisational (Bureaucratic) Microcosm

9.1 Many Subjects "Obeyed" the Experimenter but did the Experimenter

"Obey" Milgram?...

9.2 Getting All the Necessary Parties "On Board"....................................... 168

9.2.1 Project Manager: Stanley Milgram.............................................. 169

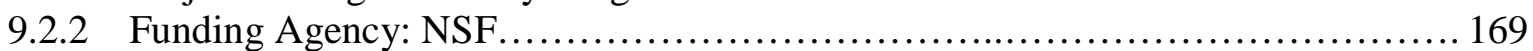

9.2.3 Facilities: Yale University.............................................. 170

9.2.4 Milgram's Key Subordinates: John Williams (Experimenter) and James McDonough (Learner).............................................. 171

9.3 Milgram's Unwitting Construction of and Dependence Upon the

Goal-Orientated Organisational Process................................... 176

9.4 “An Experimenter's Dilemma" ............................................ 183

9.5 Conclusion........................................................... 187

Chapter Ten: The "Twisted Road" to Babi Yar....................................... 191

10.1 The Nazi's “Jewish Problem”: An Overview of Events Leading

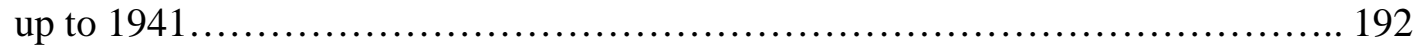

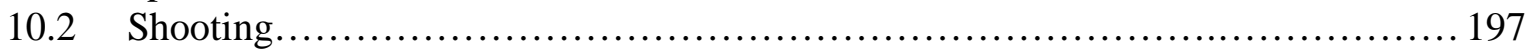

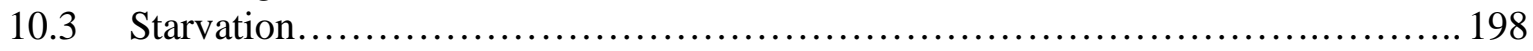

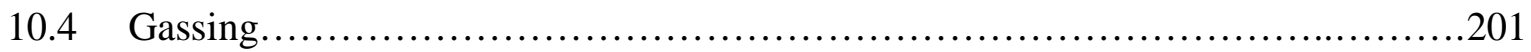

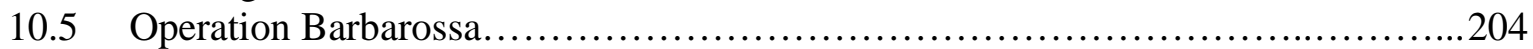

10.5.1 The Application of Top-Down Binding Factors and Strain

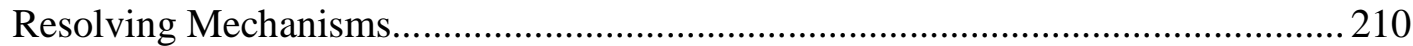

10.5.2 Application of Bottom-Up Strain Resolving Mechanisms........................ 216

10.5.3 Strain Resolving Mechanism of the ad hoc Trial and Error "Exploratory" Shooting Technique...........................................219

10.5.4 Bureaucratisation of the Mass-Shootings...................................... 225

10.5.5 The Insertion of "End Special Units" ....................................... 227

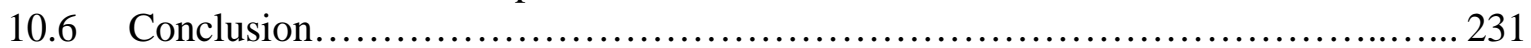

Chapter Eleven: Further Along the "Twisted Road" to Treblinka ...................... 233

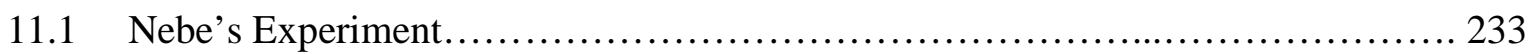

11.2 Arrival of the Einsatzgruppen Gas Vans....................................... 236

11.3 The Emergence of the First Extermination Camp: Chełmno and the Gas Vans...... 239

11.4 The Origins of Operation Reinhard............................................ 243

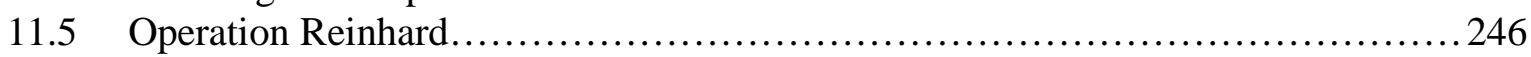

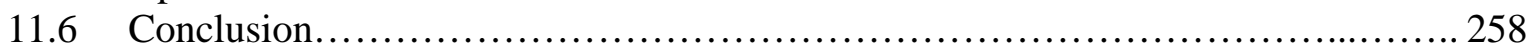

Chapter Twelve: Overview and Conclusion.......................................... 262

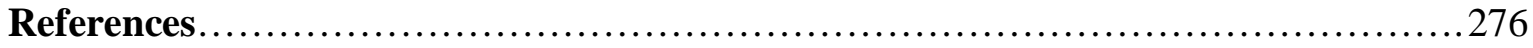




\section{List of Illustrations}

Figure 1

Figure 2

Figure 3

Figure 4

Figure 5

Figure 6

Figure 7

Figure 8

Figure 9

Figure 10

Figure 11

Figure 12

Figure 13
A document produced by Milgram during his time at Princeton University which captures the formulation of an idea to undertake "Studies in Obedience". 46

An independent transcription of Figure 1

Milgram's "Sketch of [a]. . . control panel in studies

of obedience" attached to the first-ever OTA research proposal dated 14 October 1960.

A two-dimensional front-on photograph of the student's 12 switch prototype "SHOCK GENERATOR TYPE ZL DYSON INSTRUMENT COMPANY WALTHAM MASS." which increased in 30 volt increments ending in a maximum shock of 330 volts

Milgram's 30 switch "SHOCK GENERATOR, TYPE ZLB, DYSON INSTRUMENT COMPANY, WALTHAM, MASS. OUTPUT 15 VOLTS - 450 VOLTS".

Raw scores in the Relationship condition

Milgram's early theoretical contemplations.

Factors that contribute to the agentic shift and maintain the subject within the obedience-generating agentic state.

The disparity in completion rates between experimental conditions where siding with the learner did or did not require the subject to initiate then engage in a confrontation with the experimenter.

An adaptation of Milgram's theoretical model where the cumulative influence of the Binding Factors (BFs) and Strain Resolving Mechanisms (SRMs) promoted a shift from the State of Autonomy into the $S A D$ (and not the agentic state).

The imbalance in strain imposed on the subject from the experimenter and learner in the earliest stages of the Baseline experiment.

The outcome when the subject eliminated their strongest source of strain and accepted to the experimenter's demands.

The experimenter and the learner's similar effects on the subject's emotions. 
Figure 14

Figure 15

Figure 16

Figure 17

Figure 18

Figure 19

Figure 20

Figure 21

Figure 22

Figure 23

Figure 24

Figure 25
The strain/guilt imposed by the experimenter after a subject decided to stop inflicting the shocks in the early to middle stages of the experiment. 138

The imbalance in strain/guilt that develops after the point of equilibrium, where the strain/guilt produced by the learner started to exceed and eventually overshadow the maximum strain/guilt that the experimenter was capable of generating.

Distance versus resistance to killing.

The OTA research programme's goal-orientated bureaucratic process

Einsatzgruppen mass shooting-1941

Jewish men are forced to dig their own graves before being executed

An Einsatzgruppe during the execution of Soviet civilians in Kraigonev, USSR. Summer 1941

Execution of Jews by the Einsatzkommando in Kovno....

A member of Einsatzgruppe $D$ shooting a man sitting by a mass grave in Vinnitsa, Ukraine, in 1942. The back of the photograph is inscribed "The last Jew in Vinnitsa".

Type of gas van used at Chełmno and a "recreation" of the van attached, via a ramp, to the castle.

Model of the most advanced industrialised gas chamber at Auschwitz- Birkenau-Crematorium II.

The opening in the roof through which Zyclon-B crystals were poured into the gas chamber below. 


\section{Chapter One: Introduction}

Whatever necessary detachment historians may bring to their research, the gnawing horror of the firing squads and the gas chambers intrudes. There is a dimension of understanding here that eludes us-Headland (1992, p. 205).

\section{$1.1 \quad$ A Brief Overview of the Thesis}

During World War Two the Nazi regime organised, and Germans directly participated in, a genocidal event more commonly referred to as the Holocaust, which ended the lives of about six million Jews (and many others deemed threatening and/or "inferior"). Although non-Germans were heavily involved as direct perpetrators, ordinary Germans from "all walks of life" could be found at every level of implementation from instigation, management, innovation, through to direct participation (Browning, 1998, p. $\mathrm{xvii).} \mathrm{Regarding} \mathrm{participation,} \mathrm{consider,} \mathrm{for} \mathrm{example,} \mathrm{the} \mathrm{nearly} 500$ ordinary men of Reserve Police Battalion 101 who were directly involved in the killings of about 38,000 Jews (Browning, 1992, p. 142). These everyday Germans, who were not carefully selected to undertake these tasks, clearly demonstrated a disturbing capacity to repeatedly engage in lethal acts of violence.

Although the intense anti-Semitism of the many Ukrainians, Latvians, and Lithuanians more directly involved in the killings is undisputed, ${ }^{1}$ somewhat surprising is Bauer's (2001, p. 31) point:

a high proportion of [Nazi] Party members were not extreme antisemites; rather, they shared an antisemitism that one could define as pervasive, yet not necessarily murderous, perhaps even 'moderate'. But it was not only the membership of the Nazi Party that may have been 'only moderately' antisemitic. This kind of moderate antisemitism was shared by a considerable part of the German population, although its pervasiveness is difficult to estimate.

Many other scholars agree (also see Bankier, 1992, pp. 72, 84; Heim, 2000, p. 320; Johnson \& Reuband, 2005, p 284; Kulka, 2000, p. 277) with some suggesting that most Germans felt rather "indifferently" about the fate of their Jewish victims (Browning, 1998, p. 200).

The puzzling implication of this conclusion is that the murderous yet ordinary members of, say, Reserve Police Battalion 101, were arguably a fairly representative

\footnotetext{
${ }^{1}$ Relative to Germany: "In eastern Europe, anti-Jewish feelings were very much stronger" (Bauer, 2001, p. $31)$.
} 
sample of men drawn from a wider population of moderate anti-Semites. This reality led Bauer (2001, p. 103) to ask his "real question". That is, if upon the Nazi regime's ascent to power in 1933 about 57 percent of the electorate supported non-Nazi parties who were:

either anti-antisemitic or only moderately anti-Jewish (that is, they opposed even the relatively moderate step of disenfranchising the Jews), how did it happen that by 1940-1941 the overwhelming majority of Germans became a reservoir of willing murderers of Jews? That is the problem (Bauer, 2001, p. 103).

Soon after Bauer, Browning (2004, pp. 428-429) asked the same question.

Driven partly by a desire to comprehend the Holocaust, American social psychologist Stanley Milgram $(1963,1974)$ undertook his Obedience to Authority (OTA) experiments in the early 1960s. In the Baseline condition Milgram demonstrated that most (65 percent) of his also ordinary (albeit American) subjects would inflict seemingly intense-perhaps even lethal—electrical shocks on a completely innocent person. The OTA Baseline condition was replicated a decade later in West Germany, producing an 85 percent completion rate (Mantell, 1971, p. 101).

More recently, Miller (2004, p. 196) pointed out: "Milgram's results could be likened to the Holocaust itself. Both scenarios revealed ordinary people willing to treat other people with unimaginable cruelty ..." Extending upon this, it could also be argued that another commonality between the OTA experiments and the Holocaust is that both proved capable of rapidly transforming large proportions of ordinary (Browning, 1992, pp. 47-48; Milgram, 1974, p. 6), and arguably indifferent people into willing inflictors of harm. With this commonality in mind, what this thesis suggests is that a similar question to that asked by Bauer could perhaps be directed at the OTA experiments. That is, how did Milgram transform his also ordinary and indifferent subjects into willing torturers of other human beings? Most readers of the OTA experiments find it disturbing that 65 percent of Milgram's subjects completed the Baseline experiment, just as they are appalled that small bands of ordinary Germans could shoot and later gas tens of thousands of other human beings in a single day. But because these were the end results, what might prove particularly instructive in answering Bauer's question is to delineate the start-to-finish journey that enabled Milgram to arrive at his destination. Seeking an answer to the question of how Milgram arrived at his end result/s-how he discovered to get most of his ordinary and indifferent subjects to do what they did-might prove fruitful in shedding new light on Bauer's and Browning's question of how ordinary and indifferent Germans were rapidly transformed into willing executioners. 


\section{$\underline{1.2}$ Central Aims}

This thesis aims to unravel the research journey that enabled Milgram to ostensibly convert most of his ordinary subjects into torturers of other human beings. The thesis then seeks to demonstrate how Milgram's experiments may offer insights and potential clues with which to answer both Bauer's and Browning's question about how ordinary mildly anti-Semitic Germans became willing executioners. The response will necessarily be partial, since Bauer's and Browning's question invites such a multi-faceted and complex analysis that the question itself borders on being rhetorical. Attempting to draw connections between Milgram's and the Nazi regime's journeys of discovery are inherently problematic: these are two unique historical trajectories separated by three decades of time and space. The thesis will nonetheless attempt to draw connections (and highlight differences) between both events.

The thesis also aims to provide a new theoretical interpretation of Milgram's results. Central to this interpretation is uncovering why most subjects completed the Baseline experiment and then showing how they could bring themselves to do so. This interpretation will focus on psychological factors (the individuals' resolution of a moral dilemma) and sociological factors (such as those inherent in the bureaucratic process).

These aims are important for three key reasons. First, Bauer's and Browning's questions remain unanswered. Secondly, Milgram's own explanation for his results has been rejected and no comprehensive alternative exists. Thirdly, if successful in demonstrating a theoretical connection between Milgram's experiments and the Holocaust, this thesis would counter the contemporary view held by many scholars that the OTA experiments have been relegated to only having minor explanatory power with regard to the Holocaust (Fenigstein, 1998b, p. 71). Achieving these aims will ensure that this thesis makes an originally significant contribution to the Milgram-Holocaust-related literature.

\section{$\underline{1.3 \quad \text { Key Research Questions }}$}

To achieve these central aims, the thesis will answer the following five questions (which shape its structure): first, how did Milgram rapidly transform such a large proportion of his ordinary subjects into willing torturers of other human beings? Secondly, 
what was Milgram's explanation for his results? And, thirdly, with reference to the Holocaust, what was the scholarly reaction to the OTA research programme and to the explanation Milgram provided for his results? Milgram's explanation for his own results encountered a number of substantive criticisms. These criticisms give rise to the fourth question: does a more robust explanation exist? If so, finally, can aspects of both Milgram's method of discovery, in conjunction with the alternative explanation presented, be generalised towards shedding new light on Bauer's and Browning's question as to how moderately anti-Semitic Germans were converted into willing executioners of Jews?

\subsection{Chapter Overview}

This thesis comprises twelve chapters.

Chapter One provides a general introduction and overview of the aims and research questions of the thesis.

Chapter Two presents the specific methodological approach/es used by the thesis.

Chapter Three provides a focused review of the historiography of the Holocaust, Milgram's place within it, and contextualises both in regard to Bauer's "real question".

Chapter Four delineates the influences and events that contributed to the conception of Milgram's idea for undertaking the OTA study.

Chapter Five addresses the first key research question: how did Milgram discover, by his first official experiment, to get most of his ordinary subjects to inflict what they believed to be potentially lethal shocks on another human being?

With the intention of answering the second key research question, Chapter Six provides an overview of Milgram's results, and the theoretical explanation he provided for them.

Chapter Seven answers the third key question by presenting the scholarly reaction to the OTA research programme, with particular emphasis on the wider response to Milgram's theory and its purported relationship to the Holocaust. 
After illustrating the contested nature of Milgram's explanation, Chapters Eight and Nine address the fourth key research question by providing an alternative theoretical interpretation of Milgram's results. Central to this explanation is uncovering why most subjects completed the Baseline experiment and then showing how they could bring themselves to do so.

Chapters Ten and Eleven apply the findings of the previous questions-Milgram's method of discovery in conjunction with the alternative explanation for his results-to Bauer's and Browning's question of how moderately anti-Semitic Germans became willing executioners of Jews. Particular attention is paid to the discovery of the killing techniques and their gradual refinement, application, and advancement. Chapter Ten provides a brief overview of the historical events leading up to 1941 and then explores the evolution and implementation of the Nazi regime's mass-shooting campaign during the invasion of the Soviet Union-Operation Barbarossa—from 22 June 1941. Chapter Eleven explores the evolution and implementation of the mass-gassing technique developed from 1941 onwards during what became known as Operation Reinhard-the extermination of the Polish Jews (and others). ${ }^{2}$

Finally, Chapter Twelve summarises the key findings and conclusions of the thesis.

\footnotetext{
${ }^{2}$ While there were many categories of victims other than the Jews during the Holocaust, this thesis focuses on the historiographical material relating to the extermination of the Jews (and explains why almost exclusive attention is paid to this category of victim).
} 


\title{
Chapter Two: Methodological Approach
}

\author{
Answers are always anywhere anyone asks-Tony B. Anderson (2007, p. 6).
}

Beyond the fabric there is not only the loom and the weaver but also the weaving. Beyond the social pattern there is the play of forces emanating from the endless interaction of group and environment. By studying the fabric alone we could never understand the process of weaving, and we will never come to grips with the problem of social causation by studying its contemporary resultant patterns-Robert MacIver (1933, p. 145, as cited in van Krieken, 1998, p. 27).

The methodological approach of this thesis is addressed in four main sections. The first section presents the author's journey into the $\mathrm{PhD}$ candidacy and key intellectual influences. The second section presents the research strategies employed and the sources of data. The third section provides an overview of the intricacies of the data-collection process. The fourth section explains how the data was analysed. ${ }^{3}$

\subsection{The Author's Journey into the PhD Candidacy}

In the late 1990s, the author was completing a Master of Arts (MA) thesis in criminology at Victoria University of Wellington (VUW) under the supervision of Dr. Reece Walters. The thesis basically explored the question of whether or not the removal of firearms in New Zealand would decrease, increase or have no effect on the rate of homicide (Russell, 2000). The thesis argued that because guns are specifically designed, with the pull of a trigger, to inflict massive wounds instantaneously, while also providing a level of physical detachment that the other most common alternative methods/weapons (knives, bludgeoning objects, physical beatings, and strangulation) cannot, guns are likely to be physically and psychologically easier with which to kill. As Levin and Fox (1985, pp. 58-59) wrote: "A gun distances the killer from his victims. Not only effective as a deadly weapon, it is psychologically effective for those who don't want to get their hands dirty." At the other end of the repugnance continuum and in relation to one of the rarest types of violent offenders in society who derive immense pleasure from the killing experience, Levin and Fox (1985, p. 58) add:

Among serial murders that are sexually inspired, the use of a gun is, in fact, remarkably rare. For those killers, physical contact is so crucial to satisfying their murderous sexual impulses that a gun robs them of the pleasure they receive from killing with their hands.

\footnotetext{
${ }^{3}$ As human subjects were not involved in this thesis, there was no need to seek approval from Victoria University of Wellington's Human Ethics Committee.
} 
For the vast majority in society, however, the act of killing is very unlikely to be construed as a pleasurable experience. And the easy availability of firearms may therefore increase the violent potentialities of the more squeamish in society who, despite their violent intentions, might struggle getting their "hands dirty" in the absence of such weapons.

The conclusion of the thesis was that, in all probability, the removal of guns in New Zealand would likely cause the rate of homicide to decrease because, although those with a preference to kill with firearms may hold malevolent intentions, some indeterminable proportion would prove physically and/or psychologically incapable of doing so in their absence.

While writing the MA thesis, similarities between the shock generator used by Stanley Milgram $(1963,1974)$ during his Obedience to Authority (OTA) experiments and firearms technology became increasingly obvious: with the flick of a trigger/switch both of these instantaneous means of inflicting harm enabled the users of these devices to avoid, as Levin and Fox put it, having to get their hands dirty. As suggested in the MA thesis, perhaps the physical detachment offered by firearms and the shock generator elevated the violent capabilities of those using such devices and might go some way to better helping explain Milgram's surprising results (Russell, 2000, pp. 154-167)?

After completing the thesis the author continued exploring the psychology-ofviolence research area and read a book called On Killing: the Psychological Cost of Learning to Kill in War and Society (Grossman, 1995). Milgram (1974, p. 157) observed a positive correlation between "physical distance" separating his subjects from their victim and the completion rate. Building on this observation, Grossman (1995, p. 98) noted that the greater the physical separation offered by certain military weapons in distancing military personnel from their victims, the less stress/trauma soldiers tended to experience. For example, killing with a bayonet (which necessitates close proximity) is likely to generate greater psychological distress in military personnel than when killing with a firearm used from a mid-range distance. And killing with a firearm used from mid-range is more stressful than killing with a long-range ballistic missile.

Daniel Goldhagen's (1996) Hitler's Willing Executioners: Ordinary Germans and the Holocaust ended with a conclusion that conflicted sharply with those of both Grossman and the author's research. Arguably, methods of killing could not have been important 
during the Holocaust because Goldhagen had apparently demonstrated that intense hatred of the Jews was a sufficient cause of the perpetrators' actions (a level of hatred that saw ordinary Germans engage in primitive, gratuitous, and cruel acts of lethal violence). At that time, the author had not read anything on the Holocaust, a topic that had not previously caught his attention as it does those much closer to this catastrophe (he being neither Jewish nor German). Starting with Goldhagen's book, the journey into what turned out to be a fascinating and profoundly complex research area began.

Although Goldhagen paid critical attention to the theories of other Holocaust scholars, he made no reference to the psychology or science of killing literature (Grossman, 1995; Holmes, 1985; Marshall, [1947] (2000); Shalit, 1988; Watson, 1978). What was striking about the multitude of examples of lethal violence Goldhagen used to demonstrate that hatred was a sufficient cause of the Holocaust was that there were only six examples where a direct physical connection could be established between a German perpetrator, their weapon, and victims' body. It was clear that the application of the psychology of killing literature might provide a valuable contribution to Holocaust research.

Over the next few years the author read many books on the Holocaust and through student networks, was eventually encouraged in 2003 to present the various accumulating inchoate ideas to Professor Bob Gregory at VUW's School of Government. A keen friendship developed, and under his tutelage, the author was introduced to Max Weber's work on bureaucracy, an area of research that (in conjunction with VUW criminologist Professor John Pratt's lectures on sociologist Norbert Elias), have had a profound influence on the direction of this thesis. Two years later we co-authored an article on the OTA experiments, bureaucracy and the Holocaust titled Making the Undoable Doable: Milgram, the Holocaust and Modern Government (Russell \& Gregory, 2005). Professor Gregory then suggested the author further explore, as a $\mathrm{PhD}$ thesis, some of the ideas mentioned in our paper (with him agreeing to be the primary supervisor). Dr. Simone Gigliotti, a Senior Lecturer in history at VUW specialising in the Holocaust, agreed to be the secondary supervisor. In May 2006 the author enrolled as a PhD candidate at VUW's School of Government.

\subsection{Research Strategy and Sources of Data}

Question One: To explore/understand how Milgram converted ordinary and indifferent 
subjects into willing torturers, the author draws upon a methodological approach recommended by sociologist Norbert Elias. Influenced by MacIver's above epigraphic statement, Elias (1987, p. 226) believed that in order to understand the social intricacies of any phenomenon—such as how Milgram (or even the Nazi regime) converted ordinary people into torturers-one must observe carefully the transformation of this phenomenon over time. ${ }^{4}$ As discussed, many laypersons are aware and disturbed that 65 percent of Milgram's subjects completed the Baseline experiment, just as they are that relatively small bands of ordinary Germans proved capable of shooting and (later) gassing tens of thousands of men, women and children in a single day. But it is important to note that these were the end results. Instead of focusing on the frightful end results, it is the intention of this thesis to adopt the Eliasian approach of developing a narrative that delineates, from start to finish, Milgram's OTA research journey from the influences that led up to the conception of his research idea through to data analysis. However, doing so is made difficult by the fact that Milgram's (1963, 1964b, 1964c, 1965a, 1965b, 1974) publications reveal little of how he developed his OTA paradigm/procedure. These publications understandably tend to be dominated by descriptions of his experimental procedures and their (end) results, and provide little insight into the method of discovery he relied upon that generated both.

Delineation of Milgram's research journey draws upon three main sources of data. The first and main source involved the collection of potentially relevant documents from his personal archive — the Stanley Milgram Papers (SMP)— held at the Sterling Memorial Library at Yale University. The second source came from other researchers' interviews with Milgram where he occasionally reflected upon and divulged insights into his research journey. The final source of journey-related material involved Milgram's (1963, 1964b, 1964c, 1965a, 1965b, 1974) own, albeit rare, disclosure of such matters.

Question Two: Milgram's (1974) book Obedience to Authority is the main source of information used to explain the results of the OTA experiments.

Question Three: A review of the literature was undertaken to answer the third question regarding academia's reaction to Milgram's explanation for his findings.

\footnotetext{
${ }^{4}$ When stating this Elias (1987) really had much longer term processes in mind: "The understanding of human societies requires . . . testable theoretical models which can help to determine and to explain the structure and direction of long-term social processes" (p. 226).
} 
Question Four: In attempting to develop a stronger interpretation of Milgram's results, the thesis drew upon the research strategy of armchair induction. Armchair induction is where "researchers apply inductive methods of textual analysis for the purposes of theory development" (Heaton, 2004, p. 14). ${ }^{5}$ In doing so, a variety of sources of information were drawn upon, including the OTA results, documentary evidence obtained from the SMP, other publications by Milgram, and various secondary sources (including the theoretical accounts, contemplations, and insights of other authors). It is important to note that although the author disagrees with key foundations of Milgram's (1974) explanation for his results, his theoretical insights have nonetheless had a major influence on the eventual conclusions drawn in answering this question.

Question Five: The final section of the thesis applies the insights obtained from the preceding four research questions to better understand two case studies. Case study one is Operation Barbarossa and the Nazi regime's mass-shootings of Soviet Jewry. ${ }^{6}$ Case study two is Operation Reinhard, the gassing of the predominantly Polish Jews. It is intended that these two case studies will provide a lens through which to view the Nazi regime's use of similar methods of discovery to that later inadvertently relied upon by Milgram. Both case studies will draw from a wide variety of secondary source materials published by Holocaust scholars.

In terms of scholarly and theoretical influences, the thesis employs the Eliasian methodological approach of observing phenomena over time. Also, in the reinterpretation of Milgram's results and throughout the Holocaust case studies, Max Weber's theoretical insights on bureaucracy, the division of labour, and specialisation have repeatedly been drawn upon.

\subsection{Approach to Data-Collection}

In addition to a literature review of publications on the OTA research and Holocaust, data was also sourced from the SMP. The SMP, as outlined in the Guide to the Stanley Milgram Papers: Manuscript Group Number 1406, covers the period 1927-1986, though the bulk of the papers are post-1960. The archive is arranged in five series: General Files (1954-1985); Studies (1927-1984); Writings (1954-1993); Teaching Files

\footnotetext{
${ }^{5}$ For more information on armchair induction see Thorne (1998).

${ }^{6}$ Case study one will focus mostly on the mass-shootings undertaken by the Einsatzgruppen squads, but will also look at massacres by the Order Police Battalions, Heinrich Himmler's Kommandostab, and other SS units.
} 
(1960-1984); Data Files (1960-1984). These papers, which capture Milgram's prolific academic career, highlight his work on OTA, television violence, urban psychology, and communication patterns within society. The archive is the gift of Milgram's wife,

Alexandra Milgram.

In September 2006 the author spent two months at Yale University in order to view the OTA-related material. Although only a small proportion of the 158 boxes specifically related to the OTA experiments, this still amounted to a significant number of folders filled with numerous documents - textual and non-textual (drawings, pictures and even a few boxes of audio tapes). Priority was given to examining those boxes headed with titles that appeared most likely to provide rich data and information on the OTA experiments.

The aim was to identify material shedding any light on Milgram's start-to-finish research journey, from the influences that led up to the conception of the OTA research idea through to his analysis of data. ${ }^{7}$ With the alternative interpretation of Milgram's OTA results in mind, the author collected copies of all documents that, in his view, reinforced or conflicted with the line of argument advanced in Russell and Gregory (2005), of which this thesis is, in part, an in-depth extension.

\subsection{Data Analysis: Documentary Analysis and Case Studies}

\section{Documentary Analysis:}

Approximately 300 documents of interest were identified in the SMP and were thematically divided into categories. After comparing and contrasting the material obtained with other contributions to the OTA literature that also drew on material from the SMP_like Blass (2004) and Fermaglich (2006) — these documents were analysed with the intention of building Milgram's start-to-finish research journey.

In terms of the potential limitations applicable to documentary analysis, Scott

\footnotetext{
${ }^{7}$ The boxes pursued included: Box 1 (folders a-f); 1a (folders 1-15); Box 13 (folders 181-194); Box 17 (folders 243-257); Box 21 (folders 326-339); Box 43 (folders 124-129); Box 44; Box 45 (folders 130-162); Box 46 (folders 163-178); Box 47 (folders 179-187); Box 48 (folders 188-203); Box 55 (folders 1-22); Box 56 (folders 23-46); Box 59 (73-87); Box 61 (folders 106-125); Box 152; Box 153 (audio tapes); Box 154; Box 155 (audio tapes); Box 156; Box 157. (It should be noted that some of the clearly relevant boxesparticularly from the Data Files section-could not be accessed due to privacy restrictions and will not be released until 2060 — unless one is willing to pay for its "sanitising" by Yale staff.) Lack of funding precluded this author from pursuing this possibility, although it was possible to access some of this previously restricted material because other researchers had earlier paid for its sanitising.
} 
(1990, pp. 19-35) has warned that the validity/accuracy of such material should always be treated with caution. Scott recommends that the validity/accuracy of documentary materials should be assessed using the following criteria: Authenticity (are the documents genuine?), Credibility (are they free from errors and bias?), Meaning (is the meaning unambiguous and free of hidden meanings?), and Representativeness (are the documents typical?). In terms of authenticity, being the gift from Milgram's widow to Yale University where the OTA experimental programme was undertaken, the documents held at the Sterling Memorial Library are very likely to be genuine. Some of the documentary material portrays Milgram casting himself in a bad light or, from an ethical perspective, incriminating himself. As Blass (2004, p. 117) has argued, this material does not seem to have been produced with an audience in mind, which indicates its probable credibility. Many of Milgram's on-going experimental notes were recorded in clear simple typed prose. However, for those handwritten documents which were sometimes difficult to decipher, two independent transcribers were sought. Overall, the author was confident that the meaning of the material was unambiguous. Being the only and actually quite large repository on Milgram's academic career, it could be argued the archive is more than representative of his work on OTA.

\section{Case Studies:}

A narrative delineating the two Holocaust case study's respective start-to-finish journeys was based on secondary literature. In terms of potential limitations, the case study approach is most vulnerable to the credibility/persuasiveness of the generalisations that disseminate from or, as in the case of this thesis, to it. The two case studies involved two of the three most relied upon methods of killing Jews-shooting and gassing. ${ }^{8}$ Due to the word restraint limits of a $\mathrm{PhD}$ thesis, there was not the space to go into the kind of detail that the admittedly complex Holocaust history demands (and thus, the lack of extensive detail surrounding the case studies must be considered a limitation of the present thesis).

Due to much of the material used in these two chapters being based on perpetrator statements made in documents translated into English during and, in post World War Two testimonies, after the genocide, an obvious limitation of this thesis stems from the risk of mendacity and prevarication. After World War Two, most of the perpetrators gained a notorious reputation for revising their egregious pasts to suit their more precarious present:

\footnotetext{
${ }^{8}$ The third main method-starvation/deprivation-is also, albeit briefly, discussed.
} 
potentially being executed or incarcerated. However, because the perpetrator statements used in this thesis were largely concerned with the actual processes of engaging in genocide, this author has interpreted them as being credible. The reasons for accepting many (but certainly not all) of these statements as probably credible are that, first, they are inherently self-incriminating (Westermann, 2005, p. 170). What are the chances of a person lying when, as one perpetrator admitted, for example, that "Shooting the Jews is easier than shooting the gypsies [sic]" (Benz, 1999, p. 86). Having said this, the author was alert to inherently incriminating statements that nonetheless tried to present themselves in a more positive light. Secondly, there appeared little to gain after the war in admitting to having directly engaged in genocide (other than perhaps relieving oneself of the burden of carrying such secrets within). Thirdly, in terms of the processes of mass slaughter, some of the perpetrators' admissions can be verified by bystander and survivor statements. ${ }^{9}$ Finally, such statements are accepted as likely to be credible because they have frequently been deemed as such by a variety of independent scholars of the Holocaust.

Although the author tries, where possible, to understand how ordinary people could do what they did, this should not be mistaken as sympathy. There is much merit in the words of Browning (1992, pp. xvii-xviii), who was also confronted by this problem:

Another possible objection to this kind of study concerns the degree of empathy for the perpetrators that is inherent in trying to understand them. Clearly the writing of such a history requires the rejection of demonization. The policeman in the battalion who carried out the massacres and deportations, like the much smaller number who refused or evaded, were human beings. I must recognize that in the same situation, I could have been either a killer or an evader-both were humanif I want to understand and explain the behavior of both as best I can. This recognition does indeed mean an attempt to empathize. What I do not accept, however, are the old clichés that to explain is to excuse, to understand is to forgive. Explaining is not excusing; understanding is not forgiving.

Finally, with respect to the theoretical component and case studies, the author was at all times alert to the Confirmation Bias, which is where one reinforces their preconceptions and ignores all conflicting information. The author was therefore sensitive to any counterfactual data.

Having presented the research problem, central aims, research questions and methodology, the following chapter will provide a more comprehensive review of the

\footnotetext{
${ }^{9}$ If there were conflicting accounts on any issues, the author either alerts the reader to their existence or does no include them.
} 
historiography of the Holocaust, Milgram's place within it, and contextualises both in regard to Bauer's (then Browning's) "real question”. 


\section{Chapter Three: The Problem of "Ordinary Monsters" and the Holocaust-a Review of the Literature}

Milgram's obedience experiment is the single greatest contribution to human knowledge ever made by the field of social psychology, perhaps psychology in general-Muzafer Sherif (as cited in Takooshian, 2000, p. 10).

These experiments are so vile, the intention with which they were engaged in is so vile, that nothing these experiments show has any value ...-Bruno Bettelheim (as cited in Askenasy, 1978, p. 131).

\subsection{The Holocaust: a Brief Overview}

In 1933 the Nazi party led by Adolf Hitler gained political ascendancy in Germany. As promised in its manifesto, the new regime almost immediately focused on the "Beseitigung" (which somewhat ambiguously can mean removal or elimination) of those who many of its leading party members believed were the cause of all Germany's ills: the Jews (Dawidowicz, 1990, p. 195). The Jews were held responsible for the Reich's poor economic state and, more importantly, for Germany losing World War One (along with the great loss of German lives and land). The Nazi regime's strategy for Germany's resurrection was to re-arm and go to war to at least recuperate the confiscated lands. To secure the plan's success it was necessary, so they believed, to ensure that no Jews lived in or near this expanding border.

Initially the Nazis encouraged the German Jews to emigrate elsewhere. Emigration was encouraged by way of legislation that made daily life for the Jews increasingly unbearable, in conjunction with other more aggressive attempts at intimidation. In terms of the latter, in 1938 a Nazi party radical instigated a nationwide pogrom against Germany's Jewish community which, due to the widespread smashing of shop-front windows, infamously became known as Kristallnacht (Crystal Night or Night of the Broken Glass). Thousands of Jews were then rounded up and sent to concentration camps, where their release became dependent upon their agreeing to leave Germany. This pogrom failed to generate much public support and the disorderly behaviour and wanton vandalism disgusted many German “onlookers” (see Bankier, 1992, p. 72; Browning, 2004, pp. 9-10, 428; Kershaw, 1983, pp. 262-263). Although by the late 1930s many of German Jewry were keen to leave, due to other nations' prejudices about and/or restraints on the immigration of those often without capital (or assets that the Nazis had frozen), most refused to accept any or, at best, only small numbers of Jews. 
During the lead-up to and especially upon going to war, the geographical borders of Germany underwent rapid expansion (perhaps to an even greater degree than many Nazis had previously envisioned). With these recently appropriated territories often having large Jewish populations that no other nation outside the Reich's expanding border were likely to accept, the Nazi regime's "Jewish problem" grew. After the continual failure of initial plans to resettle Jews to the island of Madagascar and later to other equally or even more inhospitable locations, many Holocaust historians agree that during the second half of 1941 the Nazi regime instead decided to exterminate all the Jews within the then-expanding German sphere of influence. Many Jews had already died of starvation and disease in the ghettos, but to exterminate all the Jews, mass-shootings began and were soon followed by the use of gas chambers. Upon Germany's defeat in 1945, about two-thirds of all the Jews in Europe—a figure approaching six million people—had been killed (Marrus, 1988, p. 24).

\subsection{Introduction to the Problem of "Ordinary Monsters"}

The vast majority of perpetrators in these mass killings were not zealous Nazi ideologues but were more likely to have been moderately anti-Semitic everyday Germans from all walks of life. Hilberg (1961), in his landmark study The Destruction of the European Jews, ${ }^{10}$ wrote:

The bureaucrats who were drawn into the destruction process were not different in their moral makeup from the rest of the population. The German perpetrator was not a special kind of German ... . However one may wish to draw the line of active participation, the machinery of destruction was a remarkable cross-section of the German population [italics added] (p. 1011).

It was after observing the 1961 trial in Jerusalem of former mid-ranking SS bureaucrat Adolf Eichmann, however, that philosopher Hannah Arendt came to a similar but far more controversial conclusion. In conflict with the Israeli prosecution's depiction of Eichmann as a sadistic monster, Arendt (1963) saw not only an ordinary man who was "neither perverted nor sadistic ... [but] terribly and terrifyingly normal” (p. 253). Eichmann, she argued, was best understood primarily as a passive recipient of orders, which he sought to carry out in the most efficient and competent way possible. He was the quintessential socalled desk murderer. Arendt (1963, p. 231) coined the term the "banality of evil" to

\footnotetext{
${ }^{10}$ Hilberg's contribution is a meticulous overview of the phases that the Nazi bureaucratic machinery of destruction passed through in implementing the regime's ultimate aim of killing all the European Jews. The four increasingly radical phases of the destruction process he identified were the definition of the victims, expropriation of their property, their physical concentration/deportation and finally their extermination.
} 
capture the reality of such ordinary and normal mid-level managers or petty administrators. Their complicity in the organised pursuit of malevolent purposes flowed not from any personal monstrosity but from their thoughtless incapacity to empathise with others, their inability to balance technical with moral competence, and their desire to achieve advancement by impressing their organisational superiors. The influences generating Arendt's perspective could be traced backwards in a straight line through earlier intellectuals from C. Wright Mills to Hans Speier back to Max Weber (Thad Allen, 2005, pp. 259-260). Nonetheless, the consequences of implying Eichmann was no monster saw Arendt (a Jewish émigrée of German descent) encounter intense and vitriolic criticism largely at the hands of an outraged Jewish community.

\subsection{Stanley Milgram and the Obedience to Authority Experiments}

Despite this reaction, soon afterwards the controversial concept of the "banality of evil" was, or so it appeared, being independently reinforced by an experimental programme headed by a young social psychologist by the name of Stanley Milgram (1963, 1974). While exploring the area of obedience to authority (OTA), Milgram (an American Jew of Hungarian/Romanian descent) had demonstrated in a controlled laboratory setting that, when ordered by an authority figure, more then half of his ordinary American subjects were willing to inflict what they were led to believe were potentially lethal electric shocks to a person locked in another room.

Although he undertook more than a score of experimental variations, Milgram's (1963) first and widely read publication on the topic of OTA presented the procedure and eye-catching results from his first official experiment, termed the Remote condition. The Remote condition involved an actor posing as a potential subject. He entered a laboratory and encountered an apparent scientist wearing a grey lab-coat (in fact, another actor, hereafter called the experimenter). The ostensible subject was then introduced to a waiting naïve, and actual, subject. The experimenter then told both the actual and supposed subject that the experiment they volunteered to take part in was designed to investigate the effects of punishment on learning. They were then told that one person was required to be the teacher and the other the learner. The selection was pre-arranged to ensure that the actor/subject was always made the learner, and the actual subject the teacher. The actual subject (now teacher) watched as the experimenter strapped the learner-a 47-year old man whom most observers found "mild-mannered and likable" (Milgram, 1974, p. 16) — to a chair and attached an electrode to his arm. Clearly, the learner was unable to terminate 
the experiment by taking flight. The learner was informed that the subject/teacher, using a microphone from another room, would ask them questions regarding a word-pair exercise. The learner was to attempt answering these questions by pressing one of four switches on a device that would electronically transmit his answer to the subject. The subject was then taken into an adjacent room and placed before what was referred to as the shock generator. There were 30 switches on the shock generator, aligned in 15-volt increments from 15 to 450 volts. Switches were labelled in groups ranging from "SLIGHT SHOCK" leading up to "VERY STRONG SHOCK", followed by "DANGER: SEVERE SHOCK". The final two switches (435 and 450 volts) were menacingly labelled "XXX" (Milgram, 1974, p. 28). To increase the credibility that the shock generator was indeed what it appeared, the subject was given a sample 45-volt shock. Then the subject was instructed by the proximate experimenter to give the learner a shock for each incorrect answer proffered; and each incorrect answer warranted for the learner a shock one level higher than its predecessor. In actuality, no shocks were administered, though most subjects did not know this at the time (Milgram, 1974, pp. 171-172).

Upon starting, the learner responded with a set of predetermined answers, 75 percent of which were purposefully incorrect. Due to the requirement to inflict a shock one level higher than the previous incorrect answer, acquiescent subjects found themselves advancing up the switchboard and rapidly delivering shocks of increasing intensity. Any signs of hesitancy by the subject to continue, implied or overt, were met with the experimenter calmly responding with one or several of the following prods:

Prod 1: Please continue, or, Please go on.

Prod 2: The experiment requires that you continue.

Prod 3: It is absolutely essential that you continue.

Prod 4: You have no other choice, you must go on (Milgram, 1974, p.

21).

If at any time the subject expressed concerns about the learner's well-being, the experimenter informed them: "Although the shocks may be painful, there is no permanent tissue damage, so please go on" (Milgram, 1974, p. 21). If at any time the subject attempted to clarify the lines of responsibility, the experimenter would confidently assert: "I'm responsible for anything that happens to him. Continue please" (Milgram, 1974, p. 74). Upon any subjects reaching the 300 and 315-volt shock switches, the learner was instructed to bang suddenly on the wall separating the two parties and thereafter fall silent. Any concerns by the subject regarding the learner seemingly wanting to discontinue were met by the experimenter stating: "Whether the learner likes it or not, you must go on until 
he has learned the word pairs correctly. So please go on. (Followed by Prods 2, 3, and 4, if necessary.)" (Milgram, 1974, p. 22). The sudden absence of any further answers to the subject's questions and the accompanying silence implied that something had gone terribly wrong and that the shocks had, at least, probably rendered the learner unconscious. The experimenter then instructed the subject to treat all subsequent unanswered questions as incorrect and accordingly inflict a shock at the next level. Any further resistance was again met with as many prods as necessary to secure the subject's continued obedience. In the absence of any categorical acts of defiance, the experiment was eventually deemed complete upon the subject having administered three successive 450 -volt shocks. The completion rate was surprising: 26 out of a sample of 40 subjects ( 65 percent) inflicted every shock.

Although the Remote condition was the first and probably most widely read of Milgram's many experiments, it was the result of a subsequent experiment, the so-called Baseline condition, that perhaps attracted most popular attention, largely because it featured predominantly in a film he later produced titled Obedience: a filmed experiment (Milgram, 1965c). The Baseline condition was very similar to the Remote experiment except that the learner mentioned before starting that he had a mild heart condition, and the learner's "pain" was this time unambiguously conveyed by way of increasingly intense verbal protests and eventually screams (actually via a tape recording). For example, at 120 volts the learner was heard from the adjacent room to say "Ugh! Hey, this really hurts" (Milgram, 1974, p. 56). If the subject continued to obey up until the 270-volt switch, the learner, in obvious agony, was heard to scream: "Let me out of here. Let me out of here. Let me out of here. Let me out. Do you hear? Let me out of here" (Milgram, 1974, pp. 56-57). At the 300-volt switch the learner refused to answer and instead responded with agonised screams. From the 345-volt switch onwards he went totally silent. As in the Remote condition, the experimenter then commanded the subject to treat all unanswered questions as incorrect and accordingly inflict a shock at the next level and continue to do so until three successive 450 -volt shocks had been administered.

Milgram (1974) beforehand described the procedure from one of his early experimental variations ${ }^{11}$ to, among other groups, 39 psychiatrists, who then predicted that only about 0.001 percent or one subject in a thousand — a "pathological fringe" (p. 31)— would administer the highest shock on the board. Although the Baseline experiment was

\footnotetext{
${ }^{11}$ The experiment in question was the Voice-Feedback condition, the second official experiment, which was the same as the Remote condition, except the learner's verbal reactions could be heard throughout.
} 
for subjects likely to have been an even more harrowing experience, it elicited the same completion rate: 26 out of a sample of 40 subjects ( 65 percent) inflicted every shock.

The obedient subjects were later asked why they continued to inflict the shocks. Most pointed out that they personally wanted to stop but the experimenter's persistent demands that they continue, frequently in conjunction with his repeated assurances that the responsibility was all his, apparently left them with little choice but to go on.

\subsection{The Milgram-Holocaust Linkage}

While Milgram (1974, p. 175) acknowledged that there were "enormous differences" between the Holocaust and his own laboratory experiments, he was quick to generalise beyond the laboratory doors when noting how the "just following orders" justification was used both by his subjects and many of the Nazi war criminals at Nuremberg and at subsequent trials. Other scholars sensed this potential connection between Milgram's results and the Holocaust, ${ }^{12}$ which Miller (2004, p. 194) termed the "M-H linkage" - the Milgram-Holocaust linkage. Milgram later came to believe that both the Nazi perpetrators and his obedient subjects were strongly influenced by a "common psychological process", and was at pains to understand how a perceived need to obey ostensibly legitimate orders from a higher authority translated into individual action (Milgram, 1974, p. 175). Central to his explanation of this psychological process was his notion of the agentic state, in which "the individual no longer views himself as responsible for his own actions but defines himself as an instrument for carrying out the wishes of others" (Milgram, 1974, p. 134). Milgram (1974, p. 146) did not suspect this was an excuse or alibi and thought that, in actuality, the obedient subjects were being honest when believing themselves to have been mere instruments of a higher authority and they genuinely did not feel responsible for their actions:

For a man to feel responsible for his actions, he must sense that the behavior has flowed from 'the self.' In the situation we have studied, subjects have precisely the opposite view of their actions-namely, they see them as originating in the motives of some other person.

As subjects so frequently pointed out themselves: " 'If it were up to me, I would not have administered shocks to the learner" " (Milgram, 1974, p. 146).

\footnotetext{
${ }^{12}$ See Bauman (1989), Blass (1993, 1998), Browning (1992, 1998), Hilberg (1980), Kelman and Hamilton (1989), Miller (1986), and Sabini and Silver (1982).
} 
The one variation in Milgram's basic experimental procedure that proved particularly influential in promoting entry into the so-called agentic state was the Peer Administers Shock condition. In this condition subjects were ordered to perform the subsidiary task of only directing the questions to the learner while another subject (actually an actor) administered the shocks for any incorrect answers. In comparison to the Remote and Baseline experiments, this variation resulted in a substantial increase in the completion rate, with 37 out of 40 subjects (93 percent) passively continuing to carry out their prescribed role while the actor administered every shock. Post-experimental interviews with these obedient subjects often revealed they did not believe their involvement made them in any way responsible for the learner being shocked, with them blaming the shockadministering peer. Yet, as the results surrounding the earlier variations demonstrated, when subjects had to shock the learner themselves, those who were obedient were then more inclined than defiant subjects to shift the blame to either the experimenter or learner (Milgram, 1974, p. 203).

Milgram believed that the Peer Administers Shock variation may have captured, in the controlled laboratory setting, the potentially destructive bureaucratic process along with its inherent characteristic of the division of labour. He described the "fragmentation of the total human act; no one man decides to carry out the evil act and is confronted with its consequences" (Milgram, 1974, p. 11). In directly connecting this experimental variation to the Holocaust and the Nazi regime's use of the disjointed bureaucratic process, he argued: "The person who assumes full responsibility for the act has evaporated" (Milgram, 1974, p. 11). With the potentially destructive bureaucratic process in his sights, Milgram (1974, p. 11) generalised beyond the confines of his laboratory: "Perhaps this is the most common characteristic of socially organized evil in modern society."

Clearly Milgram had been influenced by Hilberg's (1961) painstaking delineation of the intricacies of the Nazi regime's destructive bureaucracy (which Milgram indeed referenced in his book). Similarly, Milgram specifically saw merit in the explanatory power of Arendt's controversial concept of the "banality of evil," which he saw as being fully consistent with his own explanation (a connection that is not all that surprising considering Milgram's undergraduate education was in political science, which would have equipped him to draw links between his experiments and governmental systems). On the basis of what he had found, Milgram explicitly endorsed the general utility of Arendt's "banality of evil" thesis, which he believed came "closer to the truth than one might dare imagine" (Milgram, 1974, p. 6). 
However, other scholars have also documented the occurrence of gratuitous acts of brutality by Holocaust perpetrators. Their research has produced a body of literature that raises pressing questions about the validity of depicting "ordinary" bureaucrats apparently indifferent to the horrific human consequences that flowed from their banal papershuffling. Particularly prominent was Bernd Naumann's (1966) Auschwitz, which documented the 1963-1965 trial of a score of SS men who served in this infamous labour and extermination camp. The preface to this book was somewhat ironically written by Arendt herself (as cited in Naumann, 1966, p. xxiv), who candidly stated in reference to some of the evidence the book went on to present:

No one had issued orders that infants should be thrown into the air as shooting targets, or hurled into the fire alive, or have their heads smashed against walls; there had been no orders that people should be trampled to death, or become the objects of the murderous 'sport,' including that of killing with one blow of the hand.

Such gratuitous examples of cruelty stood in stark contrast to Milgram's and her own theories regarding supposedly indifferent perpetrators just passively following orders. However, for his part, it seems that Milgram regarded such evidence as, at best, complementary to his position, or, at worst, largely irrelevant. It was, he argued, typical of modern bureaucracy, even when designed for destructive purposes, that "most people involved ... do not directly carry out any destructive actions .... Any competent manager of a destructive bureaucratic system can arrange his personnel so that only the most callous and obtuse are directly involved in violence" (Milgram, 1974, pp. 121-122). In Milgram's view, most of the perpetrators were ordinary unthinking bureaucrats, acting purely instrumentally and who simply had carefully selected thugs inserted at the end of the hierarchical chain to do the dirty work. But this conclusion conflicted sharply with Hilberg's (1961) assertion that across the destructive bureaucratic chain the perpetrators were "a remarkable cross-section of the German population" and not, therefore, "a special kind of German". And after the publication of Browning's (1992) book Ordinary Men: Reserve Police Battalion 101 and the Final Solution in Poland, it became clear that Milgram's assumption that carefully selected perpetrators- "the most callous and obtuse" - did the hands-on dirty work was patently wrong — as reflected in the title, these executioners were "Ordinary Men”.

Reserve Police Battalion 101 consisted of less than 500 Germans who were based in the annexed Polish territories (Browning, 1992, p. xv). The battalion originated from 
Hamburg, one of Germany's least nazified cities, and the rank and file comprised mostly those from the lower social classes, who were least likely to support the Nazi regime (Browning, 1992, pp. 47-48). Except for the oldest, none had any military experience and were more or less the dregs of the armed forces pool. With respect to their ordinariness, Browning (1992, p. 48) argued: "The men would not seem to have been a very promising group from which to recruit mass murderers on behalf of the Nazi vision of a racial utopia free of Jews." In relation to what turned out to be the battalion's first mass-shooting in early 1942, the leading authority in the field, Major Trapp, did not demand but, in conflict with Milgram's assumptions, "made an extraordinary offer: if any of the older men among them did not feel up to the task that lay before him, he could step out" (Browning, 1992, p. 2). Browning (1992, pp. 71-74) pointed out that the small proportion that did not want to participate could and eventually did avoid having to partake in shooting duties (about 10 to 20 percent). Although the men who remained initially struggled with this task (many were soiled with blood, bone, and brain matter), most quickly acclimatised to the tasks ahead and "became increasingly efficient and calloused executioners" (Browning, 1992, p. 77). These ordinary men directly participated in the mass-shooting of at least 38,000 Jews (Browning, 1992, p. 142). After carefully analysing the evidence, Browning concluded that the most common motivational force to participating in the gruesome work was probably peer-pressure/conformity, whereby many did not want to be seen among their comrades and/or leaders in the field as shirkers. Although Browning's account conflicted in many ways with the OTA experiments, he still saw significant similarities: "many of Milgram's insights find graphic confirmation in the behavior and testimony of the men of Reserve Police Battalion 101”(Browning, 1992, p. 174).

Although criticism of Milgram's thesis was mounting, it was Goldhagen's (1996) Hitler's Willing Executioners: Ordinary Germans and the Holocaust (HWE) that perhaps most powerfully undermined the plausibility of any M-H linkage. Based on the same archival material as Browning's study, the difference in the title hinted at a very different conclusion: Browning's "Ordinary Men” were much more specifically believed by Goldhagen to have been "Ordinary Germans". Due to the intense furore generated in scholarly circles by this single contribution to the literature, it is necessary to present what Goldhagen believed caused the Holocaust, the evidence he used to support his explanation, the ensuing academic response, and why-irrespective of their criticisms-HWE posed such significant problems for the contributions of Milgram and other scholars.

From the outset Goldhagen (1996, p. 9) boldly declared: 
Germans' antisemitic beliefs about Jews were the central causal agent of the Holocaust. They were the central causal agent not only of Hitler's decision to annihilate European Jewry . . . but also of the perpetrators' willingness to kill and to brutalize Jews. The conclusion of this book is that antisemitism moved many thousands of 'ordinary' Germans - and would have moved millions more, had they been appropriately positioned-to slaughter Jews.

Immediately striking is how this theory stands in stark contrast to the "most fundamental lesson” emanating from Milgram's (1974, p. 6) study of “ordinary people, simply doing their jobs, and without any particular hostility on their part, can become agents in a terrible destructive process." On what grounds did Goldhagen base his assertions?

Goldhagen presented two arguments that he believed reinforced the above theory. Based on a variety of sources, Goldhagen's first argument was that, particularly from the nineteenth century, a virulent strain of eliminationist anti-Semitism spread throughout Germany. By the early 1930s this strain of anti-Semitism had not only become pervasive throughout German society—it rapidly intensified to the exterminationist level. ${ }^{13}$

Following this was Goldhagen's second argument: after the Nazi regime had given its consent during World War Two, this uniquely German strain of exterminationist antiSemitism caused ordinary Germans willingly and directly to engage in the mass slaughter of Jews. Goldhagen supported his second argument with a litany of brutally unsophisticated acts of violence that ordinary Germans staffing the primitive police battalions, work camps, and death marches more than frequently volunteered to inflict upon Jews. The following quote is a typical example of the kind of evidence repeatedly presented: A former police official testified that those serving with him " "were, with few exceptions, quite happy to take part in shootings of Jews. They had a ball!,' their killing was motivated by 'great hatred against the Jews; it was revenge' " (Goldhagen, 1996, p. 396). Based on the evidence lending support to these two main arguments, Goldhagen felt confident in asserting that a uniquely German strain of murderous anti-Semitic hatred (in conjunction with a regime bent on annihilation) was, on its own, a "sufficient" cause of the Holocaust (Goldhagen, 1996, p. 417).

\footnotetext{
${ }^{13}$ Goldhagen's (1996) evidence included nineteenth century anti-Semitic political commentaries (p. 60), community petitions against Jewish emancipation (pp. 61-62), accusations of Jewish ritualistic murders (pp. 63-64), the views of prominent anti-Semitic polemicists (pp. 54, 64), anti-Semitic pamphleteering (p. 68), and anti-Semitic electoral voting patterns (pp.75-76). Goldhagen tried to differentiate between this apparently swelling nineteenth century anti-Semitic "eliminationist mind-set" (p. 71) with what by the twentieth century had developed into an "exterminationist one" (p. 71). He posited the existence of an exterminationist mind-set by providing early twentieth century examples of blatant anti-Semitic discrimination (p. 83), riotous attacks on Jews (p. 84), and a brief overview of Hitler's antiSemitic-related "meteoric" (p. 85) rise in the electoral polls.
} 
How, then, was Goldhagen able to suggest his overall theory was a sufficient cause when other scholars long before him, including Milgram, had presented a variety of alternative theories that they more cautiously promoted only as necessary conditions contributing to the cause and eventual extent of the Holocaust? To clarify, in the Holocaust historiography there exists what Goldhagen (1996, p. 379) describes as "conventional explanations". The conventional explanations he presented were that the German perpetrators were coerced into killing; were unthinkingly obedient in following orders; pressured to conform due to social psychological influences (such as peerpressure); motivated by prospects of personal advancement; and finally, due to the fragmentation of the killing process, they did not comprehend the total implications stemming from their individual actions (Goldhagen, 1996, pp. 379-385). It would appear that the reason Goldhagen was able to promote his overall theory as a sufficient cause of the Holocaust was due to a rebuttal he presented that challenged the veracity of all the conventional explanations. According to Goldhagen, his rebuttal exposed a flaw in an underlying assumption that all the above conventional explanations took for granted. Goldhagen's (1996, p. 385) rebuttal was that each of the conventional explanations "assumes that the Germans were in principle opposed (or would have been had they not, supposedly, been rendered 'indifferent,' numbed by their institutional circumstances) to the mass slaughter of Jews, to a genocidal programme [italics added]." The institutional circumstances that Goldhagen discussed were ones that other scholars believed both diminished opposition and promoted indifference and were side-effects generated by the modern bureaucratic administrative and technological machinery of destruction. However, Goldhagen's second argument appeared to demonstrate that many of the perpetrators in the unsophisticated killing institutions did not feel indifferently towards their Jewish victims. He also demonstrated that in these unsophisticated killing institutions (and thus in the absence of the more modern machinery of destruction), the perpetrators did not oppose the slaughter of their victims. Goldhagen therefore believed the evidence he presented in favour of these two arguments placed the plausibility of all the conventional explanations and their apparently necessary conditions in a sudden state of doubt.

Although this criticism was generally directed at the contributions by scholars including Stanley Milgram, Hannah Arendt, Christopher Browning, and indirectly, Zygmunt Bauman, with its specific focus on attacking theories expounding the centrality of the Nazi regime's bureaucratic machinery of destruction, Goldhagen (1996) had his sights set on the leading figure of "Raul Hilberg, who can be seen as an exemplar of this 
sort of thinking" (p. 385). Nevertheless, having just swept Hilberg, his many supporters, and all of their necessary conditions aside, as far as Goldhagen was concerned, the path had been cleared of all the obstacles inhibiting his theory from being the most plausible. This is why Goldhagen felt confident in concluding that a uniquely German brand of murderous anti-Semitic hatred (in conjunction with a regime bent on annihilation) was, on its own, a sufficient cause of the Holocaust.

How successful, then, were Goldhagen's two arguments (and the evidence they were based upon) in supporting his overall theory? Goldhagen completely failed to persuade the vast majority of specialist academics with the first argument surrounding his historical account of Germany's unique strain of exterminationist anti-Semitism. ${ }^{14}$ Critics highlighted the existence of contradictory evidence. For example, Goldhagen could not adequately explain why German society in the nineteenth century emancipated a Jewish population that his book argued they actually hated and wanted to eliminate (Bartov, 1996b, p. 34; Finkelstein, 1997, p. 51). Also, Goldhagen's historical account of German anti-Semitism could not explain with sufficient force why other nations with demonstrably more violent historical relations with their Jewish communities, like the Soviet Union, had not tried to exterminate this minority (Finkelstein, 1997, p. 41; Hilberg, 1997, p. 724) nor why this supposed hatred suddenly seemed to disappear after World War Two (Bartov, 1996b, p. 34; Finkelstein, 1997, p. 44). The consequences of these types of criticisms saw most of Goldhagen's more senior peers conclude that his historical account of German anti-Semitism both before and/or during the Nazi regime was simply "unhistorical" (Stern, 1996, p. 129).

However, Goldhagen's second argument that ordinary Germans frequently and willingly volunteered to engage in and inflict upon Jews cruel acts of violence emerged relatively unscathed from academic criticism. ${ }^{15}$ In fact, although Browning (1998, p. 192) was highly critical of Goldhagen's first argument and overall theory, in clear support of his second argument he pointed out: "On several issues Goldhagen and I do not disagree: first, the participation of numerous 'ordinary' Germans in the mass murder of Jews, and second, the high degree of voluntarism they exhibited." However, Browning (1998, p. 192) also pointed out that, due to the findings of his 1992 book and the much earlier contributions of scholars like Hilberg: "neither of these conclusions is a new discovery in the field of

\footnotetext{
${ }^{14}$ See Aschheim (1996), Bartov (1996b), Bauer (2001), Browning (1998), Finkelstein (1997), Finkelstein and Birn (1998), Hilberg (1997), Stern (1996), and Traverso (1999).

${ }^{15}$ See Birn (1997, p. 199) for a criticism of Goldhagen's second argument.
} 
Holocaust studies." With a sting of derision, Bartov (1996b) succinctly captured the main message he took from HWE in the oxymoronic title of his book review: if Goldhagen was right, the perpetrators must have been "Ordinary Monsters" (p. 32).

Because Goldhagen's second argument emerged largely unscathed from significant academic criticism, it would seem to this author that, despite its debatable originality, it still reinforced his attack on all the conventional explanations. Regardless of this success, most of the specialist historians still rejected Goldhagen's overall theory. This was because they questioned how a uniquely German brand of anti-Semitic hatred could have caused the Holocaust when, in the first place, historical evidence is incapable of substantiating the claim that German society was virulently anti-Semitic. The majority of historians are of the opinion that most Germans, even within and particularly beyond the Nazi party, might more accurately be described as mildly anti-Semitic, even to the point of feeling "absolute indifference to their [the Jews] victimization" (Bankier, 1992, p. 84).

In response to the flood of criticism undermining the plausibility of his first argument, Goldhagen (1996b) has stated: "Even if some would conclude that I am not entirely correct about the scope and character of German anti-Semitism, it does not follow that this would invalidate my conclusions" (p. 40). With conviction, he maintains: "The central part of the study, about the perpetration of the Holocaust, logically, can stand on its own and must be confronted directly" (Goldhagen, 1996b, p. 40). Most, however, believed his inaccurate portrayal of German anti-Semitism invalidated his conclusion and it was for this reason Hilberg (1997) argued: "By the end of 1996 . . much of the academic world had wiped Goldhagen off the map" (p. 725).

Based on the tone of his late 1996 article A Reply to my Critics: Motives, Causes, and Alibis, it is not difficult to sense Goldhagen's frustration. He believed HWE had not only rendered all the conventional explanations redundant, with regards to the actual perpetration of the crime (and unlike the other explanations), he provided a theory that was consistent with nearly all of the facts-the perpetrators were cruel so they must have hated the Jews. But what really appeared to grate on Goldhagen (1996b, p. 39) was that "my critics say that my explanation is wrong without providing any coherent alternative." Instead of rebutting Goldhagen's explanation, many of his critics simply chose to ignore the existence of his contribution. In fact Goldhagen's harshest adversaries like HansUlrich Wehler (1998, p. 93) dismissively described HWE as a "thorn in the flesh", a semipermanent nuisance whose confounding influence on the discourse might hopefully 
dissipate with time (sooner preferred over later). Similarly, Hilberg (1997, p. 728) argued: "Thus the cloud that Goldhagen created will hover over the academic landscape. It will not soon disperse." Goldhagen (1996b, p. 39) issued his critics a challenge: "if some deem my explanation simplistic, then they must demonstrate that a better one exists." This challenge would appear to derive from Goldhagen's belief that none of the conventional explanations are able to account for the cruelty his thesis evidenced. Goldhagen (1996b) then derided those who instead choose to overlook the probable importance of his thesis by arguing:

Not a single critic even attempts to account for the perpetrators' cruelty with its specific features; not a single critic provides any explanation of his own for the voluntarism and the zeal of the perpetrators (p. 39).

Unable to provide Goldhagen with an adequate rebuttal to this point, prominent critics of his first argument and overall theory could only agree. For example, Browning (1998) has stated: "Goldhagen is quite correct that cruelty in the Holocaust . . . is an issue that scholars have not dealt with at length" (p. 208). Bauer's (2001) view is similar to Browning's in that, although he believes "Goldhagen's discussion about [anti-Semitic] norms that did not exist is useless" (p. 103), in relation to the controversial book's point surrounding the issue of cruelty, he conceded: "He is right to emphasize this aspect because not enough has been said about it" (p. 102). Irrespective of this concession, however, just like Browning, Bauer (2001, p. 102) still sides with Hilberg: "ordinary people were guided by the bureaucratic machine."

With respect to Goldhagen's valid point regarding the issue of cruelty, Hilberg's "wiped ... off the map" statement gives one the impression that HWE has somewhat unfairly been fast-tracked to oblivion. This may not be too surprising considering the somewhat obvious problems Goldhagen's issue of cruelty poses for Hilberg's influential thesis. Initiated by Hilberg (1961), prominent scholars like Arendt (1963), Bauman (1989), Rubenstein (1978) and—central to the present study-Milgram (1974) have all, to varying degrees, argued that the potentially destructive bureaucratic process accentuated the eventual death toll because it provided the vast majority of the perpetrators with a necessary psychological buffer. As Hilberg (1961, p. 1024) said:

It must be kept in mind that most of the participants did not fire rifles at Jewish children or pour gas into gas chambers. A good many, of course, also had to perform these very 'hard' tasks, but most of the administrators and most of the clerks did not see the final, drastic link in these measures of destruction.

Hilberg and his many adherents are of the opinion that the segmented, routinised, 
depersonalized, and thus bureaucratised killing process enabled most of the perpetrators to avoid feelings of sympathy and personal responsibility for their victims' deaths. However, Goldhagen's argument that the perpetrators who actually undertook the shootings were ordinary would question the necessity of this buffer inherent to the bureaucratic process. The importance of this buffer is questioned because if those at the "final drastic link" in the bureaucratic process were "ordinary" Germans yet capable of the grisliest of deeds-what would have stopped the "normal" 16 desk murderers from engaging in the very same behaviours in the absence of the bureaucratic process? More explicitly, those perpetrators who delivered the coup de grace — just like those blinkered to the final drastic link-were ordinary, average, and therefore generally representative of wider German society. The psychological buffers provided by the division of labour inherent in the bureaucratic process, according to Goldhagen, were therefore unlikely to have been a necessary condition contributing to the cause and eventual extent of the Holocaust.

HWE may have highlighted potential weaknesses with Hilberg's thesis, but it all but truncated the M-H linkage. That is, although like Browning (1992) and Naumann (1966) before him, Goldhagen argued that the perpetrators frequently and willingly volunteered to undertake the grisly shootings, he also went a step further. Goldhagen provided an example of lower-ranking Nazis disobeying orders from the highest authorities to stop killing. Such counterfactual information powerfully indicated that the perpetrators may not have been, as Milgram's theoretical framework assumed, externally manipulated into participating.

HWE has generated an academic impasse with a minority in support and a majority who have rejected its ambitious assertions. Nearly all historians agree that Goldhagen's (1996) first argument surrounding his historical account of anti-Semitism in German society is untenable. Nevertheless, very few dispute Goldhagen's second argument that, with regard to the Jewish victims, many ordinary Germans volunteered to engage in cruelty. Importantly, the survival of his second argument maintains the potential validity of the criticism he directed at all the conventional explanations.

Treating the less disputable aspects of Goldhagen's thesis with the kind of respect some of his undeniably valid points deserve, it was at this point in the historiography that Bauer incisively cut to the crux of the problem that HWE was ultimately incapable of overcoming but was at least willing to confront. That is, Bauer (2001, p. 103) asked his

\footnotetext{
${ }^{16}$ See Arendt (1963, p. 22).
} 
"real question" of how what appeared to be a mostly moderately anti-Semitic society like Germany in the early 1930s became, by the early 1940s, willing murderers of Jews? Reinforcing Bauer's question and juxtaposing the 1938 Kristallnacht pogrom with the mass murder of Jews in Eastern Europe three year later, Browning (2004, p. 429) asked: “How in three brief years had 'ordinary' Germans been transformed from 'onlookers' squeamish and disapproving of vandalism, arson, and assault into 'willing executioners' who could perpetrate mass murder with unfettered violence [italics added]?"

Taking into consideration the previously discussed commonality shared by the Nazi regime and Milgram, that both proved capable of rapidly transforming large proportions of ordinary people into willing inflictors of harm, perhaps a similar question to Bauer and Browning's could be directed at the OTA experiments? That is, how did Milgram so rapidly transform his also ordinary and indifferent subjects into willing torturers of other human beings? Seeking an answer to this question of how Milgram persuaded his ordinary subjects to do what they did might prove fruitful in providing an answer to Bauer's (then Browning's) former question. Thus, a potentially fruitful methodological approach to addressing Bauer and Browning's question as to how during the Holocaust ordinary and indifferent people could so quickly become willing executioners might be to unravel the journey Milgram traveled that led to what is arguably his research's ostensibly similar end.

The following two chapters will address this first key research question. That is, initially focusing on influences that led to the eventual invention of the OTA experiments, how did Milgram so rapidly transform such a large proportion of his ordinary subjects into willing torturers of other human beings? 


\section{Chapter Four: The Development of Milgram's Obedience to Authority Experiments}

Part of Milgram's genius, as reflected in his past research, was to identify questions worth pursuing and then, if needed, invent methods suited for them-Blass (2004, p. 240).

It is not unusual for those scholars largely critical of the Obedience to Authority (OTA) research programme to still concede to having been impressed with aspects of Milgram's work. One example was Marcus (1974, p. 2) who, after writing a largely negative review of Milgram's monograph, went on to conclude that the experimental programme was "devilishly ingenious, cleverly thought out, and-whatever one thinks of them-extremely provocative and probably important." How did Milgram come up with an idea that, as Miller (1986, p. 1) has argued, became "perhaps the most widely cited and provocative set of experiments in social science"? This chapter will present a narrative on the key influential events, experiences, and people most likely to have contributed to the eventual conception of Milgram's widely respected research idea. It would appear that the influences were many and varied, and the earliest can be traced as far back as Milgram's early childhood.

\subsection{Stanley Milgram: Beginnings and Early Influences}

The Nazi regime came to power in Germany in January 1933. Several months later, on 15 August in the Bronx in New York City, Stanley Milgram was born into a working class Jewish family. His Hungarian father and Romanian mother strove hard to maintain a successful small bakery and cake-decorating business. There were three characteristics that might best describe the young Milgram: he was bright, imaginative, and very curious (Blass, 2004, pp. 1-5). From an early age he showed a keen interest in a wide variety of scientific pursuits ranging from mixing sometimes explosive chemical concoctions to later, at age 15, creatively designing a dual-jet-propelled crank shaft that "uses centerfigual [sic] force" (Tavris, 1974b, p. 75). As he himself said: "I was always doing experiments; it was as natural as breathing, and I tried to understand how everything worked" (Tavris, 1974a, p. 77).

Life for young Milgram was not without a more solemn side: throughout his childhood “Stanley was very much aware of his family's worries about Nazi Germany. 
His father had family living in Europe, and he and [his mother] Adele followed developments there closely on the radio" (Blass, 2004, p. 8). Although understandably commonplace among Jews living in the post-war era, this awareness of what from the United States was the geographically distant persecution of the European Jews appears nonetheless to have extended into his formative years. This sensitivity is evidenced in his rather precocious 15 August 1946 Bar Mitzvah speech:

As I come of age and find happiness in joining the rank[s] of Israel, the knowledge of the tragic suffering of my fellow Jews throughout war-torn Europe makes this also a solemn event and an occasion to reflect upon the heritage of my peoplewhich now becomes mine (Blass, 1998, p. 49).

It was perhaps no coincidence that, first, by only two weeks, this speech preceded the verdict of the widely publicised ten-month-long Nazi war-crimes trial in Nuremburg, Germany. ${ }^{17}$ And, secondly, relatives (in-laws) who directly survived the Nazi concentration camps stayed in the Milgram household during 1946 (Fermaglich, 2006, p. $100)$.

Milgram went on to attend the Bronx's James Munroe High School where, with interests as diverse as stagecraft in school productions and a role as the editor of the school newspaper, he developed and nurtured creative talents he would later in life come heavily to depend upon. As editor of the school newspaper the teenage Milgram reveals a fascination with the more destructive and morbid side of human affairs: "my first article in 1949 was on the effects of radiation on the incidence of leukemia in the Hiroshima and Nagasaki survivors" (Tavris, 1974a, p. 77).

In the same year at James Munroe High there was an acquaintance of Milgram's by the name of Philip Zimbardo, who would later undertake another (in)famous social psychology experiment: the 1971 Stanford Prison Experiment. ${ }^{18}$

After high school Milgram enrolled at New York City's Queens College where he "fell away" from the pure sciences of chemistry and biology and instead ended up majoring in political science with a minor in the arts (Tavris, 1974a, p. 77). As an

\footnotetext{
${ }^{17}$ Assuming his Bar Mitzvah was held on the exact date of his thirteenth birthday, the above speech would have been delivered on 15 August 1946. The judges first meet for the Nazi war-crimes trial in Nuremburg on 29 October 1945. Sentences were passed on 1 October 1946 (Marrus, 1997, p. 257).

${ }^{18}$ In this study subjects were randomly assigned in a mock prison as either prisoners or guards. The experiment had to be abandoned prematurely after spiraling out of control (Zimbardo, Haney, Banks \& Jaffe, 1973).
} 
undergraduate, Milgram developed a fascination with foreign lands, peoples, and their cultures. This interest was reflected both in his becoming president of the university's international relations club and his decision in the summer of 1953 to embark on a lone backpacking tour of France, Italy, and Spain. During this trip Milgram honed his ability to speak French fluently, enrolling in a one-month language course at the Sorbonne, in Paris (Blass, 2004, pp. 11-12).

Before completing his BA with honours at Queens College in 1954, Milgram had already been accepted into Columbia University's graduate programme at the School of International Affairs. However, before graduating he had become increasingly frustrated with political science's then predominantly philosophical approach (Blass, 2004, p 13). Simultaneously, the young scholar became interested in social psychology and began considering the possibility of studying this relatively new and exciting discipline. Before long, Milgram decided to apply for a place in Harvard's Department of Social Relations graduate programme (Blass, 2004, pp. 13-14; Tavris, 1974a, p. 77).

In his 12 April 1954 Harvard application, Milgram pointed out that it was "Periods of war I find particularly interesting" (SMP, Box 1, Folder "a", Titled: "Correspondence 1954”). However, it was in his scholarship application to the Ford Foundation that he more specifically indicated where some of his interests in war lay:

My estimates of my ability to undertake sustained, independent research was boosted by my writing, last semester, an honors paper (of formidable dimensions) entitled 'The French Press Under the German Occupation,' which seems not a particularly difficult task until one learns of the paucity of secondary source material and the unassembled and scattered conditions of primary sources (SMP, Box 1, Folder "a", Titled: "Correspondence 1954").

Before entering Harvard, the crimes of the Nazi regime were already engaging his intellectual curiosity.

Never having previously studied psychology, Milgram's application to Harvard was rejected. However, during the summer of 1954 a determined Milgram swiftly remedied this deficiency by enrolling in and completing six courses (five of which were in psychology) at three local New York City colleges. Financed by his subsequently successful scholarship application to the Ford Foundation, Milgram was soon after accepted into Harvard University (Blass, 2004, pp. 14-16). 


\subsection{Harvard University and the Influence of Solomon Asch}

At Harvard's Department of Social Relations, Milgram was exposed to a number of highly regarded intellectual figures and a wide variety of their stimulating and cutting-edge ideas. In reference to scholars such as Talcott Parsons and Henry Murray, but especially Jerome Bruner, Roger Brown, and his eventual mentor, Gordon Allport, Milgram commented that: "Men of uncommon wisdom ran things at the time, and created a climate in which ideas and excellence found ready support and encouragement" (Tavris, 1974a, p. 77). It is not difficult to appreciate that this was just the kind of environment in which a hungry, fertile, and creative young mind like Milgram's was likely to thrive.

In Milgram's first two years at Harvard the topic of national characteristics and stereotypes increasingly captured and stimulated the young scholar's imagination. This is evidenced by the following quotation, taken from Milgram's first-year lecture notes when Allport, a world-renowned social psychologist, presented his class with an overview of one particular study that cross-culturally performed a discourse analysis on a sample of German and American plays:

Allport - 20'55 Cross cultural method - National Character ... .

CONTENT [Indecipherable name] performed content analysis of ANALYSIS OF 45 German and 45 American plays produced in 1927, GERMAN PLAYS. analyzing content, themes.

German plays much more about men than women, much more ideological, social. American plays centered on private problems - German hero has ideological rendezvous with destiny - must disregard personal destiny problems. In American drama, hero is successful character- because his character changes. In German plays, ending Fullfilment [sic] may be tragic but his character is fulfilled (SMP, Box 17, Folder 256, Titled: "Harvard University: Social Relations Department Course Notes 1954”).

In the left-hand margin of this document is a rather large asterisk uniquely underlined with three bold lines (signalling what one would assume to be an area of particular interest and/or importance). ${ }^{19}$ It is suspected that this purposefully highlighted section of Milgram's lecture notes, as emphasised in capital letters, may signal an extension of what

\footnotetext{
${ }^{19}$ With respect to Milgram's two lecture books held in the archive (SMP, Box 17, Folders 256 and 257 , Titled: "Harvard University: Social Relations Department Course Notes") the young scholar occasionally highlighted, with an asterisk, passages of what one would assume were his areas of interest and/or importance. However, only the above quotation had an asterisk boldly underlined three times.
} 
was at the time the young scholar's incipient intellectual curiosity surrounding Germany and the ignominy of its recent past. The following year Milgram enrolled in a course headed by Roger Brown, where he read a hundred or so articles and books on the topic of national characteristics and stereotypes (Blass, 2004, p. 31).

A particularly influential figure on Milgram at Harvard was a visiting scholar by the name of Solomon Asch. Asch was prominent in social psychology for having undertaken a deception-based study termed the Group Pressure/Conformity experiment (Asch, 1958). This experiment involved an instructor who informed eight men who were seated around a table that they were to assess which of three unequal lines presented before them matched that of a separately presented line (with the correct answer being patently obvious). Each was to express their assessment to the group, starting with the first subject and moving around the table. However, not all was as it appeared: all except the seventh person in line were actors. Sequentially the "subjects" selected the correct answers. By the third trial (and randomly thereafter) each of the actors gave the same-but this time clearly incorrect-answer. Asch was trying to assess whether or not the actors' incorrect answers might have a conforming influence on the only actual subject. Confronted quite suddenly by an internal conflict to either trust their independent assessment or yield to that of the seven actors, it was discovered that 32 percent of all the subjects' assessments $(n=50)$ conformed to that of the group, meaning that they were providing answers they probably knew to be wrong (Asch, 1958, pp. 176-177). Asch increased his confidence that the individuals' provision of incorrect answers was actually due to the group's influence by presenting the line assessment exercise to randomly selected subjects in the absence of the group $(n=37)$. This simple control experiment revealed 99 percent of all line-assessments by lone subjects were indeed correct.

In some edited notes (circa 1956-1959) Milgram cut to the crux as to exactly "Why Asch's expt [sic] is a Great Experiment":

He belives [sic] that the conflict with him is a purely private issue which concerns no one but him, and of which all others are totally unaware. He dares not betray his secret, yet by his actions, he is betrayed. The yielding subject makes frantic efforts to conceal his conflict, yet by these efforts is the conflict betrayed (SMP, Box 43, Folder 124, Titled: "Notes and data analysis, 19561959, n.d.”).

The influence on Milgram of this intrinsic feature of Asch's experiment, where subjects experience a seemingly private (yet, due to the choices made, scientifically observable) internal conflict, proved enduring. Internal conflict was not only a subtle yet inherently 
crucial feature of his eventual $\mathrm{PhD}$ thesis, its presence can be discerned in various guises in the OTA experiments which followed, and arguably even in his mid-career Lost Letter Technique experiment (Blass, 2004, p. 143). Extending and cementing this methodological influence was Allport's assignment of Milgram to be Asch's teaching/research assistant during the latter's stay at Harvard during the 1955/56 academic year (Blass, 2004, pp. 27, 31). The renowned scholar went on to stamp his indelible intellectual influence on his new apprentice (Tavris, 1974a, p. 77).

\section{$\underline{4.3 \quad \text { Milgram's PhD Thesis }}$}

Soon after his time with Asch, around the middle of 1956, Milgram conceived of an extremely ambitious experiment for the final part of his $\mathrm{PhD}$ degree. Drawing on all of the factors mentioned thus far, his idea was to undertake a procedural adaptation of Asch's experiment. Instead of using pictures of lines, Milgram wanted to present subjects with an auditory tone that they were to try and match up correctly with one of several others that soon followed. More specifically, a subject was to enter a laboratory and encounter a coat rack piled with jackets and a row of seemingly occupied closed booths, the sixth of which they were to enter. After placing on earphones and hearing the acoustic tones, the subject would hear the responses of the other subjects. In fact, the other booths were empty and the responses were pre-recorded by actors. Like Asch's experiment, initially the other "subjects" would sequentially all give the obviously correct answer but eventually they started providing the same clearly incorrect answer.

In a number of ways Milgram's adaptation was scientifically more rigorous than Asch's experiment. Unlike Asch's prototype, the actors' responses were uniform and had therefore been scientifically standardised. Also, Milgram informed his subjects that their responses would contribute to the improvement of air traffic safety signals, thus investing into their performance potentially "life and death" consequences (Milgram, 1961, p. 48). This would overcome a significant limitation applicable to Asch's original experiment in that it could be argued that his conforming subjects probably experienced little compunction in siding with the group because, due to the seemingly trivial nature of the line-judgment task, doing so had no significant consequences.

But most innovative was Milgram's plan to use subjects from different countries. Drawing on the influence of Allport and Brown, by using the adaptation on subjects of 
different nationalities, Milgram intended to undertake a cross-cultural comparison that would transform "the topic of national characteristics from armchair speculation to an object of scientific inquiry" (Blass, 2004, p. 53).

The countries that Milgram intended to include in his cross-cultural adaptation of Asch's Group-Pressure-Conformity experiment were revealed in a preliminary hypothesis dated 24 September 1956: "(Now interms [sic] of the things I have read and seen, I would predict as follows: Conformity, as measured by the mean differences of pressured responses will be G[ermans]>E[nglish]>F[rench]" (SMP, Box 43, Folder 125, Titled: "Norwegian + French Study: Notes \& data analysis 1956-1958 n.d."). Based on what he had "read and seen", Milgram's prediction that a greater proportion of Germans could probably be cajoled into conforming with the group than equivalent groups of English then French subjects is intriguing. What Milgram had "read and seen" probably related to the populist post-World War Two stereotype that, as evidenced by their broad participation in the Holocaust, Germans were probably the easiest nationality to manipulate into conforming. ${ }^{20}$ It seems ironic that Milgram himself, having just undertaken a course on national character and stereotypes, had formulated the hypothesis for his $\mathrm{PhD}$ on the basis of a then-prevalent stereotype.

On 17 October 1956 Milgram informed Allport of the idea he hoped to pursue as a thesis for the final leg of his $\mathrm{PhD}$ :

In brief, I would like to write my thesis in 1957-58, on the subject of national character, and with you as my thesis director . . . . For a long time I have had an interest in psychology as it applies to national groups. You may remember my somewhat tedious analysis of 'national stereotypes' written for your Social Psychology qualifying course in the spring of 1955 . . . I would like to run a variation of Dr. Asch's group pressure experiment across several European countries, in particular, England, France, and Germany (SMP, Box 13, Folder 183, Titled: “Allport, Gordon 1954-1967”).

Allport's response reveals that he agreed to be Milgram's thesis director, saw potential in the initial idea but, armed with far greater research experience, ultimately deemed aspects of the experiment a little naïve, unrealistic, and in need of substantive revision: "The design you outline is not feasible, I fear. Chiefly, the difficulty is your overly optimistic

\footnotetext{
${ }^{20}$ Dicks (1950, p. 137) study of German prisoners of war is an example of literature that may have encouraged this stereotype: 'Conformity and 'loyalty,' as of a servant to his master, are rated among the highest of virtues, and demonstratively stressed in home and institutional life, almost synonymous with 'honour' on the one hand and with unquestioning obedience on the other."
} 
view of facilities, availability of subjects, European collaboration. These are serious problems and you would experience endless frustration" (Blass, 2004, p. 33).

Although Milgram had already contacted government officials in England, France, and Germany with intentions of running "a psychological experiment in your country" (SMP, Box 1, Folder C, Titled: “Correspondence 1956”), upon his return to Harvard Allport convinced his underling to drastically scale down the initial idea to a two-nation comparison involving subjects from none of the above countries. Instead Allport persuaded Milgram to use subjects from the United States and Norway (Blass, 2004, p. 33). In terms of feasibility and logistics, including an American sample made obvious sense, but based on these criteria the selection of Norway is somewhat perplexing. Norway was probably chosen because English is widely spoken and Allport was aware that a number of academics from Oslo's Institute of Social Research were interested in and sympathetic towards experimentally-based cross-cultural research. Allport is therefore likely to have suspected that sending Milgram to Norway would hold a greater probability of European collaboration, and thus the probable provision of facilities and aid in the solicitation of potential subjects (Blass, 2004, pp. 33-34).

During the summer of 1956 Milgram undertook some pilot studies on a sample of American subjects (Harvard students) that, as he correctly guessed, produced high rates of conformity. In his first official research proposal, Milgram predicted that Americans would conform more than Norwegians. However, after having throughout 1957 collected the Norwegian data, Milgram discovered that the Scandinavians were little different from his American sample. Milgram's prediction of greater Norwegian independence was wrong and he needed to find a more promising comparator nation than the United States. According to Blass (2004, p. 41):

France came immediately to mind. His experience living in Paris during the summer of 1953 suggested that France was a country marked by far less social consensus than Norway, a country with a tradition that seemed to prize critical judgment and diversity of opinion. 'France seems to me to be a very good bet,' he wrote Allport. 'It takes me from the Nordic to Latin system; Norwegians and Frenchmen regard themselves as very different (and probably inter-sterile) breeds of men.'

As Blass has argued, for a wide range of reasons (the most important being that Milgram spoke the language fluently and particularly that it might offer interesting results in the very opposite direction to that of his Norwegian sample): "France came immediately to mind". However, it is curious that in the sentence immediately preceding this statement 
that "France seems to me a very good bet", the original document held at the Stanley Milgram Papers (SMP) reveals that Milgram also said: "Germany would be highly interesting, but I cannot handle the language" (SMP, Box 13, Folder 183, Titled: "Allport, Gordon 1954-1967'). ${ }^{21}$ This statement is interesting because Milgram had long suspected that Germans would be highly conformist. If he were right, there was a risk a German sample might be as dull a group as the Americans with which to compare to the conformist Norwegians. Yet, irrespective of this, for some reason there was clearly still something that drew Milgram to again contemplate undertaking his experimental procedure on what he expected to be a sample of highly conforming Germans.

During August of 1958 Milgram went to France (Blass, 2004, p. 48). After his arrival Allport's initial criticism of Milgram's original research proposal came back to haunt him. With respect to facilities, help in the solicitation of subjects, and collaboration, his suspicion of stubborn French independence unforeseeably saw Milgram experience what indeed must have felt like endless frustration (Blass, 2004, pp. 48, 50).

Milgram wrote a letter to a friend back at Harvard during this period, the contents of which illustrates that the Holocaust was never far from his thoughts:

I should have been born into the German-speaking Jewish community of Prague in 1922 and died in a gas chamber some 20 years later. How I came to be born in the Bronx Hospital, I'll never quite understand [italics original] (Blass, 2002, pp. 7172).

Milgram's misfortunes in France, however, soon changed for the better when the highly respected Harvard lecturer, Jerome Brunner, suggested he contact some of his colleagues based at the Sorbonne. After having done so, Milgram made more progress in collecting his French data (Blass, 2004, p. 50).

Although Milgram undertook in both countries five subtle variations on his basic research idea, his results revealed that on average the Norwegians and French conformed about 62 and 50 percent of the time respectively, a statistically significant difference. Particularly impressive was that, although across each of the five experimental variations the degree of conformity differed, the direction of this difference (Norwegians conforming more than the French) remained consistent throughout.

\footnotetext{
${ }^{21}$ Perhaps illustrating that this was no idle comment, Milgram repeated this statement verbatim, two days later, in a letter to Jerome Bruner, one of his Harvard lecturers (SMP, Box 1, Folder 'e', Titled: “Correspondence 1958”).
} 
It is important to mention here that before having undertaken his experiments Milgram had felt a little uneasy that, in order to obtain his results, he had to deceive his subjects and expose them to a clearly stressful situation. Milgram therefore went to great lengths to ensure the subsequent well-being of his subjects by undertaking thorough debriefings as well as administering a post-experimental check-up questionnaire. To Milgram's surprise:

It appears that most subjects were glad to have participated, despite the trickery involved. The reasons for this seem to be ... they understood that any deception used was not primarily for personal gain, but for the advancement of knowledge (Milgram, 1960, pp. 175-176, as cited in Blass, 2004, p. 44).

Blass (2004, p. 54) has argued that these rather unexpected responses had "carryover effects" which eased any remaining inhibitions Milgram might have had surrounding the use of deception and exposure to stressful situations in any future experiments.

\subsection{Milgram's Experience at Princeton: the Invention of the OTA Experiments and}

\section{Influence of the Holocaust}

Upon returning to Harvard, Milgram received and accepted an offer from Asch to edit his latest book on the topic of conformity while on sabbatical at Princeton University. Away from friends and working for the exacting Asch, Milgram found October 1959 to June 1960 a very demanding and somewhat depressing period in his life. Nonetheless, in several significant and overlapping ways, his time at Princeton ended most fruitfully for the young scholar's academic career.

First, far from Harvard's many distractions, the lonely nights at Princeton enabled Milgram to write rapidly and submit his $\mathrm{PhD}$ dissertation on time. Secondly, the subsequent glowing reviews of his thesis in conjunction with having referees like Allport (and other Harvard heavyweights), as well as the prestige of working with Asch saw both Harvard and Yale Universities offer Milgram academic positions. Milgram accepted Yale's offer as an assistant professor of social psychology starting the following September 1960. Thirdly, Milgram started (or soon thereafter) writing an abridged version of his thesis that was later accepted for publication in the internationally circulated magazine Scientific American (see Milgram, 1961). In the article Milgram announced a return of his attention to those who interested him most: 
We are now planning further research in national characteristics. In a recent seminar at Yale University students were given the task of trying to identify behavioral characteristics that might help to illuminate the Nazi epoch in German history .... A team of German and American investigators is planning a series of experiments designed to provide a comparative measure of behavior in the two countries (Milgram, 1961, p. 51).

Not only is this statement somewhat reminiscent of the first $\mathrm{PhD}$ research proposal he had presented to Allport in 1956, it also appears to add weight to the argument that the Holocaust was increasingly starting to engage Milgram's intellectual curiosity. More than a year after the above project had failed to materialise (due to funding issues), Milgram was still trying to solicit German contacts in the hope of one day making a reality his cross-cultural comparison using his adaptation of Asch's experiment on a sample of Germans. $^{22}$

Blass (2004, p. 54) has argued that the successful completion and publication of his $\mathrm{PhD}$ injected immense confidence into the young scholar, as is reflected in the bold tone of Milgram's above statement in Scientific American:

He now knew that he was capable of doing original research that would provide new insights about human behavior. It was an accomplishment that made him aim high and not settle for the mundane in his future career as a scientific researcher.

Milgram had a reputation for being ambitious, ${ }^{23}$ but it was around this period that he expressed an explicit awareness that success in academia would require that he undertake "an important and distinctive programme of research with which to make his mark. He told Roger Brown that he hoped to find a phenomenon of great consequence, such as Asch had done, then 'worry it to death [italics added]' " (Blass, 2004, pp. 61-62).

Such ambitions were soon realised with the fourth significant outcome that eventuated from Milgram's time at Princeton: the rudimentary conception of his landmark idea to undertake an experiment on OTA. The following is Milgram's own account of this process:

\footnotetext{
${ }^{22}$ See the correspondence between Robert Arndt (from Germany) and Milgram during April 1962 (SMP, Box 55, Folder 5, Titled: "Nationality and Conformity: Correspondence 1961-1962”).

${ }^{23}$ For example, with respect to his $\mathrm{PhD}$, on 21 December 1956, in a letter to Jerome Bruner, Milgram admitted: "The original plan called for a three nation study (England, France, Germany) [however] .... mostly students who have just completed their theses . . . have been trying to persuade me ... I should not overstretch myself at this time. 'Just write a good thesis Mr., and then do your grand scale research' " (SMP, Box 1, Folder C, Titled: “Correspondence 1956”).
} 
I was working for Asch in Princeton, New Jersey, in 1959 and 1960. I was thinking about his group-pressure experiment. One of the criticisms that has been made of his experiments is that they lack a surface significance, because after all, an experiment with people making judgments of lines has a manifestly trivial content. So the question I asked myself is, How can this be made into a more humanly significant experiment? And it seemed to me that if, instead of having a group exerting pressure on judgments about lines, the group could somehow induce something more significant from the person, then that might be a step in giving a greater face significance to the behavior induced by the group. Could a group, I asked myself, induce a person to act with severity against another person [italics added]? (Evans, 1980, p. 188).

Asch's research required subjects to make mere "judgments" with ultimately "trivial" implications. But, as he did with his $\mathrm{PhD}$ thesis, Milgram was interested in exploring whether or not it might be possible to raise the stakes by manipulating subjects into engaging in physical "act[s]" that had "humanly significant" implications. That Milgram intended "exerting pressure" on subjects—a skill he had become well versed in during his $\mathrm{PhD}$-is a very important point: he was toying with the idea of using group pressure to cement subjects into engaging in some other more significant behaviour. Milgram later termed such sources of pressure Binding Factors (BF): powerful bonds that can entrap a person into doing something they might otherwise prefer not to do.

Milgram then imagined a situation like Asch's experiment, where a naïve subject was placed among a group of actors:

instead of confronting the lines on a card, each one of them would have a shock generator. In other words, I transformed Asch's experiment into one in which the group would administer increasingly higher levels of shock to a person, and the question would be to what degree an individual would follow along with the group. That's not yet the obedience experiment, but it's a mental step in that direction (Evans, 1980, pp. 188-189).

In an earlier interview Milgram described the next conceptual step that moved him closer to his OTA paradigm:

I wondered whether groups could pressure a person into performing an act whose human import was more readily apparent, perhaps behaving aggressively toward another person, say by administering increasingly severe shocks to him. But to study the group effect you would also need an experimental control; you'd have to know how the subject performed without any group pressure [italics added] (Tavris, 1974a, p. 80).

Milgram was aware that Asch resolved the problem of requiring an experimental control by running the line judgment exercise on subjects in the absence of the group. However, Milgram was this time unable to draw from Asch's legacy because, as Miller (1986, p. 18) 
observed: "it was not obvious what the inducement would be for a solitary individual to administer shocks in increasing intensities to another person." Milgram had to develop his own solution to this problem. Hence, the shift from a conformity to obedience orientation:

my thought shifted, zeroing in on this experimental control. Just how far would a person go under the experimenter's orders [italics added]? It was an incandescent moment, the fusion of a general idea on obedience with a specific technical procedure. Within a few minutes, dozens of ideas on relevant variables emerged, and the only problem was to get them all down on paper (Tavris, 1974a, p. 80). ${ }^{24}$

Although this innovation provided Milgram with the crucial experimental control he desired, perhaps unwittingly it also introduced into the equation the new BF of a higherstatus authority figure trying to impose his will on a lower-status subject within a hierarchical chain of command (superordinate/subordinate relationship).

This "incandescent" moment—believed by Blass (2004, p. 63) to have taken place sometime between 2 March and the end of June 1960-was a watershed event. It initiated the journey that put Milgram on a path away from Asch-like group-conformity and increasingly towards, as Blass put it, his own "phenomenon of great consequence": the individual's response to the malevolent demands of an authority figure.

But what were the origins of these completely new additions to Milgram's ideas to introduce "orders" to "behaving aggressively"? They were probably due to the influence of the then-popular post-World War Two perception in the United States (and elsewhere) that the implementation of the Holocaust was closely associated with blind OTA. To clarify, immediately after the defeat of Nazi Germany, the victorious Allied forces placed on trial much of the surviving Nazi elite in the first of several Nuremberg war-crimes trials. Within the timeframe in which Milgram would have written his Bar Mitzvah speech, which paid homage to the "tragic suffering of my fellow Jews", the first trial saw most of those in the dock attempt to evade responsibility for their crimes by arguing that they were “just following orders". Subsequent Nazi war-crimes trials produced similar responses and the predictable "just following orders" justification gained its now long-clichéd status. Reasons for an apparently heightened German propensity to obey and enact the orders of superiors started to emerge in populist sources of literature. Highlighted were factors as diverse as the apparently ubiquitous German authoritarian style of raising children, Nazi

\footnotetext{
${ }^{24}$ Using different words, Milgram largely reiterated these thought processes in his later interview with Evans (1980, p. 189): "what would be the force that would get him to increase the shocks? And then the thought occurred that the experimenter would have to tell him to give higher and higher shocks. Just how far will a person go when an experimenter instructs him to give increasingly severe shocks?"
} 
indoctrination surrounding pledges of obedience to Hitler, and even the magnetic draw of the Führer's personality (Fromm, 1973, pp. 413-414; Koenigsberg, 2009, p. 5; Lee, 1996, p. 24). Strengthening further the association of OTA with the Holocaust were certain influential contributions to the academic literature; the most prominent example was Adorno, Frenkel-Brunswik, Levinson and Sanford's (1950) The Authoritarian Personality, which attributed the anti-Semitism that culminated in the Holocaust to authoritarian personality traits (Miller, 2004, p. 211). ${ }^{25}$ Consequently, there emerged a post-World War Two OTA zeitgeist:

Before Milgram, creative writers had incorporated striking incidents of obedience into novels, poems, and screenplays. Historians had written factual accounts of remarkably obedient individuals and groups. Psychologists had developed F- and other scales to measure inclinations towards authoritarian tyranny and subservience (Elms, 1995, p. 22).

In fact, it is "certainly possible" (Blass, 2004, p. 63) that the catalytic event that may have stimulated Milgram to incorporate "orders" into his more rudimentary idea was the highly publicised 11 May 1960 capture of the middle-ranking but central Nazi bureaucrat, Adolf Eichmann, in Argentina by Israeli secret agents (Raven \& Rubin, 1983, p. 421). His capture falls within the period in which Milgram experienced his “ 'incandescent moment' ” (Blass, 2004, p. 63). It was probably no coincidence that, concurrently with Eichmann's heavily publicised capture then trial $^{26}$ where he too argued he only did as he was told, ${ }^{27}$ Milgram was radically manipulating Asch's study into "a humanly more significant experiment" where subjects received "orders" to behave "aggressively towards another person".

Cementing the view that Milgram founded his research idea upon a stereotype about Germans, as he said himself: "I came across many statements which implied that Germans tended to obey orders more conscientious[ly] than Americans" (as cited in Fermaglich, 2006, p. 88). ${ }^{28}$ This remark is reminiscent of how he formulated the idea for

\footnotetext{
${ }^{25}$ See also McGranahan (1946), McGranahan and Janowitz (1946), and Footnote 20.

${ }^{26}$ Shandler (2001, p. 91) argued that in the United States Eichmann's trial "marked the first time that the Holocaust received prominent, extended television coverage in the form of news reports, public affairs programs, documentaries, and dramas aired over a period of months".

${ }^{27}$ In regard to the extermination of the European Jews, Eichmann said that he " 'felt something of the satisfaction of Pilate, because I felt entirely innocent of any guilt. The leading figures of the Reich at the time had spoken at the Wannsee Conference, the 'Popes' had given their orders; it was up to me to obey, and that is what I bore in mind over the future years" "(Cesarani, 2004, p. 277).

${ }^{28}$ Whilst undertaking the official experiments, Milgram stated that the "Origens [ sic] of my interest in Obedience" was the "Problem of German Behavior" (SMP, Box 46, Folder 165, Titled: "Notes general, 1961-1962”).
} 
his $\mathrm{PhD}$. Based on "the things I have read and seen", he predicted a sample of Germans were more likely to conform than otherwise comparable groups of English and French subjects. The etiology of the stereotypically conformist and/or blindly obedient nature of Germans in populist and academic literature both can be traced back to the rationalisations and justifications the Nazi war criminals provided for their actions after the war (see Footnote 20).

That Milgram's idea to include "orders" to "hurt another person" was largely stimulated by stereotypes about Germans during the Holocaust is reflected in the following previously unpublished document, probably written during the spring of 1960, while the young social psychologist was at Princeton, and thus during the period he probably conceived of the idea of undertaking an experiment on OTA: 


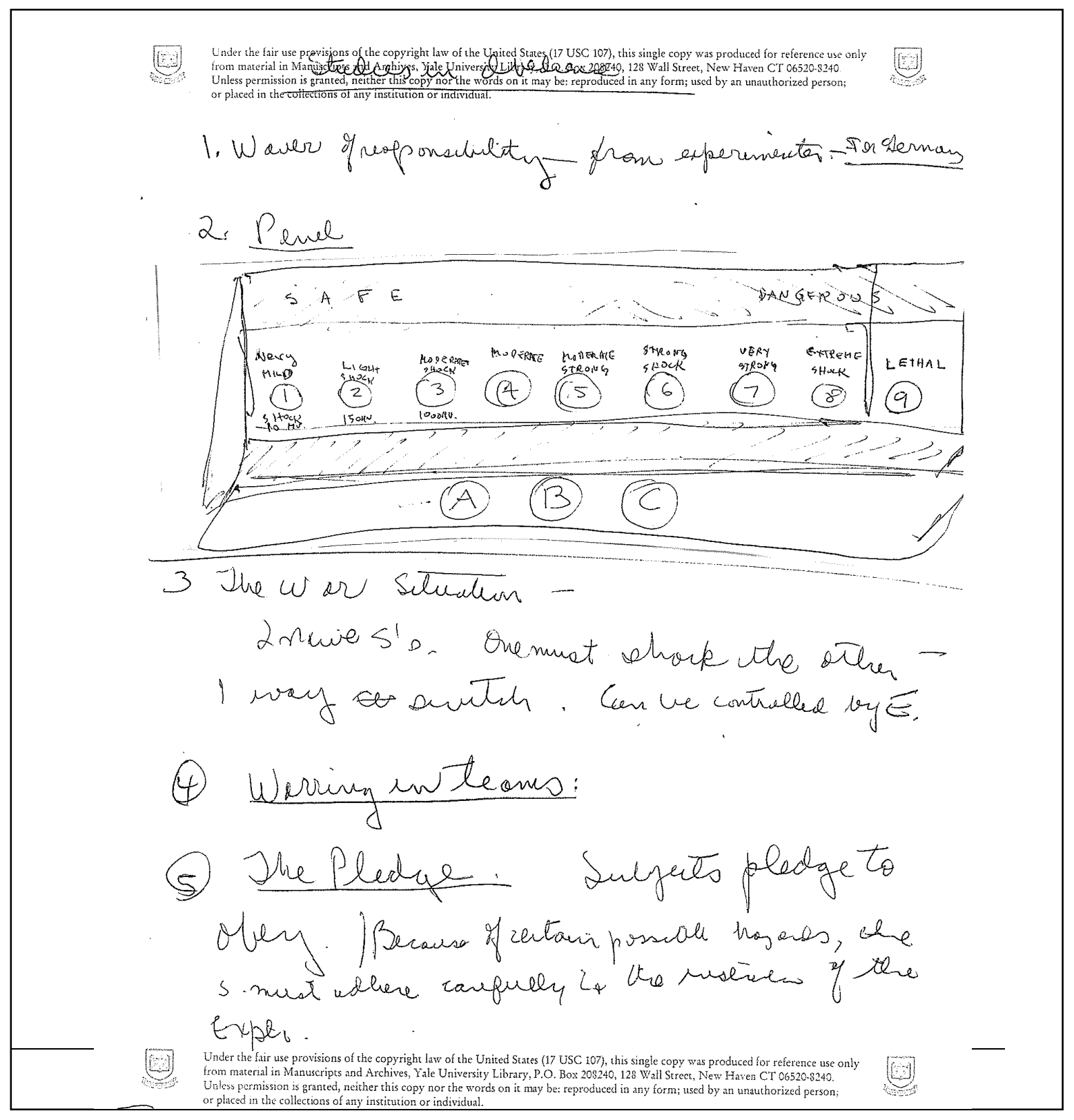

Figure 1: A document produced by Milgram during his time at Princeton University titled "Studies in Obedience" (SMP, Box 46, Folder 165, Titled: "Notes general, 1961-1962" $[$ sic $])^{29}$

Below is the independent transcription of the above document:

\footnotetext{
${ }^{29}$ The Sterling Memorial Library at Yale University has dated this document between 1961 and 1962 when Milgram was at Yale University. Yet this sketch of a shock generator is far more rudimentary than a drawing Milgram (1977, p. 95) himself dated "Spring 1960", when he was at Princeton University. It would be reasonable to infer that this document was actually produced between March and June of 1960 when Milgram's “incandescent moment" took place. This document was almost certainly produced sometime before 14 October 1960, probably around the spring of 1960, while working for Asch at Princeton University.
} 
Studies in Obedience

1. Waver [sic] of responsibility-from experimenter-For Germa[n]y

2. Panel

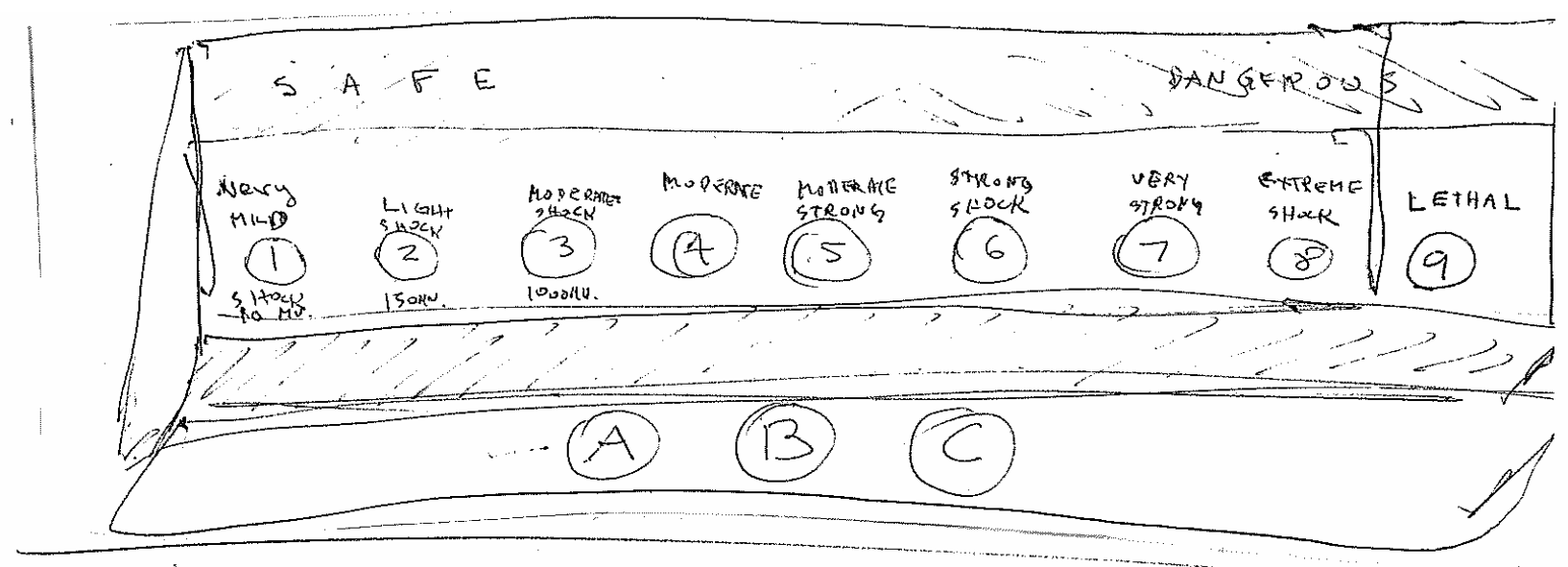

3. The War Situation -

2 naive S[ubject]'s. One must shock the other -

1 way switch. Can be controlled by E.

4. Working in teams:

5. The Pledge. Subjects pledge to obey. | Because of certain possible hazards, the S. must adhere carefully to the instructions of the Exp[erimen]t[e]r. ${ }^{30}$

Figure 2: An independent transcription of Figure 1..$^{31}$

Early in his eventual book, Milgram (1974, p. 14) explained why he decided upon such a device as his means of inflicting harm:

For technical reasons, the delivery of electric shock was chosen for the study. It seemed suitable, first, because it would be easy for the subject to understand the notion that shocks can be graded in intensity; second, its use would be consistent with the general scientific aura of the laboratory; and finally, it would be relatively easy to simulate the administration of shock in the laboratory.

Therefore, Milgram's previous experience as a student of social psychology, where the infliction of electrical shocks had long been common, proved influential in his selection of this device (see Schachter, 1959). And obviously, Milgram intuitively sensed that, with some coercion, subjects might actually be willing to use such a device to inflict harm on another human being.

\footnotetext{
${ }^{30}$ Although there is no mention of the Nazi regime or the Holocaust in the above post hoc explanation, elsewhere Milgram regularly endorsed their central role in the eventual conception of his OTA idea (Fermaglich, 2006, p. 88; Milgram, 1964a, p. 851; Milgram, 1977, p. 92).

${ }^{31}$ Dawn Yeabsley and Jean-Christopher Somers, at the School of Government, Victoria University of Wellington, independently transcribed the contents of this document.
} 
Nonetheless, in this document Milgram seems to have had in mind an Asch-like group experiment-“working in teams"-whereby all involved were, for some yet to be established hazardous reason, to accept a "pledge to obey" the experimenter's orders. Most of those involved would be actors with two naïve subjects (one of whom was presumably to be the victim and the other, using a one-way switch that could be controlled by the experimenter, a shock-inflictor). It would appear that the infliction of these shocks, which were to increase in intensity, was meant to reflect a war-like situation, in which those inflicting the shocks would not be held responsible for their actions. Only parts of this document resemble the eventual experimental paradigm, however. Few of the actual variations involved actors working in teams, and, although there was a waiver of responsibility and a shock generator that inflicted gradually escalating electrical shocks, there was no "pledge to obey" or an apparently "LETHAL" shock switch, and only nine shock switches.

Despite this, the catalytic event that may have stimulated Milgram to incorporate "orders to act with severity" into his more rudimentary idea may have been the highly publicised 11 May 1960 capture in Argentina by Israeli secret agents of the middle-ranking but central Nazi bureaucrat, Adolf Eichmann (Raven \& Rubin, 1983, p. 421). His capture falls within the period in which Milgram experienced his "incandescent moment". ${ }^{32}$ Blass (2004, p. 63) argues that: "It's certainly possible that this was the event that crystallized the obedience research in Milgram's mind." It was probably no coincidence that, concurrently with Eichmann's heavily publicised capture then trial ${ }^{33}$ where, like most other Nazis he too argued he only did as he was told, ${ }^{34}$ Milgram happened to be radically manipulating Asch's study into "a humanly more significant experiment" where subjects received "orders" to behave "aggressively towards another person".

\footnotetext{
${ }^{32}$ It has not been possible to confirm if Milgram followed closely the events surrounding Eichmann's capture. However, just over a year later he mentioned Eichmann's name in some of his written correspondence (see SMP, Box 43, Folder 127, Titled: “Correspondence 1961”).

${ }^{33}$ Shandler (2001, p. 91) argued that in the United States Eichmann's trial "marked the first time that the Holocaust received prominent, extended television coverage in the form of news reports, public affairs programs, documentaries, and dramas aired over a period of months".

${ }^{34}$ In regard to the extermination of the European Jews, Eichmann said that he " 'felt something of the satisfaction of Pilate, because I felt entirely innocent of any guilt. The leading figures of the Reich at the time had spoken at the Wannsee Conference, the 'Popes' had given their orders; it was up to me to obey, and that is what I bore in mind over the future years' " (Cesarani, 2004, p. 277).
} 


\section{$\underline{4.5}$ Conclusion}

It seems reasonable to conclude that, over time, it was the gradual confluence of several key factors that contributed to the conception of Milgram's idea to undertake an experiment on OTA. In sum, they were Milgram's long-term intellectual curiosity about the Holocaust; various experiences under a number of scholars during his $\mathrm{PhD}$ degree at Harvard; Solomon Asch (and his Group Pressure/Conformity experiment); and the populist post-World War Two zeitgeist that tended to closely associate OTA with the implementation of the Holocaust. ${ }^{35}$

In developing his inchoate OTA idea, it appears that Milgram basically threw into the mix what he suspected were important key ingredients needed to produce a Holocaustlike event: a command hierarchy of authority figures and subordinates, orders, and group pressure-all revolving around the infliction of harm on another person. It is here that the epigraph by Blass presented at the start of this chapter best rings true: Milgram frequently asked questions and would then "invent methods suited for them". ${ }^{36}$ It is clear that (as in the case of the Holocaust) the base question of interest was: how might one get rather ordinary people to severely hurt other human beings? However, due to the post-World War Two zeitgeist surrounding the association of obedience with the Holocaust, Milgram advanced a slightly different question. Discernable from his use of the words "orders" and "behaving aggressively towards another person", Milgram came to focus on the question: can orders from an authority figure lead to the infliction of harm $?^{37}$ Incorporating and building upon all the influential factors that culminated in his $\mathrm{PhD}$, Milgram went on to invent and then, as the following chapter will illustrate, refine an experimental method to produce scientific results that could help answer questions he had long held surrounding the extermination of the European Jews. ${ }^{38}$

\footnotetext{
${ }^{35}$ Other probably less important factors were probably involved (see Tavris, 1974a, p. 80).

${ }^{36}$ As Tavris (1974b, p. 75) pointed out: "Most psychologists test hypotheses; Milgram asks questions."

${ }^{37}$ As Milgram wrote in his early notes: "Stated most simply, the basic command is to hurt another person." Aware of the controversial nature of his experimental aim, he then stated: "(Don't [s]ay this in grant)" (SMP, Box 46, Folder 165, Titled: "Notes general, 1961-1962").

${ }^{38}$ As Milgram had said in relation to a different line of research: "Methods of inquiry must always be adapted to the problem at hand" (Tavris, 1974a, p. 71).
} 


\title{
Chapter Five: How Milgram Induced Most Ordinary Subjects to Complete the Obedience to Authority Experiments
}

\begin{abstract}
Much of empirical science is exploratory, and involves a methodology not at all like the traditional idea of hypothesis, prediction and test. In exploratory studies, a scientist has no very clear idea what will happen, and aims to find out. He [sic] has a feeling for the 'direction' in which to go (increase the pressure and see what happens) but no clear expectations of what to expect-Harré and Second (1972, p. 69).
\end{abstract}

This chapter will discuss how Milgram conceived of an experimental procedure that by the first official experiment produced a 65 percent completion rate. There is little published information on the development of Milgram's experimental procedure, which in its complete form did not leap suddenly from the depths of Milgram's imagination. Nor is it the case that, unlike all the psychiatrists he later approached, Milgram foresaw that his procedure would counterintuitively prove capable of producing such high completion rates.

The experimental procedure was the end result of a rather protracted process that largely involved some combination of Milgram drawing on his past experiences, shrewd intuition, and a heavy reliance on the ad hoc exploratory method of discovery. As noted in the above epigraphic statement, the exploratory method of discovery is where the scientist has an intuitive idea of the direction an inquiry should take, but little insight into what might happen along the way. They deploy as their vehicle of discovery a number of ad hoc trial and error pilot studies_- "see what happens"-in the pursuit of a vaguely delineated outcome.

\section{$5.1 \quad$ The First Obedience to Authority Research Proposal}

In September 1960 Milgram arrived at Yale University and embarked upon what would turn out to be a highly creative academic career. By the first week of October he submitted his first official research proposal. In light of his recent "incandescent moment" it is surprising that this proposal was not about obedience to authority (OTA), but concerned an observational study on the topic of art appreciation under the influence of the drug mescaline (Blass, 2004, p. 65). If Milgram, only several months earlier, had an idea involving "orders" to "inflict harm", why, upon arriving at Yale, was his first research proposal not on OTA? The probable reason is that although he clearly sensed the OTA 
idea had some potential, between its conception at Princeton and his arrival at Yale he probably suspected it needed further work.

To capture the attention of academia, Milgram had to develop an experiment that in the first official trial produced eye-catching results. Entering the academic stage with an experiment demonstrating a low rate of obedience to harmful orders would be unsurprising and hardly equate to a "phenomenon of great consequence". In a document headed "Studies in Obedience", that like Figure 1 also probably dates back to 1960, Milgram highlighted the main coercive technique he intended to deploy to achieve what was actually his initial goal: "Integrate with group process. In order to create the strongest obedience situation use findings of group dynamics [italics added]" (SMP, Box 46, Folder 165, Titled: "Notes general, 1961-1962" $[$ sic $]){ }^{39}$ But was the idea as presented in Figure 1 likely to have been capable of generating the dramatic results needed to make his mark? Were subjects likely to accept a transparently Nazi-sounding "pledge to obey" orders to inflict an apparently "LETHAL" shock? The changes which followed would suggest not.

On 14 October 1960 Milgram submitted to the Office of Naval Research his first research proposal on OTA. This document established the young researcher's intention to undertake a study on "obedience and action conformity", whereby "Given that a person is confronted with a particular set of commands 'more or less' appropriate to a laboratory situation, we may ask which conditions increase his compliance, and which make him less likely to comply" (SMP, Box 43, Folder 126, Titled: "Correspondence 1960”). Milgram then went on to describe the basic experimental procedure he intended to employ which, in the complete absence of any pilot studies, already resembled the one he would later settle upon. Specifically, the subject:

operates a control panel, consisting of a series of switches set in a line. The switch at the left is labelled '1-Very Light Shock'; the next switch is labelled '2-Light Shock'; and so on through moderate, strong, very strong, etc... the switch at the extreme right is labelled '15-Extreme Shock: Danger.' . . . . It goes without saying that ... the victim ... does not in reality suffer, but is a confederate of the experimenter .... [and] is placed behind a semi-transluscent [sic] screen so that [the] subject ... can perceive his reactions only dimly . . . Internal resistances become stronger, and at a certain point he refuses to go on with the experiment. Behavior prior to this rupture we shall consider as obedience .... The point of rupture is the act of disobedience (SMP, Box 43, Folder 126, Title: “Correspondence 1960").

\footnotetext{
${ }^{39}$ This document was probably written before the date designated by Sterling Memorial Library as it discusses rudimentary ideas like the use of a "dial that reads from . . . light-to-fatal."
} 
Attached to the end of this first research proposal was, relative to Figure 1, a far more complicated drawing of what Milgram envisioned this shock "control panel" might look like (see Figure 3 below):

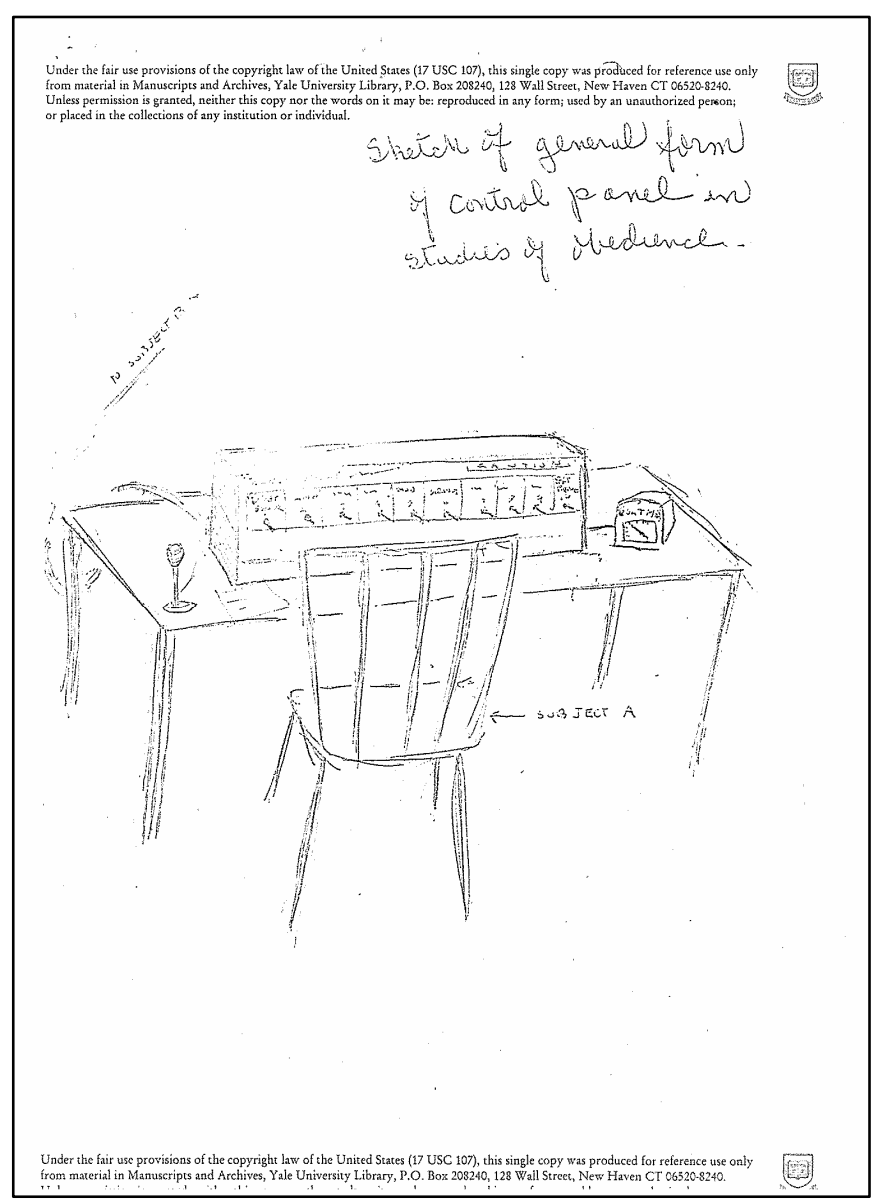

Figure 3: Milgram's "Sketch of [a] . . control panel in studies of obedience" attached to the first-ever OTA research proposal dated 14 October 1960 (SMP, Box 43, Folder 126, Titled: "Correspondence 1960”).

Milgram was aware that deceiving subjects into thinking they were inflicting shocks on another person was likely to generate within them what he would later term strain: intense feelings of tension or stress. He knew such feelings might encourage disobedience, detracting from the initial goal to create "the strongest obedience situation". Milgram countered such feelings by introducing what he would later term Strain Resolving Mechanisms (SRMs). SRMs were measures that, to varying degrees, reduced the tensions normally associated with inflicting harm on others. Revealed in the proposal was an example of Milgram's introduction of a SRM whereby, instead of some "pledge to obey", subjects were to be provided with what he intuitively sensed might be a more subtle and agreeable rationale for inflicting seemingly excruciating electrical shocks on another 
person. As Milgram himself said, to encourage a person to willingly inflict harm on another: "Obviously some acceptable rationale must be provided" (SMP, Box 43, Folder 126, Titled: "Correspondence 1960"). The acceptable rationale was now to be "achieved by setting the experiment in a context of 'social learning' " (SMP, Box 43, Folder 126, Titled: “Correspondence 1960”). In Milgram's words: "Subjects believe they are performing in an experiment in human learning. In the course of the experiment one subject finds that it is part of his role to administer 'negative reinforcements' [light electrical shocks] to another subject" (SMP, Box 43, Folder 126, Titled: "Correspondence 1960”). By contributing to some greater good, Milgram had transformed the infliction of harm from "something evil" (shocking an innocent person) into something "good" (advancing "human learning")—a strain-resolving conversion process Adams and Balfour (1998, p. xx) termed "moral inversion". 40

Another change apparent within the first proposal was a different example of a SRM, whereby the last shock previously labelled "LETHAL" had been substituted with the verbal designation “15-Extreme Shock: Danger”. This small modification was perhaps motivated by a suspicion that subjects were more likely to deploy a more ambiguously labelled final shock switch than one with a unequivocally destructive heading because, relative to the latter, the former less likely to stimulate as much strain.

Although Milgram clearly started out with an idea that attempted to capture in the controlled laboratory setting what he suspected might have led to an event like the Holocaust, by the first proposal he had come to the realisation that presenting subjects with a "pledge to obey" orders to inflict an apparently "LETHAL" shock would probably fail to create the "strongest obedience situation". Consequently, he deemed it necessary to include a less stressful and more "acceptable" justification for participating in an action that, at its worst point, now had a more ambiguously labelled outcome. Although these modifications to the earlier idea were more likely to aid Milgram in obtaining the initially high completion rate needed to make his academic mark, the basic experimental procedure was also transforming into something that increasingly looked less like the Holocaust (a potential weakness critics would later raise regarding the apparent Milgram-Holocaust linkage).

\footnotetext{
${ }^{40}$ This innovation was methodologically prudent because, as in Asch's study, Milgram was withholding from the subjects the study's actual objective of examining people's willingness to obey authority. Unlike other methodologically weaker studies (see Zimbardo et al., 1973), Milgram's subjects were therefore prevented from gratifying the researcher's wishes and/or engaging in some preconceived role-play (Nussbaum, 2007).
} 
Nevertheless, Milgram still appears to have kept some of his focus on the

Holocaust. For example, aware of the Nazi regime's reliance on propaganda, one of the four potential variations centred around the following SRM: "Obedience and Propaganda Concerning the Victim: To what extent can higher compliance be extracted by portraying the victim in unflattering terms?" (SMP, Box 43, Folder 126, Titled: "Correspondence 1960"). ${ }^{41}$ Milgram, soon after, went to some lengths to further develop this basic idea.

The first proposal also mentioned that the research programme was to be divided into two main sections. In the first, subjects were to be run through the procedure alone (that is, only in the presence of the experimenter and the partially visible learner). The second was the same as the first, except that the actual subject would be one of several members of a group. After describing the alone procedure, Milgram clarified what he meant by the second section:

Now transform the situation to one in which the critical subject is but one member of a group, and each member faces a control panel ... . the experiment is designed so that subject B receives his negative reinforcement only when all members of the group depress their control board switches in succession. Unknown to the critical subject, the first four members of the group are confederates [actors] of the experimenter, and willingly comply with E's commands on every occasion (SMP, Box 43, Folder 126, Titled: “Correspondence 1960”).

In the absence of any pilot studies, how optimistic was Milgram that this "group dynamics" section would initially "create the strongest obedience situation"?

My guess is, on the basis of considerable experience with experiments in group pressure, that certain persons will follow the group through all degrees of compliance, even to the point of administering a shock labelled 'extremely dangerous'. This guess awaits empirical confirmation (SMP, Box 43, Folder 126, Titled: "Correspondence 1960").

Despite his apparent "incandescent" or eureka-like moment, Milgram was actually not sure at the time about the kinds of results the "alone" experiments might produce. However, he hazarded a guess: "Presumably, the addition of group pressure will cause the critical subject to comply with the experimental commands to a far higher degree than in

\footnotetext{
${ }^{41}$ Probably near the end of 1960 or early in 1961, Milgram started to develop some basic ideas surrounding such an experiment: "Propoganda [sic] concerning the victim [learner]: I might say [to the subject] about the person [learner] in there, first that he is being paid 35 dollars . . . Secondly, he . . . wanted to be a subject [learner]. He said . . . those Yale fairies [as teacher/subjects] were pretty stupid .... This person, I might add, has been in court many times but has never been convicted, because of technicalities of the law, although it was established beyond any doubt that he had beat up and robbed an old man ...* Still ... I don't see that there is any special reason to exclude him, though I have certain doubts. Anyway, let's begin. *In fact, he arrogantly boasts that he did this and that the law can't touch him" (SMP, Box 46, Folder 165, Titled: "Notes general, 1961-1962").
} 
the 'alone' situation” (SMP, Box 43, Folder 126, Titled: “Correspondence 1960”). Because Milgram was not particularly optimistic about the latter series, influenced by Asch, he determined that their most important function was to "serve as necessary controls for the group experiments. It is only by using the alone situation as a standard that one can assess the strength of group pressure in the later studies" (SMP, Box 43, Folder 126, Titled: “Correspondence 1960"). But ultimately unsure how subjects might react to the potentially binding force of the experimenter's orders, Milgram cautiously added that the "alone" conditions were nonetheless still "important in their own right" (SMP, Box 43, Folder 126, Titled: “Correspondence 1960”). Building more on Asch's group conformity legacy than his own, at this time Milgram's "Obedience and Group Process" experiments “constitute[d] the major concern of the present research" (SMP, Box 43, Folder 126, Titled: “Correspondence 1960”).

The key point is that in the lead-up to the first proposal, and with the intention of making his mark, Milgram's albeit initial goal was to ensure that a surprisingly large proportion of subjects inflicted all the shocks. This was largely why he was continually adding to the inchoate experimental procedure an increasing variety of different Binding Factors (BFs) and SRMs. Upon achieving this initial goal, Milgram then intended to move on to his more explicit goal of discovering "which conditions increase his compliance and which make him less likely to comply".

Hence, this first research proposal contained all the key features of what would become known as the OTA experiments. All that was required was to run a pilot series. These would reveal the capacity of the "group" and, although less auspiciously, the "alone" (experimental control) versions to produce strongly counterintuitive results. Although this first research proposal was sent to the Office of Naval Research, a month later in mid-November 1960 Milgram also submitted it to the National Institute of Mental Health and the National Science Foundation (NSF) (Blass, 2004, p. 67).

\subsection{First Pilot Study: the Winter Pretests 1960-61}

Although he almost certainly would eventually have run a pilot study on his own volition, the impetus to do so came not from Milgram but from his students. To give his Psychology of Small Groups class some practical experience in conducting an actual experiment, Milgram provided his students with two potential research options: the 
obedience pilot or another idea he had on group communication patterns. By a narrow margin the class opted for the obedience pilot, and then set about converting Milgram's nascent idea into a concrete reality (Blass, 2004, pp. 67-68). The initial impetus may have come from the students because, although Milgram sensed he was onto something interesting, at this time he had not yet come to appreciate the idea's full potential. Irrespective of this, armed with one of Milgram's sketches and a small budget, his students produced the following shock-generator prototype:

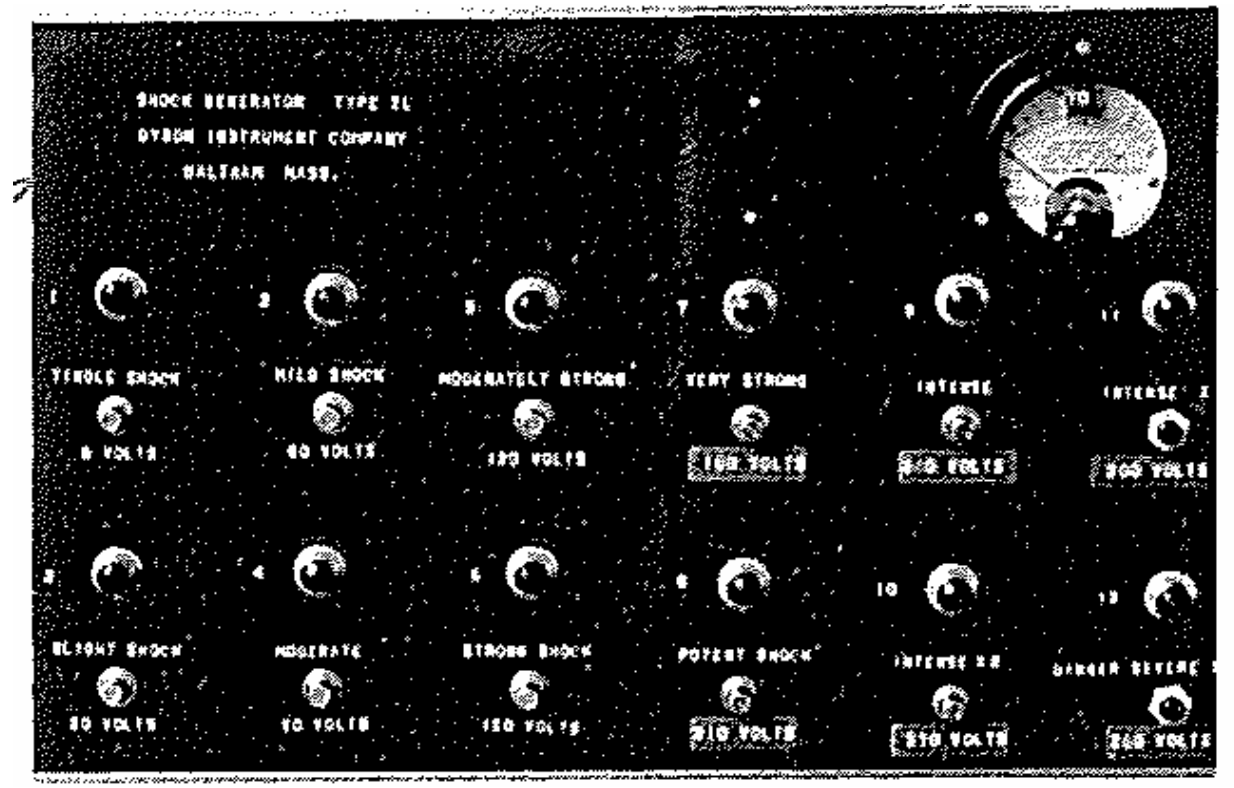

Figure 4: A front-on photograph of the student's 12 switch prototype "SHOCK GENERATOR TYPE ZL DYSON INSTRUMENT COMPANY WALTHAM MASS.” which increased in 30 volt increments ending in a maximum shock of 330 volts (SMP, Box 45, Folder 160, Titled: “Grants 1961-1967”).

Having built a shock generator, and with the intention of using Yale students as subjects, Milgram and his class then had to refine the basic experimental outline for both the "group" and "alone" conditions into a workable logistical procedure. By late November 1960 the class was finally ready to undertake the first set of trial runs-termed the "Winter pretests" (SMP, Box 46, Folder 163, Titled: "Obedience Notebook 19611970"). All that remained was to observe the outcome of his students' crude pilot study. As Milgram said:

Before an experiment is carried out it is often hard to visualize exactly what its flavor would be. Thus, there was a certain amount of excitement and anticipation as we awaited the first subject. The study, as carried out by my small groups class under my supervision, was not very well controlled (as cited in Blass, 2004, p. 68). 
The only "group" experiment Milgram later discussed in some detail produced results that may have surprised the student observers. They only confirmed, however, the accuracy of his earlier prediction that "certain persons will follow the group". As Milgram (1964c, p. 11) said:

In one of the group experiments the shock level is determined by the 'lowest level suggested by any member of the group.' Thus the naive subject can completely control the shock level. Pilot studies show that subjects follow the group, or at most, fall one step behind the group level. Frequently, subjects reverse themselves and become ardent supporters of the group action.

Although Milgram originally intended the "alone" condition to be an experimental control for the "group" experiment (and even before the trial run "conjectured that persons would not, in general, go above the level of 'Strong Shock' " [150 volts]) (SMP, Box 45, Folder 160, Titled: “Grants 1961-1967”), it was the results of these first test-runs that really caught him by surprise. As Milgram said: "even under these uncontrolled conditions, the behavior of the subjects astonished the undergraduates, and me as well" (as cited in Blass, 2004, p. 68; see also Evans, 1980, p. 193). In greater detail Milgram elaborated: "In practice, many subjects were willing to administer the most extreme shocks available when commanded by the experimenter [italics added]" (SMP, Box 45, Folder 160, Titled: "Grants 1961-1967"). ${ }^{42}$ Something about the experimenter's commands seemed to render it a far stronger BF than he had anticipated. Other than stating that "many" completed the first-ever "alone" pilot run, Milgram did not specify the exact proportion of obedient subjects. ${ }^{43}$ However, if he initially thought that in the "alone" conditions "persons would not, in general, go above the level of 'Strong Shock' ", "many" subjects completing the experiment would have greatly exceeded his expectations.

While the first trial run left those present "astonished", and for his students "there was a general sense that something extraordinary had happened", Milgram did "not believe that the students could fully appreciate the significance of what they were viewing" (as cited in Blass, 2004, p. 68). As this statement implies, however, he could. And this was probably because only he would have known the original idea had evolved from his inclusion of a variety of variables he suspected may have played some role in producing

\footnotetext{
${ }^{42}$ Because Milgram states that subjects were reacting to the experimenter's commands, this statement is clearly in reference to one of the "alone" conditions.

${ }^{43}$ Milgram (1973, p. 64) has said: "When the very first experiments were carried out, Yale undergraduates were used as subjects, and about 60 percent of them were fully obedient" (see also Milgram, 1974, p. 170). But Milgram was not specific as to whether this percentage related to the "group" or "alone" variations.
} 
the Holocaust. In other words, what the students deemed merely to be a fascinating spectacle, Milgram sensed might provide insights into how something like the Holocaust could happen. It was probably around this period that the ambitious young scholar thought that within a few months of starting his academic career he had already found, as Blass put it, his "phenomenon of great consequence".

The initial surprise and ease with which many students would complete the basic experimental procedure was soon over-shadowed by Milgram's curiosity as to why so many were willing to complete the procedure: "The laboratory procedures were changed frequently in order to explore various possibilities of the experimental situation" (SMP, Box 45, Folder 160, Titled: “Grants 1961-1967”). One change driven by this curiosity involved increasing the intensity of the learner's protests because, according to Milgram (as cited in Meyer, 1970), the earlier more gentlemanly version “ 'didn't seem to have as much effect as I thought it would or should' " (p. 128). Despite having already obtained completion rates beyond his initial expectations, he increased this source of strain by having " "more violent protestation on the part of the person getting the shock. All of the time, of course, what we were trying to do was not to create a macabre situation, but simply to generate disobedience'" (Meyer, 1970, p. 128).

While trialing these variations the class also observed some unexpected behaviours:

Subjects frequently averted their eyes from the person they were shocking, often turning their heads in an awkward and conspicuous manner. One subject explained: 'I didn't want to see the consequences of what I had done.' . . . . Observers write: ['] ... . When this fact was brought to their attention they indicated that it caused them discomfort to watch the victim in agony. We note, however, that although the subject refuses to look at the victim, he continues to administer shocks['] (SMP, Box 45, Folder 160, Titled: "Grants 1961-1967”).

This was a particularly interesting observation because instead of using the SRMs provided by Milgram, these subjects appeared to be showing initiative in trying to reduce the tension associated with shocking another person by inventing then deploying their own such devices.

The first pilot study, nonetheless, revealed two key counterintuitive findings. First, how much easier it was to get many subjects to obey the experimenter's escalating demands. Secondly, and somewhat related to this, was the surprising discovery that many subjects in the "alone" series - the supposed control for the "group" experiments—were willing to inflict every shock. Milgram considered the second finding to be especially 
important because, should he decide not to use the "alone" series as an experimental control, but as a stand-alone series of experiments, he would be exploring a phenomenon that, in its surface features, would appear to have little or nothing to do with group conformity. Thus, pursuing the "alone" series could result in the development of his own, rather than contributing to Asch's, research legacy. Furthermore, the "alone" OTA variation also had an obvious Asch-like control: would a lone subject complete with no orders to continue?

Although the pilots generated some surprising results and hinted at having implications beyond the research laboratory, Milgram remained cautious about his students' "not very well controlled" experiments. In a document dated 6 August 1961, he revealed there was "something [about the student pilots] I was never conviced [sic] of" (SMP, Box 46, Folder 163, Titled: “Obedience Notebook 1961-1970”). Milgram was not specific about the content of his doubts, but his subsequent actions hint that, due to the pilot study's rather amateurishly disjointed procedure, fake-looking shock generator, and some of his students' weak acting skills (Elms, 1995, p. 24; Parker, 2000, p. 110), some of the subjects may have sensed the experiment to have been a ruse and only completed because they believed the learner was not really being harmed. Upon receiving funding, Milgram immediately addressed these three issues.

However, one would suspect that the more believable the experiments' seemingly destructive implications became, the more resistant to obeying the subjects were likely to become. This potential obstacle could defeat Milgram's initial desire to produce a strikingly high completion rate. Milgram's solution to this potential problem seems to have been to introduce into his basic experimental procedure even more BFs and SRMs that might increase the probability of completions. One obvious example of the latter was a procedural innovation that can be traced back to an idea Milgram proposed in Figure 1, regarding a "Waver $[$ sic $]$ of responsibility—from experimenter-For Germa[n]y".

Upon completion of the winter pretests and in a document headed "Report on Pilot Resarch [sic]" dated 4 December 1960, Milgram pointed out that "One major argument of subjects is that the victim has volunteered for the experiment", and consequently some subjects resisted completing because it was apparently the learner's prerogative to "leave whenever he wants to" (SMP, Box 46, Folder 164, Titled: "Notes general, 1961-1962"). It would seem this argument may have emboldened some subjects to successfully resist the experimenter's demands that they continue. Milgram proposed: 
Therefore: the following change should be made; . . the assistant should report to the main experimenter that the subject does not want to continue .... The experimenter requires that the experiment continue. Possible conversation: .... ASSISTANT: Sir, the subject says he will refuse to answer and demands to be released.

EXPERIMENTER: I Have responsibility for this situation, and I say, let's go on with the experiment. According to the rules when the subject gives a wrong answer or no answer he will receive an electric shock. Now if he refused to answer on every occasion he will just get shocked. So it is in his interest to learn the correct responses; now, let s [sic] go on. Proceed with the next question (SMP, Box 46, Folder 164, Titled: "Notes general, 19611962”).

Here Milgram was introducing another SRM: accepting the offer that only the experimenter was responsible for the subject's actions might reduce the latter's tension regarding their continued participation. This idea was refined further in the official research programme to the point where the experimenter would simply respond to any form of subject resistance by curtly stating: "I'm responsible for anything that happens to him [the learner]. Continue please" (Milgram, 1974, p. 74).

\subsection{The Second OTA Research Proposal}

After the first pilot studies, Milgram wrote a second research proposal. On 25 January 1961 he sent this to the NSF, which, of the three originally approached funding agencies, appeared to be the most receptive (Blass, 2004, p. 69). It began with a more detailed overview of the procedural technique. The project's potential was this time more powerfully bolstered by an overview of the winter pretests which "yielded unexpected results of considerable interest” (SMP, Box 45, Folder 160, Titled: “Grants 1961-1967”).

Milgram was unsure as to why so many subjects in the pilots were totally obedient but "with an ultimate view towards theoretical integration", he intended to find out (SMP, Box 45, Folder 160, Titled: “Grants 1961-1967”). His approach to producing what was obviously to be a post hoc theoretical account was to be divided into two why phases. The first why phase, actually "The crux of the study", was to "illuminate the process of obedience" by "systematically vary[ing] the factors we believe alter the degree of obedience to the experimental commands" (SMP, Box 45, Folder 160, Titled: "Grants 1961-1967'). This was possible because the basic experimental procedure was amenable to "extensive parametric variation" and, in conjunction with plenty of deductive reasoning would, so he believed, eventually expose the key factor/s behind the obedient subjects' 
behaviour (SMP, Box 45, Folder 160, Titled: “Grants 1961-1967”). In support of these points, Milgram stated in the proposal: "I cannot emphasize too strongly the importance of identifying and reducing to quantifiable form unanticipated variables as they arise in the course of experimentation" (SMP, Box 45, Folder 160, Titled: “Grants 1961-1967”).

Milgram wanted to maintain a free hand that would enable him to test ad hoc then eliminate any emerging potential explanations:

Increasing familiarity with the subjects' performance, thoughtful consideration of the quantitative relationships obtained, and intensive interviewing of subjects breed the most penetrating hypotheses. At this stage it is unwise to allow any narrow theoretical view limit the kinds of insights provided by the experiments themselves (SMP, Box 45, Folder 160, Titled: “Grants 1961-1967”).

The second why phase was to "be considerably more focused, concentrating on motive processes underlying the subject's behavior. The inquiry remains experimental, though supplemented by tools of personality research" (SMP, Box 45, Folder 160, Titled: “Grants 1961-1967”). It was envisaged that this line of enquiry, which was to involve the expertise of some of Milgram's colleagues, might include the post-experimental analysis of fantasy material and the application of certain psychoanalytical techniques. Milgram had little interest in such areas of personality psychology. However, this second phase clearly illustrates how open-minded he was regarding the potential of other approaches in shedding theoretical light on why subjects might complete the experiment.

The second proposal also presented several potentially fruitful variations on the basic experimental procedure that, after observing the winter pretests, Milgram had come to suspect might prove capable of altering the completion rate. The first mentioned, presumably because at that time it was of most interest, was a new idea stimulated by the earlier observations surrounding the unexpected reaction of some subjects who looked away from the learner while continuing to inflict the shocks. This observation suggested:

the salience of the victim may in some degree regulate their performance. This can be tested by varying the 'immediacy' of the victim. Three conditions are suggested: 1) the victim is completely within view of the subject, without obstruction of any kind between them; 2) the victim is placed behind soundproof glass, as in the pilot studies; 3 ) the victim is placed in another room, and though his presence is assured, can neither be seen nor heard by the subject (SMP, Box 45, Folder 160, Titled: “Grants 1961-1967”).

Another suggested variation related to suspicions during the winter pretests that the high completion rates may have been due to the highly competitive characteristics of Yale's Ivy League student population (Milgram, 1974, p. 170). Thus, as a variation, 
Milgram suggested the possibility of "two replications . . . with adult populations" (SMP, Box 45, Folder 160, Titled: “Grants 1961-1967”). Soon afterwards this was changed to using only adult subjects from the wider community. A particularly prominent change was also discussed in the section on potential variations surrounding the issue of "obedience and group process". That is, although the "group" experiments were apparently still to "constitute a major concern of the present research", since the winter pretests they had, for reasons mentioned, been relegated from dominating the research programme to consisting of a couple of minor variations (SMP, Box 45, Folder 160, Titled: “Grants 1961-1967”). Finally, for reasons that will later become apparent, the propaganda variation mentioned in the first proposal had slipped from second to last place in the line-up (and was eventually dropped altogether).

The increasing focus on the "alone" over the "group"-type variations showed that Milgram's research idea was transforming into something very different from that of his main intellectual mentor, Solomon Asch, and more towards that of the individual's response to OTA. However, it is important to note that the OTA idea still retained a central intrinsic feature that Milgram had long known was responsible for making "Asch's expt $[s i c]$... a Great Experiment". That is, Asch's group/conformity experiment required the subject to encounter and then resolve a seemingly "private" internal "conflict" to conform with or rebel against the group. Similarly, Milgram's idea also required that the subject resolve a seemingly private internal conflict: to obey or disobey a legitimate authority figure demanding that they inflict increasingly intense shocks on an innocent person. This internal conflict, as noted by Seibel (2005, pp. 350-351), may have produced Festinger-like cognitive dissonance.

Even this similarity, however, was evolving into something quite different: by the second proposal Milgram was conveying a belief that, inherent within his but absent from Asch's experiment, was a dilemma with a significant moral dimension. To clarify, in Milgram's (1974, p. 41) view, across all societies there exists a widely held axiom that it is a "fundamental breach of moral conduct to hurt another person against his will" (see also Kaufmann, 1967, pp. 321-322; Strudler \& Warren, 2001, p. 157; Wilson, 1993, pp. 1-54). Any decision to obey would (unlike the trivial implications of conforming in Asch's experiments) necessitate the violation of this moral axiom. Milgram believed there was a wrong and a right way of resolving the intrinsic moral dilemma within his experimental 
paradigm, ${ }^{44}$ and he was strongly of the opinion that total obedience was, as Miller (1986) has pointed out, an example of a "moral failure on the part of the subjects" (p. 45).

On 3 May 1961 an obviously impressed NSF research committee informed Milgram of its acceptance of his second proposal. Across a two-year period starting 1 June 1961, Milgram received two instalments totaling about \$US 60,000 (Elms, 1995, p. 26). ${ }^{45}$ Upon receiving the funding Milgram prepared for a second and much more intensive set of pilot studies, which would soon be followed by the official research programme.

Milgram hired a graduate psychology student, Alan Elms, as his research assistant, whose main task was to ensure a continuous supply of adult subjects from the wider New Haven Connecticut area. In a letter to Elms dated 27 June 1961, Milgram stated that at this early stage: "The goal this summer is to run from 250-300 subjects in nine or ten experimental conditions. Only if this is accomplished can the summer be considered a success" (SMP, Box 43, Folder 127, Titled: “Correspondence 1961”). On the topic of subject recruitment, Milgram added: "The advertisement was placed in the New Haven Register and yielded a disappointingly low response. There is no immediate crisis, however, since we do have about 300 qualified applicants" (SMP, Box 43, Folder 127, Titled: "Correspondence 1961"). This is a little surprising because his generous research grant meant he could now better attract subjects with the offer of financial remuneration. For the official research programme, Milgram settled upon the sum of $\$ 4.50$ per subject, which at the time was a generous but not excessive amount of money. Whether it was intentional or not, it could be argued that paying the subjects introduced yet another BF-a contractual obligation to do as one is asked and complete the experiment. ${ }^{46}$

In this letter to Elms, Milgram drew an analogy between the organisation of the OTA experiments and the Holocaust, while also articulating his belief that the resolution of the internal conflict within his experiment involved an issue of personal morality:

But before long, in your role of Solicitor General, you will have to think of ways to deliver more people to the laboratory... I will admit it bears some ressemblence

\footnotetext{
${ }^{44}$ As Milgram said in April 1968: "Disobedience in this situation requires nothing more than activation of the most basic moral values in each individual” (SMP, Box 46, Folder 168, Titled: "Notes; Binding 1961-1968”).

${ }^{45}$ Blass (2004, p. 114) states that Milgram received three grants from the NSF.

${ }^{46}$ However, as Milgram (1963) later noted: "Forty-three subjects, undergraduates at Yale University, were run in the [pilot] experiment without payment. The results are very similar to those obtained with paid subjects" (p. 377). Nevertheless, as it will soon be shown, payment was still likely to have been an issue of importance to many eventual subjects.
} 
[sic] to Mr. Eichman's [sic] position, but you at least should have no misconceptions of what we do with our daily quota. We give them a chance to resist the commands of malevolent authority and assert their alliance with morality (SMP, Box 43, Folder 127, Titled: "Correspondence 1961").

Perhaps in reference to the unauthentic appearance of his students' prototype shock generator, in this letter Milgram also commented: "The apparatus is almost done and looks thoroughly professional” (SMP, Box 43, Folder 127, Titled: “Correspondence 1961”).

Illustrating just how authentic the new device appeared, Milgram stated in a letter written a few weeks later to Henry Riecken from the NSF that: "The new device passed the acid test when two electrical engineers examined the instrument and failed to realize it was a simulated device. Details were very carefully handled to insure an appearance of authenticity" (SMP, Box 43, Folder 127, Titled: "Correspondence 1961”). The final device is shown in Figure 5:

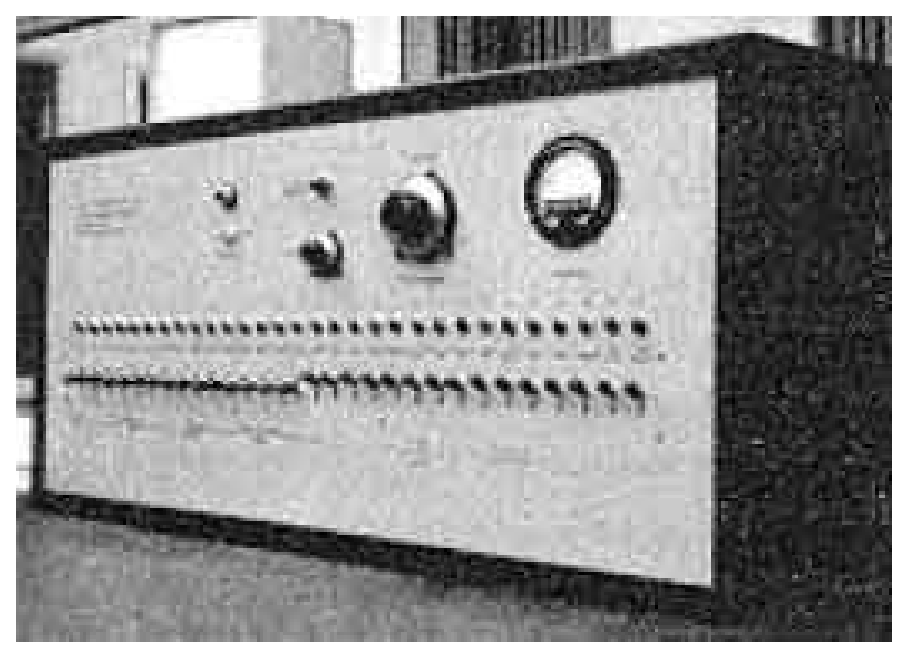

Figure 5: Milgram's 30 switch “SHOCK GENERATOR, TYPE ZLB, DYSON INSTRUMENT COMPANY, WALTHAM, MASS. OUTPUT 15 VOLTS - 450 VOLTS” (Blass, 2004, p. 79).

Apart from its more professional appearance, one obvious difference between this and his students' shock generator was that the final version had 30 rather than 12 switches. Also, instead of increasing in 30-volt increments ending in a 330-volt shock, the newer version increased in 15-volt increments and ended in a much more significant 450 -volt shock. As the following will illustrate, these modifications probably represented an additional BF aimed at increasing the completion rates.

In the second research proposal (dated 25 January 1961), while alluding to his initial goal, Milgram asked the following question: "if one is trying to maximize 
obedience, is it better to inform a person of the worst of what he may be asked to do at the outset, or is compliance best extracted piecemeal?" (SMP, Box 45; Folder 160, Titled: “Grants 1961-1967”). The coercive power of piecemeal compliance was, as shown in Figure 1, included in Milgram's earliest drawings of his nine-switch shock generator. Although Milgram was aware of the probable importance of this BF in increasing the probability of completions (see Milgram, 1974, p. 149, 1977 p. 129), he did not discuss its likely implications to the extent of subsequent commentators. For example, Gilbert (1981) discerned a resemblance between the OTA experiments' gradual escalation in shock intensity and a method of persuasion that, several years after the OTA study, became known as the foot-in-the-door technique (Freedman \& Fraser, 1966). The foot-in-the-door technique is where persons are more likely to agree to a significant request if it is preceded by a comparatively insignificant request. Gilbert (1981, p. 692) has explained, this BF:

may have two important consequences: (a) it engages subjects in committing precedent-setting acts of obedience before they realize the 'momentum' which the situation is capable of creating, and the 'ugly direction' in which that momentum is driving them; and (b) it erects and reinforces the impression that quitting at any particular level of shock is unjustified (since consecutive shock levels differ only slightly and quantitatively). Both consequences of the gradated shock procedure may conspire to deprive subjects of the credible rationale they need to quit at any given point before completing the experiment (see also Eckman, 1977, p. 97; Mooks, 2004, p. 338; Sabini \& Silver, 1982, pp. 69-71).

Something not discussed in the literature is that, probably with an eye towards his goal of initially maximising the completion rate, Milgram appears to have engaged in an extension of the foot-in-the-door logic. That is, compared to his students' 12-switch shock generator, the new version had many more smaller steps that ended in the infliction of a much more powerful final shock.

The shock generator not only had design features that, via incremental entrapment, increased the likelihood of binding subjects into inflicting the shocks, it also potentially enabled them to do so from a remote distance, and was therefore another SRM increasing the likelihood of completions. In Milgram's (1974, p. 157) words some years later:

Thus, creating physical distance between the subject and victim, and dampening the painful cries of the victim, reduces strain. The shock generator itself constitutes an important buffer, a precise and impressive instrument that creates a sharp discontinuity between the ease required to depress one of its thirty switches and the strength of impact on the victim. The depression of a switch is precise, scientific, and impersonal. If our subjects had to strike the victim with their fists, they would be more reluctant to do so. 
As mentioned, Milgram invented/selected this device because he intuitively sensed and/or past experiences suggested that, with some coercion, most ordinary people might use it on another human being.

\section{$5.4 \quad$ Second Pilot Series: Summer Pre-tests 1961}

According to Blass (2004, p. 75), Milgram worked assiduously during the months of June and July 1961 to logistically organise, then "fine-tune", the basic experimental procedure to his "exacting specifications". Upon completion of the more authentic-looking shock generator, Milgram (acting for the most part as the learner) and Elms (as the experimenter) embarked on the second series of pilot studies known as the "Summer Pretests 1961" (SMP, Box 46, Folder 163, Titled: “Obedience Notebook 1961-1970”). This time, using only adult subjects and focusing on the issue of victim proximity (first mentioned in the second research proposal), three separate pilot-runs were organised (27 July, 2 and 4 August). According to the above document dated 6 August 1961, the first session test-ran the "voice feedback condition" where the subject could only hear the learner's verbal responses to the shocks. In the second session, they again test-ran the "voice feedback" experiment, but also what Milgram termed the "no feed back" condition (later termed the Truly Remote Pilot). Although in this condition the learner could not be seen or heard, the subject was led to believe that the learner was receiving shocks. Initially there were problems - a few "subjects penetrated the cover story". However, after some minor trial and error refinements, and unlike the first pilot which procedurally he "was never conviced $[s i c]$ of", by the second pilot run the "Procedure worked extremely well" with "No penetration". Blass (2004, p. 75) seems to have captured what Milgram was trying to achieve during these pilot sessions when he said "Pretest subjects were 'run' through the procedure until all the kinks were worked out."

Once the basic procedure was running smoothly, after running the "no feed back" condition it became clearer again that it was going to be difficult to get a large proportion of subjects to disobey:

It was thought that the verbal and voltage designations on the control panel would create sufficient pressure to curtail the subject's obedience. However, this was not the case. In the absence of protests from the learner, virtually all subjects, once commanded, went blithely to the end of the board, seemingly indifferent to the verbal designations ('Extreme Shock' and 'Danger: Severe Shock') (Milgram, 1965a, p. 61). 
By the final set of pilot studies, Milgram had achieved his initial goal of maximising the completion rate. As Milgram (1965a, p. 61) noted, however, having produced near total obedience raised a problem:

This deprived us of an adequate basis for scaling obedient tendencies. A force had to be introduced that would strengthen the subject's resistance to the experimenter's commands, and reveal individual difference in terms of a distribution of break-off points.

Milgram changed the no feed back procedure so that in the first official experiment subjects experienced at least some perceptual feedback - auditory stimulation-through the learner banging on the wall upon the infliction of the 300 and 315-volt shocks, and thereafter falling silent. The intention of this procedural adaptation was (instead of his more typical approach of attempting to reduce tension) now to slightly increase the intensity of strain experienced by the subjects.

The second set of pilots revealed several other potential issues. For the learner's taped responses to the shocks-where, after swapping roles, "Elms is voice" (SMP, Box 46, Folder 163, Titled: “Obedience Notebook 1961-1970”)—Milgram suspected he would need an older, probably more authentic, voice for the learner's role. Related to this point, upon later testing the "proximity condition", where the learner was in full view of the subject, Milgram thought Elms's acting (again, as the learner) was unconvincing and increased the probability of subjects penetrating the cover story (SMP, Box 46, Folder 163, Titled: “Obedience Notebook 1961-1970”). A more believable learner was needed. Milgram probably felt similarly about his students' first pilot study because before the second set of pilots he had already hired people who he thought, after much practice, would appear more authentic and convincing than Elms and himself. Around this period Milgram had selected John Williams and James McDonough to play the central roles of the experimenter and learner, respectively. The two men had been invited to observe the 4 August session. Although neither were professional actors-Williams was a high school biology teacher and McDonough a payroll auditor-after many rehearsals, and as Milgram's (1965c) Obedience (a filmed experiment) illustrated, both proved extremely convincing in their respective roles. ${ }^{47}$

\footnotetext{
${ }^{47}$ Mixon (1989, pp. 37-38) has suggested that McDonough "was not a very good actor" and that his screams "are neither convincing nor moving." It is true that, as Milgram (1974, p. 173) himself conceded, a small proportion of subjects were clearly unconvinced by the deception. But compared with the few who suspected that McDonough and his screams were fake, as documents and audiotapes at the SMP illustrate, many more remained unsure: "Little doubt in my mind ... whether my legs were being pulled, I was pretty sure they were but I wasn't sure" (SMP, Box 153, \#2301). Also, most conceded to having been fooled: "You're quite an actor, maybe you'll get the Oscar" (SMP, Box 153, Audiotape \#2327). Afterwards, some subjects remained sceptical that the learner did not receive any shocks: "Since I'm not convinced that the learner in
} 
That Milgram deemed it important to obtain an experimental team who were competent and convincing actors makes sense, but it does not appear to have been the most important prerequisite. For example, consider the following written statement made by Milgram during McDonough's job interview: “* Definitely desired as victim The only trouble is he cannot act to [sic] well - in my estimation" (SMP, Box 43, Folder 127, Titled: “Correspondence 1961"). Milgram clarified what he meant on this document when he said: "Probably could not act face to face, however". Although Milgram clearly assessed McDonough's apparent inability to act as undesirable, there was clearly something else about this man that made him, as Milgram said on this document, "Excellent" even "perfect". Milgram continued: "This man would be perfect as a victim" because "he is mild and submissive; not at all academic". He would later describe McDonough as "affable" and "unthreatening" (SMP, Box 46, Folder 174, Titled: "Notes: Method 1962"). It would seem that Milgram intuitively desired a benign learner because he sensed that subjects were more likely to continue shocking such a person, over a learner they assessed to be the converse (SRM). This, it would seem, made McDonough the "perfect" learner. And, as Milgram noted himself during McDonough's interview, his apparent inability to act face-to-face was probably not all that significant an issue because he "can train" (SMP, Box 43, Folder 127, Titled: "Correspondence 1961"). On top of this, rehearsals would only build confidence and, anyway, because most of the learner's role was to be prerecorded on tape (a procedure amenable to allowing for many rehearsals to perfect his lines), only a small proportion of McDonough's role involved direct subject interaction.

Milgram's hiring of Williams as the experimenter also revolved around the latter's personal characteristics: as a type of BF, subjects were surely more likely to obey a "stern, intellectual looking man" who played his experimenter's "role in a cold, austere manner" rather than, say, a more carefree person with no semblance of intellectual authority (SMP, Box 46, Folder 174, Titled: “Notes: Method 1962”).

After introducing many ad hoc trial and error innovations and refinements, on 7 August 1961 Milgram was finally ready to embark on the official research programme.

The first official experiment Milgram undertook was termed the Remote condition where, except for the banging on the wall after the 300 and 315-volt switch, the learner 
could not be heard, seen, or need not be touched. This experiment resulted in a 65 percent completion rate. Milgram was probably expecting a higher rate of completions than this, considering that he introduced only subtle changes (infrequent wall-banging) to the "no feed back" pilot where "virtually all" completed the experiment. Nonetheless, with most subjects still inflicting all of the shocks, the still surprisingly high 65 percent result ensured Milgram's achievement of his initial goal of maximising the completion rate.

Armed with this data, Milgram soon afterwards started writing his first article on the OTA research programme, titled Behavioral Study of Obedience, which was submitted for publication in December 1961. The first two paragraphs of this article mentioned the Holocaust, hinting that there was some connection between this event and the OTA experiments. ${ }^{48}$ These initial paragraphs were followed by an overview of the general method and procedure of his experimental paradigm, and a more specific outline of the article's centrepiece: the Remote condition and its counterintuitive 65 percent completion rate. In the absence of any theory, the article ends with a number of potential factors Milgram believed "go some distance in explaining the high amount of obedience observed" (Milgram, 1963, p. 377). A footnote indicates that the results from other experiments testing the validity of these and other factors were forthcoming. The article raised "extraordinarily vital and sobering questions" (Miller, Collins \& Brief, 1995, p. 4) but, in the absence of any concise theoretical component, it provided no answers, and this deficiency resulted in reviewers twice recommending its rejection. One reviewer, Edward E. Jones, argued that because the article had no theoretical formulation or hypothesis, the Remote experiment was, at best, a “ 'triumph of social engineering' ” (Parker, 2000, p. 112). Nonetheless, after some amendments, in October of 1963 the Journal of Abnormal and Social Psychology agreed to publish the piece. Irrespective of the initial rejections, the article's presentation of the Remote experiment and its surprising 65 percent completion rate became Milgram's “best-known result” (Miller, 1986, p. 9). It had its intended effect.

\section{$\underline{5.5 \quad \text { Conclusion }}$}

How did Milgram rapidly transform a large proportion of ordinary people into willing torturers of other human beings? Several key factors were presented which were all likely to have contributed to the achievement of what was clearly Milgram's initial goal to maximise the proportion of subjects willing to complete his experiment and inflict harm

\footnotetext{
48 "Obedience, as a determinant of behavior, is of particular relevance to our time. It has been reliably established that from 1933-45 millions of innocent persons were systematically slaughtered on command" (Milgram, 1963, p. 371).
} 
on other human beings. First, Milgram drew on some of his past experiences with strainresolving or binding innovations. One example was his early decision to use the inherently strain-resolving Shock Generator-the remote infliction of electric shocks-as his means of inflicting harm (a common form of punishment in psychology).

Secondly, Milgram relied upon his acute intuition: the seemingly unconscious incorporation of strain-resolving or binding innovations that he suspected were most likely to work. An example of this is manifest in his very first sketches of the then-hypothetical shock generator into which Milgram intuitively incorporated the idea that across a number of shock switches the intensification of pain should be inflicted gradually-by many small steps-better known as the foot-in-the-door phenomenon.

A third, and particularly powerful factor contributing to the Remote condition's high completion rate, was Milgram's use during the pilot study-stage upon the also intuitively driven ad hoc trial and error exploratory method of discovery. As stated in the epigraphic statement at the start of this chapter, the ad hoc trial and error exploratory method of discovery is where:

a scientist has no very clear idea what will happen, and aims to find out. He [sic] has a feeling for the 'direction' in which to go (increase the pressure and see what happens) but no clear expectations of what to expect (Harré \& Second, 1972, p. 69).

During the extensive pilot studies, this approach saw Milgram gradually introduce to his increasingly more refined experimental procedure an expanding variety of increasingly powerful BFs and SRMs (many of which enhanced the manipulative power of some of his weaker intuitive binding and/or strain-resolving-type ideas or even led to the introduction of altogether new ideas for SRMs and/or BFs that were completely beyond the realms of his creative imagination ${ }^{49}$ ). With regard to this method of discovering new SRMs/BFs, as Milgram (as cited in Evans, 1980, p. 191) said: "Many of the most interesting things we find out in experimentation you don't learn until you carry it out."

Milgram's surprising results were largely due to the creative synthesis of the above three factors, which gradually led to his discovery and then incorporation of the following BFs and SRMs: the more-likely acceptable rationale for inflicting the shocks (SRM), the piecemeal escalation of shock intensity (BF), the ability of the shock generator to inflict

\footnotetext{
${ }^{49}$ For example and as mentioned, after running his student's pilot, some subjects would look away from the person they were shocking. This observation led Milgram to manipulate victim proximity, the apogee of which led to the "no feed back" pilot study where basically every subject inflicted all the shocks.
} 
harm remotely (SRM), the removal of responsibility for the subjects actions (SRM), providing an ambiguously labelled outcome for the last shock switch-XXX (SRM), a pushy experimenter (BF), and a seemingly harmless learner (SRM), to name a few.

From the inception of his first inchoate ideas through to the end of the pilot studies, the gradual accumulation, refinement, and incorporation of these BFs and SRMs seemed to increase cumulatively the probability of any one subject completing the experiment (see Tilker, 1970, p. 100). In fact, during the second set of pilot studies, Milgram had introduced so many patently powerful BFs and SRMs that he went too far resulting in "virtually all" subjects completing the experiment, achieving his initial goal of maximisation of the completion rate. Because he required a scale to measure obedient tendencies, Milgram decided to introduce a potential source of strain-auditory stimulation - that he was confident would "strengthen the subject's resistance to the experimenter's commands" (illustrating that, when it was necessary, Milgram was clearly capable of engaging in the reverse). It was this adaptation that ended in his Remote condition and its most (in)famous 65 percent completion rate.

Having achieved his initial goal of discovering how to ensure a large proportion of ordinary people inflicted harm on another human, Milgram was now in a position to address the "crux" of his research programme. That is, he could pursue his aim of explaining why so many of his subjects were willing to torture an innocent human being. 


\title{
Chapter Six: The Obedience to Authority Research Programme and Milgram's Explanation of His Findings
}

\begin{abstract}
He seemed to have an intuitive 'feel' for what would be an interesting or relevant experimental variation. Thus, he would first perform the experiment and then concern himself with formally accounting for the result. Given that there was virtually no previous systematic research on obedience, it was understandable that Milgram's focus was essentially in a context of discovery or exploration rather than confirming or disconfirming specific hypotheses-Miller (1986, p.45).
\end{abstract}

Having purposefully obtained a high completion rate in his first official experiment, Milgram then moved on to the crux of his study: an attempt to explain his subjects' obedient behaviour. As outlined in the second proposal, his aim was to convert emerging questions into a variety of testable propositions, thus generating an array of slight variations on the basic experimental procedure. After having noted the direction and degree of (dis)obedience obtained, Milgram believed that new questions, insights and potential explanations (also eventually testable) would emerge. As he said in the second proposal: "Increasing familiarity with the subjects' performance . . . breed[s] the most penetrating hypothesis". Not only had Milgram used an exploratory trial and error method in discovering how to obtain a high completion rate, with his attention now on the "why" question he was expecting that this approach would illuminate all the key factors-positive and negative - capable of increasing the probability of (dis)obedience. He assumed his advancing knowledge would provide a strong foundation from which to then engage in post hoc theoretical development. Having outlined Milgram's strategy, what was Milgram's exploratory journey? What results did he obtain? And how did he theoretically explain these findings?

The previous chapter pointed out that the first pilot studies immediately drew Milgram's attention to the potential relationship between physical distance (separation between the subject and the learner) and the completion rate. The Remote condition, the first official experiment, was actually the first of a set of experiments termed the Proximity Series. The increasingly more proximate variations on the Remote experiment included the Voice-Feedback condition (where the subject could hear all the learner's verbal reactions to the shocks) and then the Proximity condition (where the subject and learner were in the same room and so that the learner's reactions to being shocked could directly be heard and seen). As expected, increased proximity resulted in a lower completion rate, with $65,62.5$, and 40 percent of subjects completing the Remote, Voice-Feedback, and Proximity experiments, respectively. The results may have been in the direction Milgram expected but, confirming the difficulty in generating disobedience, he was surprised by the large 
proportion of subjects who were still willing to complete the Proximity experiment (where the screaming learner was only an arm's length away). Due to this result, Milgram ad hoc decided to devise an additional variation in this series-the so-called Touch-Proximity experiment.

The Touch-Proximity experiment was similar to the Proximity condition until the infliction of the 150-volt shock, when the learner would suddenly refuse to put his hand on the shock plate. The experimenter would then instruct the subject to force the learner's hand on the plate so punishment for any further incorrect answers could be administered. As Milgram said before undertaking this variation: "I seriously doubt that many subjects will go allong [sic] with the command for very long" (SMP, Box 46, Folder 175, Titled: "Notes: Proximity"). But, much to his surprise, even though the learner, according to Milgram, " "was screaming his guts out' " and the subject "had to physically struggle with him in order to get his hand down on the shock generator" (Meyer, 1970, p. 130), 30 percent of subjects completed this variation. As he neared the completion of this specific condition, on 21 September 1961, Milgram made a particularly explicit statement in a letter addressed to Henry Riecken at the NSF, suggesting some connection between the experimental programme and the perpetration of the Holocaust:

I once wondered whether in all of the United States a vicious government could find enough moral imbeciles to meet the personnel requirements of a national system of death camps, of the sort that were maintained in Germany. I am now beginning to think that the full complement could be recruited in New Haven (Blass, 2004, p. 100).

The Touch-Proximity condition further broadened Milgram's earlier estimations of the likely parameters of blind obedience. He had become increasingly confident that it would be possible to introduce other highly stressful modifications-new sources of strain - to the basic experimental procedure that, to the surprise of outsiders, would still probably generate a high completion rate. Soon after the completion of the above series of experiments Milgram lost access to his laboratory facilities, and the obedience to authority (OTA) research programme was transferred to the basement of the same building. This seems to have provided Milgram with sufficient reason to start all over again by replacing his intended baseline study (the Remote condition) with a new and much more disturbing one (Milgram, 1974, pp. 55-56).

The new Baseline experiment resembled the Voice-Feedback condition (where subjects could hear the learner's verbal reactions to the shocks), except for the inclusion of 
the following strain-inducing innovations. First, while being hooked up to the shock plate, the learner (in the presence of the subject) would from then onwards casually point out: " 'When I was at the Westhaven V.A. Hospital, a few years ago, they detected a slight heart condition. Nothing serious, but are these shocks dangerous?" (Milgram, 1974, p. 56). The experimenter explained in a dismissive tone that although the shocks may be painful, they caused no permanent tissue damage. Secondly, during the standardised tape recordings, the learner would make explicit references to this medical condition at the 150 , 195, and 330-volt switches, with minor variations on "My heart's bothering me" (Milgram, 1974, p. 56). Finally, unlike the earlier experiments (where from the 300 to 450 -volt switch the subject refused to answer any questions and, upon being shocked, would cry out until all the shocks had been inflicted), ${ }^{50}$ from the 345 -volt switch onwards the learner's increasingly excruciating reactions to the apparent shocks would suddenly stop (giving the more disturbing impression that he had, at least, been rendered unconscious).

These strain-inducing additions to the Voice Feedback procedure failed to raise levels of disobedience. In the different laboratory premises the (new) Baseline condition also generated a 65 percent completion rate. Along with the first Remote condition, this was to become Milgram's other most (in)famous experiment, largely because it was the centerpiece of the widely viewed Obedience (a filmed experiment) (see Milgram, 1965c).

Having completed the first five experiments, Milgram found himself in a position that, before the first pilot study, he could never have envisioned. He had come to the counterintuitive realisation that obtaining high completion rates was actually the easy part, and what was going to be difficult was introducing sources of strain that might better promote disobedience. In his words:

At many points we attempted to establish a boundary. Cries from the victim were inserted; not good enough. The victim claimed heart trouble; subjects still shocked him on command. The victim pleaded that he be let free, and his answers no longer

\footnotetext{
${ }^{50}$ As Milgram (1965a, p. 62) said in relation to the first four experiments: "At 300 volts the victim shouts in desperation that he will no longer provide answers to the memory test; and at 315 volts, after a violent scream, he reaffirms with vehemence that he is no longer a participant. From this point on, he provides no answers, but shrieks in agony whenever a shock is administered; this continues through 450 volts." This statement is an exaggeration, as highlighted by the following learner response from the Proximity experiment after the penultimate 435-volt shock: "Ahhh. What's the use in going on with this thing? I told you, I'm not going on with the experiment anymore" (SMP, Box 155, Audiotape \#0303). Upon which, the experimenter said, "Just relax please. Try and concentrate on what the teacher is saying. Please continue Teacher" (SMP, Box 155, Audiotape \#0303). Although these first four experiments were included in the official research programme, because Milgram was still refining the experimental procedure they were really extensions of his pilot studies (or should have been labelled as such). He could have re-run the Proximity Series using the standardised (new) Baseline procedure. It certainly would have been interesting to observe how subjects in the Touch-Proximity condition would have reacted at the 345-volt switch to the experimenter's demand that they force the unconscious learner's hand on to the shock plate.
} 
registered on the signal box; subjects continued to shock him. At the outset we had not conceived that such drastic procedures would be needed to generate disobedience, and each step was added only as the ineffectiveness of the earlier techniques became clear [italics added] (Milgram, 1965a, p. 74).

Milgram wondered around this point in the experimental programme: "What is the limit of such obedience?" (Milgram, 1965a, p. 74).

With the intention of systematically varying the factors he suspected were most likely to alter the degree of obedience, Milgram introduced a score of variations on the (new) Baseline experiment over the next eight months. Most of these variations were later presented by Milgram (1974) under the following three general categories. First, Further Variations and Controls (which this thesis has broken down further into Ad Hoc Testing of Justifications, Conditions Stimulated by Emerging Questions, and the Proximity of Authority Series). Secondly, there were the Role Permutations Series and finally the Group Effects Series. The following will present Milgram's remaining findings in this order.

\subsection{Further Variations and Controls: ad hoc Testing of Justifications}

In the first few conditions Milgram noted that subjects frequently justified their blind obedience on the grounds that the learner had earlier freely agreed to participate and had not stipulated any conditions regarding their subsequent treatment. Therefore, according to some subjects, irrespective of the learner's eventually excruciating plight, they felt contractually bound to complete the experiment. Milgram therefore decided to test the veracity of this justification by undertaking a slight variation on the Baseline experiment. He termed this variation The Victim's Limited Contract. From the start and in the presence of the subject, the learner pointed out: " 'I'll agree to be in it, but only on condition that you let me out when I say so; that's the only condition' " (Milgram, 1974, p. 64). Begrudgingly, the experimenter would agree. Unlike the Baseline experiment, the learner in this variation explicitly stipulated prior conditions that were to dictate his continued participation. Upon reaching the 150-volt shock switch, the learner would demand that the experiment be immediately discontinued. However, the experimenter ignored the request and, in clear breach of the verbal contact, continued to demand that the subject inflict further shocks. Irrespective of this, 40 percent of all subjects completed this variation. Because this result was 25 percent lower than the Baseline condition, it was clearly a source of strain for many subjects. However, for the 40 percent of obedient 
subjects more powerful forces were clearly more influential.

Another frequently encountered justification offered by subjects for completing was that the experiment was conducted at an elite institution of learning-Yale University. This "gave them confidence in the integrity, competence, and benign purposes of the personnel" (Milgram, 1965a, p. 69). Many also stated that had the experiments been conducted by a far less distinguished institution, they would not have inflicted all the shocks. Milgram decided to test the credibility of this justification in a variation termed Institutional Context (Bridgeport). He moved his research programme to a rather shabby office block located on the main street in the industrial town of Bridgeport, Connecticut. With no ties to Yale (or any other recognisable organisation), and under the auspices of a company titled Research Associates of Bridgeport, Milgram undertook a replication of the Baseline experiment. The experiment produced a 47.5 percent completion rate (clearly less than the Baseline's 65 percent but not statistically significant). Running the experiment under the auspices of a far less impressive institution only proved to be a weak source of strain.

The following section will present a number of variations stimulated by some of Milgram's (and others') emerging questions. The first of these is a rarely discussed experiment also undertaken at Bridgeport.

\subsection{Further Variations and Controls: Conditions Stimulated by Emerging Questions}

Musing over the results obtained during the Proximity Series, Milgram stated in a document dated March 1962:

As the Victim is brought closer to the subject the relati ship [sic] between them strengthens.,[sic] relative to the relationship between Vand [sic] $\mathrm{E}$ and $\mathrm{S}$ and $\mathrm{E}$. He becomes a real person, acquires a face, stands as a concrete individual. Proximity is important for relationship [sic]. Or a husband and wife team as V and $\mathrm{S}$ would have a disaterous $[$ sic $]$ effect on the power of E over S . . . Only a genuine relationship between the Victim and the Subject, based on identification, or marriage, etc. couodld [sic] reverse these results. How could this be fostered in the labora[t]ory? (SMP, Box 46, Folder 163, Title D: "Obedience Notebook 19611970").

A few months later Milgram developed a variation that tested the importance of a relationship between the subject and learner. In notes written soon after the completion of the Relationship experiment, Milgram provided the following brief overview: 
RELATIONSHIP --This experiment was done in Bridgeport, and thus uses condition 23 [Institutional Context] as itsproper [sic] control. Subjects were asked to bring a friend to the labortoy [sic]. When the subjects arrived, the [sic] did an actual drawing to determine who would be teacher and who would be learner. The learner was then taken in the next room. There he was caoched [sic] by Milgram on how to yell. The e [sic] experimenter then conspicuously put him in the electric chair, and his friend looked on as instructions were given in the regular manner. After the teacher returned to the shock machine, Milgram unstrapped the learner, and stayed with him coaching him how to yell, using very closely, the Model [sic] of McDonough's yelling. Note: Our usual victim, McDonough, did notpartipate [sic ] in this experiment. The purpose of the experiment was to see if the relationship of the teacher to the learner would be important in obedience and defiance [italics added] (SMP, Box 46, Folder 163, Titled: "Obedience Notebook 1961-1970”).

The results of this variation indicated that a positively affective relationship between teacher and learner was indeed a powerful source of strain. As the Raw Score Sheet below in Figure 6 illustrates, in a sample of 20 pairs who were at least acquaintances, only three-15 percent—went on to inflict all the shocks.

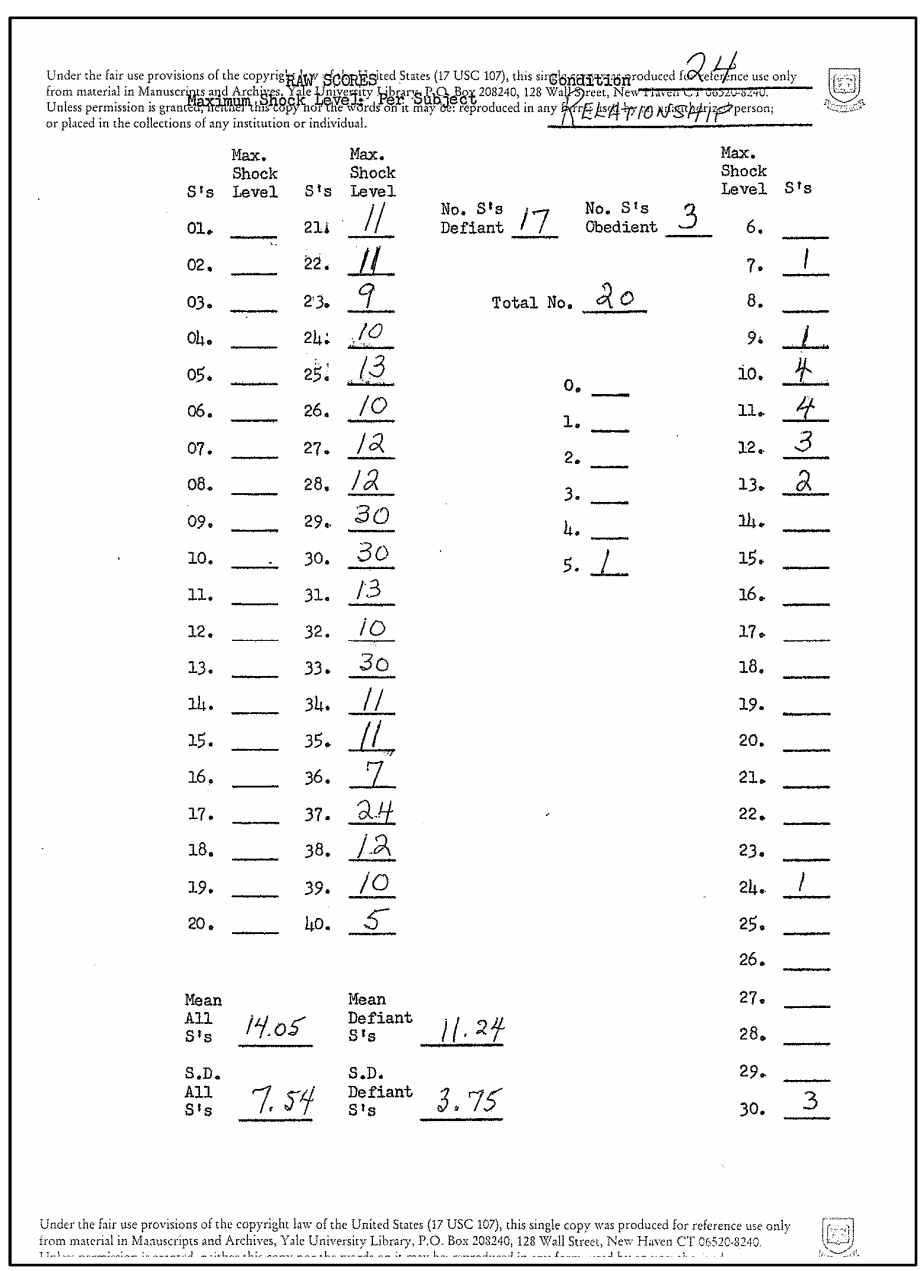

Figure 6: Raw scores in the Relationship condition (SMP, Box 46, Folder 163, Titled: "Obedience Notebook 1961-1970"). 
reveal that Milgram recognised the probable importance of a positive relationship between the subject and learner in undercutting the power of obedience to malevolent authority. For example, in one subject's post-experimental debriefing, the experimenter, probably pointing in the direction of the $11^{\text {th }}$ or 165 -volt shock switch, stated: "This is about where everybody stops right here . . . in this condition with friends." Then Milgram added: "It makes quite a difference see." The subject responded: "I would imagine, yeah" (SMP, Box 153, Audiotape \#2438). ${ }^{51}$ In one of his subsequent publications he briefly mentioned the Relationship variation (Milgram, 1965a, pp. 70-71), adding that a more comprehensive discussion of this condition would be forthcoming in his monograph. ${ }^{52}$

Another variation on the Baseline experiment tested Milgram's long-held suspicion that subjects may have been responding to the personality of the experimenter and learner. It was previously argued that Milgram's selection of an unthreatening learner and a forceful experimenter may have had both a strain-resolving and binding impact on the subjects' responses, respectively. In an experiment termed Change of Personnel, Milgram attempted to reverse these personal characteristics. He substituted his usual experimenter/learner team, of the "stern, intellectual looking" Williams and "unthreatening" McDonough, with an experimenter by the name of Emil Elges "who posses [sic] about him a certain soft intertness [sic], that almost borde rs [sic] on passivity" and a "lean, and hard looking" learner played by Robert J. Tracy who "frequently clenches his fist" (SMP, Box 46, Folder 174, Titled: "Notes: Method 1962"). This variation resulted in 50 percent of subjects remaining obedient until the end. Milgram concluded: "The personal characteristics of the experimenter and victim were not of overriding importance" (Milgram, 1974, p. 59). ${ }^{53}$

Although Milgram selected his participants from a broad cross-section of society, one variable that he intended to hold constant across all variations was the use of maleonly subjects. Could, consequently, the results of the Baseline study have been due to the perhaps inherently more aggressive nature of males? Would a sample of female subjects

\footnotetext{
${ }^{51}$ In another excerpt during a different debriefing session Milgram asked: "did he [the experimenter] tell you about the strangers ...?" Teacher: "Yeah." Milgram: "And in that situation a lot of people will go right up till the end. Cause they don't know the person and they don't give a damn .... he can be screaming his ahhh bloody head off" (SMP, Box 153, Audiotape \#2428).

${ }^{52}$ The very same information was repeated in a subsequent compendium of his then work to date (Milgram, 1977, pp. 115-117).

${ }^{53}$ Milgram (1974, pp. 58-59) did not state whether or not this difference was statistically significant from the Baseline experiment.
} 
react any differently to the Baseline experiment? After running the baseline procedure using only female subjects, in an experiment termed Women as Subjects, Milgram found they were no different from the men, with 65 percent of the women inflicting all of the shocks.

On the topic of aggression, another potential explanation of the high completion rates for both men and women in the Baseline experiment was that perhaps in all people there exists an instinctual aggressive drive, which the experiment unleashed. The implication of this potential explanation was that the Baseline study's high completion rate may have had nothing at all to do with OTA. Milgram tested the potential veracity of this alternative explanation by running the Baseline's Asch-like experimental control: a condition that eliminated the experimenter's demands that the shock intensity be increased for each incorrect answer. In a variation termed Subject Chooses Shock Level, subjects were informed that for any incorrect answers received they were free to inflict a shock of any intensity. The results revealed that in the absence of the experimenter's demands, nearly every subject repeatedly chose to inflict shocks of a very low intensity, with only one out of 40 subjects-2.5 percent—going on to inflict shocks of 450 volts. Any inherent human aggressive impulse was clearly not responsible for the Baseline results.

Whatever the reason for the Baseline's results, this experiment appeared to be of central importance: in the absence of the authority figure's demands only 2.5 percent went on to the end of the shock board but, in the presence of this potential Binding Factor (BF), 65 percent did so. One can therefore appreciate Milgram's heightened interest in the authority figure of the experimenter. As he later concluded in reference to this specific variation: "Whatever leads to shocking the victim . . . needs to be explained by the transformation of behavior that comes about through obedience to orders" (Milgram, 1974, p. 72).

Milgram progressively eliminated his subjects' various justifications for their behaviour, then developed and tested his emerging questions. The most powerful force producing the high completion rates seemed to be, as the above control to the Baseline experiment indicated, the role of the authority figure and/or the compelling content of the demands. As the following will demonstrate, this emerging conclusion was further reinforced by a series of experimental variations that attempted to distance the authority figure from the subject. 


\subsection{Further Variations and Controls: the Proximity of Authority Series}

In a condition termed Experimenter Absent, subjects were given the usual baseline instructions, except that after the practice session the usually proximate experimenter received a rigged phone call, ostensibly requesting his immediate presence elsewhere. After informing the subject of the situation, the experimenter then instructed them to complete the experiment in his (the experimenter's) absence. Before leaving the laboratory the experimenter gave the subject a contact phone number in case of any further questions. In response to those subjects who became concerned about the learner's reactions to the shocks and eventually made use of the phone, the experimenter strongly urged them to continue their role in the procedure (as in the Baseline). The question being: even in the physical absence of any direct authority, what percentage of subjects would go on to complete the experiment? In stark contrast to the Baseline experiment where the experimenter was only several feet away, in this variation only 9 out of 40 subjects -20.5 percent—were willing to inflict all the shocks.

The Experimenter Absent variation also generated a behaviour not observed in any of the other experimental conditions. That is, it was not unusual for subjects to inform the experimenter over the phone that they were, as instructed, increasing the shock intensity for each incorrect answer, but in reality they were repeatedly undermining the experimenter's authority by surreptitiously inflicting light shocks. It seemed to Milgram (1965a, p. 66) that these subjects "found it easier to handle the conflict in this manner than to precipitate an open break with authority."

Taking this experiment a step further, in another variation termed the NoExperimenter condition, the subject would arrive at the laboratory only to be confronted by a tape-recorder and a note, the latter pointing out that the experimenter was unable to attend and that what was required of them would be relayed to them on the enclosed cassette recording. Although this condition "led to significantly lower obedience" than the Baseline, due to "technical difficulties that require extensive discussion", Milgram (1965a, p. 66) chose not to disclose details of this variation.

The results from both of these variations (as well as a third one in this series) ${ }^{54}$

\footnotetext{
${ }^{54}$ Milgram (1965a, p. 66) mentioned a "third condition"-actually the "second part" (SMP, Box 163, Titled: "Obedience Notebook 1961-1970") of the Experimenter Absent condition-whereby the experimenter would
} 
indicated that the physical presence of the authority figure was an important BF in the production of the Baseline experiment's relatively high completion rate (Milgram, 1965a, p. 66). The emerging conclusion that there was something very important about the role of the experimenter in procuring the Baseline condition's high completion rate was reinforced by a further series of experiments, termed the Role Permutations Series. This series attempted to shed more light on what it was about the authority figure that enabled him to bend so many of the subjects to his will.

\subsection{The Role Permutations Series}

Milgram undertook a series of variations on the Baseline experiment with the intention of answering the following question: "is the subject responding principally to the content of the command to shock or to the status of the person who issues it? Is it what is said or who says it that largely determines his actions? [italics original]" (Milgram, 1974, p. 90). Milgram's strategy was to undertake a set of variations that, where possible and unlike any of the other variations, reconfigured the status (an equal ordinary man or a higher-status authority figure), the content of the commands (advocating shocking or stop shocking the learner), and the position (prescribes, administers, or receives shocks) of all those involved.

In the first such variation, termed Learner Demands to be Shocked condition, after the infliction of the 150-volt switch the experimenter ordered that, in light of the learner having a slight heart condition, the subject cease inflicting the shocks. However, the learner pointed out that irrespective of the pain, he wanted to continue receiving the shocks because apparently he did not want to be outdone by a friend who, having earlier been in the experiment, bravely endured all the shocks. Milgram was curious as to whose command the subject would accept: the (higher-status) experimenter's orders to stop or the (more-equal-status) learner's request to continue? In this variation all 20 subjects ignored the learner and immediately obeyed the experimenter's request to stop inflicting the shocks. Milgram (1974, p. 92) concluded: "It is not the substance of the command but its source in authority that is of decisive importance."

return to the laboratory and attempt to persuade the subject to continue participating in the procedure. Apparently, the experimenter was frequently successful in encouraging subjects to re-engage in the procedure. However, Milgram does not appear to have published any further details of the exact procedure and its results. 
To confirm that status was indeed of greater importance than the command's content, Milgram devised an experiment whereby the command to inflict the shocks was not delivered by the experimenter but by another equal-status subject. In this variation, termed Ordinary Man Gives Orders, two subjects were initially involved (one being the naïve subject whose role was to inflict the shocks and the other a time-keeping actor). After providing the standard instructions (minus what levels were to be administered), a rigged phone call resulted in the experimenter having to vacate the laboratory immediately. Before departing the experimenter asked the two subjects to complete the experiment in his absence (which was possible because all responses could be recorded automatically). However, in the experimenter's absence the actor suddenly became insistent that for each incorrect answer the subject inflict a shock of increasing intensity. Thus, a person of equal status was issuing the orders. The results strengthened the conjecture that status was more important than the content of the command: only 4 out of 20 subjects -20 percentcompleted the experiment.

Milgram then ran a second experiment using the 16 resistant subjects which he termed the Subject as Bystander experiment. In this, the boisterous ordinary man enquired whether, as a compromise, each of the 16 recalcitrant subjects would instead be willing to fulfil the timekeeper's role (with the actor switching places and assuming the subjects' previous role of the shock inflictor). Although at some stage all subjects complained (with five trying to physically impede the actor from inflicting the shocks), 11 out of the 16 initially resistant subjects -68.75 percent — went on to participate fully in the process by assuming the timekeeper's role. Although not prepared to inflict the shocks themselves, these 11 subjects were willing to allow the actor to do so.

What would happen if the high-status experimenter were relegated to a lower-status role? In an experiment termed Authority as Victim, the intended learner would point out that, before committing to the role, he wanted first to observe someone experience the learner's role. In a role-reversal, the experimenter agreed to fulfil the learner's tasks, with the intended learner fulfilling the experimenter's tasks. Upon exposure to the shocks, the experimenter (as learner) soon conceded that the punishment was too painful to endure and demanded the subject end participation in the procedure. The learner (as experimenter) would then demand that the equal-status co-worker (the subject) continue inflicting the shocks. In this variation all 20 subjects stopped inflicting the shocks and immediately withdrew from the experiment. 
All of the Role Permutation experiments presented thus far indicated that subjects obeyed the content of whatever orders (shock or not shock) were supplied by the authority figure (irrespective of their being in a low or high-status role).

In the penultimate experiment of this series, termed Two Authorities: Contradictory Commands, Milgram explored what might happen if there were two equally high-status authorities, one of whom after the 150-volt switch demanded the subject stop and the other insisting they continue. In this variation none of the 20 subjects completed the experiment (with one subject stopping before the 150-volt switch, 18 immediately after, and one following the infliction of the 165-volt switch).

In the final experiment of this series termed Two Authorities, One as Victim, the naïve subject was told that a second subject had not turned up so, via a rigged draw, one of the two experimenters would fulfil the lower-status learner role. Once under way, the lower-status experimenter as learner demanded after the 150-volt switch that the experiment be stopped, but the higher-status experimenter demanded that the subject ignore these orders and continue inflicting the shocks. Milgram was interested in whose demands the subject would yield: the higher-status experimenter or the lower-status experimenter as learner? Just as in the Baseline experiment, 13 out of 20 subjects -65 percent-inflicted all the shocks.

The results from the Role Permutation series would seem to indicate that subjects responded more to the status of the person issuing a command than to the command's content. Subjects tended to do whatever the authority figure demanded of them-thus OTA. Having said this, if the key factor generating completions was indeed closely related to the authority figure's higher-status, the fact that 20 percent of all subjects in the Ordinary Man Gives Orders condition followed the self-initiated orders of a person of equal status must have sowed some seeds of doubt in Milgram's mind. Nonetheless, if these experiments had led Milgram to the conclusion that the high rate of obedience in the Baseline experiment was largely a function of the authority figure's higher-status, the next series of experiments should have undermined any such confidence.

\subsection{The Group Effects Series}

Because of his experience with Asch's group conformity research, Milgram was 
well-versed in the binding influences of group forces. This was why his earliest ideas surrounding OTA centered on Asch-like group forces. However, as discussed earlier, soon after the pilot series where the "alone" conditions demonstrated significant potential, the group conformity experiments were relegated from "a major concern" to a minor diversion. The end result was a set of variations termed the Group Effects Series.

The first in this series was termed the Groups for Disobedience (or Two Peers Rebel) condition. The basic procedure was as follows: under the pretext of exploring the effects of punishment on collective learning and memory, via a rigged draw, the subject became one of three teachers (two of whom were actors). The first actor/teacher was assigned the task of asking the learner questions, the second actor/teacher was then to assess and inform the learner of the accuracy of their response, with the naïve subject going on to inflict increasingly intense shocks for incorrect answers. After the 150-volt switch the first actor/teacher suddenly expressed his concerns regarding the learner's wellbeing, refused to continue with the procedure, and relocated to a chair on the other side of the room. Failing to persuade him to return, the experimenter then put the onus on the remaining teachers to complete the experiment. However, after the 210 -volt switch the second actor/teacher also pulled out of the experiment and joined the first actor/teacher on the other side of the room. After failing to persuade the second actor/teacher to return, the experimenter could then rely only upon the naïve subject to complete the experiment. Under these conditions, most subjects pulled out and joined the two actors: only 4 out of 40-10 percent—went on to inflict all of the shocks.

The second variation of this series, termed the Groups for Obedience condition, was similar to the Groups for Disobedience condition, except that, instead of rebelling against the completion of the experiment, the two actors expressed their determination to finish. If at any time during the experiment a subject expressed a desire to stop inflicting the shocks, the two actors would support the experimenter and express their disapproval, stating: " 'You can't quit now; this experiment has got to get done'” (Milgram, 1965b, p. 133). There was a slight increase in obedience over the Baseline, with 29 out of 40 subjects-72.5 percent - completing the experiment (a difference that was not statistically significant).

The third group effects experiment was the Peer Administers Shock condition, where the naïve subject was assigned one of the more subsidiary teacher roles, with an actor fulfilling the role of shock inflictor. Although the subjects' participation still saw 
them complete a necessary part of the procedure and contribute to the overall process, in this variation they themselves avoided having to inflict any shocks. This variation produced the highest completion rate in the entire (official) experimental programme, with 37 out of 40 subjects - 92.5 percent—continuing to fulfil their minor but nonetheless essential role until all the shocks had been inflicted.

This high completion rate was probably due to the introduction into the equation of another Strain Resolving Mechanism (SRM). As in the Subject as Bystander experiment, even though the subject was indisputably contributing to the overall process, they did not directly inflict the shocks and thus did not feel responsible for the ostensibly harmful outcome. This reduced their personal levels of strain (thus a SRM). Again, it could be argued that Milgram captured, within a controlled laboratory setting, the potentially destructive bureaucratic process whereby, via the step-by-step division of labour, a malevolent goal had been broken down into a number of seemingly unrelated and benign tasks to the point where nobody felt totally responsible for the eventually destructive outcome.

The final variation of this series was termed the Group Pressure and Action Against a Person experiment. This required the naïve subject to become the shock inflictor (with the two actors fulfilling the two auxiliary roles). Before starting, the experimenter explained that, upon receiving an incorrect answer, the three teachers were themselves to decide on the intensity of punishment that the learner was to receive. Starting with the two actors, each teacher was to suggest the degree of shock intensity, and the learner was to receive the lowest of the three recommendations. However, unbeknown to the naïve subject, for each incorrect answer received the two actor/teachers would (starting with the first 15-volt switch) repeatedly increase their recommendations in 15 volt increments. Again introducing the BF of group pressure into the equation, Milgram was interested to see whether the two actor/teachers' suggestions would influence the subject's recommendations. Seven out of 40 subjects- 17.5 percent-followed the actors' recommendations and went on to the end of the shock board.

This result may suggest that group pressure was not a particularly powerful coercive force. However, the 17.5 percent completion rate may have been a little misleading. The control of this variation was the Subject Chooses Shock Level experiment, where the maximum shock inflicted by 38 out of 40 subjects was 150 volts or less. Yet, in the above variation only 13 out of 40 inflicted a maximum shock of 150 volts, while 15 
subjects-37.5 percent-went on to inflict a maximum shock of at least 315 volts.

Although a proportion of the subjects clearly proved resistant to group pressure when compared to the control, Milgram (1964b, p. 141) rightly concluded that many "subjects were substantially influenced by group pressure."

As Milgram's trial-and-error method of discovery tended to highlight, the coercive influence of the authority figure appeared to be the independent variable producing the obedient subjects' seemingly destructive actions. However, the results from the above experiment were likely to have left Milgram a little confused. In his procedural overview of this experiment, he went to some lengths to point out that because the experimenter gave no orders: "This is not an obedience experiment. It is a group influence experiment" (SMP, Box 46, Folder 163, Titled: “Obedience Notebook 1961-1970”). Reinforcing this initial assessment is the fact that on the left-hand side of this typed document is, in Milgram's handwriting, the word "CONFORMITY". However, if many subjects in the absence of the experimenter's demands were "substantially influenced by group pressure", where did this leave Milgram's increasingly confident conclusion that the high completion rates were due to the authority figure's influence (Lutsky, 1995, p. 59)? ${ }^{55}$

This apparent conundrum must have raised some concerns because on 27 May 1962 the data-collection phase ended (Blass, 1998, p. 46), and Milgram was then faced with the task of explaining his findings. With respect to this next phase, Milgram's plan all along was that the ad hoc variations on the Baseline condition would gradually move him closer to identifying the most influential key factor/s affecting the completion rates. These would, he assumed, provide a strong platform from which to engage in theoretical integration. However, statements made just a month after the completion of the last experiment indicated Milgram's growing uncertainty about his previous assumptions regarding the emergence of some coherent theoretical model.

\footnotetext{
55 This counterfactual with an apparent theory of OTA can be detected as far back as the group variations from the student-run pilots. The second research proposal dated 25 January 1961 stated: "while the control (non-group) subjects turned beseechingly to the experimenter at various times to secure information or commands, the subject in the experimental group reacted much more to the group than to the experimenter" (SMP, Box 45, Folder 160, titled: "Grants 1961-1967”). So, in this variation group forces seemed to be more powerful than the experimenter's orders.
} 
Building on an earlier idea about the subject having been "reduced to an agent, through [which] . . . forbidden acts . . bypass his conscience and guilt system" (SMP, Box 13, Folder 183, Titled: “Allport, Gordon 1954-1967”), in July 1962, a month after the completion of the experimental programme, Milgram argued:

before perfoming [sic] some novel action we would ordinarily bring to bear all our critical faculties and make some judgment as to whether we should perform it. In obedience, these functions are now derived from the authority. This applies not only to those judgments of the ego, but also of the superego. Certain acts we would not perform because conscience tells us not to. But in the obedience situations, there is so to speak a short circuiting of the system so that actions are no longer filtered though the superego or or [sic] ego, but stem from the authority (SMP, Box 46, Folder 164, Titled: “Notes General, 1961-1962”).

To illustrate his point regarding obedience situations which were somehow short-circuiting many subjects' conscience, Milgram produced the following diagram juxtaposing a

"NORMAL PERSONALITY" with one under the influence of "OBEDIENCE":
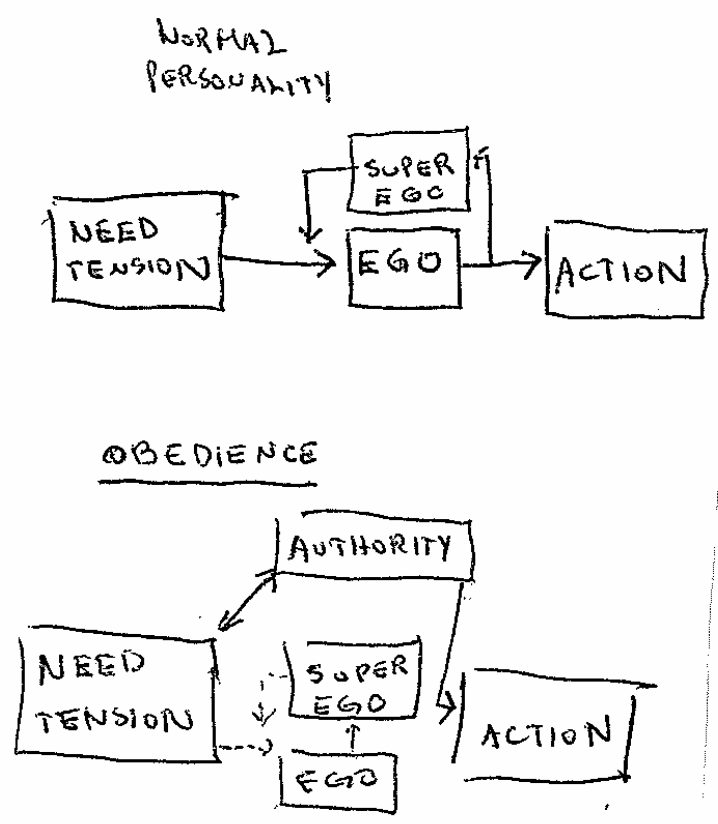

Figure 7: Milgram's early theoretical contemplations (SMP, Box 46, Folder 164, Titled:

“Notes General, 1961-1962”).

One obvious problem with this diagram is that it does not explain how

“AUTHORITY" might have caused the short-circuiting of the subjects' consciences.

Putting this issue aside, the whole idea in the diagram is founded on the premise that OTA 
was somehow central to the production of high completion rates. Of course, a theoretical model centred on OTA would almost certainly struggle to account for the Ordinary Man Gives Orders and the Group Pressure and Action Against a Person conditions-both of which saw proportions (albeit small) of subjects inflicting all the shocks in the absence of any demands by a higher-status authority figure. A potential solution to this problem was that there may have been more than one theory capable of accounting for the Baseline experiment's high completion rate. Before long Milgram started to suspect this may have been the case. In a July 1962 document titled "Theory[:] One Theory or Many", after making the point that in physics there were at least six discrete explanatory domains, Milgram stated:

The most serious problem in physics now is for adequate theory to explain new particles: purely empirical discoveris $[\mathrm{sic}]$. That does not mean that the discovery of each new particle is not a significant achievement in physics. People are awarded Nobel prizes for such discoveries. Now in regard to these [OTA] experiments also we are cnfronted $[\mathrm{sic}]$ with somewhat similar problems. There are several explan tory [sic] schemes which cover the same findings; none covers all the findings; and then there are certain phenomena for which there seem to be no truly adequate theoretical explanaions $[\mathrm{sic}]$. Itmay [ $\mathrm{sic}]$ be that --as in physics several theoreticl $[\mathrm{sic}]$ conceptions are needed at present .... The discontinuity between them should not be too upsetting. It is the only way that we could do full justic [sic] to the pomplexity [sic] of the phenomenon, while not neglecting the responsibility to fill the gaps with speculation (SMP, Box 46, Folder 164, Titled: "Notes general, 1961-1962").

Whether there existed one theoretical explanation of his findings or whether many theories were required to "fill the gaps", in the same month of July 1962, a clearly puzzled Milgram started to question the prudence of his methodological approach. It was clearly failing to pay the explanatory dividends he had earlier so confidently expected: "Sometimes the research does not seem to have advanced my understanding in any important way. And perhaps the way we went about it was the fault" (SMP, Box 46, Folder 164, Titled: "Notes general, 1961-1962”). In this same document Milgram more specifically clarified what he meant by this statement, using a parable about a fictitious $13^{\text {th }}$ century character by the name of Sylvanus who had tried to develop a system of knowledge about a candle's flame:

Man with a Candle? .... [Sylvanus] was curious about flames and wanted to study them. He decided to limit his study to the flame of a candle; and his manner of proceeding was as follows. He would study the height of candle's flame. That was his primary dependent variable. He chose it because he could conveniently obtain a rather exact measure of this variable; thus he could be objective and quite accurate. He would change those conditions which he thought affected the height of the candles [sic] flame (just as we chose those conditions we thought we [sic] alter the level of obedience) .... Then he took all his findings, thought about them, and 
wrote a treatise called: The Height of a Candle's Flame as it is Altered by Various Conditions. In the treatise he had little more to report than the hard findings and while he knew he had contributed little, he had the feeling that there was at least something there, something he did not know before (SMP, Box 46, Folder 164, Titled: "Notes general, 1961-1962").

Probably reflecting his own recent experience of the repeated rejection of his first articleMilgram (1963)—the parable then states:

He took his treatise to the wisest man in the realm and asked for his judgment. The wisest man read it carefully ... . he said to Sylvanus: I have read your treatise with interest, and I find your efforts admirable. However, there is a very important question that you did not answer: What is the nature of burning? Sylvanus then said: I am sure that is an important question, but the height of the flame is all I could measure, so that is all I could know. Then the wise man adjoined: Perhaps Syvlanus [sic], if you had climbed fewer mountains, and explored more ideas, you would have found the right method; for in choisng [sic] an easy method, you have lost the question (SMP, Box 46, Folder 164, Titled: "Notes general, 1961-1962”).

Although his method had failed to reveal the causes, perhaps all was not lost:

I would like to answer this parable. First if the height of a cnadle's [sic] falme [sic] were as important for the human society as obedience is, and if differences in its height were relevant to human experience, then by all means Sylvanus was studying someting [sic] important, and by appropriate means. Moreoever [sic], although in some investigations it is important to probe the 'nature' of the phenomenon, in others what one really wants to know are the conditions under which it functions, or even just a model of its effects (SMP, Box 46, Folder 164, Titled: "Notes general, 1961-1962").

Now increasingly confused as to what the cause/s might have been, perhaps he was not interested in such things after all. Maybe it was enough that he had captured a model of the effects of OTA. In the months that followed, and as illustrated in a letter written on 28 October 1962 to Gordon Allport, Milgram's confidence declined further:

The obedience to authority experiments are completed, and I am now writing some articles and a book on this work. My secret estimate is that the material is illuminating, though I don't know if I can convey its import in writing. The narrative bogs down in a superfluity of technical details (SMP, Box 13, Folder 183, Titled: “Allport, Gordon 1954-1967”).

According to Elms (1995, p. 28), one of the articles Milgram was working on during this difficult period in 1962 was eventually titled Some Conditions of Obedience and Disobedience to Authority (Milgram, 1965a) and, like his first OTA article, publication took a few years. While attempting to "account for this effect" (Milgram, 1965a, p. 62), he returned to his Asch-like style of presenting a variety of factors, including some insightful remarks on what he referred to as "Empathic cues", "Denial and 
narrowing of the cognitive field" and "Reciprocal fields [italics original]" (Milgram, 1965a, pp. 63-64). In some detail this article discussed all of the Proximity Series, the Proximity of Authority Series, and the Institutional Context (Bridgeport) condition. Milgram also very briefly mentioned "FURTHER EXPERIMENTS", including the Woman as Subjects condition, three of the Role Permutation Series, the Relationship condition and the Group Effects Series (Groups for Disobedience, Obedience, Peer Administers Shocks and the Group Pressure and Action Against a Person conditions) (Milgram, 1965a, p. 71). In the absence of any specific details or results, Milgram said of these experiments: "These will have to be described elsewhere, lest the present report be extended to monographic length." Milgram (1964b) later published a more detailed article that focused solely on this last experiment and, although he was earlier quite certain it was "not an obedience experiment", he soon after came to the opposite conclusion: ${ }^{.6}$

Insofar as he [the experimenter] does not object to the shocks administered in the course of the experiment, his assent is implied. Thus, even though the effects of group pressure have been clearly established by a comparison of the experimental and control conditions, the effects occurred within the context of authoritative sanction. This point becomes critical in any attempt to assess the relative effectiveness of conformity versus obedience as means of inducing contravalent behavior (Milgram, 1963). If the experimenter had not approved the use of all shock levels on the generator, and if he had departed from the laboratory at an early stage, thus eliminating any sign of authoritative assent during the course of the experiment, would the group have had as powerful an effect on the naive subject? (Milgram, 1964b, p. 142).

Milgram may have been correct: no tacit consent by the experimenter, no completions. However, in the Ordinary Man Gives Orders condition the experimenter never approved the use of all shock levels and left the laboratory at an earlier stage. Yet, in the total absence of the authority figure, 20 percent of subjects still followed the orders of a person of equal status to inflict all the shocks.

Nonetheless, Milgram (1965b) wrote another article, titled the Liberating Effects of Group Pressure, which presented, as he had earlier promised, a more in-depth overview of the previously discussed Groups for Obedience and Disobedience conditions. Again he highlighted "a number of specific factors" likely to have contributed to the experimental effect (Milgram, 1965b, p. 132), without an accompanying explanatory model. Without a theory, this exposed the piece to the same criticism applicable to all the other OTA articles preceding it.

\footnotetext{
${ }^{56}$ Milgram (1965a) preceded Milgram (1964b), remembering that the former article was written in 1962.
} 
Milgram went on to pursue some potentially fruitful theoretical avenues. ${ }^{57}$

However, due to a combination of writer's block, family commitments, and other academic pursuits (Blass, 2004, pp. 212-214; Darley, 1992, p. 206; Elms, 1995, pp. 28-29; Parker, 2000, p. 113), he did not publish a theoretical model attempting to explain his obedient and disobedient subjects' behaviour until 1974-14 years after having undertaken his first official experiment. In answering the second of the five questions in this thesis, the following will present the eventual explanation Milgram provided for his experimental programme.

\subsection{Milgram's (1974) Theory of Obedience}

After much pressure from his editor, in 1974 Milgram published his book Obedience to Authority: An Experimental View. The book starts out by presenting 18 experimental conditions and a survey he had undertaken over a decade earlier. Although Milgram (1965a) had earlier promised to include in the monograph an in-depth overview of the Relationship condition, he did not do so. This condition would remain almost unheard of until Rochat and Modigliani (1997) published a comprehensive overview of its methodological procedure and results. Also absent from the monograph was any comprehensive overview of the Group Pressure and Action Against a Person condition (which Milgram initially believed was "not an obedience experiment" but then several years later decided it was). ${ }^{58}$

Regardless of which experiments he had and had not decided to include, arguably the most important section of the monograph was Milgram's first theoretical explanation of his findings. As Milgram (1974, p. 123) said: "We must attempt to grasp the

\footnotetext{
${ }^{57}$ At one stage Milgram sought the answer to his theoretical problem in the discipline of mathematics. For example, "Probability Nets Summary Equations, $\underline{\text { Sept } 1964}$ I'll bet, given the probability structures of a field, the entire field can be stated as an equation or set of equations that specify the field, or specify how any given person will respond in the field. That is, the equation should include a variable term that represents the person. What I have to do is go to a mathematician and ask him to do this work for me; thatis [sic], set up the integrating equations that spell out or express the probability field. * Isometric contours. Distance and position. Theoretical" (SMP, Box 46, Folder 164, Titled: "Notes general, 1961-1962"). It may have been a coincidence, but half a year later, on 15 March 1965, one of Milgram's students in "Soc. Rel. 207b", Colin Martindale, wrote a three paged document titled "Theoretical Explanation of Milgram Experiment" that introduced the following mathematically-based formula, " $\mathrm{O}=\mathrm{f}(\mathrm{DI}$ and LA)". Milgram wrote on the document "Excellent paper" and asked if Martindale could "...return it to me for my files" (SMP, Box 46, Folder 164, Titled: "Notes general, 1961-1962”).

${ }^{58}$ The closest the condition got to a mention in the monograph was, ironically, in the footnotes alongside Asch’s Group Conformity study: “Asch, 1951; Milgram, 1964” (Milgram, 1974, p. 207).
} 
phenomenon in its theoretical aspect and to inquire more deeply into the causes of obedience."

Using evolutionary theory, Milgram began by pointing out that, like many animals, human beings function in hierarchical structures. Due to the survival value of organisation over disorganisation, hierarchical structures have, via breeding, led humans to develop significant advantages over their competitors in the natural environment. He is careful to point out that obedience to those higher in the chain of command-the behavioural currency of being in a hierarchical structure-is not innate. "Rather, we are born with a potential for obedience, which then interacts with the influence of society to produce the obedient man [italics original]" (Milgram, 1974, p. 125).

He argued that the potentially destructive impulses in mankind are frequently kept in check by the conscience of an autonomously acting individual. However, when the individual is introduced into a hierarchical chain of command, a homeostatic-driven internal change can take hold in which conscience-driven control over one's actions can be suppressed and supplanted by the demands from a higher authority. Milgram termed this process the agentic shift, which having taken place results in the individual entering what he termed "the keystone of our analysis"- the agentic state (Milgram, 1974, p. 133). The agentic state is a condition in which "the individual no longer views himself as responsible for his own actions but defines himself as an instrument for carrying out the wishes of others" (Milgram, 1974, p. 134). He continued:

The most frequent defense of the individual who has performed a heinous act under command of authority is that he has simply done his duty. In asserting this defense, the individual is not introducing an alibi concocted for the moment but is reporting honestly on the psychological attitude induced by submission to authority. For a man to feel responsible for his actions, he must sense that the behavior has flowed from 'the self.' In the situation we have studied, subjects have precisely the opposite view of their actions-namely, they see them as originating in the motives of some other person. Subjects in the experiment frequently said, 'If it were up to me, I would not have administered shocks to the learner' (Milgram, 1974, p. 146).

According to Milgram, the agentic state is likely to have several attitudinal consequences on the lower-status individual. First, upon entry to a hierarchical chain of command an individual is more likely to accept an authority's definition of a particular situation. Secondly, they are likely to render themselves open to the demands of those of a higher-status. And finally, with respect to the implementation of these demands, an individual is likely to attribute all responsibility for their (the individual's) subsequent actions to the authority figure. 
Milgram then identified what he termed Antecedent Conditions (ACs), which could impel the agentic shift, moving the individual from a state of conscience-driven autonomy into the instrumental agentic state. They included pre-experimental factors affecting individuals, such as the long-term influence of institutional systems of authority-parental, school, workplace experiences- that would have rendered many subjects subservient to authority figures. ACs were also inherent in the set-up of the experiment, including the seemingly authentic appearance of what appeared to the subjects to be a legitimate authority figure, as well as the overarching legitimating belief in "scientific" inquiry.

Milgram argued that, having entered the agentic state, a subject could be influenced and maintained within this state by BFs. Although there were probably many BFs, Milgram (1974, p. 149) provided only two examples. The first was the "Sequential Nature of the Action", whereby one incremental step led to the next with this process generating a momentum that made withdrawal from the experiment increasingly difficult. The second was "Situational Obligations", whereby subjects arrived at the laboratory with the intention of participating in some experimental task but, upon wishing to withdraw, came to feel uncomfortable about reneging on their implied contractual agreement to help the experimenter obtain results.

Having presented the potentially powerful ACs and BFs that he believed accelerated the subjects' entry into the agentic state, Milgram then argued: "If the individual's submergence in the authority system were total, he would feel no tension as he followed commands, no matter how harsh" (Milgram, 1974, p. 155). During the experiments, however, many subjects displayed what Milgram termed strain (sweating/trembling). Because of strain, Milgram noted that "transformation to the agentic state is, for some subjects, only partial" (Milgram, 1974, p. 154). Milgram argued that strain was enhanced by the cries of pain from a clearly innocent person who, in conflict with the experimenter, was pleading that the shocks be stopped. These cries upset subjects' self-perception as being someone with a humane disposition.

Offsetting the impact of strain in encouraging disobedience, were certain buffersMilgram's SRMs — that reduced feelings of stress and tension normally associated with hurting other human beings. Some of the SRMs Milgram (1974, pp. 158-162) mentioned in his book were, first, the ability of the shock generator itself to relieve feelings of tension. Secondly, avoidance-type behaviours, like looking away from the learner. Thirdly, 
subjects blaming the learner for the predicament they (the learners) found themselves in. Fourthly, complying fully but reducing the accompanying feelings of tension by engaging in simultaneous acts of sabotage, such as signalling to the learner, via verbal emphasis, the correct answer.

Using the following diagram, Milgram (1974, p. 154) illustrated his central concept of the agentic state and its close relationship with ACs, BFs, strain and the SRMs:

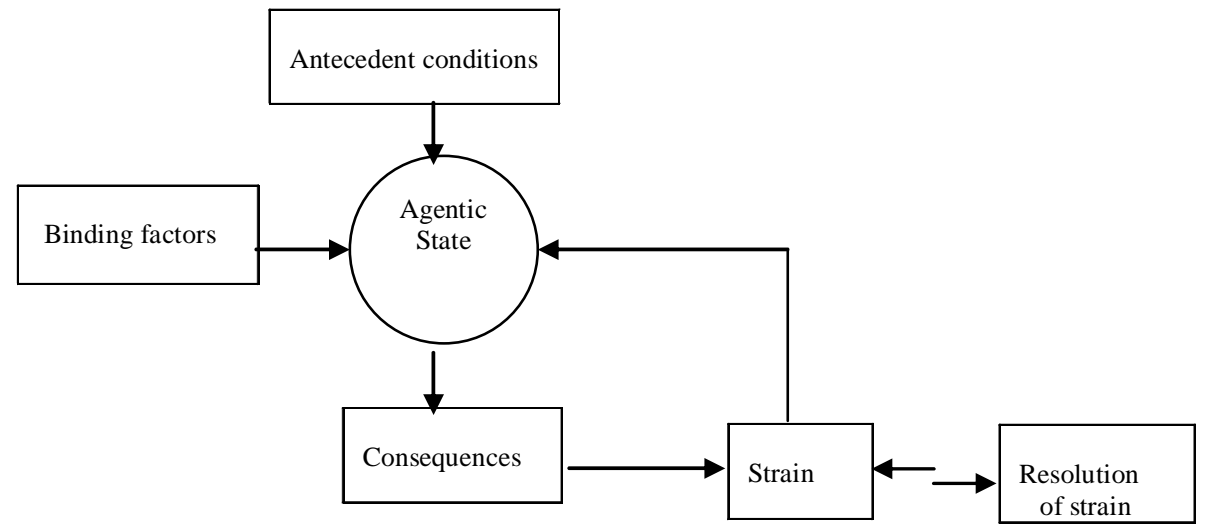

Figure 8: Factors that contribute to the agentic shift and maintain the subject within the obedience-generating agentic state.

In explaining not only obedience but also disobedience, Milgram succinctly conveyed his theoretical model by way of the following formula, and its accompanying explanation:

$$
\begin{aligned}
& \mathrm{O} ; \mathrm{B}>(\mathrm{s}-\mathrm{r}) \\
& \mathrm{D} ; \mathrm{B}<(\mathrm{s}-\mathrm{r})
\end{aligned}
$$

in which $O$ represents obedience; $D$, disobedience; $B$, binding factors; $s$, strain; and $r$, the strain-resolving mechanisms. Obedience is the outcome when the binding factors are greater than the net strain (strain as reduced by the resolving mechanisms), while disobedience results when net strain exceeds the strength of the binding forces [italics original] (Milgram, 1974, p. 154).

After 14 years of contemplation, Milgram believed that this model explained most of his subjects' behaviour.

What did his theory have to say, if anything, about understanding the perpetrators of the Holocaust? Although Milgram (1974, p. 175) readily conceded to there being 
"enormous differences" between his experiments and the Holocaust, ${ }^{59}$ he maintained that, via the hierarchical chain of command, "a common psychological process is centrally involved in both events"- the agentic state. As Milgram (1974, pp. 7-8) clarified early in his book:

The most common adjustment of thought in the obedient subject is for him to see himself as not responsible for his own actions. He divests himself of responsibility by attributing all initiative to the experimenter, a legitimate authority. He sees himself not as a person acting in a morally accountable way but as the agent of external authority. In the postexperimental interview, when subjects were asked why they had gone on, a typical reply was: 'I wouldn't have done it by myself. I was just doing what I was told.' Unable to defy the authority of the experimenter, they attribute all responsibility to him. It is the old story of 'just doing one's duty' that was heard time and time again in the defense statements of those accused at Nuremberg. But it would be wrong to think of it as a thin alibi concocted for the occasion. Rather, it is a fundamental mode of thinking for a great many people once they are locked into a subordinate position in a structure of authority. The disappearance of a sense of responsibility is the most far-reaching consequence of submission to authority.

\section{$\underline{6.8 \quad \text { Conclusion }}$}

This chapter has provided an overview of the "crux" of Milgram's research programme: to unravel why so many subjects completed his Baseline experiment. Milgram suspected his ad hoc exploratory methodological approach would, by deductive reasoning, eventually lead him to an all-encompassing explanation for the obedient subjects' behaviour. After systematically eliminating various alternative explanations, he seemed to get closer to what was behind their behaviour: something closely related to the higher status of the authority figure. However, some of the variations (perhaps the Ordinary Man Gives Orders and the Group Pressure and Action Against a Person conditions) were in conflict with his main explanatory schema. These particular experiments would probably have sown seeds of doubt in Milgram's mind as to what was encouraging many of his subjects to complete the Baseline experiment.

After the data-collection stage Milgram stalled in developing a comprehensive theoretical component that might help explain his subjects' behaviour. When, many years later, he finally did present a theory, it was one that he had actually toyed with before the completion of the official research programme. That is, upon entering a hierarchical

\footnotetext{
${ }^{59}$ These included the absence in his experiments of victim vilification as life unworthy of life, long-term ideological indoctrination, and unlike the Nazi execution squads, the subjects were told that their victim would not receive permanent injuries (Milgram, 1964a, p. 851, 1974, pp. 175-178).
} 
structure (as was apparently the case with the Germans), the lower-status subjects tended to lose control over their subsequent actions and, via the agentic state, came to see themselves as an instrument executing the wishes of a higher-status authority figure. Milgram was careful to point out that his subjects, just as with the Nazis, honestly did not feel personally responsible for their actions, and genuinely felt themselves to be instruments in the hands of a higher authority.

In answering the third of the five research questions addressed in this thesis, with particular regard to the Holocaust, the next chapter will discuss the reactions of the academic community to Milgram's OTA research programme and his theoretical explanation. 


\section{Chapter Seven: The Response of Academia to Milgram's Findings and Explanation}

A piece of literature makes its way into canon based largely on the meaning it imparts in our lives. Milgram's experiments are indisputably in the canon. And yet, no one can agree on the theme... . What message has Milgram sent us, in what sort of bottle, on which sea?-Slater (2004, p. 61).

The first significant scholarly response to the obedience to authority (OTA) research programme was from Diana Baumrind (1964). Published in American Psychologist, Baumrind's article inadvertently drew further attention to Milgram's work (Miller, 2004, p. 203). Baumrind was sharply critical of Milgram's study on multiple and frequently overlapping fronts. She argued that the experiments were unethical, methodologically flawed, and could not be generalised to an event like the Holocaust. ${ }^{60}$ Baumrind's criticisms of Milgram's (1963) article were swiftly weakened or invalidated by Milgram's (1964a) rejoinder, which discussed data from the wider research programme. However, his response was far from conclusive and certain questions lingered. In terms of the experiments' potentially unethical nature, methodological weaknesses, and attempts to generalise the results beyond the laboratory walls (especially to the Holocaust), Baumrind's seminal article drew other academics into the debate, both for and against. Thus, Baumrind's criticisms proved the catalyst of debates that would rage for years to come (Miller, 1986, pp. 89, 116). Providing a comprehensive review of this extensive literature is beyond the parameters of this thesis (see Blass, 2004; Miller, 1986; Mixon, 1989). Nonetheless, while drawing upon unpublished materials obtained from the Stanley Milgram Papers (SMP), this chapter will provide a brief overview of these key debates. Then it will explore the scholarly reaction to Milgram's explanation for his own results.

\section{$\underline{7.1 \quad \text { Ethical Issues }}$}

Perhaps the most common negative reaction to Milgram's first OTA publication centred upon the study's arguably unethical treatment of subjects (Baumrind, 1964; Bettelheim, as cited in Askenasy, 1978, p. 131; Kelman, 1972). Of particular concern were the long-term psychological and/or physiological harms potentially associated with participation. Consider the following statement by one of Milgram's (1963, p. 377)

\footnotetext{
${ }^{60}$ For more detail on the Milgram/Baumrind debate see Eckman (1977, pp. 93-94) and Miller et al. (1995, pp. 10-12).
} 
observers: "I observed a mature and initially poised businessman enter the laboratory smiling and confident. Within 20 minutes he was reduced to a twitching, stuttering wreck, who was rapidly approaching a point of nervous collapse" (see also Parker, 2000, p. 116). And if there was a danger of long-term psychological and/or physiological harm, the experiments could also be accused of having been unethical on the grounds of not informing subjects of these potential risks. Some believed the experiments were unethical on the basis that Milgram failed to obtain his subjects' informed consent before proceeding (Baumrind, 1964, p. 423). With participants having been told by the experimenter "you must continue", others such as Schuler (1982, p. 125) considered the experiments unethical because Milgram had blatantly attempted to supplant the subjects' right to withdraw. Miller (1986, p. 120) believed that this particular criticism was perhaps "one of the most convincing ethical arguments against the obedience research." Finally, with the experiments having converted some of the subjects into "stuttering wrecks" on the verge of "nervous collapse", others were critical because they believed the debriefing sessions were at best "casual" and unlikely to be capable of restoring the subjects' potentially damaged well-being (Baumrind, 1964, p. 422).

In response to Baumrind, Milgram (1964a, p. 849) argued:

A most important aspect of the procedure occurred at the end of the experimental session. A careful postexperimental treatment was administered to all subjects. The exact content of the dehoax varied from condition to condition and with increasing experience on our part. At the very least all subjects were told that the victim had not received dangerous electric shocks. Each subject had a friendly reconciliation with the unharmed victim, and an extended discussion with the experimenter [italics added].

On top of this, six weeks after collecting the data, Milgram surveyed every participant (Blass, 2004, pp. 124-125) and in 1963 even had a psychiatrist interview the 40 most upset subjects. ${ }^{61}$ Consequently, Miller (1986) concluded: "in terms of the thoroughness of the debriefing, as well as the empirical assessment of subjects' post-experimental attitudes, the procedures used by Milgram would seem to qualify as a model for laboratory research with human subjects" (p. 96). Irrespective of this generous assessment, evidence obtained from the SMP hints at the possibility that the post-experimental debrief was unlikely to have been "a most important aspect" and far more experimental than Milgram was willing to publicly concede.

\footnotetext{
${ }^{61}$ In a document titled "Interviews with Forty 'Worst Cases' in the Milgram Obedience Experiments" dated 20 June 1963, Paul Errera, an Assistant Professor of Psychiatry, stated: "Single 50 minute interviews were held . . . some twelve months after the termination of the study . . . None were found by this interviewer to show signs of having been harmed by their experience" (SMP, Box 45, Folder 162, Titled: "long interviews 1963”).
} 
In the post-experimental survey later sent out to all subjects, Milgram somewhat mysteriously stated: "Actually, the other man did not receive any shocks. Indeed, he was an actor employed by the project to play the part of the learner" (SMP, Box 45, Folder 159, Titled: "forms, mailing n.d."). If at "the very least all subjects were told that the victim had not received dangerous shocks", why did Milgram feel the need to underline the above point in the post-experimental survey? The answer to this question is that certainly during the first half of the research programme (perhaps even later), variability in the content of the dehoax was so great that, in conflict with Milgram's assurances, at least some subjects were not informed before leaving the laboratory that the learner had not received dangerous shocks (Parker, 2000, p. 108). ${ }^{62}$ As one subject stated in his response to the post-experimental survey:

I actually checked the death notices in the New Haven Register for at least two weeks after the experiment to see if I had been involved and a contributing factor in the death of the so-called 'learner' - I was very relieved that his name did not appear in such a column (SMP, Box 44, Divider “9”, \#0716).

Another subject, this time from the $11^{\text {th }}$ of the 24 experiments, said: "From what I've learned from others who've taken part, it would seem you have been somewhat irresponsible in permitting disturbed subjects to leave without informing them that they didn't half kill the shockee [sic]" (SMP, Box 44, Divider (no label), \#1137). ${ }^{63}$ Then again, although one subject claimed "I was not dehoaxed after the experiment" (SMP, Box 44, Divider “12”, \#0625), reinforcing Milgram's admission that the debrief varied, another subject from the same condition suggested they were partially dehoaxed. ${ }^{64}$

The important point to note is that there was probably greater variation in the debrief than Milgram was willing to admit. And in conflict with his published assurances,

\footnotetext{
${ }^{62}$ After two visits to the SMP, Australian psychologist and postgraduate student at the University of Melbourne, G. Perry (personal communication, August 21, 2008) has obtained evidence that indicates Milgram did not develop and apply his model debrief until well into the second half of the research programme.

${ }^{63}$ See also SMP, Box 44, Divider (no label), \#0711 or SMP, Box 44, Divider “12”, \#1007.

64 "I seriously question the wisdom and ethics of not completely dehoaxing each subject immediately after the session. The standard 'decompression' treatment I received was not successful in reducing my anger and concern below the boiling point" (SMP, Box 44, Divider (no label), \#0623). Milgram trialed a deceptive instead of honest debrief, whereby the experimenter informed subjects at the end of the experiment that the shock designations were not as painful as the shock generator or the subjects' reactions might have suggested. This was because the machine was apparently calibrated for use on "mice and small rats. Ahrrr the verbal designations on this machine 'Slight' to 'Danger' are for these small animals. They are not exactly applicable to human beings" (SMP, Box 155, Audiotape \# 0303).
} 
this variability resulted in at least some subjects leaving the laboratory feeling that, in the absence of a "friendly reconciliation", they had inflicted "serious shocks". It would appear that Milgram did not start out with a model debriefing, rather he arrived at one. In the end, it is fair to conclude that Milgram was unlikely to have treated the debriefing stage with the degree of importance he both earlier promised ${ }^{65}$ and later claimed. ${ }^{66}$ Subject welfare, it would seem, was generally relegated in favour of other priorities.

There were a few factors that may have contributed to Milgram's delay in settling upon a model debrief. First, the model debrief was, much like the experimental procedure, likely to have been invented via an ad hoc trial and error process which improved as the experimental programme progressed. As it turns out, not only was the experimental programme at the cutting edge of social psychology, so was Milgram's (eventual) model debrief-an assertion reflected in Milgram being credited with the origin of the word “debrief" (Harris, 1988, as cited in Blass, 2004, p. 112). ${ }^{67}$ A second factor also probably contributing to the variability in the debrief was what Blass earlier termed "carryover effects" from Milgram's PhD research. That is, Milgram may have suspected, as was the case with his $\mathrm{PhD}$ subjects, that the vast majority of the OTA subjects would not have minded, in the name of science, the variability in the debrief or even at having been stressfully deceived. ${ }^{68}$ Had this been the case, then Milgram perhaps assumed subjects would later appreciate his reasoning for also failing to obtain their informed consent (along with his attempt to remove their right to withdraw).

The main reason why, from the start, Milgram failed to administer his model debrief, seek his subjects' informed consent, and was at ease in removing their right to withdraw, was his firm belief that, other than experiencing "momentary excitement"

\footnotetext{
${ }^{65}$ As Milgram said in the second research proposal dated 25 January 1961: "Every effort will be made to set the subject at ease .... An extended discussion with the experimenter, and a friendly reconciliation with the confederates will be an integral part of each subject's experience. In time all interested subjects will be informed of the full details of the experimental program." Then again, immediately after this, Milgram stated: "Beyond this, no rigid rules are possible: each subject must be treated individually, but always with the respect due to one who has aided in scientific inquiry [italics added]" (SMP, Box 45, Folder 160, Titled: "Grants 1961-1967”).

${ }^{66}$ However, as Blass (2004, p. 127) has indicated, Milgram's post-experimental survey and his having a psychiatrist interview some of the subjects were measures unheard of at this time (a point the influential professor of social ethics, Herbert Kelman, has concurred with).

67 "Milgram was a pioneer in the debriefing procedures that are now a matter of course in psychological experiments on human subjects" (Elms, 1995, p. 27).

${ }^{68}$ Of course, if Milgram did suspect this, he would have been assuming that the OTA experiment were, in terms of infliction of psychological/physiological stress, commensurate with that generated by his PhD study (surely an invalid assumption).
} 
(Milgram, 1964a, p. 849), the experiments were psychologically and physiologically harmless. As Milgram later said in an interview with Meyer (1970, p. 132): “ 'I had to ask myself, was this harming the person or not? My judgment is that it was not. Even in the extreme cases, I wouldn't say that permanent damage results.' "'

The flaw in this logic is Milgram's assumption he was capable of anticipating every possible consequence associated with participation (Schlenker \& Forsyth, 1977, p. 373). Yet this was something he could only know in hindsight after the potential damage was done. Despite Milgram's opinion, documents obtained from the SMP suggest that there probably existed the potential for long-term, psychological and/or physical damage (which he both failed to anticipate and/or ameliorate).

Regarding long-term psychological harm, it could be argued that participation probably impacted negatively on some subjects' self-image/esteem (Kelman, 1972, p. 167; Bok, 1978, as cited in Pigden \& Gillet, 1996, p. 243). For example, it is difficult to imagine that completing the Relationship condition did not impact adversely on the selfimage of the 15 percent of subjects who inflicted all the shocks on someone who was at least an acquaintance. That is, completing this variation may have generated a new selfconcept of being a rather treacherous and unsavoury character. Milgram certainly sensed the potential of this experiment to fracture-harm?-friendships, and, in applying a deceptive debrief, attempted to avert any post-experimental bitterness. As he later said to one subject who inflicted all the shocks on his screaming friend:

the main purpose of the experiment was to see how you would react to taking orders. He wasn't really getting the shock, we just set this up this way to see ... whether you would be happy to give him the shocks or whether you weren't so happy about it .... So ahrrr ahrrrr lets tell him that ahhrrrr you knew you weren't giving him the shocks ... alright? (SMP, Box 153, Audiotape \#2429).

The criticism that the experiments were unethical seems hard to refute in the case of the Relationship condition. Furthermore, on three occasions teacher/learner teams in this variation were, as mentioned, members of the same family: \#2422 were brothers-in-law (maximum shock: 165 volts); \#2428 were uncle and nephew (maximum shock 180 volts); \#2435 were father and son (maximum shock: 165 volts) (SMP, Box 153, Audiotape \#2422, \#2428, \#2435, respectively). The Relationship condition was the last of the research programme and at the time Milgram was, as the audiotapes clearly indicate, struggling desperately to recruit teacher/learner teams for the last few trials. In desperation to bring the data-collection phase to an end, in approaching 1,000 experimental trials Milgram took 
a phenomenal risk in accepting a father and son team. The father refused early on to continue but the question remains - what would the long-term implications have been if he had completed the experiment? ${ }^{69}$ Prioritising his pursuit of results over the subjects' friendship (and the long-term psychological harm this could have generated) was deplorable. And if many of Milgram's critics were left appalled at his having undertaken the Remote condition, one can only imagine their reaction had they known about the Relationship condition. On this note, as the ethical criticisms post-Baumrind (1964) intensified, this could explain why, despite promises made in 1962, Milgram never published a detailed account of the Relationship condition and its results. ${ }^{70}$ Although publishing this experiment would surely have stimulated an ethical firestorm, as will be argued later in this chapter, ironically it may be capable of shedding new light on what arguably turned out to be the most enduring methodological criticism directed at the OTA research programme.

There were arguably other examples of potential long term psychological harm. It was not unusual for obedient subjects to mention having experienced post-experimental episodes of guilt. ${ }^{71}$ Related to this, some obedient subjects later reported that loved ones went on to compare them with infamous historical figures such as the Nazi bureaucrat Adolf Eichmann (Milgram, 1974, p. 54). ${ }^{72}$

Although subjects may have acquired potentially disturbing knowledge about themselves (termed inflicted insight), others construed this to have been a beneficial outcome. As one subject said: "I will remember this, and will think for myself, and act on

\footnotetext{
${ }^{69}$ For evidence of Milgram struggling to recruit subjects and his desire nearing the end of the programme to complete the data-collection stage, see SMP, Box 153, Audiotape \#2440.

${ }^{70}$ As stated in Chapter Six, Milgram promised to (but never did) provide a detailed overview of the Relationship condition in his book. The reason for this could be that the experiment was too different from the Baseline, too uncontrolled, and therefore not worthy of inclusion (potentially poor acting by the acquaintance/learners; responses not standardised; no mention of a heart condition, etc). However, these are unlikely to be the reasons explaining its exclusion because similar arguments are applicable to the entire Proximity Series, which he did publish (that were really just pilot studies that, in just as many ways as the Relationship condition, differed from the Baseline experiment). It is instead suspected that Milgram did not publish a detailed account of the Relationship condition because, in light of Baumrind's (1964) critical article, he came to fear his detractors' irrefutable criticisms that, with total disregard for his subjects' welfare, in the pursuit of results he indeed went too far. Milgram would have had no avenues of recourse or redemption had Baumrind and others found out about his inclusion in the Relationship condition of a father (teacher)/son (learner) team.
}

${ }^{71}$ As one subject stated: "I can't understand myself for going all the way. It's left me with a guilty feeling" (SMP, Box 44, Divider “9”, \#2013). For not disobeying, another subject pointed out that he "hated" himself (SMP, Box 44, Divider “9”, \#0116).

${ }^{72}$ For other Eichmann comparisons, see SMP, Box 44, Divider “12”, \#0328 and SMP, Box 44, Divider “10”, \#0222. 
my own thoughts and frindings[sic]" (SMP, Box 44, Divider "8", \#1311, see also Mantell \& Panzarella, 1976, p. 241; Milgram, 1964a, p. 850). As Kaufmann (1967) put it: “The social theory of evil may be distressing and humiliating to the stature of man, but then, learning to know oneself is seldom a gratifying experience, yet one which few of us would forego" (p. 322). Then again, as Kelman (1972, pp. 167-168) argued: "But do we, for the purpose of experimentation, have the right to provide such potentially disturbing insights to subjects who do not know that this is what they are coming for?" Elms (1972, p. 156, as cited in Miller, 1986, p. 132), who assumes that Milgram's experiments hold significant insights into the Holocaust, would have demurred:

Should we instead leave people to their moral inertia, or their grave moral laxity, so as not to disturb their privacy? Who is willing to justify privacy on this basis? Who would have done so, with fore-knowledge of the results, in pre-Nazi Germany? ${ }^{73}$

In regard to long-term (even permanent) physical harm, despite Milgram's optimistic conclusion that the experiments were harmless, early potential warning signs were probably not treated with the seriousness they merited. For example, Herbert Winer, a disobedient subject, later confronted Milgram and expressed his deep concerns surrounding the potentially dangerous physiological stress being imposed on subjects:

But at that time, he was fresh out of his own doctoral studies, and was very much concerned with my somewhat inchoate but very strong talk about ethics, about deception, and about what struck me at the time, in view of what I felt to be my own physical reaction to this conflict, as imposing altogether unwarranted strain on people who had had no previous medical screening of any kind .... And I was very upset . . . because I felt that had I had a heart condition, I could have been seriously inconvenienced [italics original] (Blass, 2004, p. 117).

Although other subjects echoed Winer's concern, ${ }^{74}$ Milgram never introduced any safety measures involving medical screening. This was poor judgment on Milgram's part because these concerns were unlikely to have been exaggerations. As one "IRATE" subject stated in the post-experimental survey:

My comment to my wife on arriving home was that this had been the most unpleasant night of my life. I would here inject a word of caution - since taking part in the experiment I have suffered a mild heart attack - the one thing my doctor tells me that I must avoid is any form of tension - For this reason I feel that it is

\footnotetext{
${ }^{73}$ As Pigden and Gillet (1996, p. 244) said: "If you don't know you are sick, you can't seek a cure."

74 "Since I became so upset during the experiment, I'm not sure that you were entirely responsible in picking your subjects. Suppose I'd had a heart condition?” (SMP, Box 44, Divider “12”, \#2032; see also Blass, 2004, p. 116).
} 
imperative that you make certain that any prospective participant have a clean bill of health (SMP, Box 44, Divider “T.R.”, \#0216).

The reason nobody was "seriously inconvenienced" was probably due more to luck than planning. With no medical safety-net in place, it really could have gone horribly wrong.

But then again, in Milgram's favour is that numerous replications and slight variations of the OTA experiments have been undertaken throughout the world and it seems nobody has ever suffered permanent harm. Miller (1986, pp. 104-105) arrived at the same conclusion after assessing all of the evidence: "if one asks this question: 'Is participation in the Milgram paradigm psychologically damaging?,' the best evidence is that the answer is 'no.'"- - a conclusion he was still promulgating nearly two decades later (Miller, 2004, p. 198). Miller draws attention to a much more complex issue: "However, if one asks a slightly different question: 'Does a research psychologist have the right to expose subjects to intense stress and conflict?,' the answer is less clear."

Researchers frequently resolve such dilemmas by engaging in cost/benefit analyses whereby they assess whether or not the probable benefits associated with a research idea are likely to exceed the anticipated costs. Milgram was aware before the completion of the data-collection stage of the potentially unethical, albeit what he believed momentary, costs surrounding his experiments' reliance on deception and infliction of intense stress. ${ }^{75}$ In terms of potential benefits, however, Milgram was quietly confident from the start that the study could provide new insights into destructive obedience (something he had long suspected was in some way centrally related to the extermination of the European Jews):

Under what conditions does one ask about destructive obedience? Perhaps under the same conditions that a medical researcher asks about cancer or polio; because it is a threat to human welfare and has shown itself a scourage [sic] to humanity. Perhaps the need to understand and conquer the disease becomes more pressing when a member of the family has been hurt by it. The nightmare that engulfed Europe in 1933-45 claimed many victims; none was hit so hard as European Jewry (SMP, Box 62, Folder 126, Titled: "Drafts and Fragments. Ethical Issues of the Experiment pre-1974").

Milgram's belief was that the benefits to humanity in understanding and perhaps conquering the so-called "disease" of "destructive obedience" were potentially of immense

\footnotetext{
75 In a document dated "January 1962" Milgram argued: "The ethical issue, then, boils down to two points .... a) Is it ethical to apply pressures to a person which may lead him into what he believes to be an act which he would otherwise not perform for reasons of personal conscience? . . he has harmed --although temporarily-- another individual . . . b) . . . is it ethical to decieve [sic] persons in spcyhological [sic] experiments ... [and] subject persons to emotional stress es [sic] of an extreme sort in the course of experimentation?” (SMP, Box 46, Folder 165, Titled: “Notes general, 1961-1962”).
} 
importance. One is left wondering how much greater cost Milgram, clearly with an eye on the Holocaust, was willing to impose on his subjects to obtain this knowledge. With so much apparently at stake, how far was too far? With variations such as the Relationship condition, Milgram seems to have been willing to risk the possibility of his subjects paying a high physical/psychological/ethical price.

Offended by Milgram's presumption in deciding what costs his subjects would pay, Baumrind (1964, p. 422) was the first to dispute Milgram's view that the costs were likely to be outweighed by the benefits (for which she could see none): "Indeed such a rationale might suffice to justify the means used to achieve his end if that end were of inestimable value to humanity" (Baumrind, 1964, p. 422). Like others soon after, Baumrind disputed Milgram's belief that his research was likely to have provided insights into the Holocaust or anything else for that matter. ${ }^{76}$

Was the OTA research ethical or unethical? Producing an answer to this question is impossible because the ethical debate between Milgram (and his adherents) and Baumrind (and hers) appears irresolvable. This is because, as Miller (1986, p. 115) noted: "the ethical status of a particular research project resides, to a significant extent, in the eye of the beholder" and that it is "a question, then, of values, of priorities, of what one views as important knowledge, and whether the price of that knowledge is worth paying" (Miller, 1986, pp. 104-105). ${ }^{77}$ Having placed the Holocaust in the background, Milgram thought the knowledge his research would produce was important and that the potential costs to his subjects were worth paying. Baumrind did not.

Perhaps Miller's (1986, p. 136) point in relation to Humphreys' (1970) creative yet also highly controversial research on male sexual gratification in public toilets is pertinent: "Put succinctly if not delicately, the issue often seems to come to this: Either one is going

\footnotetext{
${ }^{76}$ There had been complaints made earlier. On 23 November 1962 Milgram received a letter from the American Psychological Association informing him that his membership had been delayed because someone from Yale University had officially laid a complaint about his experiments (Blass, 2004, pp. 112-113).

${ }^{77}$ The dispute between Milgram and many of those who disputed the OTA experiments on ethical grounds generally comes back to an irresolvable and complex philosophical debate between teleologists (whose focus is, as Milgram's was, on the potentially beneficial consequences of a research project) and deontologists (who generally believe that it is totally unethical to use any means-like deception or the infliction of stress/conflict—as a vehicle to arrive at a worthy scientific end). As Schlenker and Forsyth (1977, p. 373) point out: "Whenever a teleologist and a deontologist discuss morals, there will be an inevitable value conflict. The fundamental moral guide for the teleologist is the test of consequences, a consideration that the deontologist cannot abide." Other than concluding that the debate between teleologists and deontologists is ultimately irresolvable, delving further into this complex debate is beyond the parameters of this thesis (Miller, 1986, pp. 110-116; Schlenker \& Forsyth, 1977).
} 
to do the research and pay the ethical costs, or one will remain ignorant about this particular arena of social life." Whether one agrees with him or not, Milgram decided for his subjects that they would pay the probably low (but actually unpredictable) participatory costs because he suspected humanity could not afford to remain ignorant.

Milgram had taken an enormous gamble because he assumed that his results could be usefully generalised beyond his laboratory walls. But had Milgram failed to consider the price his subjects might pay for findings that in fact might have no value to humanity, as subsequently claimed by Baumrind? Perhaps in the eyes of many an impartial observer, Milgram's name would be redeemed and his daring (arrogant?) decision to proceed mitigated if the OTA research programme could be generalised to the outside world. Can Milgram's results and eventual explanation be generalised beyond the walls of the laboratory and particularly to the Holocaust which stimulated them? Before it is possible to assess the applicability of generalising the OTA findings and Milgram's theories to an event like the Holocaust, it is important that the study be capable of overcoming the most resilient methodological criticisms it went on to attract. This is because if in the first place the experiments are methodologically weak, then there is no use in attempting to generalise from a flawed foundation (Eckman, 1977, p 94; Miller, 1995, p. 34; Orne \& Holland, 1968, p. 282). Consequently, assessing the research programme's methodological strength precedes an assessment of its ability to be generalised beyond the laboratory walls.

\subsection{Methodological Criticisms}

The most important methodological criticism directed at the OTA research centred on whether or not Milgram successfully deceived his subjects into believing that the learner was receiving potentially dangerous electric shocks (Milgram, 1972, p. 139). Successfully deceiving the majority of his subjects was "absolutely critical" because, as Miller (1986, p. 143) pointed out: "the entire foundation of the obedience research rests on the believability of the victim's increasingly mounting suffering." In this regard, the two most powerful methodological critiques directed at the internal validity of the OTA experiments were Orne and Holland (1968) soon followed by Mixon (1972, 1976, 1989).

There were four main reasons that Orne and Holland (1968) thought Milgram's attempts to deceive his subjects into believing the learner was being shocked probably failed. First, these authors believed the incongruity of the stoic equanimity of the 
experimenter in the face of the learner's escalating screams would surely have cued most subjects to the reality that the learner was not actually being shocked. Secondly, subjects would apparently have noticed that the experimenter could themselves have performed the teacher's role, thus signalling it was all a ruse. Thirdly, despite the learner's persistent and increasingly desperate demands that the experiment be stopped, for the first two-thirds of the procedure (up until the 300-volt switch), they bizarrely cooperated by responding immediately to the subject's questions. Finally, subjects trusted that the experimenter would not knowingly allow extremely dangerous shocks to be inflicted on the learner and assumed that, despite any evidence to the contrary, "everything is going to be all right" (Orne \& Holland, 1968, p. 287). It was for these main reasons that Orne and Holland (1968) believed Milgram's attempt to deceive his subjects probably failed and knowing the learner was not actually being shocked best explains why so many went on to complete his experiments.

Orne and Holland (1968) were actually using Milgram's research as an example of an experiment influenced by what Orne (1962) had termed demand characteristics.

Demand characteristics are where subjects detect cues within the experimental setting to engage in behaviours that they suspect are most likely to please the researcher by confirming a hypothesis. The implication being that most subjects would have worked out that the experiment was actually about OTA and, knowing the learner was only pretending to be under intense stress, many subjects gave Milgram the results he desired.

Although conceding that a small minority did not believe the shocks were genuine, Milgram (1972, p. 141) responded by pointing out that in the post-experimental interviews 56.1 and 24 percent "fully" and "probably" believed the learner was being shocked, respectively. Therefore, a total of 80.1 percent seemed convinced by the procedure (a conclusion independently and much more rigorously confirmed by other researchers). ${ }^{78}$

After listening to some of the audio tapes and considering the evidence and arguments, the author agrees with Eckman (1977, p. 94): "when one reads the actual transcripts of Milgram's subjects' verbal behavior, it is hard to conclude it was all a put-on.

\footnotetext{
${ }^{78}$ After undertaking a replication of the OTA experiment, David Rosenhan was cited by Milgram (1972, p. 141 ) as later having had independent judges rigorously interview subjects asking them in astonishment: “" 'You really mean you didn't catch on to the experiment?' " In response 70 percent admitted to having been fooled by the deception (see also Meeus \& Raaijmakers, 1985, as cited in Miller, 1986, p. 156). As the largely critical Helm and Morelli (1979, p. 332) conclude: "Milgram is probably on safe grounds in contending that 'the majority of the subjects accept the experimental situation as genuine, a few do not.' " But see Parker (2000, pp. 118-119) for a conflicting view.
} 
There was just too much conflict and stress" (see also Pigden \& Gillet, 1996, p. 236). Milgram (1972, p. 140) was less patient with Orne and Holland's claim: "that the subjects only feigned sweating, trembling, and stuttering to please the experimenter [italics original]" and he responded that their argument "is pathetically detached from reality, equivalent to the statement that hemophiliacs bleed to keep their physicians busy." In sum, Orne and Holland's claim struggled to account for the subjects' patent internal conflict and stress.

There are two other reasons why the author does not believe demand characteristics were the key determinant of Milgram's results. First, if subjects knew the shocks were fake yet continued on to please the experimenter, why after the completion of the experiment would 73 percent of obedient subjects in the Remote condition later decline an opportunity to experience the kind of apparently fake shock (450-volts) they had (supposedly) just inflicted on the learner (see Milgram, 1974, p. 57) ${ }^{79}$ Secondly, if subjects were only acting to please the experimenter, why did so many go to the trouble of purposefully engaging in acts of sabotage $?^{80}$ Again, there is believed to be much merit in Eckman's (1977, p. 95) conclusion on this matter:

To invoke the charge 'demand characteristics' against Milgram's work is foolish. Most of the experimental research in social psychology is more vulnerable to the generation of 'artifactual' evidence than his work is. The 'demand characteristics' criticism should certainly be judiciously applied to weak studies that are published. In the case of Milgram's work, however, such criticisms give one the impression that the critics may be exploiting a controversial study to give attention to their favorite subject, demand character[istics. $]^{81}$

Although Milgram (1972, pp. 151-153) forcefully addressed three of Orne and Holland's (1968) four methodological criticisms, there was one that continues to linger. This was the issue of trust, where apparently subjects knew all along the experimenter would never have allowed an innocent person to be seriously harmed, and that when the

\footnotetext{
${ }^{79}$ One such example obtained from the SMP being: Experimenter: "How painful to the learner were the last few shocks that you administered to him ... ?" Subject: "From his reaction I would say . . . extremely painful ..." Experimenter: "Well . . how arrh how high a sample shock would you take on this machine right now?" Subject: "I would like to say, ha ha, cautious me, alright, I'd go up to . . 60 [volts]. I've had 10,000 volts but, ha ha, it felt different to [the earlier 45-volt test shock]" (SMP, Box 155, Audiotape \#0303). In a replication of the OTA experiments, Rosenhan $(1969$, p. 142) found that every subject later refused to participate in another trial this time as the learner.

${ }^{80}$ With the intention of avoiding having to inflict further shocks on the learner, it was not unusual for subjects to covertly attempt transmitting the correct answer to subjects by emphasising verbally the correct answer (for an example, see Chapter Eight, p. 152).

${ }^{81}$ In fact Milgram's procedure was so convincing that one subject had even been informed by a friend who had earlier been a subject 'that the experiment was 'a fake, the learner does not get any shocks' but I didn't believe this" (SMP, Box 44, Divider "8”, \#1014).
} 
experimenter demanded that the subject continue inflicting the shocks, he was also implying that it was safe to do so (Harré, 1979, p. 105). As Eckman (1977, p. 94) stated: "This position cannot easily be dismissed, because there is a good deal of evidence to back it up." In support of the trust issue, one fully obedient subject (of potentially many) stated: "the way I figured it, you're not going to cause yourselves trouble by actually giving serious physical damage to a body" (SMP, Box 153, Audiotape \#2430). ${ }^{82}$ The most prominent proponent to bolster the validity of this significant criticism was Mixon (1972, 1976, 1989).

Mixon (1972) was one of the first to replicate the OTA experiments using roleplaying (where, as an alternative to the potentially unethical use of deception in the OTA experiments, subjects are informed before starting that the learner is an actor, the shocks are not authentic, and they are to pretend the experiment is real). ${ }^{83}$ Mixon produced results in favour of Milgram but, irrespective of his supportive findings, with an emphasis on the issue of trust, he became a harsh and unyielding methodological critic of the OTA experiments.

Mixon (1976, p. 93) argued that the reason the OTA experiments were so convincing to observers was the subjects' outpouring of emotional tension. Their palpable displays of stress appear to illustrate that subjects believed the shocks were real and harmful (and thus did not trust that the experimenter would secretly protect the learner's well-being). Where Orne and Holland failed, however, Mixon presented a more convincing explanation for the displays of tension. That is, Mixon argued that Milgram's subjects were tense because they were confronted with a highly ambiguous situation in which the information coming from both the experimenter and learner were mutually contradictory: the shocks were apparently harmful but not dangerous, the learner was screaming in agony but the experimenter looked calm. The consequence of this being: "No wonder many subjects showed such stress. What to believe? The right thing to do depends on which actor is believed" (Mixon, 1989, p. 33). His conclusion:

The extreme emotional reactions of many of the participants are due not to the certain knowledge that they are inflicting serious harm, but to the fact that they cannot be certain. The evidence of their senses tells them they are, but background

\footnotetext{
82 Another example being SMP, Box 153, Audiotape \#2429.

${ }^{83}$ Role-playing might eliminate the need for deception but ironically, as Miller (1986, p. 175) pointed out: "An even less complimentary view is that role-playing procedures increase the likelihood that demand characteristics will influence behavior."
} 
expectations and the expert responsible for the well-being of participants tells them they are not (Mixon, 1976, p. 94).

According to Mixon (1989), as "increasingly large chunks of the social and physical world that we live in can be understood only by experts" (p. 35), most subjects resolved the stressfully ambiguous situation by trusting the authority figure's word that the learner would not be hurt (see also Patten, 1977b, p. 357; Strudler \& Warren, 2001, pp. 162-163).

Bolstering Mixon's claim that some combination of ambiguity and trust encouraged most subjects to complete the experiment were the following lines of evidence. First, Mixon (1976, p. 95) pointed out that in Milgram's (1974) three least ambiguous experiments, where it was explicitly made clear that if the subject continued the learner would definitely be hurt, all refused to complete the experiment. Secondly, the more ambiguous the learner's fate in Milgram's variations, the higher the completion rates (Mixon, 1976, pp. 92-94). Finally, removing any ambiguity surrounding the learner's fate, Mixon (1972) undertook a role-play replication where the experimenter informed the subject that "The learner's health is irrelevant ... continue as directed" (p. 164). Consequently, predicted completions slumped. ${ }^{84}$

That Milgram may have purposefully inserted ambiguity into his experiment to obtain, initially anyway, surprisingly high completion rates is an accusation supported by evidence presented earlier in this thesis. For example, Milgram changed the designated title of the last button on his proposed shock machine from "LETHAL" to "XXX", presumably because the former was unlikely to create the "strongest obedience situation". 85

\footnotetext{
${ }^{84}$ In this series of experiments the subject was provided with an overview of the Remote experiment up until the 300-volt switch was inflicted. The subject was then to imagine and describe the succeeding events. By manipulating this description, Mixon obtained wide variations in predicted completion rates. When the descriptions clearly conveyed the learner was being harmed, predicted completions slumped. However, ambiguous descriptions resulted in very high predicted completion rates. "I used nonactive role playing scripts of Milgram's study to check my assumption that if I described the experimenter in the 'learning study' behaving as if he believed the learner is being seriously harmed, participants would refuse to obey his commands. The series of scripts supported my assumption; the script that made it most clear that the experimenter believed the consequences harmful elicited no obedience (Mixon, 1972)" (Mixon, 1976, pp. 9495).

${ }^{85}$ Lending more weight to this criticism is that Milgram tended to introduce more disturbing (less ambiguous) innovations to his basic experimental procedure only when he was confident they were unlikely to detract significantly from obtaining a high completion rate. For example, it was only after the Proximity Series illustrated how difficult it was going to be to get most subjects to engage in disobedience that Milgram decided that in his new (and even more impressive?) Baseline condition he would reduce the ambiguity by informing subjects that the learner had a mild heart condition.
} 
However, there are two lines of evidence which lend weight to the validity of Milgram's methodology over his critics. First, research using authentic victimsanimals-went on to produce similar high completion rates. One such study was by Sheridan and King (1972) who specifically set out to test the issue of trust. They replicated Milgram's Proximity condition (victim could directly be seen and heard: 40 percent completion rate) whereby the subject was ordered to inflict real, painful, but not lethal electric shocks on "a cute, fluffy puppy" (Sheridan \& King, 1972, p. 165). The results revealed that 54 percent of the male and 100 percent of female subjects followed all orders to continue increasing the shock intensity on the genuinely yelping puppy.

Although the subjects were later reunited with the frightened but (apparently) unharmed puppy, during the experiment they displayed the same kinds of symptoms of stress and tension as Milgram's subjects. Sheridan and King (1972, p. 166) concluded: “The findings are in consonance with the view that Milgram's findings may correctly be taken at face value. Ss are willing to follow repugnant commands, even when it is clear that the victim is truly receiving shocks. ${ }^{" 86}$ Of course the limitation with this (and all research on animals for that matter) is that the results are not necessarily applicable to experiments on humans (Miller, 1986, p. 156).

The second line of evidence that lends more weight to Milgram's claims over those of Mixon that subjects may not actually have trusted the experimenter comes from the following exchange after the 150-volt shock switch taken from the Relationship condition:
Teacher: "I, see I don't believe this, I mean, go ahead."
Experimenter: "You don't believe what?"
Teacher: "Alright, go ahead, ask me a question."
Experimenter: "No no, what don't you believe?"
Teacher "I don't believe you were giving him the shock."
Experimenter: "Then why, why won't you continue?"
Teacher: "Well I, I just don't want to take a chance, I mean I, I"
Experimenter: "Well if you don't believe that he's getting the shocks, why don't you just continue with the test and we'll finish it?"
Teacher: "Well I, I can't, because I can't take that chance" (SMP, Box 153, Audiotape \#2439).

This exchange may imply something about all the other experiments where the learner was a stranger: the reason many completed the non-relationship conditions relative to the Relationship condition may not have been because they trusted the experimenter. Instead, it may have been because the learner was a stranger and consequently subjects felt they could afford to take the risk and trust the experimenter. With this point in mind, Mixon's

\footnotetext{
${ }^{86}$ For other studies using authentic victims that produced similar results see Foddy (1971) and Penner, Hawkins, Dertke, Spector and Stone (1973).
} 
interpretation makes little sense: if ambiguity confused the subjects as to whether the learner was being shocked or not, surely it would have made the most sense, as many (particularly in the Relationship condition) did, to err on the side of caution and stop the experiment (see Coutts, 1977, p. 520, as cited in Darley, 1995, p. 133). As a subject in one of the non-relationship conditions who also thought he was being deceived reasoned: “When I decided that I wouldn't go along with any more shocks, my feeling was 'plant or not ... I was not going to take a chance that our learner would get hurt' " (SMP, Box 44, Divider (no label), \#1106).

But it would seem that because in the non-relationship variations the learner was a stranger, for some reason, most subjects found it relatively easier to assume it was probably a hoax and thus take the risk to trust the experimenter and inflict all the shocks. Of course, had the shocks and experiment turned out to have been real, the obedient subjects would always have the justification that, due to the ambiguous situation, they could probably only be blamed for trusting the information supplied to them by someone who appeared to be an expert. The important conclusion to draw from this line of evidence is that Milgram's attempts to deceive his subjects across all his variations may in actuality have been much greater than critics such as Orne and Holland (1968) and Mixon (1989) believed. It does not discredit Mixon's claim but, in favour of Milgram, it certainly sheds greater light on this otherwise protracted methodological impasse.

In light of the above "methodological battle" between Milgram and Mixon (Miller, 1986, p. 171), ${ }^{87}$ there is one particularly good reason to conclude the OTA experiments were internally valid. That is, on different types of victims (Foddy, 1971; Shanab \& Yahya, 1977; Sheridan \& King, 1972), settings (Hofling, Brotzman, Dalrymple, Graves \& Pierce, 1966) ${ }^{88}$ and in different countries (Ancona \& Pareyson, 1968; Burley \& McGuinness, 1977; Mantell, 1971), a diverse range of replications (Martin, Lobb, Chapman \& Spillane, 1976; Meeus \& Raaijmakers, 1986, 1995; Rosenhan, 1969) of the OTA experiments have been undertaken—nearly all of which lend weight to Milgram's legacy (Miller et al., 1995, pp. 11-12). Drawing on Donald Campbell's observation, Miller et al. (1995, p. 12) add "a range of diverse methodologies that triangulate on the same

\footnotetext{
${ }^{87}$ With explicit reference to the methodological critiques of Orne and Holland then Mixon, the otherwise highly critical Helm and Morelli (1979, p. 332) have argued: "Milgram has parried quite effectively most of the criticisms of his work."

${ }^{88}$ This study - in which doctors ordered nurses to administer to patients clearly lethal dosages of medicinewas undertaken independently of the OTA experiments (but, in the real-life setting, arguably lends weight to its credibility).
} 
conceptual issues is a vital criterion of scientific inquiry (e.g., Brewer \& Collins, 1981; Campbell \& Fiske, 1959)." And this methodological triangulation continues to reinforce the internal validity of Milgram's research and more recently saw Miller (2004, pp. 196197) conclude: "Although there have been methodological criticisms of the Milgram paradigm ... the current view on the part of most social psychologists is that the Milgram findings are a reliable phenomenon in the laboratory." The consequence of this conclusion is that the OTA experiments are likely to be internally valid.

The following section explores the scholarly reaction to the Milgram-Holocaust linkage (M-H linkage): the generalisation of Milgram's findings and eventual theory to the Holocaust.

\subsection{Generalisation: the Milgram-Holocaust Linkage}

In Milgram's 1961 letter to Henry Riecken at the National Science Foundation (NSF) and the opening paragraph of his first article in 1963, he made explicit statements that early on conveyed a belief that his experiments captured, in the laboratory setting, behaviour synonymous with the perpetration of the Holocaust (Blass, 1993, p. 32; Miller, 2004, p. 203). In her critique, Baumrind (1964) was the first to engage in what Mooks (1983, p. 386) later facetiously termed “count-'em mechanics": the listing of differences between the OTA experiments and the Holocaust in an attempt to render the former externally invalid. She pointed out that, unlike the OTA experiments, the victims of the Holocaust were labelled subhuman and, with the perpetrators believing in the ultimate goal, they did not feel any guilt or conflict (Baumrind, 1964, p. 423). Perhaps sensing he had gone too far, Milgram's quickly moderated his view, and he went on to identify an even wider variety of differences. These included the absence in his experiments of victim vilification as "life unworthy of life", long-term ideological indoctrination and, unlike the Nazi execution squads, the subjects were told their victim would not receive permanent injuries (see Milgram, 1964a, p. 851, 1974, pp. 175-178). In a letter dated 9 April 1964, Milgram went so far to say to a correspondent who saw strong parallels between the OTA research and Nazi Germany's concentration camps: “ 'it is quite a jump . . . from an experiment of this sort to general conclusions about the Nazi epoch, and I, myself, feel that I have sometimes gone too far in generalizing. Be cautious in generalizing' " (Blass, 2004, p. 279). 
Milgram (as cited in Blass, 2004, pp. 269-270) frequently placed distance between his experiments and the Holocaust, but sometimes he could not resist bridging that gap, as he did in the German translation of his book:

It is fitting that this book be translated into German, since it has a special relevance to Germans. Obedience is, after all, their favorite alibi. My guess is, after conducting the experiments reported in this book, that if the same institutions arose in the United States - the concentration camps, the gas chambers-there would be no problem finding Americans to operate them.

As Miller (2004, p. 204) noted: "Milgram's views could thus be termed complex and diverse by his supporters or inconsistent and ambiguous by his detractors."

Particularly after the publication of Milgram's book, by the mid-1970s and 1980s, more researchers than not were making generalisations from the OTA experiments to the Holocaust (see Askenasy, 1978, pp. 131-132; Charny, 1982, pp. 13-16; Dicks, 1972, p. 269; Etzioni, 1968, p. 280; Rosenbaum, 1983, p. 36; Steiner, 1980, p. 431). ${ }^{89}$ But it was Sabini and Silver (1982) who most notably contributed to and then expanded upon this purported connection.

Sabini and Silver highlighted that during the Holocaust cruelty and hatred were indisputably present but they were not necessary features. For a goal as broad as the extermination of the European Jews, the capricious beast had to be replaced by the seemingly monolithic and emotionless bureaucratic machine:

The requisite bureaucracy ... would be responsive to the will of the ultimate authority through a hierarchy of responsibility .... It was this bureaucratization of evil, the institutionalization of murder, that marked the Third Reich (Sabini \& Silver, 1982, p. 56).

Central to their argument was that, in a microcosm, the OTA experiments captured key aspects of the bureaucratic process that, as it did for the Nazi regime during the Holocaust, expedited the pursuit of malevolent ends. How might bureaucratic organisation do this? In their view, functionaries in both the OTA experiments and the Holocaust used a variety of features inherent in the bureaucratic process that aided in reducing subject/perpetrator feelings of responsibility for their ultimately destructive actions. First, there was the mutual presence in both the Peer Administers Shock condition (subject just asked the questions: 92.5 percent completion rate) and the Holocaust of the division of labour, whereby the larger goal had been broken into a variety of seemingly unrelated

\footnotetext{
${ }^{89}$ Those against generalisation included Fromm (1973, p. 51), Miale and Selzer (1975, pp. 7-13), Patten (1977a, p. 438), and Tedeschi, Lindskold and Rosenfeld (1985, pp. 211-212).
} 
tasks. In direct reference to those who organised, filled and guarded the trains, built the death camps, and produced the poisonous gas, Sabini and Silver (1982, p. 60) stated: "The vast majority of the millions implicated in the Holocaust were [just as in the Peer Administers Shock experiment] involved in analogous, subsidiary but essential functions." Secondly, reference was made to Milgram's discovery during the Proximity Series that the greater the distance separating the subject from the learner, the higher the overall completion rate. In connecting this finding with the Holocaust, Sabini and Silver (1982, p. 60) note that, due to the division of labour, most Nazi perpetrators involved were distanced "from the actual gassings, burnings, and shootings." Thirdly, also discussed was the entrapment process (the foot-in-the-door phenomenon) surrounding the incremental increase in commitment discernable in both the OTA experiments and the Holocaust where, as Hilberg (1961) most convincingly demonstrated: "Hitler's program . . . similarly advanced by degrees" (Sabini \& Silver, 1982, p. 70). With its more concentrated focus on the Holocaust and bureaucracy, Sabini and Silver's work not only seemed to strengthen the M-H linkage, it moved the OTA experiments much closer to Hilberg's (1961) classic on the Nazi bureaucratic machine. ${ }^{90}$

Two years after Milgram's death in $1984,{ }^{91}$ Miller (1986) published his comprehensive overview of the literature on the OTA research. After praising Sabini and Silver (1982), Miller (1986, pp. 257-258) strongly endorsed the relevance of Milgram's work in better understanding the Holocaust.

Using an even wider variety of non-Holocaust examples, others expanded on the connection between Milgram's findings and the potentially destructive bureaucratic process (see Brief et al., 1995; Hamilton \& Sanders, 1995; Hamilton \& Sanders, 1999; Kelman \& Hamilton, 1989; Luban, Strudler \& Wasserman, 1992). According to Miller (2004), it is interesting to note this literature has generated "no noticeable controversy" (p. 199). However, as he then also pointed out, with respect to the works of scholars such as Sabini and Silver and Milgram himself, when it comes to the Holocaust: "generalizing the obedience research ... has been anything but noncontroversial" (Miller, 2004, p. 200).

A probably significant shift detracting from the $\mathrm{M}-\mathrm{H}$ linkage in psychology (arguably the bastion maintaining this association) came in 1993 when one of the leading

\footnotetext{
${ }^{90}$ Regarding the M-H linkage, Hilberg (1980) saw clear connections but was also aware of counterfactual evidence.

${ }^{91}$ With his work still highly controversial, on 20 December 1984, at the age of 51, Milgram died of a heart attack in New York City (Blass, 2004, pp. 257-258).
} 
OTA scholars started to express certain reservations. That is, after noting Arendt's

awareness of the more brutal, cruel, and not so banal side of the Holocaust where, as she noted, in Naumann's (1966) disturbing book, infants were used as shooting targets, Blass

(1993, p. 35) stated:

The historical evidence on the spontaneity, inventiveness, and enthusiasm with which the Nazis degraded, hurt, and killed their victims also argues against explaining their behavior as simply responses to an authority's commands despite the perpetrators' abhorrence of their own actions, and without hate towards their victims. It must have come from within.

That such actions must have "come from within" was reviving an old debate between social and personality psychologists: do the situations in which people find themselves determine their actions or are they determined by their dispositional characteristics? With respect to the Holocaust, the OTA experiments were promoted by many social psychologists as the epitome of the power of situations in determining actions (Berkowitz, 1999, p. 247; Blass, 1991, p. 399; Blass, 1993, p. 31): subjects did not want to complete the experiments but the manipulative external situational forces saw them act in ways contrary to their dispositions (not wanting to hurt an innocent other person). This debate may explain why, early on in the research programme, Milgram eventually decided against pursuing his original plan to run the propaganda variation (that intended on igniting with subjects internal hostilities towards a certain type of learner-such as an arrogant petty thug). Early on Milgram perhaps sensed the opportunity of his experimental programme to powerfully contribute to this debate by demonstrating the pure unadulterated power of situational forces. ${ }^{92}$ Although some were clearly impressed by this feat, ${ }^{93}$ as Blass pointed

\footnotetext{
${ }^{92}$ As stated earlier, in Milgram's second research proposal the so-called propaganda variation had slipped from second place in the first proposal to last place in the intended line-up of variations he intended to pursue. Milgram may have sensed that obtaining fascinating results in the absence of dispositional factors would more powerfully aid in the resolution of this debate (as opposed to pursuing the propaganda variation and injecting ambiguity into the debate). As Elms (1995, pp. 28-29) said: "He raised the possibility of predispositional factors and of 'highly complex, and possibly, idiosyncratic motive structures' (1962a, p. 17), but in the research itself he directed his efforts mainly towards identifying situational factors that increased or decreased obedience .... Though he had collected demographic information on all participants and had supported my collection of personality data from subsamples of obedient and disobedient subjects (Elms \& Milgram, 1965 [sic]), he gave short shrift to such data in his book, concluding that 'It is hard to relate performance to personality because we really do not know very much about how to measure personality' ( $p$. 205)." Milgram (1974, p. 205) later argued: "the disposition a person brings to the experiment is probably less important a cause of his behavior than most readers assume. For the social psychology of this century reveals a major lesson: often, it is not so much the kind of person a man is as the kind of situation in which he finds himself that determines how he will act" (see also SMP, Box 46, Folder 163, Titled: "Obedience Notebook 1961-1970"). But he also says: "I am certain that there is a complex personality basis to obedience and disobedience. But I know we have not found it" (Milgram, 1974, p. 205). After having obtained fascinating results using only situational forces, Milgram (1974, pp. 9-10) could nonetheless speculate about the kinds of results he would have obtained if he did try to stimulate dispositional forces: "In all likelihood, our subjects would have experienced greater ease in shocking the victim had he been convincingly portrayed as a brutal criminal or a pervert."
} 
out, due to the likely importance of hostility during the Nazi regime, the unexpected consequence of Milgram's purely "situational approach [is that it] does not provide a wholly adequate account" of this historical event (Blass, 1993, p. 37). In the shadow of literature like Naumann's (1966) then Browning's (1992), Blass was of the opinion that although the OTA experiments could account for the "dutiful destructiveness" of the Nazi bureaucrats who transported Jews to concentration camps like inanimate objects: "it falls short when it comes to explaining the more zealous hate-driven cruelties that also defined the Holocaust" (1993, p. 37).

If this did not signal a change in the tide of the mostly positive generalisations regarding the M-H linkage, Goldhagen's (1996) “extremely dispositional” (Miller, 2004, p. 226) book-a veritable litany of examples denoting zealous hate-driven cruelties by ordinary Germans against Jews—certainly did. With Goldhagen having sensed the gap in the literature, as discussed earlier, he painted a very different picture of the Holocaust where, in conflict with all the conventional explanations (of which Milgram's was one), the perpetrators were apparently far from "indifferent" and "passive" bureaucrats.

After providing numerous examples of ordinary Germans volunteering to do cruel and sometimes sadistic things to Jews, Goldhagen then presented what Zangwill (2003) has described as "his best card" (p. 98). That is, some of the ordinary perpetrators went even further again and, in conflict with Milgram's thesis, willingly disobeyed SSReichsführer Himmler's direct orders to stop killing:

On the [Helmbrecht death] march's second day, an SS lieutenant, who was a courier from Himmler, found their column and communicated . . . a directive from Himmler regarding the prisoners .... Himmler had expressly forbidden that any more Jews be killed ... but to release them in the woods ... [but the march and the killing continued and, therefore,] their killing and cruelty was . . . in violation of their duty. These Germans chose, against orders, authority, and all reason, to act as they did (Goldhagen, 1996, pp. 356-357). ${ }^{94}$

On top of the voluntarism and acts of gratuitous cruelty, this example clearly highlighted that there was likely to be much more to the Holocaust than, as Milgram (1974) had argued: "ordinary people, simply doing their jobs ... without any particular hostility on

\footnotetext{
93 Saltzman (2000, p. 140) has pointed out that Milgram was "the first psychologist to propose a situational theory of perpetrator behavior". And Pigden and Gillet (1996, p. 234) were impressed: "If people were prepared to torture an experimental volunteer just like themselves, how much more likely would they be to torture a yid, a gook, a commie, or a kulak!"

${ }^{94}$ This was not a first in Holocaust research. Similar examples of Germans disobeying orders to not kill can be found in the works of Hilberg (1961) and Bartov [1986] (2001, pp. 109, 118).
} 
their part" (p. 6). Unlike other prominent Holocaust scholars, such as Hilberg (1980, pp. 98-101) and Browning (1992, p. 174), who identified potential limitations with the OTA experiments, only Goldhagen (1996, p. 383) was willing to reject them:

Arguments holding that Germans inflexibly obey authority-namely that they reflexively obey any order, regardless of its content-are untenable. By extension, so are the claims by Stanley Milgram and many others that humans in general are blindly obedient to authority. All 'obedience', all 'crimes of obedience' ... depend upon the existence of a propitious social and political context, in which the actors deem the authority to issue commands legitimate and the commands themselves not to be a gross transgression of sacred values and the overarching moral order.

The influence of Goldhagen's challenge against Milgram and Hilberg was soon reflected in the psychology literature:

People do not gas other people, young and old, or shoot them or smash their skulls out of mere obedience to orders. People do not engage in wholesale murder out of administrative momentum, or in retail killing out of bureaucratic inertia" (Gonen, 2000, p. 192).

Because Sabini and Silver's (1982) supportive views on the M-H linkage moved Milgram a little closer to Hilberg's widely respected perspective, Goldhagen's (1996) subsequent criticisms of Hilberg's thesis were equally applicable to Sabini and Silver's research (which only further detracted from the strength of the OTA experiments). Remembering from Chapter Two, however, that the vast majority of leading Holocaust historians eventually rejected Goldhagen's theory of exterminationist anti-Semitism (most agreeing that German society was largely moderately anti-Semitic), for some psychologists the pendulum may have swung too far in favour of dispositionist over situationist explanations of the Holocaust. Not long after the publication of Goldhagen's book, there was a sudden string of articles by psychologists detracting from the M-H linkage (see Berkowitz, 1999; Fenigstein, 1998a, 1998b; Mandel, 1998; Mastroianni, 2002). Having long ago been critical of this tendency of academics to engage in "count-'em mechanics", Mooks (1983, p. 386) has argued: "Ultimately, what makes research findings of interest is that they help us understand everyday life. That understanding, however, comes from theory or the analysis of mechanism; it is not a matter of 'generalizing' the findings themselves [italics added]."

However, the theory Milgram (1974) provided to explain his findings_-particularly the "keystone" agentic state, where subjects who completed the experiment felt they were mere instruments for those in positions of higher authority-failed to convince the 
academic community. More specifically, in their replication of the OTA experiment, Mantell and Panzarella (1976, p. 242) found that some subjects who completed the experiment continued to hold themselves responsible (as in fact did 36.3 percent of a sample of Milgram's (1974, p. 203) own subjects) and therefore: "A monolithic view of the obedient person as a purely passive agent who invariably relinquishes personal responsibility is a false view" (see also Bandura, 1999, p. 197; Lutsky, 1995, p. 59). The agentic state also failed to explain the variance in completion rates across Milgram's many conditions (Blass, 2004, p. 216). Russell and Gregory (2005) argued that Milgram's agentic state, where obedient subjects honestly believed themselves blameless and mere instruments of a higher authority "obscures the fact that it is chosen behavior that is at issue, rather than some form of involuntary entrancement or entrapment" (p. 341). ${ }^{95}$ There is therefore little empirical support for the agentic state (Darley, 1992, pp. 206-207; Mantell \& Panzarella, 1976, p. 244; Marcus, 1974, p. 2; Miller, 2004, p. 210; Russell \& Gregory, 2005, pp. 340-341). In his book, Milgram (1974, p. 42) also discussed an apparent "tendency to obey" which, according to Lutsky (1995, p. 58), saw Milgram explaining "that behaviour as deriving, fundamentally, from a human disposition to be obedient under appropriate circumstances.” However, as Lutsky (1995, p. 56) pointed out, this lens is flawed: just because a particular behaviour can be described as obedience does not necessarily mean that "obedience to authority explains why subjects acted as they did [italics original]." With the idea of "obedience" locked firmly in his head, Milgram failed to make this distinction. ${ }^{96}$ Milgram may not have noticed it, but his conflation of description with explanation was actually tautological whereby obedience was being explained by obedience (Lutsky, 1995, p. 58; see also Mandel, 1998, p. 82). The consequence of such criticisms is that the theoretical component of Milgram's monograph was the book's "weakest" section (Blass, 2004, p. 216). Not only does "the precise meaning and relevance of these experiments remains obscure" (Mantell \& Panzarella, 1976, p. 245), as Miller (2004, p. 233) more recently said, there is "no conclusive theory to account for destructive obedience—or defiance, either." Finally, in terms of others trying

\footnotetext{
95 As Barnard (1968, p. 163) famously said: "the decision as to whether an order has authority or not lies with the persons to whom it is addressed, and does not reside in 'persons of authority' or those who issue these orders." Although Milgram believed his findings were purely or largely determined by situational forces that promoted the so-called agentic state, when defending his position he would occasionally contradict himself with arguments that suggested subjects did make a choice to continue (inadvertently supporting the more dispositional perspective that detracted from his situational view). Such an example being: "I started with the belief that every person who came to the laboratory was free to accept or to reject the dictates of authority. This view sustains a conception of human dignity insofar as it sees in each man a capacity for choosing his own behavior" (Milgram, 1964a, p. 851; also see Milgram, 1974, p. 134).

${ }^{96}$ One rare exception from his earlier publications: "to obey and to disobey, as used here, refer to the subject's overt action only, and carry no implication for the motive or experiential states accompanying the action" (Milgram, 1965a, p. 58).
} 
to make sense of Milgram's results, as Elms (1995, p. 29) pointed out, although “A number of alternative or additional explanations of Milgram's results remain as operable hypotheses . . . none has decisively carried the day." 97

And Milgram's theoretical foundation also failed when applied to the Holocaust. As Mantel and Panzarella (1976, p. 245) pointed out, like some of Milgram's subjects, some of the Nazi perpetrators also later believed themselves responsible for their actions. And in relation to "divided self theories" like the agentic state, Waller (2002, p. 126) indicates that most social scientists remain committed to "the notion of a unitary self in understanding perpetrators of human evil" because as:

Berel Lang puts it: 'It is more plausible to infer a single moral agent-one that granted greater conviction to evil than to good-than two independent moral domains that were constantly being transversed.' In other words, there is no credible reason to believe that we temporarily become wholly different people .... It is more plausible to believe that we have one unitary self that is forever altered by participation in evil.

Other scholars felt the agentic state tended to exonerate or extenuate the undeniably complicit actions of the Nazi perpetrators (Fenigstein, 1998b, p. 62; Mandel, 1998, p. 91).

The gathering momentum detracting from the M-H linkage has recently seen Arthur Miller moderate significantly his earlier generous conclusions. Although Miller (2004, p. 234) firmly maintains:

The experiments certainly generalize to those persons in Nazi Germany who obeyed orders, despite having personal reservations about what was happening to the Jews, and who did not harbor what Goldhagen terms eliminationist, antiSemitic beliefs. I do not think we would be able to understand the behavior of these individuals - and the countless bystanders, who may be said to have obeyed by omission (Staub, 1989) — as well as we do had the obedience research not been conducted.

But then he concedes:

On the other hand, the critics pose some very compelling arguments to those who would assert the presence of a strong inference regarding the $\mathrm{M}-\mathrm{H}$ thesis. I would suggest that any serious discussion of the $\mathrm{M}-\mathrm{H}$ thesis that did not include a simultaneous consideration of the importance of dehumanization would constitute an inadequate coverage of the issues (Miller, 2004, p. 234).

\footnotetext{
${ }^{97}$ See Collins and Brief (1995), Helm and Morelli (1985, pp. 610, 618-624), Katz (1993, p. 26), Kühl (2005), Nissani (1990), and Strudler and Warren (2001, pp. 162-163).
} 
Again, highlighting the power and influence of Goldhagen's criticisms:

Anti-Semitism in Nazi Germany is simply too compelling a reality to dismiss as crucial simply because Milgram demonstrated that prejudice on the part obedient persons was not necessary to obtain extreme harm-doing (Miller, 2004, p. 234).

Converging with Blass (1993, pp. 35, 37), the conclusion of Miller's (2004, p. 226) rethink being: "my own views regarding the $\mathrm{M}-\mathrm{H}$ thesis have become more complex or perhaps ambivalent." “Ambivalent" may be too generous a word; as Parker (2000, p. 121) stated: "It's odd to hear Arthur G. Miller-one of the world's leading Milgram scholarsacknowledge that there have been times when he has wondered, just for a moment, if the experiments perhaps mean nothing at all." Even John Sabini who, as discussed in Sabini and Silver (1982), once supported the situational/bureaucratic M-H linkage, has also retreated in the direction of a more dispositional perspective (see Sabini, Siepmann \& Stein, 2001a, 2001b). ${ }^{98}$

After drawing upon the views of authors such as Lutsky (1995), Staub (1989) and Waller (2002), the present consensus with respect to the $\mathrm{M}-\mathrm{H}$ linkage seems to be that OTA "should be given a qualified causal significance in the Holocaust" (Miller, 2004, p. 220). However, with reference to the dehumanisation of the Jews and other victims, the voluntarism, acts of sadism, cruelty, the role of obligatory obedience and a sense of duty "should be placed in the context of the crucial importance of many other factors" (Miller, 2004, p. 220). It is probably fair to say that, in terms of the larger picture that has, with time, emerged regarding the Holocaust, Milgram's OTA experiments have been relegated to a minor explanation (Fenigstein, 1998b, p. 71; Lutsky, 1995, pp. 62-63).

\section{$\underline{7.4 \quad \text { Conclusion }}$}

The ethical debate over whether or not Milgram should have run the OTA experiments remains an unresolved and probably irresolvable issue-an assessment of the research's ethical status is based upon subjective opinions over what one constitutes as valuable knowledge. Less ambiguous is that Milgram's treatment of his subjects, particularly during the first half of the data-collection stage, was at best disconcerting and at its worst plain reckless. In terms of the study's methodological strength, however,

98 "Sabini, Siepmann and Stein (2001a, 2001b) have recently advocated a pronounced reemphasis on the role of 'the person' and of dispositions in social-psychological theory and research" (Miller, 2004, p. 221). 
numerous independent replications/variations across different nations suggest that the OTA research programme was in all likelihood internally valid; a point few would challenge. Finally, neither generalising Milgram's findings nor his eventual theory in a direction towards explaining aspects of the Holocaust has, with time, proven very convincing and thus successful.

The OTA experiments continue to attract a great deal of scholarly and popular attention. As Slater (2004) said in the epigraphic statement at the start of this chapter, "Milgram's experiments are indisputably in the canon" (p. 61), although it has proven difficult to articulate exactly why. The shortcomings of Milgram's own explanation for his results afford an opportunity to develop a more convincing explanation. 


\section{Chapter Eight: Rethinking Milgram's Theoretical Model - the State of Autonomous Denial (SAD)}

There is no question that one weakness of the obedience research resides in the lack of a substantiated theory-Miller (2004, p. 233).

The lens through which Milgram continued to view his subjects' actions restricted his understanding of why so many subjects completed the obedience to authority (OTA) experiments. As he did during his PhD studies, Milgram originally founded the OTA idea on what soon after World War Two was a commonly held stereotype: “ 'I came across many statements which implied that Germans tended to obey orders more conscientious[ly] than Americans' " (as cited in Fermaglich, 2006, p. 88). The results he obtained in the rudimentary pilot study reinforced part of this stereotype: there indeed appeared to be an inclination in ordinary people to obey authority figures. Many aspects of the official research programme only served to confirm his initial preconception. For example, in the Baseline experiment where subjects were presented with orders to obey, 65 percent completed. However, in another variation where subjects were not given any orders and could inflict shocks of any intensity, only 2.5 percent went to the end of the switchboard. Although there were some counterfactual "gaps" that detracted from the socalled "compelling tendency to obey" (recalling Milgram's musing over there perhaps being "One Theory or Many"), he still became increasingly convinced that obedience due to "The experimenter's influence is the independent variable" (Schuler, 1982, p. 62). Milgram then struggled to appreciate how his results could be explained in any other way.

What else might explain why 65 percent of subjects completed the Baseline experiment? In addressing this question, this chapter is divided into three main sections. The first section will explain why most subjects completed this experiment. The second section will advance an adaptation of Milgram's theoretical model. Using empirical examples, the third section will explore the adaptation's credibility.

\section{$\underline{\text { 8.1 Why Did Most Subjects Complete the Baseline Experiment? }}$}

Although it is impossible to establish the probable content of the motivating force/s preceding the actions of any one subject, Milgram's numerous experimental variations may allow for some calculated speculation as to why most subjects completed the Baseline 
experiment. This requires a closer look at the central junction in the experimental procedure: the inherent moral dilemma. In essence, the OTA procedure is, with each incorrect answer received, about forcing subjects into making a decision to side with either the experimenter, who wants them to continue inflicting shocks, or the learner, who wants them to stop doing so. The subject cannot please both parties simultaneously and must decide whether it is more important to inflict shocks to help the experimenter obtain results, or to stop inflicting increasingly strong electrical shocks on an innocent person with a mild heart condition:

when he [the experimenter] said 'continue' ahh I was thinking your side of it too ... you're trying to get some scientific ahh information, and I had to balance ahh in my own mind ... will there be any any real harm to to [sic] the fella on the other side versus ahh what value it's going to be to you (SMP, Box 153, Audiotape \#2306).

As the learner's pained reactions to the shocks intensified, subjects frequently gesticulated and/or made more explicit statements expressing their sympathetic concerns for the learner's well-being (Milgram, 1974, pp. 49, 73). These expressions of sympathy seemed to highlight a desire within most subjects to stop inflicting the shocks, and with this outcome in mind, they appeared to be seeking the experimenter's approval to do so. But an unperturbed experimenter smothered immediately any such desires to alleviate the learner's unfortunate predicament by firing out one, or if necessary, a sequential barrage from his preconceived arsenal of prods. The experimenter's insistence that the subjects continue inflicting the shocks resulted in them often making explicit statements of disapproval (Milgram, 1974, pp. 48, 51, 85). As one disobedient subject stated: "Surely you've considered the ethics of this thing" and "I don't understand why the experiment is placed above this person's life" (Milgram, 1974, p. 48). This subject seemed offended by the experimenter's blatant prioritisation of collecting scientific data over an innocent person's welfare. Similarly, another disobedient subject later explained that causing pain offended his personal ethical philosophy: "If I have to continue to hurt another human being, I don't believe in it" (Milgram, 1965c). Such subjects located themselves in the State of Autonomy, they believed themselves responsible for their own actions and, controlling the infliction of harm, they felt an obligation to stop the experiment. As this particular subject stated: "As far as I'm concerned . . . in my mind I was hurting that guy" and, as reflected in his disobedient actions, this was something he did not "believe in" (Milgram, 1965c). ${ }^{99}$

\footnotetext{
${ }^{99}$ Much of this resistance was traceable to a subjects' ability and/or willingness to empathetically imagine themselves in the learner's position (Blass, 2004, p. 106). Disobedient subjects frequently made the
} 
Milgram (1974, p. 6) asked independent audiences of varying backgrounds "to render a moral judgment on what constitutes appropriate behavior in this situation". Much like the above disobedient subjects, these independent audiences "unfailingly" saw “disobedience as proper" (Milgram, 1974, p. 6). This conclusion appears to have been stimulated by the experimenter's "fundamental breach of moral conduct to hurt another person against his will” (Milgram, 1974, p. 41). The audiences never raised Morelli's (1983, pp. 187-188) argument that some subjects may have felt a competing moral obligation to obey legitimate authority figures. For each of the different audiences Milgram approached, disobedience was clearly the right, and obedience the wrong, option. $^{100}$

However, forces invisible to outsiders were obviously at play because despite the numerous signs of sympathy and disapproval, 65 percent still went on to complete the Baseline experiment. Milgram (1974, p. 43) observed: "in the present situation even where tension is extreme, many subjects are unable to perform the [disobedient] response that will bring about relief." With only a minority of subjects proving capable of converting their feelings of sympathy and disapproval into disobedient action, the majority seemed to have concluded that for some reason it was more important to side with the experimenter than with the learner. What then was most likely to have held the majority of subjects back from acting on their feelings of sympathy and disapproval, and saw them instead endure a prolonged state of extreme tension? Contemplating this issue, Milgram (1974, pp. 42-43) deduced:

If sympathetic concern for the victim were the exclusive force, all subjects would have calmly defied the experimenter. Instead, there were both obedient and defiant outcomes, frequently accompanied by extreme tension .... Therefore there must be a competing drive, tendency, or inhibition that precludes activation of the disobedient response. The strength of this inhibiting factor must be of greater magnitude than the stress experienced, or else the terminating act would occur [italics added].

Competing with "the deeply ingrained disposition not to harm others" was what Milgram believed to be the apparently "equally compelling tendency to obey others who are in authority" (1974, pp. 42-43). For reasons mentioned, the inhibition competing with

following kinds of comments: "if it was me I'd want to stop too if it was hurting like he claimed it was hurting him" (SMP, Box 153, Audiotape \#2312).

${ }^{100}$ The only people to acknowledge the competing moral imperative that one has an obligation to follow the orders of a legitimate authority to hurt an innocent person were subjects who, after completing the experiment, tried to justify their actions. 
sympathy cannot have been an inclination to obey. But whatever the most common reason was, one can be confident that it will not be obvious and, even if identified, probably unbelievable. This is because if the most common reason why most completed the Baseline experiment was obvious and believable, it would have become common knowledge long ago.

What then does this author believe the inhibition precluding disobedience to have been (and why 65 percent completed the Baseline experiment)? Meeus and Raaijamakers' (1995, pp. 164-165) OTA variation provides one of several clues that lead to an answer. They speculated whether:

the subject [would] be obedient and complete his task if he were legally liable for the consequences of his actions? .... The experimenter then asked the subject to sign a statement to the effect that the subject was aware that the victim might be harmed by the experiment and that the subject accepted legal liability for possible damages .... The percentage of obedient subjects was significantly lower in the 'Legal liability' condition than in Baseline I.

Meeus and Raaijamakers (1995, p. 164) added that others have found that obedience to orders resulting in serious personal danger:

such as picking up a poisonous snake (Rowland, 1939), taking a coin from a dish of nitric acid (Orne \& Evans, 1965; Young, 1952), and carrying out a break-in at their own risk (West, Gunn, \& Chernicky, 1975), a low level of obedience was found, ranging from 0 to $17 \%$. Subjects are clearly able to defy authority when obedience involves a serious risk to themselves [italics added]."

One of Milgram's own subjects sensed this: "I feel that no one will follow distasteful orders, unless it causes or costs that person a personal lost [sic]" (SMP, Box 44, Divider "11", \#0908). The conclusion that most subjects can and will disobey when obedience clearly poses some kind of personal serious risk/loss—legal, financial, physical—is supported by Milgram's own Relationship condition. In this, subjects were faced with the prospect of inflicting (seemingly) life-threatening shocks on someone who was at least an acquaintance known to the subject for two or more years (Rochat \& Modigliani, 1997, p. 238). Completion of this variation was unlikely to be in a subject's best interests, and this was reflected in both their statements and in the completion rate. As one disobedient subject informed the experimenter: "it may be important to you, but it isn't that important to me, for a friendship anyway" (SMP, Box 153, Audiotape \#2425). ${ }^{102}$ Contemplating the

\footnotetext{
${ }^{101}$ For counterfactual examples see Costanzo's (1976) unpublished doctorial dissertation, Martin et al., (1976), Scott (1980), and Tarnow (2000).
} 
potentially longer-term implications of completing, the same subject stated: "I thought, this guy's my neighbour, I'm talking to his wife this afternoon . . . all of a sudden I realised, this is a man [Inaudible] driving me home ... . It's a long ride home!" (SMP, Box 153, Audiotape \#2425). ${ }^{103}$ Despite the so-called "compelling tendency to obey", only three out of 20 subjects (15 percent) completed this experiment. Not only did most subjects demonstrate a remarkable ability to disobey, but 80 percent in this variation did so before the relatively low 195-volt switch (see Figure 6).

Meeus and Raaijamakers' observations and the Relationship condition provide further clues as to the nature of the inhibition that frequently precluded disobedience during the Baseline condition. That is, whatever was holding back so many subjects from acting on their feelings of sympathy and disapproval was probably something that, as in the above Legal liability and Relationship conditions, did not detract from, but actually appealed to their self-interested desires. And probably easing their conscience in the pursuit of this self-interested desire was that, unlike the Relationship condition, the victim in the Baseline experiment was a stranger-a person they were unlikely to really care about. It may be difficult to imagine subjects would be willing to risk what might have been another human's life in pursuit of some relatively trivial self-interested desire. However, there were post-experimental responses that clearly revealed that some subjects were more than willing to pursue the seemingly most trivial of self-interested desires. For example, as one subject later admitted: "My only incentive [for completing the experiment] was the money" (SMP, Box 44, Divider “13”, \#1517). ${ }^{104}$ But since Milgram's pilots obtained high completion rates in the absence of pecuniary reward, payment was unlikely to have been the most common inhibition during the Baseline condition. Another example was that some subjects in the Group Pressure and Action Against a Person condition seemed less concerned about the learner's well-being and more swayed by mere peer pressure. As Milgram (1964b, pp. 141-142) noted:

It might have been thought that the protests of the victim and inner prohibitions against hurting others would have operated effectively to curtail the subject's compliance. While the experiment yields wide variation in performance, a

\footnotetext{
102 One learner/friend eventually responded: "You and I are buddies. Hey, no more" (SMP, Box 153, Audiotape \#2434). The subject then refused to continue.

${ }^{103}$ Another example: "I have to face this guy. I have be be [sic] with him. He's my neighbour and I can't go on with this" (SMP, Box 153, Audiotape \#2425).

${ }^{104}$ Obviously this subject did not realise (or believe) that irrespective of whether or not they completed, payment was guaranteed.
} 
substantial number of subjects submitted readily to pressure applied to them by the confederates.

However, near the end of his monograph Milgram (1974, p. 150) touched upon what is believed to have been the subtle self-interested desire that most frequently discouraged subjects from disobeying:

The teacher cannot break off and at the same time protect the authority's definitions of his own competence. Thus, the subject fears that if he breaks off, he will appear arrogant, untoward, and rude. Such emotions .... suffuse the mind and feelings of the subject, who is miserable at the prospect of having to repudiate the authority to his face [italics added].

Most realised that stopping the experiment required them to shoulder, on behalf of a stranger, the burden of engaging in a direct confrontation with the experimenter. This is the concern that is believed to have been the most common inhibition that competed with the subjects' feelings of sympathy for the learner. ${ }^{105}$ These two simultaneous consequences - fear of a confrontation with the experimenter, on the one hand, and feelings of sympathy for the learner, on the other-generated a moral dilemma for most subjects.

Lending weight to this assertion is that in all of Milgram's experimental variations that eliminated the risk of the subject having to initiate then engage in a confrontation with the experimenter, none or few inflicted all the shocks. Put another way, with the fear of a confrontation eliminated, there was nothing or little competing with most subjects' preference to stop inflicting the shocks. Consequently, they rarely completed the experiment. Consider the following experimental conditions:

- Authority as victim: from the 150-volt switch the experimenter (as learner) demanded the subject stop inflicting the shocks (no risk of a confrontation with the authority figure: zero completion rate);

- Learner demands to be shocked: after the 150-volt level, the protesting learner wanted to continue receiving shocks (because his friend had earlier endured more shocks than himself). However, the experimenter demanded that the subject stop administering shocks (no risk of a confrontation with the authority figure: zero completion rate);

\footnotetext{
${ }^{105}$ As Miller et al. (1995, p. 9) argued, concerns about "being 'impolite' ... . would seem absurd. However, in the actual context of the situation, these concerns are influential."
} 
- Two authorities, each giving contradictory demands: the subject was faced with two options, to stop or continue. Both options would end in a confrontation with the rejected experimenter, but subjects knew the remaining experimenter would endorse their decision. The difference between both options is that one coincides with and the other conflicts with the subjects' preference to stop harming the learner (all subjects side with their preference to stop harming the learner: zero completion rate);

- Subject free to choose shock level: there was no risk of a confrontation with the experimenter because there were no orders to inflict increasingly intense shocks for each incorrect answer (no risk of a confrontation with the authority figure: 2.5 percent completion rate);

- Groups for disobedience: in the subject's presence two actor/teachers consecutively confronted then disobeyed the experimenter (10 percent completion rate-probably because the actor/teachers had initiated then engaged in the confrontation, thus demonstrating the ease of doing so);

- Group pressure and action against a person: two actor/teachers recommended that the subject increase the punishment by 15 volts for each incorrect answer received, with the subject controlling the casting vote regarding the actual degree of punishment inflicted, and the experimenter agreeing to whatever decision was made. (There was no risk of a confrontation with the authority figure but a risk of having to confront the two equal-status actor/teachers: 17.5 percent completion rate.);

- An ordinary man gives orders: no experimenter present, orders were issued to the subject by an ordinary man of equal status. (Although there was no risk of a confrontation with the authority figure there was a risk of one with the equal-status ordinary man: 20 percent completion rate.);

- Experimenter absent (but available via phone): with nobody physically present to ensure the experimenter's instructions were being followed, an "interesting form of behavior that had not occurred under his surveillance" ensued (Milgram, 1965a, p. 66). Some subjects on the phone informed the experimenter that his instructions 
were being obeyed, but had actually stopped delivering the more intense shocks (20.5 percent completion rate). In this variation "Subjects seemed able to resist the experimenter far better when they did not have to confront him face to face" (Milgram, 1974, p. 62). This was probably because disobedience in the experimenter's absence precluded any risk of a confrontation. Lending weight to this interpretation, Milgram (1974) then noted: "Although he had exhausted his power via telephone, the experimenter could frequently force further obedience when he reappeared in the laboratory" (p. 62). This was probably because lying to the experimenter was no longer possible and, should they refuse to continue there was a renewed risk of a confrontation.

However, siding with the learner in all the remaining experimental variations required subjects to initiate then engage in a direct confrontation with the experimenter. Conversely, relatively large percentages of subjects completed these experiments (as illustrated by the dark bars below in Figure 9): 


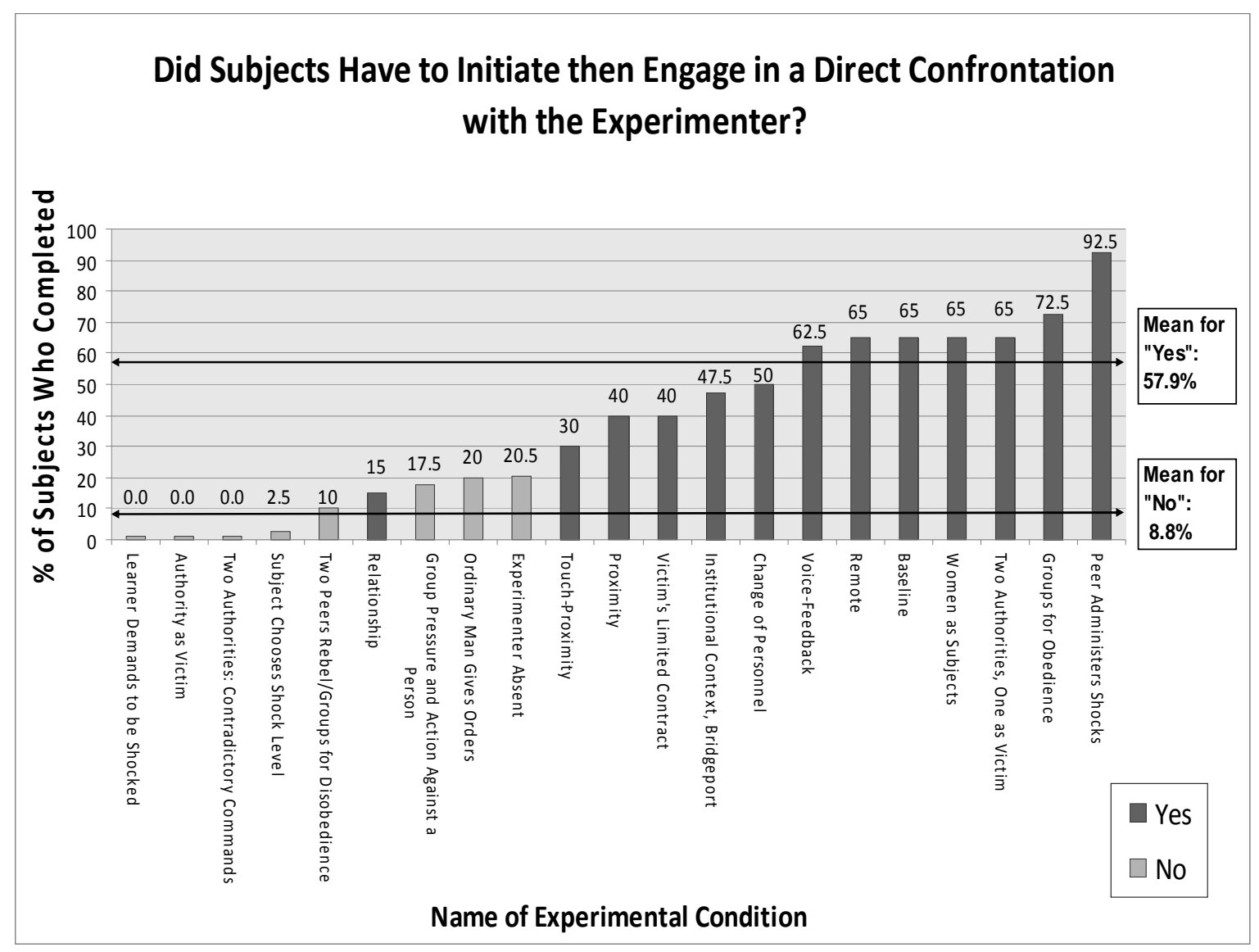

Figure 9: The disparity in completion rates between experimental conditions where siding with the learner did or did not require the subject to initiate then engage in a confrontation with the experimenter. ${ }^{106}$

The Relationship condition was the only exception to this general rule, because siding with the learner did require subjects to engage in a direct confrontation, yet 85 percent did so. However, this was because, unlike in all the other conditions, completing this variation required them to inflict (seemingly) intense shocks on someone who was at least an acquaintance. The strain generated from seemingly electrocuting such a person superseded their trivial fear of having to initiate then engage in a direct confrontation with the experimenter. Therefore, unlike the other variations, the Relationship condition was likely to detract sharply from the subjects' self-interests. Excluding the unique Relationship condition, the average completion rate for experimental variations where siding with the learner did and did not necessitate subjects initiate then engage in a direct confrontation with the experimenter was 57.9 and 8.8 percent, respectively. In fact, had

\footnotetext{
106 This graph excludes the Subject as Bystander condition because it was only a sub-experiment ("Part B") of the Ordinary Man Gives Orders experiment.
} 
the Group Pressure and Action Against a Person (17.5 percent complete), Ordinary Man Gives Orders (20 percent complete), and Experimenter Absent (20.5 percent complete) variations not required the subject to engage in a direct confrontation with the less imposing peer teachers, ordinary man and absent experimenter (respectively), all three variations would almost certainly have produced much lower completion rates (detracting from the above 8.8 percent average).

As illustrated, every experimental variation Milgram undertook (for which he supplied a completion rate) lends weight to the argument that most subjects in the Baseline experiment prioritised a self-interested desire to avoid a confrontation with the experimenter over the learner's well-being, rendering this as the most common (but not the only) motivating force for completing this experiment. ${ }^{107}$ How then could most subjects in the Baseline experiment prioritise a fear of a confrontation with the experimenter over the learner's personal well-being? This question will be addressed in the following rethink of Milgram's theoretical model.

\subsection{Rethinking Milgram's Theoretical Model}

If most subjects completed the Baseline experiment because they feared a confrontation, this implies something far more sinister was at the heart of Milgram's theory than the agentic state, where the subject honestly "no longer views himself as acting out of his own purposes" (Milgram, 1974, p. 133), a mere instrument to be used by a higher authority. By contrast with Milgram's theoretical model (see Figure 8), this thesis proposes that the antithesis of the State of Autonomy (where one believes themselves responsible for their actions) was not the agentic state, but what can be called the State of Autonomous Denial (SAD). The $S A D$ is defined as a state of mind in which subjects knew that they were most responsible for their own actions, but sensed the existence of opportunities that might enable them to avoid a confrontation with the experimenter and evade feeling and/or appearing personally responsible for electrocuting the learner. Thus, they attempted to conceal this awareness of responsibility internally (via self-deception) and/or externally (via the deception of others present). Subjects sensed that they could prioritise their personal desire to avoid a confrontation ahead of any need to withdraw from the experiment in response to the learner's urgent pleadings. For this

${ }^{107}$ Although fear of a confrontation was the most common reason why most subjects completed the Baseline experiment, there were some other reasons for completing. Some completed for the money; and in the Subject Chooses Shock Level experiment there was no risk of a confrontation, yet one subject still completed. 
reason the agentic state should be removed from Milgram's theoretical model (see Figure 8 ) and replaced with the $S A D$ (see Figure 10 below):

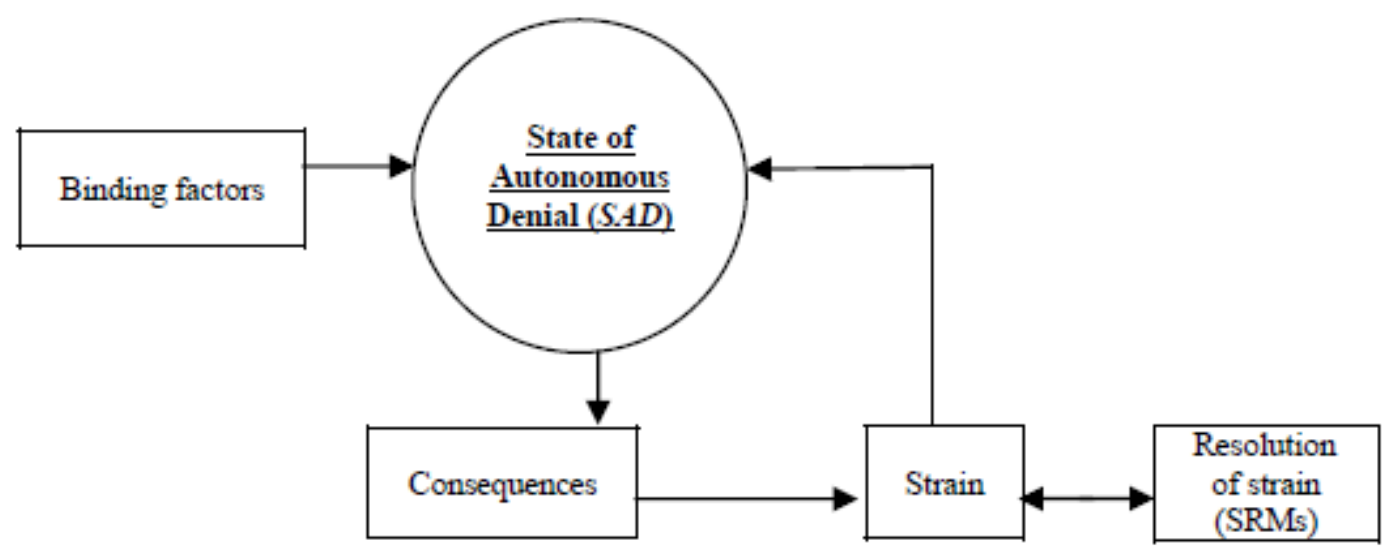

Figure 10: An adaptation of Milgram's theoretical model where the cumulative influence of the Binding Factors (BFs) and Strain Resolving Mechanisms (SRMs) promoted a shift from the State of Autonomy into the SAD (and not the agentic state). ${ }^{108}$

It is important to mention here that the sense in which the term "state" is used is more metaphorical than literal, whereby people act as if they are in a particular "state" of autonomy or autonomous denial. The State of Autonomy and SAD are not two independent moral domains where the subject temporarily becomes a wholly different person. As the following section will demonstrate, they are single unitary moral agents who, for selfinterested reasons, sense the existence of opportunities and try to deceive themselves and/or others into believing they are not responsible for their harmful actions. The $S A D$ shares much in common with Katz's $(1993$, pp. 74-75, 97) "autonomy" in the creation of barriers separating two realms, and Seibel's (2005, p. 351) “intentional ignorance”.

Drawing on many of Milgram's insights, the next section of this chapter will both explain, and bolster with examples, what these opportunities were, and show how they aided most subjects' shift in the Baseline experiment from the State of Autonomy into the $S A D$. The reason so many subjects brought themselves to inflict all the shocks was Milgram's "devilishly ingenious" manipulative, strain-resolving, experimental procedure (situational), and its efficacy in exposing most of his subjects' otherwise well concealed self-interested tendencies (dispositional). As previous chapters have demonstrated, and those which follow will reinforce, Milgram's experimental procedure was a carefully

\footnotetext{
${ }^{108}$ Another adaptation to this model is the removal of Milgram's concept of Antecedent Conditions (which the author believes is better subsumed under the category of SRMs).
} 
designed trap — a web of obligation—-that, with each subsequent shock inflicted, more slightly compromised the unsuspecting subjects' moral compasses.

\subsection{Milgram's Web: the Gradual Seduction and Systematic Ensnarement of Subjects}

Milgram's experimental procedure starts out by flooding the subject with a barrage of subtly coercive BFs. Their purpose is to increase the probability of subjects agreeing to inflict light electrical shocks on an innocent person with a mild heart condition. Upon arrival, the subject was made aware of the importance of their performance, and as a result, most became eager for the Yale University experimenter to consider them a useful and worthwhile participant (BF) (Milgram, 1974, p. 59). In conjunction with feeling contractually bound, the payment of $\$ 4.50$ heightened this eagerness to please (BF) (Milgram, 1974, p. 149). On top of this, any signs of hesitation to inflict the shocks stimulated an intimidating confrontation with the curt, proximate, and looming experimenter (BF). Milgram (1965a, p. 73) was not exaggerating when he said the experiment was like being "thrown into a swift-flowing stream . . . The individual, upon entering the laboratory, becomes integrated into a situation that carries its own momentum."

Some carefully placed reasons for concern detracted somewhat from this momentum. Subjects were made well aware that they were required to inflict electrical shocks (albeit initially light ones) on a clearly restrained person with a mild heart condition. Even at the very earliest stages of the experiment, the moral dilemma of whether to side with the learner or experimenter should at least have generated within the subject a tinge of apprehension-what Milgram termed strain. However, with the learner (and his initially mild reactions to the light shocks) imposing very little, and the experimenter and his barrage of BFs imposing most of the tension on the subject, during the early stages of the experiment there was an imbalance in the intensity between these two sources of strain. As depicted in Figure 11 below, for the dispositionally more egocentric and insensitive participants, this situationally manipulated imbalance in strain tended to increase the likelihood of the experimenter being at the centre and the learner (hidden away in another room), at the periphery of many subjects' emotional universe: 


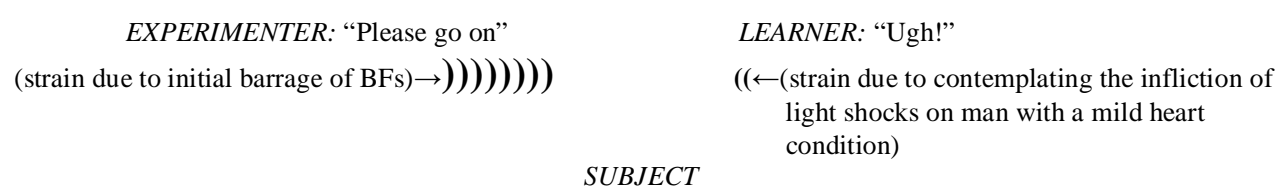

Figure 11: The imbalance in strain imposed on the subject from the experimenter and learner in the earliest stages of the Baseline experiment.

As Milgram (1965a) observed: "When a person is uncomfortable, tense, or stressed, he tries to take some action that will allow him to terminate this unpleasant state. Thus, tension may serve as a drive that leads to escape behavior" (p. 69). Wanting to escape the strongest potential source contributing to their painful experience, the simplest solution to the moral dilemma was to appease the desires of the experimenter and inflict the next shock. As illustrated below in Figure 12, inflicting the next shock would relieve the subject from the experimenter's hounding demands. The negative consequence was living with the knowledge that they were inflicting shocks on an innocent person and, as a result, would have to endure the learner's gradually intensifying cries of discomfort.

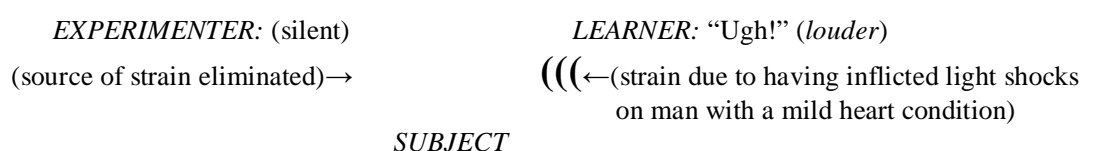

Figure 12: The outcome when the subject eliminated their strongest source of strain and accepted to the experimenter's demands.

All subjects seemed comfortable enough having sided with the experimenter because, in conjunction with the rationalisation that sometimes the pursuit of scientific knowledge requires sacrifice (SRM), at this early stage the shocks were not very painful"Ugh!" And the relief from the experimenter's demands that came with having done as they were told was an added bonus. Consequently, all subjects in the Baseline experiment inflicted the first six shocks (15-90 volts). This was important for Milgram because it meant that all his subjects had met the most important criterion of the foot-in-the-door phenomenon: fulfilment of one or several small requests that, unbeknown to them, were 
about to be followed by far greater ones. But repeatedly appeasing the experimenter from the 90-volt switch onwards generated an issue of rising tension: what would the subject do about the intensifying strain generated by the learner? After the 90-volt switch, all but one of the 40 subjects in the Baseline condition went on to inflict both the 120-volt switch (“Ugh! Hey, this really hurts”) and the 135-volt switch (“Ugh!!”) (Milgram, 1974, pp. 56, $58)$.

The experimenter would attempt to keep the subject inflicting the shocks by responding to any signs of hesitation with one or several of the standardised prods. For the subject, bearing the brunt of this volley of prods intensified the strain they felt. Although doing as they were told would immediately relieve them of this strain, it also saw them inflict shocks on the learner that started to generate adverse reactions bordering on desperation. For example, after inflicting the 150-volt switch (as 39 out of 40 subjects did), the learner, in obvious pain, shouted: “Ugh!!! Experimenter! That's all. Get me out of here. I told you I had heart trouble. My heart's starting to bother me now . . . . I refuse to go on. Let me out" (Milgram, 1974, p. 56). In comparison with the earlier stages of the experiment, the shocks could no longer be construed as being quite harmless and the learner's increasingly distressed reactions strongly affected the subjects' emotional universe. Although there would have been individual differences in sensitivity, as the screams gradually intensified, eventually a point was reached where the subject sensed that both sources of strain were of equal intensity and thus, for themselves, equally painful (as illustrated in Figure 13 below).

EXPERIMENTER: "The experiment requires that you continue" $($ (train from more intense prods $\rightarrow)))$ )) )) )) ))) )
LEARNER: "Ugh!!! That's all..."

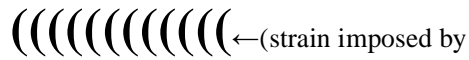
screaming learner complaining of a heart condition)

SUBJECT

Figure 13: The experimenter and the learner's similar effects on the subject's emotions.

With the learner and experimenter imposing comparatively similar intensities of strain, subjects felt the urge to reassess their earlier resolution of the moral dilemma (repeatedly siding with the experimenter). An important determinant of the outcome of this reassessment was the consequence/s on the subject associated with their siding with 
the experimenter or learner. That is, the subject could either choose to continue meeting the experimenter's needs to obtain results (along with, perhaps more importantly, also satisfying their own desire to avoid a confrontation) and continue to inflict what now appeared to be very painful shocks on an innocent person. Or they could convert their sympathy and disapproval into action by suddenly refusing to continue and instead meet the learner's needs to avoid experiencing any further shocks (therefore sacrificing their own desire to avoid a confrontation). Doing what independent audiences unanimously agreed was the morally right course of action and siding with the learner was attractive because it meant the subject would no longer have to inflict shocks on a clearly innocent person, relieving them of all the strain (or what this author would rather term guilt) associated with doing the wrong thing. ${ }^{109}$ Greatly elevating the attractiveness of pursuing the morally wrong option was the fact that, because the experimenter was urging the subject to continue participating in the procedure, the subject was purposefully led to suspect they could inflict further shocks with total impunity (and in the process evade having to engage in a confrontation with the experimenter). Upon weighing up the consequences for the learner, experimenter and, most importantly, themselves, many subjects encountered an intensifying Asch-like inner conflict as to how to resolve the moral dilemma. It was an Asch-like inner conflict because the internal dialogue surrounding the OTA experiments probably closely resembled that generated by Asch's Group Pressure/Conformity experiment. That is, the subject believes the "conflict with him is a purely private issue" of which "all others are totally unaware". Although the "subject makes frantic efforts to conceal his conflict" he "dares not betray his secret, yet by his actions, he is betrayed".

The inner conflict was stressful because subjects were contemplating whether to make the morally right or wrong choice. Would they stand up for their beliefs and confront the Yale University employee, or would they submit to his will? “The subject's problem then is how to become disengaged from a situation which is moving in an altogether ugly direction" (Milgram, 1965a, p. 73). Then again, it is also possible that some obedient subjects never engaged in such moral calculus (the weighing up of options) but, with little thought or concern for the learner, simply moved in whatever direction felt easiest (least stressful and/or demanding) for themselves (see Milgram, 1974, pp. 45-47). Either way, the OTA-trap had been set, and in his notes Milgram captured in one eloquent

\footnotetext{
${ }^{109}$ It appears that Milgram used an ambiguous word like strain to describe the tension experienced by subjects instead of a more specific word like guilt, because the latter would imply subjects actually knew that what they were doing was wrong and felt responsible for doing it. This would have contradicted the agentic state, in which subjects were apparently being honest when they said they did not feel responsible for their actions.
} 
sentence the true essence of his entire experimental paradigm: "the experimental set up relies ... on seduction, the systematic ensarement $[$ sic $]$ of the subject into a web of obligation and uncritically from which he is unable to escape" (SMP, Box 46, Folder 167, Titled: “Notes: Antecedent conditions 1961-1963”).

Some resolved the moral dilemma by refusing to inflict further shocks. By doing so they stopped the learner's strain/guilt inducing screams. However, having apparently ruined the experimental trial they stimulated the experimenter's barrage of strain/guilt generating prods:

\footnotetext{
EXPERIMENTER: "It is absolutely essential that you continue" LEARNER: (silence)

$($ strain/guilt from more intense prods $) \rightarrow()))))))())))(\leftarrow($ source of strain/guilt eliminated $)$
}

SUBJECT

Figure 14: The strain/guilt imposed by the experimenter after a subject decided to stop inflicting the shocks in the early to middle stages of the experiment.

It was common for those who chose this course of action to try to neutralise the above imbalance in strain/guilt by offering to return the $\$ 4.50$ and make amends for having ruined the experimental trial (Milgram, 1974, p. 47).

As the results illustrated, however, most subjects instead chose to continue inflicting further shocks. Doing so meant that they would pass the point of strain/guiltequilibrium (see Figure 13), resulting in the learner's reactions to the shocks surpassing (and eventually eclipsing) the maximum strain/guilt the experimenter was capable of imposing on an insubordinate subject with his mere words. Doing as they were told would end the experimenter's demands, but being beyond the point of equilibrium ensured they would then have to experience the learner's guilt-inducing reactions to the far more intense shocks (as illustrated in Figure 15 below): 
EXPERIMENTER: (silence)

(source of strain/guilt eliminated) $\rightarrow$
LEARNER: "Ugh! Let me out... My heart...You

have no right to keep me here!..."

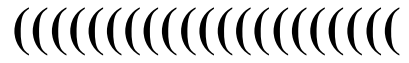

(strain/guilt imposed by screaming learner)

SUBJECT???

Figure 15: The imbalance in strain/guilt that develops after the point of equilibrium, where the strain/guilt produced by the learner started to exceed and eventually overshadow the maximum strain/guilt that the experimenter was capable of generating.

Again, as the learner's reactions to the shocks intensified, haunted by feelings of sympathy, disapproval, and/or guilt, the subjects' desire to side with the learner increased. But in the back of their minds was the "inhibiting" realisation that stopping the experiment necessitated they shoulder, on behalf of a stranger, the burden of engaging in an uncomfortable confrontation with the experimenter.

\subsection{The Shift from the State of Autonomy to the SAD}

Those subjects who resolved the moral dilemma by continuing to side with the experimenter dealt with the downside of their decision-having to inflict potentially lifethreatening shocks on an innocent person-by shifting into the $S A D$. The shift into the $S A D$ helped to neutralise the over-balance in strain generated by the learner's intensifying reactions, because subjects were able to convince themselves (self-deception) and/or others present (deception) that they were not responsible for the pain the learner was experiencing. (And if they were not responsible then they need not feel guilty for continuing to inflict even more painful shocks.) The following section will demonstrate how, with varying degrees of success, certain BFs and SRMs provided subjects with opportunities to evade feeling and/or appearing responsible for their harmful actions (promoting the shift into the $S A D$ ). 


\section{Responsibility}

The foot-in-the-door phenomenon-many small steps-was an important BF at the start of the experiment. But throughout the entire experiment this BF had an on-going coercive influence on subjects (particularly in reducing feelings and/or the appearance of being responsible for the infliction of harm). As Eckman (1977, p. 97) observed, continuing on to inflict all the shocks could protract a state of ignorance of responsibility for one's actions:

To interrupt a behavioral sequence one has already set in process implies that one has made a bad decision, and is responsible for having behaved wrongly in all the completed steps of that sequence. On the other hand, to continue without stopping allows the individual to view the authority as responsible for the (in)correctness of both the past and present behavior. The problem is, in a sense, a product of all-ornothing, either-or thinking: If I admit that this behavior, now, is wrong and that I have the power to change it, then all the behaviors I have performed from the beginning of this sequence are wrong, and I must accept responsibility for them. But if I carry out the orders of the authority now, then he, not I, must be responsible-for all the actions I have taken here.

As the experiment progressed, and fearing a confrontation, some subjects may have sensed this opportunity to deny responsibility for their actions. And, if successful at convincing themselves (self-deception) and/or others present (deception) then-having entered into the $S A D$ - they did not need to feel and/or appear guilty/nervous while inflicting further shocks on the screaming learner.

Before inflicting the 255-volt switch, the pseudonymous Jan Rensaleer seems to have sensed such an opportunity. However, after inflicting this shock, the learner's screams had become so intense that Rensaleer's guilt feelings, and accompanying nervous reactions, shattered his self-deception and/or the deception of others by which he had convinced himself and/or the others present that he was not responsible for his own actions. Having cracked under this pressure, he then rather sheepishly shouldered the burden of responsibility for having inflicted as many shocks as he had: "I can't continue. I'm very sorry. I think I've gone too far already, probably" (Milgram, 1974, p. 51). Acknowledging that he had "gone too far already", Rensaleer conveyed an awareness that he was personally responsible for his own actions; but before extricating himself he tried to 
convince himself and/or others that this was not the case. ${ }^{110}$ Upon accepting responsibility for inflicting all the previous shocks, Rensaleer then returned to the State of Autonomy. ${ }^{111}$

\subsection{The Supplied Strain Resolving Mechanism of Rationalising Away Feelings of}

\section{Responsibility}

The experimenter's many prods were a particularly powerful SRM in shifting subjects from the State of Autonomy into the $S A D$. Initially implicitly but eventually explicitly, the standard then more specialised prods gradually encouraged subjects to take advantage of opportunities which enabled them to continue inflicting the shocks while at the same time evading responsibility for doing so (enabling them to avoid having to engage in a confrontation with the experimenter).

At the first signs of hesitation in inflicting punishment on the learner, the experimenter would fire out one or, if necessary, several of his standardised prods: "Please continue", "The experiment requires that you continue", "It is absolutely essential that you continue", and finally, "You have no other choice, you must go on" (Milgram, 1974, p. 21). For those subjects less concerned about their fear of a confrontation and more concerned about alleviating the learner of their pain, these prods were construed as a barrier impeding them from helping the learner. Firmly rooted in the State of Autonomy, for these subjects the prods generated indignation then recalcitrance. This is why the prods failed in encouraging them to complete the experiment (Saltzman, 2000, pp. 137-138).

However, for those subjects less concerned about the learner, and more concerned about relieving themselves of their painful predicament, the standard prods were not perceived as a barrier but rather as an opportunity that might enable them to avoid having to engage in an undesirable confrontation. For example, the standard prod, "Please continue", implied that since the experimenter was asking the subject to inflict the next shock, the former would probably accept at least some responsibility for the latter's actions. Being reluctant to engage in a confrontation, many subjects started wanting and/or

\footnotetext{
${ }^{110}$ Milgram (1974, p. 52) overlooked this interpretation but his observations seem to validate it: "Although this subject defied the experimenter at 255 volts, he still feels responsible for administering any shocks beyond the victim's first protest."

${ }^{111}$ Another subject similarly admitted: "I felt I'd gone far beyond what I should have" (SMP, Box 153, Audiotape \#2310). And another conceded: "In fact, I even went on after I should have stopped back here when he hollered 'let me out of the chair'" (SMP, Box 153, Audiotape \#2428).
} 
wanted others to believe that the experiment indeed "required" they continue and/or that it was "absolutely essential" they go on and/or that they had "no other choice". If accepted by the subject - and the temptation appears to have been great—via self-deception and/or the deception of others, these supplied strain-resolving rationalisations for continuing helped to relieve the subject of the strain/guilt associated with shocking the screaming learner in the early to mid-stages of the Baseline experiment. In response to the prods, one subject said apparently to himself (but obviously loud enough for others present to hear): “ 'It's got to go on. It's got to go on' " (Milgram, 1974, p. 9). As Baumeister (1997, p. 311) put it: "People will settle for any vaguely plausible argument when they want badly enough to believe that their hurtful actions are justified."

As the experiment proceeded and the learner's reactions intensified, these standardised prods sounded increasingly implausible to the subjects, and perhaps more importantly, to others present ("results" were clearly being prioritised over an innocent person's well-being). Trying to think on their feet, many subjects attempted to seek out non-confrontational ways-potential escape routes-which, without having to directly stand up to the experimenter, might enable them to inoffensively extricate themselves from the experiment. For example, as the screams intensified, many subjects enquired into the shocks' possible impact, sensing it would only be fair and reasonable to stop if the learner was being physically harmed. Having learnt during the pilot studies to anticipate such concerns, the experimenter attempted to cut off this non-confrontational attempt to escape by trying to relieve the subjects of the strain they were experiencing. He did this by supplying them with the following specialised prod (SRM): "Although the shocks may be painful, there is no permanent tissue damage, so please go on" (Milgram, 1974, p. 21). Even if the shocks caused no permanent injury, from the 150-volt switch onwards it was indisputable that the learner was experiencing alarming levels of pain that were likely to intensify. Although independent audiences agree that continuing was morally the wrong course of action, if at face-value the subject chose to accept the experimenter at his word, they suspected the offer might relieve them of their responsibility of engaging in a direct confrontation. This was because, as the experimenter had just said, the shocks caused no permanent injury.

One participant in the Women as Subjects condition who accepted this strainresolving rationalisation was the pseudonymous Karen Dontz. After the learner's agonising and hysterical reaction to the 330-volt switch, Dontz "accept[ed] . . . the experimenter's comment saying, 'I'll continue, providing it's not dangerous' " (Milgram, 
1974, p. 77). Dontz seemed to accept this offer because if it turned out the shocks actually were dangerous, via self deception and/or the deception of others, she believed herself to be beyond reproach. She may have experienced feelings of relief, safe in the knowledge that she could only be blamed for believing and trusting in the accuracy of the experimenter's information. Again, such reasoning aided the shift from the State of Autonomy into the $S A D$, because the experimenter said it was harmless so only he could be held responsible for her actions. The experimenter's response provided a tempting opportunity to avoid having to engage in a confrontation. It is important to note that it was in Dontz's self-interest to trust the experimenter's word over and above the learner's screams (which clearly suggested the possibility of "tissue damage"). In the postexperimental interview, Dontz enquired: " "did any of the men go through and follow the 450 volts?" (Milgram, 1974, p. 79). The interviewer asked for her opinion, and she speculated: “ 'No, I don't think men would comply' ” (Milgram, 1974, p. 79). Perhaps the reasoning behind her answer was that she thought men were braver than herself and so were less likely to cave into the experimenter's seemingly inhumane demands. As the results demonstrate, it would appear that men also, as one frankly admitted, frequently "gave in and finished the experiment [italics added]" (SMP, Box 44, Divider "Problems", \#1706).

As the learner's reactions intensified, the rationalisation that the shocks caused no permanent injury became more implausible. Having rendered the learner at least unconscious, many subjects reassessed the accuracy of this rationalisation. Since they were the only ones inflicting the shocks, with the intention of covering themselves many subjects then felt it necessary to inquire about the direct lines of responsibility. Because some subjects sensed that since they were the ones inflicting the shocks, the experimenter probably would have been unwilling to accept all responsibility for what were clearly their (the subject's) actions. Had the experimenter refused to accept total responsibility, it would have enabled subjects to inoffensively extricate themselves from the experiment. However, when such a verbal exchange took place, it ended in the experimenter closing off this potential escape route by confidently responding: "I'm responsible for anything that happens to him. Continue please" (Milgram, 1974, p. 74). This response was a particularly powerful supplied strain-resolving rationalisation, increasing the probability of the subject entering the $S A D$. This was because, should they accept this rationalisation, not only would they avoid having to engage in a confrontation, as the experimenter this time explicitly stated for the record, they would in no way be rendered culpable-morally or legally_for having inflicted all the shocks. The experimenter's offer to accept total 
responsibility for the subject's actions proved extremely enticing, with many then going on to side with the experimenter. The consequence of this specific exchange was that, via self-deception and/or the deception of others present, subjects made the shift from the State of Autonomy to the $S A D$, as they inflicted the next shock, confident they could now act with impunity. Thus, many exhibited obvious signs of relief.

The pseudonymous Fred Prozi, until the 180-volt switch in the Baseline experiment, explicitly expressed awareness that he was most responsible for the learner's pain (State of Autonomy):

I'm not going to kill that man in there .... I'm not going to get that man sick in there .... I refuse to take the responsibility .... I mean who's going to take the responsibility if anything happens to that gentleman [italics added]? (Milgram, 1974, pp. 73-74).

When the experimenter accepted total responsibility, Prozi capitulated, slipping into the SAD: “ 'All right ....' LEARNER (screaming): 'Let me out of here, you have no right to keep me here. Let me out of here ... .' (Subject shakes head, pats the table nervously.)" (Milgram, 1974, p. 74). As the screams intensified Prozi was nervously drawn back to the State of Autonomy: “ 'Aw, no. I'm not going to kill that man'” then, soon after the learner had stopped screaming and all subsequent questions were met with the ominous sound of silence, at the 390-volt switch he stated: " 'Something's happened to that man in there ... .' EXPERIMENTER: 'Continue. Go on, please'” (Milgram, 1974, pp. 75-76). Prozi then took advantage of an opportunity he had earlier sensed might enable him not only to avoid having to engage in a direct confrontation but also to evade responsibility for his actions. Enabling him to shift back into the $S A D$, Prozi sought further confirmation of the earlier offer: “' 'You accept all responsibility?' EXPERIMENTER: 'The responsibility is mine. Correct. Please go on' " (Milgram, 1974, p. 76). Patently, Prozi did not really believe the experimenter was most responsible ("I'm not going to kill that man"). Prozi knew he was most responsible for his actions. But like all those who accepted this particularly powerful strain-resolving rationalisation, he wanted to believe it because, at the learner's expense, accepting the offer would enable him to evade responsibility for engaging in what he anticipated would have been an emotionally uncomfortable confrontation with the experimenter. Prozi may not have been willing to later admit this, but other subjects were more forthcoming: "I thought the 'shocks' might harm the other 'subject' however, I mentally 'passed the buck' feeling the one running the experiment would take all responsibility” (SMP, Box 44, Divider “2”, \#0608). 
Prozi appears to have been influenced by some "compelling tendency to obey" an authority figure. But had the experimenter instead responded: "I refuse to accept any responsibility for your harmful actions but the experiment still requires you to continue, you have no other choice", the power of "obedience" as an explanation would have been tested. ${ }^{112}$ Paradoxically, Milgram's OTA experimental paradigm has less to do with "obedience" to an authority per se, and much more to do with the availability of opportunities that enabled subjects to evade then pass on responsibility for their harmful actions. This explains why some variations resulted in subjects completing in the total absence of any authority figure. The most obvious example was the Ordinary Man Gives Orders condition, where four out of 20 subjects (20 percent) were willing to "obey" in an experiment with no authority figure. It will be recalled there was a second part to this experiment: the ordinary man asked the 16 dissident subjects if they would instead continue participating, but instead as a timekeeper-the Subject as Bystander condition. Probably sensing it would be easier to later evade being held responsible for the potentially harmful outcome (the ordinary man would inflict the apparent shocks), 11 of 16 (69 percent) agreed to continue participating in the experiment until the end. When the results of both experiments are combined, 15 of 20 subjects -75 percent - continued to participate and complete an OTA variation in which no authority figure took part.

As was the case in most of the other variations, when the person who is to be pinned with, or is willing to accept, responsibility for the subjects' harmful actions happens to be of higher authority, elevated status, or an apparent expert, the credibility of the excuse that the subject was not responsible sounded much more plausible to themselves and/or others present. To repeat- the OTA experiments had less to do with OTA and much to do with the availability of opportunities that enabled subjects to evade shouldering responsibility for their own harmful actions.

However, some subjects remained unconvinced that, having seemingly rendered the learner unconscious, they would be able to evade responsibility for their harmful actions. What frequently eventuated was that, in conjunction with opportunistically accepting one or several of Milgram's top-down supplied strain-resolving rationalisations,

\footnotetext{
${ }^{112}$ In support of this assertion see Meeus and Raaijmakers (1995). Also see, Tilker (1970, p. 99) found that all observers ( 5 out of 5 ) of a replication of the proximity experiment (victim seen and heard), who were previously informed that they were totally responsible for the learner's welfare stopped a teacher/actor who was determined to inflict all shocks.
} 
as the following will illustrate, some subjects felt compelled to bolster these excuses for continuing by inventing, from the bottom-up, their own rationalisations.

8.7 The Self-Invented Strain Resolving Mechanism of Blaming the Victim-the Just

World Phenomenon-Lerner (1980)

As Milgram (1974, p. 10) noted:

Of considerable interest, however, is the fact that many subjects harshly devalue the victim as a consequence of acting against him. Such comments as, 'He was so stupid and stubborn he deserved to get shocked,' were common. Once having acted against the victim, these subjects found it necessary to view him as an unworthy individual, whose punishment was made inevitable by his own deficiencies of intellect and character.

Similarly, another subject was "angry at the learner for being so slow and forcing me to shock him harder" (SMP, Box 44, Divider “17”, \#0226). With the learner being so "stupid" and "slow", these subjects were trying to convince themselves (self deception) and/or others present (deception) that the learner was most responsible for their (the subjects') actions. As Staub (1989, p. 17) put it: "Blaming others, scapegoating, diminishes our own responsibility."

8.8 The Self-Invented Strain Resolving Mechanism of Blaming Military Service in $\underline{\text { Reducing Feelings of Responsibility }}$

Struggling to later explain themselves, other subjects blamed a previous life experience, which they felt was similar to the situation in which they found themselves in Milgram's laboratory. Some subjects invented a SRM, namely, a propensity to obey acquired during their time in the military. As one obedient subject later explained:

Subject: “Guess I'm pretty good at obeying orders, I mean ahrrrr, military service."

Milgram: "What if he were actually being murdered in there?"

Subject: "[Inaudible] ...."

Milgram: "Well why did you listen to this man [the experimenter] rather than the other guy [the learner]?"

Subject: "Well it's like I say, I'm used to taking orders . . I've been through quite a bit of combat" (SMP, Box 153, Audiotape \#2433). 
The implication was that had he never been in the military then he would not have completed the experiment. Thus, he convinced himself (self-deception) and/or tried to convince others present (deception), that he was not to blame for his harmful actions. Rather, his experiences in the military were to blame.

However, all of the above supplied and self-invented opportunities that helped subjects to evade responsibility for their harmful actions were mind-games. These mindgames were used so that most subjects could evade a confrontation with the experimenter. The Relationship condition (especially when the subject and learner were much more than just acquaintances) was the best illustration of this. Consider, for example, one subject who refused to continue, and then tried to justify his actions:

Subject: "But since he was my brother [Inaudible] I stopped ...."

Milgram: "Why do you think you stopped for a brother-in-law?"

Subject: "Well ahhrrr .... Why should I keep on going? It's not that necessary to keep on going right? That's the reason why I stopped" (SMP, Box 153, Audiotape \#2422).

Irrespective of the experimenter's prods, this subject expresses an awareness that it was not that necessary that he inflict every shock. But, with respect to resolving the inherent moral dilemma, this subject's response to the question of what he would have done had the learner instead been a stranger, is revealing:

Subject: "Well . . they told me I should keep on going, I keep on going." Milgram: "Why? What's the difference?"

Subject: "Well . . [ [Inaudible] is not dangerous, nothing will happen to me."

Milgram: "But that's what you were told ahhrrr with your brother in-law."

Subject: "Yeah but there's a difference."

Milgram: "What's the difference?"

Subject: “... If it is a stranger I don't listen. Right? We are doing an experiment .... They told me to do it, I keep on doing it. He told me keep on going, I keep on going" (SMP, Box 153, Audiotape \#2422).

The difference was that the subject anticipated that shocking his brother-in-law would come with consequences, while shocking a stranger probably would not. When asked this same question other subjects gave similar responses. ${ }^{113}$

\footnotetext{
${ }^{113}$ For example, another subject stated: "if this was a complete stranger in here, to me, ahrr it would be much easier to continue on" (SMP, Box 153, Audiotape \#2426). (See also SMP, Box 153, Audiotape \#2428 \& \#2438).
} 
Another subject, faced with the prospect of inflicting a 165-volt shock on his son, illustrates just how obvious it was for subjects in the many non-relationship variations that it was "not that necessary to keep going":

Subject: "Wrong, I'm gonna give you 165 volts."

Learner: "Ahhh, let me out of here .... I'm gonna rip this place up! Let ME OUT ..." (SMP, Box 153, Audiotape \#2435).

The subject, trying to conjure up a non-confrontational means of ending the experiment, rather creatively pointed out:

Now listen, he'll he'll [sic] do that too . . . you better let him out because he'll do it! If you think any of your equipment . . . we'll give you back your cheques and let it go at that, to hell with it. Because I'm not gonna have him get hurt, and he'll rip your equipment up (SMP, Box 153, Audiotape \#2435).

This strategy fails and the experimenter then insists the subject continue inflicting the shocks. The subject realised there was no amiable way out, and facing the prospect of inflicting a 180-volt shock on his own son, the subject burst into a heated and occasionally incoherent tirade:

Subject: “I DON'T GIVE A GOD DANG WHAT 'THE EXPERIMENT REQUIRES'. IF SOMEONE'S GETTING HURT AND HOLLERING THERE IS NO SUCH THING AS ANYONE GONNA MAKE CONTINUE WITH [sic] SO DON'T GIVE ME THAT LINE OF HOOLEY IF IF [sic] YOU'RE GETTING AN EXPERIMENT, AND IT'S HURTING YA [mumble] THAT'S GONNA MAKE YOU CONTINUE WITH IT-SO DON'T GIVE ME THAT LINE OF HOOLEY. I'M NOT SO DUMB THAT I DON'T KNOW THAT. AND AS I SAY, YOU CAN HAVE YOUR TWO DAMN CHEQUES BACK! IF HE'S GONNA HOLLER LIKE THAT I'M NOT GONNA KEEP GOING THROUGH WITH IT!"

Experimenter: "You have no other choice Teacher."

Subject: "WHAT DO YA MEAN I HAVE NO OTHER CHOICE!"

Experimenter: "If you don't continue we're going to have to discontinue the entire experiment."

Subject: $\quad$ (suddenly calming down) “... discontinue the entire thing! I an't gonna have my boy, would you have your boy hollering in there like that?"

Experimenter: "Well we'll have to discontinue, may I ask you a few questions . . . ?"

Subject: 'I'm not going to sit there, after all that's my boy, and I'm not gonna sit [mumbles]” (SMP, Box 153, Audiotape \#2435). 
As this subject repeatedly emphasised, that the experiment "requires" he continue is a "line of hooley". He also highlighted that—never having attended high school ${ }^{114}$ —his lack of formal education did not prevent him from knowing that he did not have to continue. He was also aware that he had a choice, one of which was to discontinue participating in the experiment. The difference was that in the Baseline experiment, helping the learner required subjects to engage in a confrontation on behalf of a stranger. For most subjects, helping a stranger paled in comparison to satisfying their personal desire to avoid having to engage in a distasteful confrontation. It is therefore suspected that the obedient subjects were just as capable as the independent audiences of identifying that inflicting the shocks was the morally wrong course of action. This may explain why 36.6 percent of a sample of subjects who completed later still held themselves most responsible (Milgram, 1974, p. 203). As one subject admitted: "I was surprised to learn that I did a thing even though $I$ knew it was wrong to do it [italics added]" (SMP, Box 44, Divider: "Problems", \#2321). Another subject stated: "It's left me with a guilty feeling" (SMP, Box 44, Divider "9", \#2013). As one disobedient subject said: "I was glad to find that I had the 'guts' to refuse to continue" (SMP, Box 44, Divider “14”, \#0837). With regards to all the non-relationship variations, Damico (1982) understood the situation well:

most revealing ... in the Milgram experiment is not the inability of his subjects to understand the difference between right and wrong - anxiety was often the most visible emotion-but their failure to care about the difference in a way that would have made it the controlling factor in their behavior (pp. 424-425).

It would have been interesting to note how many subjects would have completed the experiment had they known before inflicting the first shock that they would later swap roles with the learner. Irrespective of what the subject might have said-_"but I don't like what's happening to that fella in there" (Milgram, 1965c)—most did not care enough about the learner to sacrifice their lesser important desires. Actually, Zimbardo (1974, pp. 566567 ) went so far as to argue that most of the disobedient subjects were not all that concerned about the learner:

what did the disobeying minority do after they refused to continue to shock the poor soul, who was so obviously in pain? Did they intervene, go to his aid, denounce the researcher, protest to higher authorities, etc.? No, even their disobedience was within the framework of 'acceptability'; they stayed in their seats, 'in their assigned place,' politely, psychologically demurred, and they waited to be dismissed by the authority. ${ }^{115}$

\footnotetext{
${ }^{114}$ See SMP, Box 153, Audiotape \#2435.

${ }^{115}$ Lending support to Zimbardo's point is the Subject as Bystander condition, in which, as a compromise, the ordinary man asked the 16 recalcitrant subjects from the Ordinary Man Gives Orders condition to
} 
This is true, with the exception of the then unpublished Relationship condition, which provided many examples of genuinely concerned behaviour and defiance. After inflicting the 150-volt shock on his friend, one subject suddenly hesitated, and the experimenter then issued the prod: "It's absolutely essential that you continue teacher." Ignoring the experimenter, the subject stood up from his chair and tried to make his way to the learner/friend in the adjacent room. On encountering a locked door, he then demanded of the experimenter: "You gonna open up the door?" Sensing the seriousness of the situation, the experimenter did not issue the final prod, "You have no other choice" and, seemingly fearing for his own safety, responded instead: "We'll have to discontinue the experiment" (SMP, Box 153, Audiotape \#2424). ${ }^{116}$

\subsection{The Self-Invented Strain Resolving Mechanism of Avoidance Behaviour in}

\section{Reducing Feelings of Responsibility}

Another example of a self-invented SRM that lends weight to the argument that subjects knew they were acting immorally was a behaviour that Milgram termed avoidance. As subjects reached the higher end of the shock board, some started to anticipate the learner's excruciating screams and purposefully talked over his pained appeals, as if to try to neutralise their impact (see SMP, Box 153, Audiotape \#2301). Similar behaviours were observed during the pilot runs where it was noticed that some subjects would avert their eyes from the learner, whom they could see through a silvered glass, then continue delivering the shocks. Milgram (1974, p. 158) termed such behaviour avoidance, whereby "the subject screens himself from the sensory consequences of his actions." He believed avoidance was a type of SRM, because those who engaged in it did "not permit the stimuli associated with the victim's suffering to impinge on them ... . In this way, the victim is psychologically eliminated as a source of discomfort" (Milgram, 1974, p. 158). As one subject from the pilot later admitted, they looked away because "it caused them discomfort to see the victim in agony [italics added]" (Milgram, 1974, p. 34).

continue participating in the procedure by performing instead the timekeeper role (with 11, 69 percent, completing). Most who completed this condition were not as concerned about the learner's well-being as they were about the possibility of later being blamed for the destructive end result. If they were really concerned about the learner, they (as a minority did) would also have refused to participate in the second part of the experiment.

${ }^{116}$ Also see SMP, Box 153, Audiotape \#2421, \#2425, \#2440. 
Like all subjects who, in fear of a confrontation, decided to resolve the moral dilemma by repeatedly siding with the experimenter, those who engaged in avoidance knew they were choosing the wrong option. But a problem confronting these subjects was that with the cause (the subject flicking switches) being so closely related to an intensifying effect (the screaming learner), they (and others present) were repeatedly and more intensely reminded of the existence of this cause/effect relationship. These subjects were clearly manipulating their immediate environment, so as to screen themselves from having to experience and react to the strain/guilt-inducing sensory consequences of their actions. Paradoxically, it would seem these subjects did not want to know about the harm they knew they were mostly responsible for inflicting-Seibel's "intentional ignorance". As far as these subjects were concerned, if nothing were physically cueing them into feeling guilty or stressed about the implications associated with their harmful actions then, relying on self-deception, there was no need to feel responsible. By placing the victim out of sight and/or neutralising their increasingly desperate screams, it became easier to keep them out of mind (as well as promoting the appearance to others present that because the subject apparently never saw/heard the learner's reactions, they could then deceive them by denying having known the learner was in pain). Therefore, via self-deception and/or the deception of others, avoidance-type behaviours could aid in reducing some subjects' feelings and/or appearance of being responsible for their actions.

\subsection{The Self-Invented Strain Resolving Mechanism of Positive Self-Image in Reducing}

\section{Feelings of Responsibility}

The pseudonymous Elinor Rosenblum was a self-styled pillar of the community, who believed herself "unusual; I'm softhearted, I'm a softy” (Milgram, 1974, p. 83). Not long into the experiment she encountered the moral dilemma: to withdraw or continue? She later admitted: "I was tempted so much to stop and to say: 'Look I'm not going to do it anymore. Sorry. I'm not going to do it' " (Milgram, 1974, p. 83). But as her repeated infliction of shocks indicated, the prospect of disobedience obviously involved a burden that, on behalf of the learner, Rosenblum was unwilling to shoulder. At the learner's expense, it was instead easier for her, albeit marginally, to continue administering the shocks.

Continuing to choose the path easiest for herself_-and well aware of what this decision meant for the increasingly pained learner-seemed to have stimulated, for all to 
see, her reaction of uncontrollable shaking. Perhaps fearing this nervous reaction might convey an awareness of wrongdoing, she attempted to justify her actions to the others present by offering an explanation that was compatible with her positive self-image: “ 'Must I go on? Oh, I'm worried about him .... Can't we stop? I'm shaking. I'm shaking'" (Milgram, 1974, p. 80). As Milgram observed: "She construes her expressions of tension purely as a sign of virtue: she was nervous because she cared about the victim" (Milgram, 1974, p. 83). But had Milgram's machine been real, Rosenblum failed to recognise that she was professing her concern for a person on whom she nonetheless inflicted potentially lethal shocks. According to Baumeister (1997, p. 307) the use of such "bizarre rationalizations" involves a twofold process:

First, the perpetrator wants very strongly to believe them. Second, they are superficially plausible enough that the person can accept them as long as he or she doesn't think about them very carefully .... Such a combination is apparently necessary for biased thinking or self-deception in general.

But Rosenblum's destructive actions spoke far louder than her "worried" words. Explicitly defining herself as opposed to her harmful actions had more to do with her bolstering a desirable positive self-image (Milgram, 1974, p. 162).

Although tempted to challenge the experimenter, the most she was willing to do for the learner was surreptitiously sabotage the experiment. As Rosenblum later said to the learner in a statement whose accuracy was corroborated by the measured recording of her performance: “ 'As a matter of fact I tried to push the switch down very lightly. Did you hear me stressing the [correct] word[?] I was hoping that you would hear me.' " (Milgram, 1974, p. 82). ${ }^{117}$ However, this admission of signalling to the learner only invalidated her justification for continuing: "It is an experiment ... . So I had to do it. You said so" (Milgram, 1974, p. 83). If she was just following orders for the betterment of science, why did she purposefully try to sabotage the experiment? It was actually common among subjects to inflict the briefest of shocks, in the way Rosenblum did. But, as Milgram (1974, p. 159) observed:

When interviewed, these subjects stress that they 'asserted their humanity' by administering the briefest shock possible. Handling strain in this manner was

\footnotetext{
${ }^{117}$ As was the case with Rosenblum: "Some subjects could be observed signaling the correct answer to the victims by stressing it vocally as they read the multiple-choice words aloud. That is, they attempted to prompt the learner and thus prevent his receiving shocks. These subjects are willing to undermine the experiment but not to cause an open break with authority .... The subject is unable to act openly on his humane feelings, deflecting them into a trivial subterfuge of no real consequence. Yet 'doing something,' even if of only token significance, helps preserve his self-image as a benign man” (Milgram, 1974, pp. 159160).
} 
easier than defiance. It permits the maximum expression of individual benignity within the constraints of an oppressive system. But there is an element of selfdelusion in this type of minimal compliance. It does not challenge authority. It may diminish but does not nullify the exercise of authority's will and is chiefly important as a balm to the subject's conscience.

A clearly embarrassed Rosenblum went on to justify her actions to the learner:

You're an actor, boy. You're marvelous! Oh, my God, what he [the experimenter] did to me. I'm exhausted. I didn't want to go on with it. You don't know what I went through here. A person like me hurting you, my God. I didn't want to do it to you. Forgive me, please. I can't get over this. My face is beet red. I wouldn't hurt a fly (Milgram, 1974, p. 82).

Rosenblum was left confused. She was not the kind of person who would normally do such a thing; she was a volunteer who taught "dropouts . . . . leather-jacket guys . . . . respect for people, respect for older people" (Milgram, 1974, p. 81). Rosenblum was convinced she was a good person, but she nonetheless sensed that this experiment implied that she was not so. In less than one hour, Milgram's experiment had challenged the credibility of Rosenblum's strongly positive self-image. Or had it?

In a questionnaire filled out months later, and thus with much time to reflect on the experiments' wider implications, Rosenblum again relied upon her remarkable capacity for the deception of others and/or herself. Apparently her " 'mature and well-educated brain' had not believed the learner was getting shocks" (Milgram, 1974, p. 84). ${ }^{118}$ Although at the time she experienced uncontrollable shaking, she seems to have convinced herself that people like her simply do not do such things, so actually she must have known the shocks were fake. The alternative explanations were simply inapplicable to a person of her calibre. Slater (2004, p. 40) observed of subjects like Rosenblum: "The power of Milgram's experiments lies, perhaps . . . in the great gap between what we think about ourselves, and who we frankly are."

Unlike Rosenblum, others were more willing to acknowledge the disconcerting gap between who they thought they were, and what they actually did:

The thought also occurred to me that for a supposedly highly civilized and, in my mind, 'soft hearted' person I had carried the experiment on a lot longer than I should have were I as 'soft hearted' as I had led myself to believe. (I try to make myself believe that it was because I had agreed to complete the experiment but

\footnotetext{
${ }^{118}$ Such post-experimental rationalisations were common. Another example: "Briefly, I am happy to have been of service. The money was donated to the cancer fund. You see, my interest lay in being of service" (SMP, Box 44, Divider “T.R.", Titled: (no label), \#2205).
} 
without much success). It makes me wonder if I would be a real 'resistance fighter' in the event that our country should ever find itself in the position of a France or a Denmark under occupation (SMP, Box 44, Divider “9”, \#0202).

Another subject later observed:

It has bothered me that I went all the way and obeyed the experimenter. At times I threatened to stop and refuse to go further, but I gave in and finished the experiment . . . . I consider myself better informed, and I hope more cultured then [sic] the average non-college graduate ... . In spite of all this I gave the same performance that the average slob, taken off the street, would probably have done. I consider this frightening (SMP, Box 44, Divider "Problems", \#1706).

One subject more succinctly recognised: "For me, personally, it was an awakening" (SMP, Box 44, Divider “13”, \#2001).

It is important to note that of all the BFs and SRMs involved, some were much more powerful than others. There was, in fact, one SRM, in particular, on which Milgram's high completions rates were almost totally dependent.

\subsection{The Supplied Strain Resolving Mechanism of the Shock Generator: The Most}

Powerful Mechanism Capable of Reducing Feelings of Responsibility

Milgram may have believed the shock generator to be an "important" SRM (Milgram, 1974, p. 157), but relative to his obsession with OTA, he never considered it absolutely critical in producing his results: "The precise mode of acting against the victim is not of central importance" (Milgram, 1974, p. 14). Although not a sufficient condition, the shock generator-the means of inflicting harm-was a most necessary one, probably the single most powerful element in the achievement in the high completion rates (Russell $\&$ Gregory, 2005). The following will explain why.

Subjects were aware that in flicking the switches on the shock generator seemingly inflicted much pain on the learner. The subject saw the learner strapped into a shock device from which they then also received a test-shock. Subjects therefore knew their actions were directly responsible for causing the learner's pain. But because they dreaded a direct confrontation with the experimenter that would result if they stopped what they were doing, many subjects became motivated not to know what they knew they were responsible for. Many sensed they might be able to avoid having to shoulder this burden 
of responsibility, by drawing upon a variety of supplied/self-invented SRMs. However, the shock generator had two characteristics that set it apart from all the other SRMs.

First, the shock generator, not the subject, inflicted blows (seemingly) strong enough to render another human being unconscious (if not dead). Secondly, this device could inflict these (supposedly) intense blows in the total physical absence of the initiating subject. The simultaneous presence of these two characteristics made it possible to physically separate: "the act [flick switches] and its effects [seemingly rendering the victim unconscious]" (Milgram, 1974, p. 39) therefore ensuring: "the victim's suffering possesses an abstract, remote quality for the subject. He is aware, but only in a conceptual sense, that his actions cause pain to another person; the fact is apprehended but not felt" (Milgram, 1974, p. 36). Being only conceptually aware of the victim's pain injected into the situation what this author terms ambiguous responsibility: potential confusion over who- the subject, experimenter, perhaps even the learner-was most responsible for the learner's painful experience. The shock generator made responsibility ambiguous because its separation of the act from its effect subtly prevented subjects from feeling and/or appearing as directly responsible as they in fact were for their harmful actions. If they did not feel and/or appear most responsible for the effects of their actions then, somewhat conveniently, perhaps in their own and/or others' minds, they were not responsible? Maximising or minimising the simultaneous use of these two characteristics most powerfully dictated whether Milgram obtained high or low completion rates.

The only condition that maximised the effect of the shock generator's two key characteristics was the Truly Remote Pilot study (initially termed the "no feed back" condition) in which, due to the way the shock generator was set up, from the start the subject never heard, could not see, and did not need to touch a person on whom they inflicted three consecutive 450-volt shocks. Although Milgram (1965a, p. 61) did not provide the exact figure, in this variation "virtually all subjects went blithely to the end of the board, seemingly indifferent to the verbal designations ('Extreme Shock' and 'Danger: Severe Shock')."

However, across the Proximity Series Milgram subtly changed the set-up of the shock generator, forcing subjects into hearing, seeing, and eventually feeling the harmful consequences of their actions. As the subjects' conceptual awareness that the learner was receiving shocks was gradually bolstered by these cumulative sources of perceptual information, the harder it became to convince themselves and/or others present that they 
themselves were not most responsible for their actions. For an increasing proportion of subjects, supplied and/or self invented rationalisations for continuing became, for themselves and/or others present, less believable. And for an increasing proportion of subjects across the Proximity Series, their sense of personal responsibility for what was happening to the learner became much stronger and eventually unavoidable (Remoteheard some banging on wall: 35 percent pulled out; Voice-Feedback-heard all verbal reactions: 37.5 percent pulled out; Proximity — saw and heard all reactions: 60 percent pulled out). As it became harder to deny responsibility for one's harmful actions, across the Proximity Series an increasing proportion of subjects felt a compelling obligation to pull out.

Of all Milgram's variations, it was the last of this series- the Touch-Proximity experiment - that least used the shock generator's potential to physically separate the learner from the perceptual implications associated with inflicting high intensity shocks. Participants were not only conceptually aware that their actions were producing pain, but across multiple senses they also became perceptually aware of this fact by seeing and hearing a man screaming in pain under the force of their own hands. The relationship between cause and effect—-the subject's actions and the learner's pain-was no longer ambiguous; and, consequently there was no ambiguous responsibility. Forcing the learner's hand on to the shock plate made it difficult for subjects to convince themselves (self-deception) and/or others present (deception) that they were not most responsible for the learner's painful predicament (70 percent pulled out). What might have sounded like a plausible rationalisation for continuing in the Truly Remote Pilot - "I had to do it. You said so"- - had by the early to mid stages of the Touch-Proximity experiment become for most subjects totally implausible. They had come to suspect that if blame were to be apportioned they could not convincingly rely upon the popular excuse that they were just following orders (or any other justification, whether it was supplied or self-invented) who would have been gullible enough to have believed them? Not helping matters was that for most subjects in this variation, relative to the intense stress associated with continuing to inflict further shocks, engaging in a confrontation had become the easier option. Particularly when faced with having to touch the learner, most subjects could not help but feel and/or appear most responsible for their actions. Thus, they felt obligated to shift out of the $S A D$ and return to the State of Autonomy. ${ }^{119}$

\footnotetext{
${ }^{119}$ Another inhibiting factor was that the learner in the last two experiments of the Proximity Series could see the subject: "the actions of the subject now come under scrutiny by the victim . . . His surveillance of the action directed against him may give rise to shame or guilt, which may then serve to curtail the action" (Milgram, 1974, pp. 38-39).
} 
Milgram incorrectly predicted that very few would complete the Touch-Proximity condition. He was surprised that almost a third of subjects completed this variation. However, this result is less surprising when one realises that although the Touch-Proximity condition had removed the shock generator's second characteristic (the potential to inflict pain remotely), it retained in full the first characteristic (the shock generator, not the subject, inflicted the seemingly forceful blows). This gives rise to a central question: what kind of results might Milgram have obtained in a variation where the means of inflicting harm was devoid of both characteristics? Hypothetically, speaking, it would not have been difficult to run what would have been the control experiment to the Truly Remote Pilot: simply remove the shock generator from the experimental paradigm. When one contemplates such an experiment, it becomes clearer just how central a role the means of inflicting harm actually played. Completing the experiment without the shock generator would have left subjects experiencing a physical connection between themselves (or some instrument/weapon) and the effects directly caused by those actions. Furthermore, the subject would not only have to feel (and thus see and hear) the implications of their actions, they would have to produce force of sufficient intensity to render the learner at least unconscious. Russell and Gregory (2005, pp. 333-334) have argued:

one need only consider what results Milgram might have obtained if instead of requiring participants to inflict punishment by means of the shock generator the participant had been required to administer some other, more direct, physical penalty. For example, how far would Milgram's participants have gone if they had been required personally to beat, bludgeon, or whip the learner, ultimately to the point of unconsciousness or beyond? Under such conditions, there would have been no 'lack of unity.'

Should any subjects have agreed to complete such an experiment, and increasingly beat the learner into at least a state of unconsciousness, to a far greater degree than in the Touch-Proximity condition, there could be no ambiguous responsibility. It would be indisputably clear who was responsible for the outcome. The shock generator was so central that, in fact, its absence would also have rendered all the previously mentioned BFs and SRMs useless. Physically striking the learner with immense force and then later explaining that they were "just following orders", that science required they do it, that the experimenter convinced them the learner would not be harmed, or, that the experimenter said he was totally responsible for the subjects actions, would most likely seem patently ridiculous to all involved (including the subject). It is quite possibly because they did not 
fully consider the impact of the shock generator that the psychiatrists approached by Milgram before the experiment predicted that only one in a thousand, a "pathological fringe", would complete the experiment (Milgram, 1974, p. 31).

Clearly, the shock generator injected ambiguity into the scenario, so again, there may be merit in Mixon's criticism that many a subject completed only because they were not exactly sure if the learner was being hurt. If subjects were led to believe that they were indisputably hurting another person (as they would in the above hypothetical variation), it is highly unlikely many would have agreed to complete. Although this issue will be addressed soon, not feeling and/or appearing responsible was of central importance. ${ }^{120}$

Establishing the shock generator as the key determinant of Milgram's high completion rates helps to reveal many connections beyond the laboratory walls. Directly influenced by and then creatively elaborating upon Milgram's (1974, p. 157) observation regarding the positive correlation between distance and the probability of subjects' completing the experiment, Grossman (1995) has hierarchically ranked various types of military weapons on the basis of physical distance separating those deploying them from their eventual victim/s. ${ }^{121}$ The greater the distance that certain weapons can be deployed from their target, the less is the resulting strain/guilt or, what Grossman more lucidly termed, resistance to killing. His thesis is succinctly captured in the graph below:

\footnotetext{
${ }^{120}$ Milgram asked one subject who completed the Relationship variation and shocked his friend, "Is there anything he could have said that would have gotten you to stop the experiment?" Subject: "I don't think so." Milgram: "Um, what if we ... gave you . . . a gun and said 'shoot him in the head', now seriously?" Subject: "Seriously ... if they gave me a gun to shoot him in the head I wouldn't have done it. I think my reasoning behind it . . . was this thing is set-up . . . . But the way I figured it, you're not going to cause yourselves trouble by actually giving serious physical damage to a body." Milgram: "Um, do you think that would have been the point where you would have not done it, if there were any kind of physical damage?" Subject: "Yeah, if it was open to my senses, as you say, if ahhrr, if a a [sic] gun [Mumble] I wouldn't [Mumble]. No matter what anyone told me concerning say phony bullets or anything like that" (SMP, Box 153, Audiotape \#2430).
}

${ }^{121}$ The connection between the OTA experiments and frequently relied upon methods of mass-killing has been made by both Milgram (1974, pp. 7-9, 38) and others (see Bandura, 1973, p. 177). 


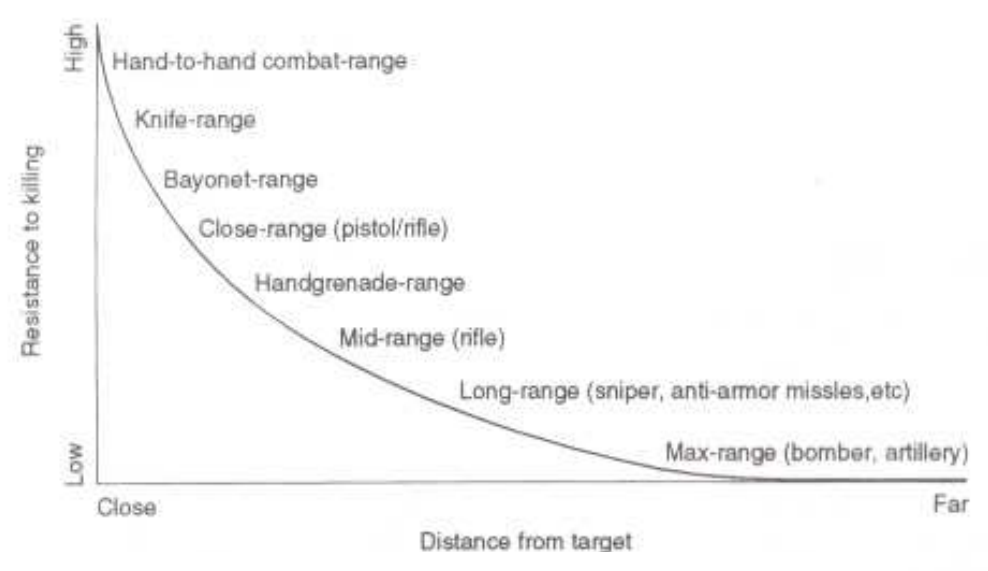

Figure 16: Distance versus resistance to killing (Grossman, 1995, p. 98).

Grossman has argued that resistance to killing diminishes with longer-range weaponry, because this technology inhibits the stimulation of potentially powerful emotions such as guilt, stress, trauma, and something not explored by Milgram, repugnance. As will be shown below, this may have implications for Goldhagen's “issue of cruelty".

In conflict with Grossman, there is believed to be a much stronger relationship between resistance to killing and stimulation of an aggressor's perceptual senses, than there is between resistance to killing and distance per se. Some of Grossman's own evidence lends support to this assertion. For example, according to Grossman, during the trench battles of World War One the grenade was one of the most popular weapons used against the enemy. It seemed to generate a lower resistance to killing than the longer-range rifle. According to the above graph, however, the hand-grenade should generate a higher resistance to killing than the longer-range rifle because it is frequently deployed from more proximate distances to the intended victim/s. In providing an explanation for this anomaly in his graph, Grossman points out that when attacking with a grenade the soldier must shield their body behind cover and close their eyes and ears to avoid being injured by their own attack. As a result, when killing: "grenades were psychologically and physically easier to use ... . [because] the killer does not have to look at his victims or hear them die" (Grossman, 1995, p. 113). In other words, killing with a grenade is psychologically easier than using a more distant rifle because, not having to see or hear their victim/s die, the person doing the killing experiences less perceptual stimulation. Resistance to killing therefore has a stronger relationship with stimulation of the aggressor's perceptual senses than it does with physical distance per se. This point may have relevance to the Holocaust: Germans pouring Zyclon B pellets through ceiling vents were separated from their many 
victims by only one or two metres (victims who could not be seen, need not be touched, and who could not be heard dying by the perpetrators if they, the perpetrators, quickly vacated the scene).

This author has synthesised the concept of perceptual stimulation with many of Grossman's insightful observations, to produce the following innovation on his above graph. At one end of what has been termed the killing method hierarchy $(\mathrm{KMH})$, and eliciting the highest levels of resistance to killing are methods like the following martial arts technique. The person killing is to:

Punch a thumb through ... [the victim's] eye and on into the brain, subsequently stirring the intruding digit around inside the skull, cocking it off toward the side, and forcefully pulling the eye and other matter out with the thumb (Grossman, 1995, pp. 131-132).

This method is believed to produce a higher resistance to killing than, say, using a sharp weapon in a piercing action (such as stabbing with a knife or bayonet), because to cause a fatality an aggressor must directly force, internally and slowly feel, clearly see, and hear their victim die. A sharp instrument used in a piercing action is likely to produce a greater resistance to killing on the part of an aggressor than similar instruments used in a slashing action (like slashing with a knife). The reason for this difference is: "To pierce is to penetrate, while to slash is to sidestep or deny the objective of piercing into the enemy's essence" (Grossman, 1995, p. 121). Next, a sharp instrument used in a slashing action is likely to produce a greater resistance to killing than a blunt instrument (like the butt of a rifle) used in a bludgeoning action. This is because bludgeoning does not require the victim to be attacked internally. Blunt instruments used in a bludgeoning action are likely to produce a greater resistance to killing than using a firearm, which itself-not the shooter-generates the force of the blow. The pulling of the trigger stimulates the firing of a projectile which takes a straight line path to its target. Although a firearm requires the person killing to see the consequences of their actions, unlike all the previously mentioned weapons/methods, they do not necessitate the establishment of a direct connection between the victim, the weapon, and the aggressor. Finally, a firearm involving a direct fire projectile is likely to produce a greater resistance to killing than a firearm involving an indirect fire projectile (where the projectile fired takes a curved or less direct path towards its target). Indirect fire projectiles, such as artillery, or in the case of intercontinental missiles, clearly eliminate tactile and auditory perceptual stimulation and, depending on the distance from and the course towards the target, can eliminate most if not all perceptual 
stimulation. It should be noted that this hierarchical ranking from high to low levels of perceptual stimulation also, albeit generally, moves in a direction of slow to more instantaneous methods of killing.

Increasingly over the last several centuries, particularly in the Western World, there has been increasing inventiveness of, and, as a consequence, proliferation and reliance upon perceptually benign killing technology — the bayonet to aerial bombardment, "hungdrawn-quartered" to the automatic lethal injection machine. Is it possible that the increasingly reliance on gradually more benign methods of killing may have sensitised subsequent generations of modern people to the comparably bloody "hands-on" methods of killing so heavily relied upon by their ancestors? The dearth of exposure to and experience when killing with the much more primitive technology/methods used by our ancestors may have increased modern people's resistance to killing with such weapons/methods. It is for this reason that the $\mathrm{KMH}$ probably has greater applicability to modern Westerners more than anybody else.

Other than having implications for Goldhagen's issue of cruelty, ${ }^{122}$ the KMH may also have potential as a heuristic device that enables one to objectively identify both how and why some methods of killing are psychologically easier to engage in than others (by ameliorating a range of inhibitory emotions such as guilt, trauma, and/or repugnance). For example:

certain forms of killing were less liable to incur guilt. This was particularly the case in the most anonymous forms of modern warfare. In aerial warfare, for example, there was a strong correlation between altitude and guilt .... Such anonymity in the slaughtering process even enabled the navigator of the Enola Gay, which dropped the atomic bomb on Hiroshima, to deny any adverse emotional reactions: he claimed to have 'come off the mission, had a bite and a few beers, and hit the sack, and had not lost a night's sleep over the bomb in 40 years' (Bourke, 1999, p. 209).

Obviously, this member of the Enola Gay crew was conceptually aware that his mission had just instantly killed tens of thousands of people. However, because he was able to

\footnotetext{
${ }^{122}$ Goldhagen provided only six examples of lethal violence where a direct physical connection was established between a German perpetrator, their weapon, and victim/s, causing the perpetrator/s to experience intense and unavoidable levels of tactile, visual, and auditory stimulation (see Goldhagen, 1996, pp. 301-302; $307 ; 351 ; 351 ; 358-359 ; 401)$. Such primitive technology, like for example the bayonet, was readily available (see Goldhagen, 1996, p. 217) but, relative to gassing and shooting, were rarely used to kill. The likelihood that fatal stabbings, bludgeonings, whippings, and beatings were actually relatively rare appears to have been lost on Goldhagen, who instead presents the reader with a myriad of non-fatal bludgeonings, whippings, beatings, verbal assaults and "bizarre and self-abasing acts" (Goldhagen, 1996, p. 386). This is a major weakness in Goldhagen's resilient second main argument—relating to gratuitous cruelty-because such lethal violence in the relatively unsophisticated killing institutions was by no means the norm.
} 
avoid becoming perceptually aware of all the human carnage he had just had a direct hand in creating, he could be a part of a team which could kill without actually feeling that they were killing. ${ }^{123}$

The type of negative psychological repercussions being referred to are those elicited by methods of killing that do require the victim to be heard, seen and, to some degree, felt. Consider, for example, a method of killing from the opposite end of the KMH spectrum:

An American who joined the Foreign Legion recalled bayoneting a 'young Fellow ... as delicate as a pencil'. For months afterwards he could not sleep 'for remembering what that fellow looked like, and how my bayonet slipped into him and how he screamed when he fell' (Bourke, 1999, p. 210).

In greater detail, an Australian by the name of I.L. Idriess (as cited in Holmes, 1985, p. 379) has described a bayonet attack he observed at the first battle of Gaza in 1917 as:

just berserk slaughter ... the grunting breaths, the gritting teeth and the staring eyes of the lunging Turk, the sobbing scream as the bayonet ripped home. ... Bayonetfighting is indescribable ... words are incapable of describing feelings. ${ }^{124}$

The psychological reactions to the killing of just one person with a bayonet stands in stark contrast to the responses felt by those complicit in the perceptually "benign" nuclear attack which, according to Glover (1999, p. 99), had killed 200,000 people by 1950 (a point readily conceded by those involved in bombing Japan). ${ }^{125}$

Obviously, means of inflicting harm like the shock generator and aerial bombardment are psychologically easier to deploy because they insert significant perceptual (but not conceptual) ambiguity into the destructive end results. This observation detracts from Mixon's $(1976,1989)$ criticism that ambiguity surrounding the outcome of the shocks on the learner contributed to Milgram obtaining high completion rates (and that less ambiguity would have resulted in lower completion rates). The fact that

\footnotetext{
${ }^{123}$ As World War Two bomber pilot J. Douglas Harvey later reflected in relation to a mission that targeted Berlin, " 'I could not visualize the horrible deaths my bombs . . . had caused here. I had no feeling of guilt. I had no feeling of accomplishment' " (Fussell, 1989, p. 143).

${ }^{124}$ See Grossman (1995, p. 124) for an exception to this general rule in the modern era.

${ }^{125}$ Paul Montgomery, who was involved in the bombing of many Japanese cities during World War Two has said: “ 'It's not like I was going out and sticking a bayonet in someone's belly, OK?' ” (Rees, 2001, p. 119, as cited in Rees, 2005, p. 293).
} 
Milgram purposefully created ambiguity in the experimental procedure-changing the last switch from saying "LETHAL" to "XXX"-may not, as Mixon would argue, mean that Milgram's results were methodologically flawed. What was important as far as the OTA experiments were concerned was that (1) Milgram ensured subjects believed that the learner was being shocked; and (2), irrespective of any purposefully inserted ambiguity, Milgram succeeded in ensuring a substantial majority of his subjects inflicted all the shocks. He succeeded on both counts. ${ }^{126}$

\section{$\underline{8.12 \text { Conclusion }}$}

The main (although not exclusive) reason why most subjects completed the Baseline experiment was that they found it easier to continue inflicting the shocks than to help the learner-which would have required they engage in a confrontation with the experimenter. In conflict with Milgram's agentic state, where subjects honestly did not believe themselves to be responsible for their actions (and were simply instruments of the experimenter), this explanation implies they knew they were acting immorally.

Consequently, Milgram's agentic state was replaced with the State of Autonomous Denial $(S A D)$ : a state of mind where subjects were aware that they were mostly responsible for their own actions, but due to the personal costs associated with shouldering responsibility for their actions and a suspicion they could act with impunity, they attempted to conceal this awareness internally (via self-deception) and/or externally (via attempts to deceive others present). A variety of opportunities (supplied and/or self- invented) facilitated "access" to the SAD, greatly aiding subjects in evading feeling and/or appearing responsible for their harmful actions.

However, the single most powerful mechanism, that in conjunction with an ideology that legitimised the infliction of harm, was undoubtedly the SRM of the shock generator. It was unique in that it physically ameliorated subjects' emotionally traumatic

\footnotetext{
${ }^{126}$ As Mixon $(1972,1976,1989)$ has argued, both his role plays and even Milgram's own results support the assertion that when it is made clear to subjects that the learner is being electrocuted, predicted and actual completions slump. Thus, Mixon believes that Milgram's high completion rates were due to his purposeful insertion of ambiguity surrounding the learner's fate. However, this thesis suggests that greater clarity over the learner's fate reduced the completion rate because it increased the subjects' feelings and/or appearance of responsibility for their harmful actions. Greater clarity also reduced the opportunities for subjects to pass the "responsibility-buck" for their harmful actions. When the consequences of our harmful actions are made clear (and therefore undeniable), we cannot later say that we "did not know", because we clearly did know. Of course, greater ambiguity over the learner's fate (as in Milgram's Truly Remote Pilot condition) produces the converse effect.
} 
experiences. The shock generator introduced what was termed ambiguous responsibility: confusion over who was most responsible for the learner's pain. In fact, it was the shock generator's attenuation of the strain of inflicting harm that infused an air of plausibility into all the other BFs and SRMs, whether supplied or self-invented. However, in the absence of the shock generator, there could be little if any ambiguous responsibility, and all the other SRMs and BFs would not have sounded nearly as plausible to the obedient subjects themselves and/or others present. In sum, this re-think suggests that Milgram's experimental paradigm was not about OTA per se, and much more about the subjects' resolution of a moral dilemma. Furthermore, the resolution of this dilemma meant that the subjects had to make a personal choice for which the outcome was strongly (although certainly not exclusively) determined by the availability of a wide variety of supplied and/or self-invented opportunities used with the intention of evading responsibility for their actions.

This conclusion is congruent with literature on the resolution of moral dilemmas. For example, Bandura's (1999, p. 194) concept of moral disengagement in the perpetuation of inhumanities, where "there are many social and psychological maneuvers by which moral self-sanctions can be disengaged from inhumane conduct." Bandura's mechanisms of moral disengagement include Moral Justifications, Euphemistic Labeling, Advantageous Comparisons, Displacement of Responsibility, Diffusion of Responsibility, Disregard or Distortion of Consequences; Dehumanisation, Attribution of Blame, and Gradualistic Moral Disengagement (most of which Milgram termed SRMs).

Nonetheless, a possible criticism of the above re-assessment is that, as with Milgram's theory, it focuses solely on explaining obedient subjects' actions while failing to explain why others, such as Milgram and his research team, also willingly participated in the experiments. It should be kept in mind that unlike the subjects who thought they were inflicting harm, Milgram and his team repeatedly participated in the actual infliction of harm. That "others" obviously condoned this duplicitous and in some ways inhumane experiment—particularly the experimenter and Yale University—was a significant factor for continuing in the eyes of most subjects. Obedient subjects regularly pointed out they would never have acted as they did on their own accord-that "others" were involved was, for them, central in facilitating their actions. Trying to explain the subjects' actions in the OTA experiments, without at the same time explaining the actions of all people involved in them, may inhibit a more comprehensive understanding of the human behaviour displayed 
therein.

The following chapter will complement the above individual/psychological explanation for most subjects' behaviour, offering a more group/structural/sociological explanation in regard to why Milgram, his research team, and their subjects did what they did. The chapter will apply a broader Weberian sociological lens to the OTA experiments. That is, Milgram's experimental programme will be viewed as microcosmic goalorientated bureaucratic process. 


\section{Chapter Nine: Milgram's Obedience to Authority Experiments as an Emergent Organisational (Bureaucratic) Microcosm}

You have all heard the saying that a bureaucrat is merely a cog in the wheel-it turns whenever the wheel is turning. As a political scientist, I have a different view: The bureaucrat drives the wheelwithout him, it would not turn-Hilberg (1980, p. 101).

By the time Milgram ran his first official experiment, an extensive goal-orientated organisational process had already been constructed around the subjects. The interdependent links in this structural chain included, among others, the inherently bureaucratic National Science Foundation (NSF) funding process, Yale's provision of facilities, the hiring then deployment of technical specialists, research assistants, and numerous actors, all with prescribed roles. Their respective contributions were to be coordinated by Milgram himself, the "project manager".

In the wake of insights generated by intellectual giants such as Max Weber, scholars have come to understand the inherently coercive power of the bureaucratic process in achieving particular objectives, irrespective of their moral status (Arendt, 1963, 1970; Gerth \& Mills, 1974; Hilberg, 1961; Rubenstein, 1978). Some of these coercive forces can include the chain of command (top-down authorisation of an order), bureaucratic momentum (Milgram's “swift-flowing stream” where individual links feel pressured by other links within the bureaucratic chain into performing their specialist role/task), and displacement/diffusion of responsibility (where responsibility for an eventual "negative outcome" is passed on and eventually dissipated across the numerous links in the bureaucratic chain).

It is tempting to believe that of the three above coercive forces, the chain of command was of greatest relevance to the obedience to authority (OTA) experiments. However, as this chapter will show, across the experiment's goal-orientated organisational process, of central importance was the displacement/diffusion of responsibility, whereby across the bureaucratic chain the person ultimately responsible for the destructive end result seemed to disappear. As discussed earlier, and as this chapter will reinforce, OTA is not just an inadequate explanation for Milgram's results, it may even be a misleading description of most subjects' behaviour. 


\subsection{Many Subjects "Obeyed" the Experimenter but did the Experimenter "Obey"}

\section{Milgram?}

Milgram's attention throughout the experimental programme was solely focused on the subjects' actions. But scholars like Harré have wondered why, unlike large proportions of actual subjects, Milgram's assistants never raised objections whilst they themselves were wreaking near "nervous collapse" (Milgram, 1963, p. 377) on many subjects:

Milgram's assistants were quite prepared to subject the participants in the experiment to mental anguish, and in some cases considerable suffering .... The most morally obnoxious feature of this outrageous experiment was, I believe, the failure of any of Milgram's assistants to protest against the treatment that they were meting out to the subjects (Harré, 1979, p. 106). ${ }^{127}$

Miller (1986, p. 123) has been critical of such arguments: “The accusation that Milgram's personnel were, themselves, obedient is, to say the least, novel. Where are the orders, the conflict, the tension, etc.? Were not these individuals investigating obedience rather than displaying it?" This counter argument is only valid if one views the experiments, as Miller does, solely through the lens of "OTA". Miller might have dismissed Harré's point but during the data-collection stage Milgram himself sensed a similarity between the subjects' seemingly harmful actions and his research team's actually harmful ones:

Consider, for example, the fact --and it is a fact indeed, that while observing the experiment I ---and many others-- know that the naive subject is deeply distressed, and that the tension caused him is almost nerve shattering in some instances. Yet, we do not stop the experiment because of this ... . If we fail to intervene, although we know a man is being made upset; why separate these actions of ours from those of the subject, who feels he is causing discomfort to another [italics added]. And can we not use our own motives and reactions as a clue to what is behind the actions of the subject. The question to ask then is: why do we feel justified in carrying through the experiment, and why is this any different from the justifications that the obedient subject's feel [italics added] (SMP, Box 46, Folder 163, Titled: “Obedience Notebook 1961-1970”). ${ }^{128}$

But why stop there? Milgram, the experimenter, and the learner were not the only ones involved in converting the OTA research idea into a reality. For example, why did the NSF funding agency, Milgram's employer-Yale University—and every other person and

\footnotetext{
${ }^{127}$ Brandt (1978, p. 65) pointed out that Milgram did what his subjects did-inflicted harm for "science". See also Helm and Morelli (1985, p. 624).

${ }^{128}$ This quote was largely in reference to the many observers who came to watch, but in using the collective pronoun "we" to "carrying through the experiment", it was also made in reference to the research team and himself, who all observed the same phenomena.
} 
group involved — research assistants, technicians, and administrators-make their ongoing contributions? And why did they do so when from the first pilot, or soon after, "it became evident" to most involved that many subjects in the official experiments "would experience" intense (therefore potentially dangerous) levels of "stress" (Milgram, 1974, p. 194)—what Meeus and Raaijmakers (1986, p. 311) would call "administrative violence"? A useful starting point to explore why all those individuals and groups behind the subject felt justified in carrying through the experiment might be to examine how Milgram drew them all into performing their roles.

\subsection{Getting All the Necessary Parties "On Board"}

Not long after the conception of his idea, and especially after running the first pilot, Milgram had discovered an effective way to get most subjects to complete his basic experimental paradigm. He convinced subjects by providing them with a rationale/ideology that, via moral inversion, condoned/legitimated the infliction of harm (a scientific study exploring the impact of punishment on learning). He then tempted them into participating by appealing to their needs and/or desires (by tapping into the common desire to avoid having to engage in a confrontation with the experimenter). However, the conversion of his idea from a rudimentary pilot study into a professional research programme was a large undertaking, necessitating his drawing upon the aid and expertise of many others. He required a significant research grant, professional laboratory facilities, a range of technical experts, technical equipment, and the hiring and management of research assistants, actors, and administrative personnel. If such an undertaking were not difficult enough, with the innocent subjects placed under immense stress, there was also a significant risk that at least some of the above individuals and groups might deem the experiments unethical and refuse to fulfil their role/s. To ensure that all remained committed to the experiment, as he did with the subjects Milgram needed to alleviate any such concerns should they arise.

Milgram drew in and eased the concerns of the following essential individuals and groups: (1) Milgram himself; (2) the NSF funding agency; (3) Milgram's employer and provider of facilities, Yale University; (4) Milgram's subordinate employees, specifically John Williams (experimenter) and James McDonough (learner). Much as he did with the subjects, Milgram convinced and/or tempted all of them into fulfilling their necessary yet frequently harmful contributions. Many of these human links in the bureaucratic chain 
encountered moral dilemmas of their own because, just like the subjects, their participation also required them to inflict harm. To resolve these dilemmas, it can be argued they were also influenced by certain Binding Factors (BFs), and drew upon various supplied and/or self-invented Strain Reducing Mechanisms (SRMs).

\subsubsection{Project Manager: Stanley Milgram}

The first person Milgram needed to draw in was, in fact, himself. He pursued his idea probably because of a suspicion that the basic idea fitted both his ambition to pursue, as Blass earlier argued, a "phenomenon of great consequence", and because from the first pilot he sensed he had tapped into something which helped to explain the Holocaust. On the downside, having observed the pilots, Milgram knew subjects would experience intense stress. However, he firmly believed that the experimental procedure was harmless (Meyer, 1970, p. 132). Consequently, from start to finish, Milgram never publicly expressed any ethical or moral reservations regarding his own research programme. For Milgram, the rationale/ideology that legitimated the infliction of harm seems to have been the contradictory belief that the experiments were actually harmless. After observing the first pilot study, Milgram was sufficiently convinced and tempted into pursuing the idea to its eventual conclusion because (at least outwardly) he believed the seemingly negative effects to be benign (SRM) and potential implications on understanding the Holocaust immense (BF).

\subsubsection{Funding Agency: NSF}

As conveyed in their motto "where discoveries begin", ${ }^{129}$ the NSF's core organisational objective has long been to fund potentially innovative research (BF). In his second research proposal, Milgram used keywords and phrases that probably caught their attention. His idea was "a relatively unexplored domain of social behavior", where the "Pilot studies ... yielded unexpected results of considerable interest" that observers apparently found "startling" (SMP, Box 45, Folder 160 Titled: “Grants 1961-1967”). The NSF panel was clearly impressed, describing the idea as "a bold experiment on an important and fundamental social phenomenon" (Blass, 2004, p. 72). That the NSF committee sensed the potential significance of Milgram's idea to perhaps shed new light

\footnotetext{
${ }^{129}$ Retrieved October, 2008, from: http://transcoder.usablenet.com/tt/www.nsf.gov/about/glance.jsp
} 
on how something like the Holocaust could occur, added greatly to their willingness to

fund the project. ${ }^{130}$

However, early on there was one major hurdle to be overcome: the NSF was repeatedly concerned about subject safety. The NSF was so nervous about this issue that before deciding to become formally involved, they visited Milgram at Yale University. The NSF's moral dilemma of whether or not to fund this potentially unethical study was largely resolved by Milgram's strain-resolving assurances that no subjects would be harmed (Blass, 2004, p. 71) and that all would receive a thorough debriefing (SRM). ${ }^{131}$ The NSF was convinced by the rationale/ideology that the experiments were harmless (SRM), which allowed them to condone the infliction of harm on people. In the end the NSF appears to have felt that, in terms of subject safety, it had done all it could, that is, short of refusing to fund the project. Thus, the NSF decided to financially support Milgram.

\subsubsection{Facilities: Yale University}

Yale University-Milgram's provider of laboratory facilities, and his employer-is a research-based institution whose reputation had long been dependent on the continued production of new knowledge (BF). This commitment to the production of new knowledge probably tempted Yale into supporting their employee's experimental endeavors. Milgram told Herbert Winer (a subject in the experiment and, at the time, also an assistant professor at Yale), that the OTA "proposal had been approved at the level of the president's office, and that a lot of people knew about it, and they all felt that the objective justified whatever [the] risks [italics original]" (Blass, 2004, p. 117). If Milgram was telling the truth, Yale saw no dilemma and, with the NSF eager to generously fund a project it described as "bold" and "fundamental", the university seems to have had no doubts about backing Milgram's proposal.

\footnotetext{
${ }^{130}$ Milgram candidly expressed this apparent connection in early correspondence with NSF committee head Henry Riecken (Blass, 2004, p. 100).

${ }^{131}$ See SMP, Box 45, Folder 160, Titled: “Grants 1961-1967”.
} 


\subsubsection{Milgram's Key Subordinates: John Williams (Experimenter) and James}

\section{McDonough (Learner)}

Methodologically, the OTA experiments required that the same learner and experimenter be used throughout, lest their premature departure result in replacements introducing potentially confounding variables to the programme (SMP, Box 43, Folder 128, Titled: "Correspondence 1962"). ${ }^{132}$ Milgram needed to retain McDonough and Williams until the end. However, unlike the other more remote contributors, the experimenter and learner were proximately involved in the infliction of intense stress upon an innocent person, therefore rendering their own tasks inherently stressful. The experimenter and learner were at greatest risk of refusing to participate or, at any stage during the programme, resigning. This was particularly so for the experimenter, who was employed to hound subjects into inflicting further shocks on the learner (occasionally resulting in him being threatened with violence ${ }^{133}$ ). Securing the long-term participation of these two key members was obviously going to be more difficult than for the above, more remote, groups.

Milgram's recruitment strategy for the front-line experimenter position was initiated on 26 July 1961, when the following advertisement ran over several days in the New Haven Register:

ASSISTANT IN RESEARCH to supervise physcological [sic] experiments concerning memory and learning process. Age requirement 30 to 50 years., [sic] college education preferred but not necessary, evening hours and-or weekendsideal for school teacher seeking additional employment. Please apply at Yale University personnel office, 143 Elm St., New Haven. m-S (SMP, Box 46, Folder 163, Titled: "Obedience Notebook 1961-1970”).

This strategy was similar to the one Milgram used to attract subjects: an offer to earn extra income under the pretense of participating in experiments concerning "memory and learning". ${ }^{134}$ Milgram attracted his ideal person for the "experimenter" role: John Williams was a high school teacher presumably interested in additional employment (to

\footnotetext{
${ }^{132}$ The exception to this was obviously the Change of Personnel variation, in which Milgram tried to determine the power of his usual experimenter/learner team.

${ }^{133}$ One subject later asked Williams: "Has anyone ever physically attacked you?" Williams responded: "Once or twice" (SMP, Box 153, Audiotape \#2430).

${ }^{134}$ Milgram could hardly have said in the local newspaper what his experiments were actually about. The first four lines in Milgram's (1974, p. 15) advertisement to attract subjects were: "Public Announcement WE WILL PAY YOU \$4.00 FOR ONE HOUR OF YOUR TIME Persons Needed for a Study of Memory *We will pay five hundred New Haven men to help us complete a scientific study of memory and learning."
} 
supplement his income).

Milgram's strong desire to select staff likely to remain until the end of the project was reflected in the notes he took during his interview with James McDonough, the person chosen to fulfil the learner role. Milgram noted that McDonough had worked loyally for the "Railroad [for] 25 years and is completely reliable", was "willing to work for 1 year" and, because he "has 8 Children", even if the job was not really about "memory and learning", he would presumably be desperate for the extra income (BF), and unlikely to leave. $^{135}$

After getting their foot-in-the-door into the Yale University personnel office (as the ad literally instructed) (BF), Milgram would soon after have to disclose to Williams and McDonough what the experiments actually entailed and what was required of them, respectively. Although McDonough's part was obviously quite taxing, the entire experimental programme hinged on the willingness of Williams to repeatedly perform his role.

Although Milgram's immediate research team was well aware subjects would find the experiments highly stressful— "we know a man is being made upset" (SMP, Box 46, Folder 163, Titled: “Obedience Notebook 1961-1970”)—after observing some of the pilot runs, they may have been convinced by the experimental programme's potential significance. As Williams explained to one subject during the post-experimental debrief:

we had to ... set you up this way so to speak because ... we want you to really think ... you're really paining this guy ... but we feel that the results from the experiments will be ahhrr very important and actually be of tremendous value (SMP, Box 153, Audiotape \#2304).

For Williams, the infliction of intense stress had been morally inverted into something much more positive. Williams' post-experimental justification reflects the rationale/ideology condoning the infliction of harm that Milgram instilled into his research team: "We don't like to fool you this way but ahhrr it must be done" (SRM) (SMP, Box 153, Audiotape \#2433). Milgram believed the research had to be carried out because, under the legitimating ideological banner of scientific inquiry, the programme was uncovering insights into the "disease" of "destructive obedience". Dannie Abse (1973, p. 29) well captured how Williams could treat subjects so callously: "in order to demonstrate

\footnotetext{
${ }^{135}$ Hornstein's (1986) "results show that managers who have children (and who therefore bear the heavy financial burdens associated with childrearing) are particularly unlikely to challenge their superiors on any issue" (Brief et al., 1995, p. 181).
} 
that subjects may behave like so many Eichmanns the experimenter had to act the part, to some extent, of a Himmler." Milgram had unwittingly provided his research team with a slightly different "acceptable rationale" with which to legitimate the infliction of harm on an innocent other.

But Milgram was aware that providing McDonough and especially Williams with a convincing rationale/ideology would probably, on its own, prove insufficient in securing their committed participation. He needed to repeatedly bolster this rationale/ideology by appealing to their specific needs and/or desires. Milgram suspected pecuniary reward would prove most effective in securing their long-term loyalty. As he explained in a letter dated 14 February 1962 to the NSF in an eventually successful request for further funding:

Why supplemental support just now? Additional support is needed immediately to preserve the continuity of research. A tightly organized experimental team has been functioning effectively since August, 1961 . . . It would not be possible to hold this able group of workers together unless the work and salary payments were continuous (SMP, Box 43, Folder 128, Titled: “Correspondence 1962”).

Milgram could maintain his research team by providing them with regular income (BF), and repeatedly raising the hourly rate would only increase this BF's effectiveness. Two weeks after sending the above letter, on 1 March 1962, Milgram offered Williams and McDonough their third successive pay increase in eight months. ${ }^{136}$ Yet Milgram had other strategies of financial reward to better ensure the unquestioning loyalty of his immediate research team. Upon completing the research programme, Milgram offered McDonough and Williams the option of an immediate one-off $\$ 100$ cash bonus, or an eventual two percent cut in the American book royalties (both accepted the more immediate bonus) (SMP, Box 43, Folder 128, Titled: “Correspondence 1962”). But because the role of Williams was by far the most stressful and dangerous, Milgram had to go further. Two months before the end of the data-collection phase (and heading into the particularly unethical and predictably highly stressful Relationship variation) Milgram awarded Williams (a temporary part-time casual worker) full-time Yale University employee benefits. $^{137}$

\footnotetext{
${ }^{136}$ Williams hourly rate in September 1961 was $\$ 2$, by November 1961 it was $\$ 2.20$, and by March 1962 it had risen to $\$ 2.40$. McDonough's hourly rate in September 1961 was $\$ 1.75$ by November 1961 it was $\$ 2.00$, and by March 1962 it had risen to $\$ 2.25$ (SMP, Box 43, Folder 127, Titled: "Correspondence 1961"; SMP, Box 43, Folder 128, Titled: "Correspondence 1962").

137 "March, 31, 1962 TO WHOM IT MAY CONCERN: This is to certify that Mr. John Williams, residing at Route 6, Southbury, Connecticut, is a full-time employee at Yale University, and is entitled to the relevant employee benefits .... Yours truly, Stanley Milgram Assistant Professor" (SMP, Box 43, Folder 128, Titled: "Correspondence 1962").
} 
In sum, it would seem the key to Milgram implicating himself, the NSF, Yale University, McDonough, Williams (and in all probability, every other person involved not mentioned here), came by way of the provision of a sometimes different yet convincing rationale/ideology that legitimated the infliction of harm (the belief that the experiments were harmless and/or important). This rationale/ideology was bolstered by his appealing to each of his team's often different needs and/or desires. Thus, to secure the acquiescence of each individual and group in fulfilling their role would seem to have had much to do with Milgram predicting then applying what he suspected might be the most successful motivational formula. Upon agreeing to participate, there quickly followed a string of cementing BFs and many supplied or self-invented SRMs. Regardless of the content of these BFs and SRMs, the individual contributions which followed all moved in the same direction-participation in the infliction of harm. Although all the above individuals and groups, in some way gained from participation, they came to believe the experimental results would be of "tremendous value" and, despite any evidence to the contrary, they were told and/or believed the procedure to be harmless. Although subjects also arguably benefited from participation (avoiding the burden of engaging in a confrontation), they too could feel justified in contributing to science (and, as they too were told, doing so was apparently harmless). There existed then a common thread connecting the basic thought processes of the "obedient" subjects, Williams, McDonough, Yale, the NSF, through to even Milgram himself. That is, via different routes, all had been convinced and/or tempted into making their actual or seemingly harmful contributions. ${ }^{138}$ From this perspective it would seem Milgram and his research team had much more in common with the "obedient" subjects than they ever might have imagined.

Milgram required the experimenter, learner, and subject all to engage in remarkably similar functions. And best illustrating this point is that, had Williams or McDonough expressed any ethical concerns, followed by intentions of resigning, it is not difficult to imagine Milgram imploring them to "Please continue". To preserve the research programme's methodological strength: "The experiment requires that you continue"; and,

\footnotetext{
${ }^{138}$ Milgram's approach in getting everyone onboard mirrors Breton and Wintrobe's (1986, p. 909) model of bureaucracy whereby, "superiors and subordinates, in effect, trade with each other. Superiors seek to buy 'informal services' - that is, services that cannot be codified in formal documents and that are the result of the initiative and enterprise of subordinates - to advance their own ends; in exchange they are willing to make 'informal payments,' which can include more rapid promotions, better offices, travel and signing privileges, use of company car, and so on, all quid pro quos that are not part of formal contracts."
} 
"It is absolutely essential that you continue". Concerned about the harm they were inflicting, Milgram might have then assured his teacher/learner team that although "painful" there would be no "permanent damage, so please go on". In fact, with respect to the continued provision of funding, facilities and overall management of the experiments, Milgram could have used the same line of reasoning with the NSF, Yale, and even himself, respectively.

However, upon all of the above individuals and groups making their small but necessary contributions, something very subtle took place that was of central importance to the manipulative power of the experiments. Although some subjects were on the brink of "nervous collapse" (strongly indicating that the experiments were harmful), Milgram's reassurances to all those involved that the procedure was harmless implied that if any subjects were harmed, he would accept all responsibility for their contributions. Therefore, all the others involved may have sensed the existence of an opportunity: they could probably continue reaping whatever benefits were associated with participation, and do so with impunity. And although the learner appeared to the subject to eventually have been left at least unconscious (rendering the experiments almost certainly harmful), the experimenter's prods that the shocks were not dangerous and implied/explicit acceptance of total responsibility conveyed the same message. That is, the subjects sensed they too could continue reaping the rewards for continuing (confrontation avoidance) with impunity. Ironically, upon completion many subjects probably thought the experimenter was most responsible, while the experimenter probably thought that Milgram was most responsible. But not actually having directly hurt anyone, perhaps Milgram also did not feel totally responsible. If this was indeed the case, then clearly the person ultimately responsible for the seeming or actual infliction of harm was always someone else and the person responsible had evaporated.

There exists, however, a good explanation for how it is possible for the person responsible to disappear. In agreeing to participate, all of Milgram's helpers had unwittingly become links in an intrinsically coercive and strain-resolving goal-orientated organisational chain of Milgram's making. 


\section{Organisational Process}

Having studied political science as an undergraduate student, Milgram had some understanding of the nature of bureaucracy. In the Peer Administers Shocks condition (92.5 percent completion rate), Milgram came to suspect he had captured elements of this organisational tool in the controlled laboratory setting. This condition was where subjects were ordered to perform the subsidiary task of directing questions to the learner, while for any incorrect answers received, another subject (actually an actor) administered the shocks. Those that completed often later explained that they did not believe themselves responsible for the learner's painful experience because, unlike those administering the shocks, they did not inflict pain on anyone. Yet in the first four variations (the Proximity Series), where subjects did flick the switches, those who completed were more inclined than defiant subjects to shift the blame to either the experimenter or learner (Milgram, 1974, p. 203). With its inherent characteristic of the division of labour- "fragmentation of the total human act"-and the person seemingly responsible having evaporated, Milgram sensed strong parallels between the potentially destructive bureaucratic process and the Peer Administers Shock condition. Generalising beyond the laboratory, Milgram (1974) argued: "Perhaps this is the most common characteristic of socially organized evil in modern society" (p. 11).

Milgram may have been aware of the coercive power of the potentially destructive bureaucratic process. But he seems to have been completely oblivious to the fact that as he co-opted all the parties into participating, behind the subjects lay what had unobtrusively grown into a goal-orientated bureaucratic process (that aimed to insure that subjects at the last link in the chain inflicted every shock). 


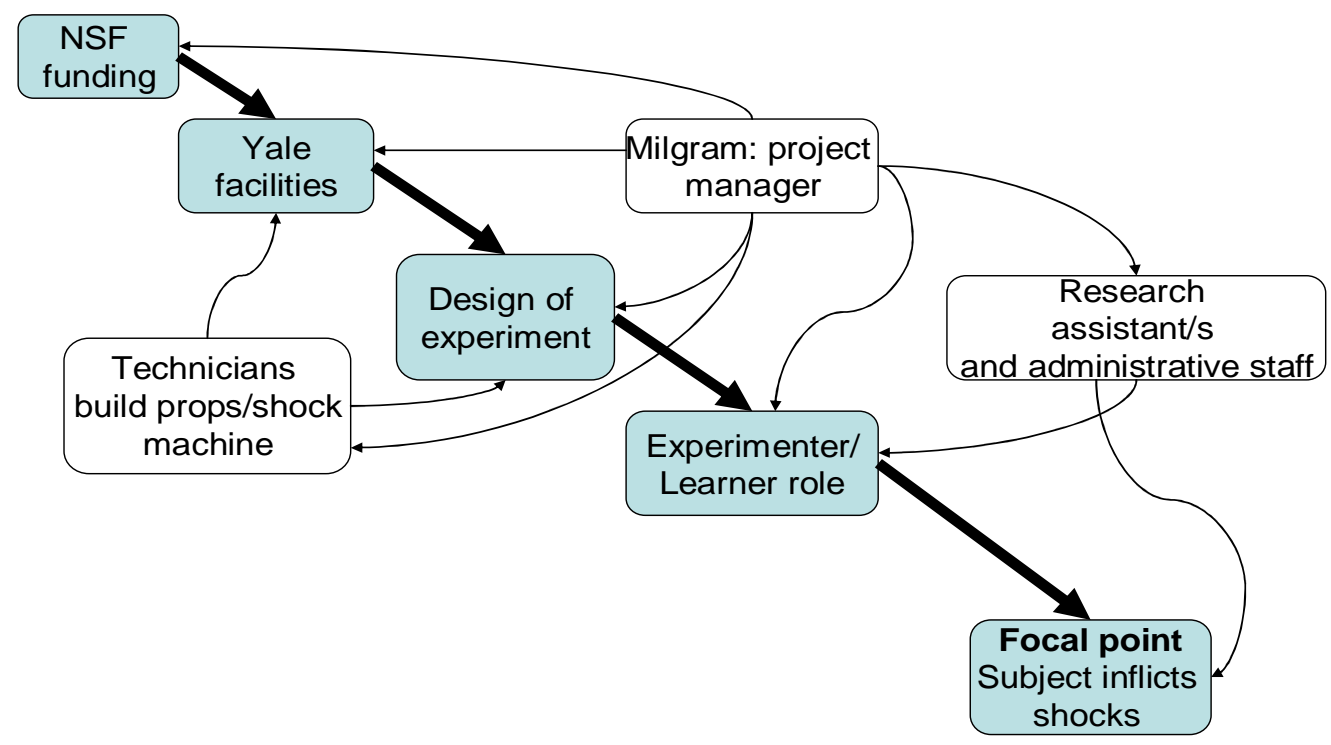

Figure 17: The OTA research programme's goal-orientated organisational process.

Fragmentation of the total act may, as Milgram (1974, p. 11) noted, aid modern organisational structures by obfuscating personal responsibility in a bureaucratic hierarchy; but this observation was equally applicable to every person working within his own harmful bureaucratic process.

To show that the displacement/diffusion of responsibility may also have been applicable to every functionary involved in the OTA experiments' bureaucratic processfrom the subject, to Milgram himself, the subordinate staff, and his superiors at Yale and the NSF-the following hypothetical scenario may be considered. What would have happened if some ex-subjects, armed with compelling evidence, lodged a civil case against all of those involved in the OTA experiments, claiming that in some way they had been seriously harmed by having participated? How might Milgram and all those others involved have responded to a thorough investigation with the sole intention of establishing who was to be held responsible for the harm inflicted? Any answer to such a question must be speculative. However, as was the case with most subjects' responses to Milgram's post-experimental interviews, it is hard to imagine that any of his sponsors/helpers would have been eager to claim total responsibility for having seriously harmed the innocent subject/s, especially in the face of possible civil action.

It could be argued that Williams and McDonough personally gained from participation in the experiments, at the subjects' expense. However, if they had been faced 
with an investigation, they would probably have experienced a strong temptation to argue that they were only doing what Assistant Professor Milgram-the expert clearly in charge — told them to; that they were "just following orders". G. Perry (personal communication, August 21, 2008) interviewed the learner's son Bob McDonough who stated: "No one questioned the ethics of it until later saying, you know was it right for him [James McDonough] to put people through this? And everybody said, Nah, it's Milgram's fault (laughs)." Later in the interview McDonough's son said: "I don't think he questioned the ethics of it so much and maybe he was doing what he was told."

Williams and McDonough could certainly have used obedience as an explanation, and what they did largely fitted the description of "obedience". But is "obedience" really an accurate explanation, or even description, of what they did? Williams and McDonough could point out that they would not have engaged in such actions on their own accord and that, as Milgram proclaimed publicly, their employer had assured them that the procedure was harmless. Consequently, one could well imagine the entire research teamparticularly those nearer to the harm-infliction end of the process-pointing an accusatory finger of responsibility in Milgram's direction.

The Yale University president's office and the NSF panel probably believed that their organisations would gain from their close association with the experiments. However, a burdensome civil case against them would render any such connection unfavourable; so it seems plausible that they too would have argued that Milgram had assured them that the experiments were harmless.

It seems reasonable to assume that with the potentially detrimental repercussions of a civil case hanging over them, all links in the chain would have felt a strong inclination to turn on Milgram - if someone had to be held accountable, why should it be any one of them?

Milgram could have faced financial ruin and an abrupt end to his academic career, so he too would have been strongly inclined to try and avoid being held culpable for having harmed innocent people. He could have claimed that he should not be held totally responsible because he genuinely believed the experiments to be harmless. ${ }^{139}$ He could also have presented a number of other mitigating circumstances. For example, he might

\footnotetext{
${ }^{139}$ Although he did so after it was clear that nobody had been hurt, Milgram (1964a, p. 852) stated: "This author accepts full responsibility for the design and execution of the study."
} 
have admitted that he had underestimated the dangerousness of the experiments, and that the harm inflicted was actually an unforeseen and unfortunate accident. Milgram could even have suggested that he never intended to harm anybody and was only motivated by the very best of intentions: to better understand, perhaps even help prevent, a future human tragedy like the Holocaust. Moreover, Milgram might have pointed out that when running the experiments he was a lowly assistant professor, in his late twenties. The implication being that the supportive NSF and Yale University deserved some of the blame for letting such a person, fresh out of graduate school and totally unsupervised, pursue such a potentially controversial project. In response, one might imagine a defensive NSF and/or Yale University retaliating that Milgram was the dominant driving force behind the study. Both the NSF and/or Yale could even claim that had they known what Milgram was actually doing they would have shut down the OTA research programme.

Milgram could have suggested that the experimenter deserved some of the blame because, as if on a personal mission to crack the nerves of subjects, Williams frequently deviated from using only the seven prods that Milgram had earlier stipulated (Darley, 1995, p. 130; Lutsky, 1995, p. 61). As the following will show, on encountering insubordinate subjects Williams often invented his own, far more stressful, responses. Williams might have responded to this accusation by pointing out that Milgram never once corrected him, thus implying tacit consent. Milgram could then have pointed out that, unlike Williams, he himself never actually hurt anybody, yet was being burdened with shouldering all the responsibility.

Had there been such an investigation, and had everyone involved sought to "pass the buck" or run for moral cover, perhaps only then would Milgram (1974, p. 11) have come to realise the relevance of his words regarding not only the Peer Administers Shock condition, but also all those working within his organisational structure:

Thus there is a fragmentation of the total human act; no one man decides to carry out the evil act and is confronted with its consequences. The person who assumes full responsibility for the act has evaporated. Perhaps this is the most common characteristic of socially organized evil in modern society.

Nearing the end of the book, Milgram commented on several disconcerting historical events with reoccurring administrative themes (with particular reference to the trials of Henry Wirz, Adolf Eichmann, and the perpetration of the 1968 My Lai massacre in Vietnam). Although nobody died, Milgram's (1974, pp. 186-187) comments are still applicable to all those who worked within his own organisational structure: 
We find a set of people carrying out their jobs and dominated by an administrative, rather than a moral, outlook .... Euphemisms come to dominate language ... guarding the person against the full moral implications of his acts.... Responsibility invariably shifts upward in the mind of the subordinate .... The actions are almost always justified in terms of a set of constructive purposes, and come to be seen as noble in the light of some high ideological goal .... psychological adjustments come into play to ease the strain of carrying out immoral orders .... where social relationships, career aspirations, and technical routines set the dominant tone.

Although this scenario is speculative, it does illustrate that had there been such an investigation, all involved in the experiments could have generated self-exculpative arguments. It also demonstrates that all those involved were little different from those subjects who completed the experiment and then tried to justify their actions by arguing that they were not responsible for what they did.

However, there is evidence that some of those people further up the hierarchical chain knew much more about the potential for harm than they were publicly willing to admit. Much like the subjects who completed, the intentions of those who converted the experiments into a reality may not have been nearly as innocent as they might later have suggested. For example, the NSF which, despite frequently raising concerns about the potential for harm, was eventually convinced that Milgram's procedure was safe. But just in case: "the committee raised the question with their general counsel of who would be responsible - the National Science Foundation or Yale - for any negative effects on the subjects. The [NSF] lawyer thought that Yale would be legally responsible" (Blass, 2004, p. 71). Therefore, as it turns out the NSF committee were actually aware of the possibility of harm being done to the experimental subjects. But having sensed they could probably make their essential contributions to the process with legal impunity (Yale was responsible), they deemed it safe enough to risk the welfare of innocent people. However, if the NSF thought Yale had intentions of shouldering full responsibility for any injurious effects on the subjects, they were in for a surprise because, as the last line of the following statement from a document dated "October 16, 1961" illustrates, Milgram deemed it prudent to incorporate within his experimental procedure a precautionary indemnity clause of his own:

A fu ther [sic] small difference in this condition is this: in the 4 earlier conditions the payment of the check was so arranged that it was only the naive subject and not the victim who received payment and signed the receipt and release. This was done because it was felt that many subjects would use the fact of the victim's having signed the release to justify their own action, and did not want this to happen. So we devised the procedure whereby--after the victim is strapped in the chair the 
experimenter 'rmembers' [sic] the check, but by them [sic] it is too late so that only the naive subj ct $[\mathrm{sic}]$ can sign therelease [sic]. [The release, of course, was not used for experimental purposes, but to protect us against legal claims [italics added].] (SMP, Box 46, Folder 163, Titled: “Obedience Notebook 1961-1970”). ${ }^{140}$

If Milgram genuinely believed his own public statements that the OTA experiments were harmless, why then did he feel the need to introduce what appears to have been such a patently underhanded legal measure? In other words, he was either self-deceived or deliberately disingenuous. His actions speak louder than his words: as was the case with the NSF, Milgram (perhaps Yale University) ${ }^{141}$ was clearly aware of the possibility that subjects might be harmed. Having introduced legal protections, and consequently believing that his employer (Yale University, therefore himself, and his employees) would be legally blameless, perhaps during his quest for dramatic results Milgram also sensed an opportunity that he might be able to act with relative if not full impunity?

So some of those in higher positions of authority, like the NSF, Milgram (and perhaps Yale University), definitely knew there was a risk of harm to the subjects. And nor were the lower order functionaries "just following orders". Williams, for example, as Milgram (1974, pp. 21-22) stated in his monograph, was meant to react to the subjects' resistance with just a handful of clearly specified sequential prods. Instead, it was not unusual for Williams to stray from his prescribed role and invent his own vigorously demanding lines (Darley, 1995, p. 130). For example, so he could stop inflicting the shocks, one subject offered to return the $\$ 4.50$, evoking Williams' response: "The money is not the issue ... it's essential that you continue the experiment." The subject then offered to change places with the learner, eliciting a forthright rejection from Williams: "No we can't do that once we've started ... . You have no other choice Teacher, please continue ... The next word is 'rich' " (SMP, Box 153, Audiotape \#2430).

Another subject wanted to talk to the learner, upon which the experimenter stipulated: "There is to be no contact between the teacher and the learner until the test is over." Then, as the subject procrastinated, the experimenter barked: "I don't understand what the problem is?" (SMP, Box 153, Audiotape \#2322). The subject explained his concerns

\footnotetext{
${ }^{140}$ Milgram (1974, p. 64) mentioned a general release form signed by subjects.

${ }^{141}$ Further research may be required to establish if this release was initiated by Milgram or whether it was a stipulation upon which Yale's continued support was contingent. If Yale officials had initiated this legal waiver, they probably believed that it protected the university against any legal culpability. They therefore had to concern themselves only with the potential advantages of being associated with such an innovative project.
} 
about the possibility of being held responsible for hurting the learner, to which Williams responded: "Well I am legally responsible” (SMP, Box 153, Audiotape \#2322).

As forceful as Williams could be, he would point out to subjects during the debriefing that his actions were not personal-he did not "like to fool" them. Why then, with such purpose, did he treat subjects during the experiments with such callous disregard? Williams may have been influenced by what Friedrich (1946, p. 589) has termed the "rule of anticipated reactions", which according to Brief et al. (1995, p. 180):

implies subordinates may, and are expected to, ask themselves, 'How would my superior wish me to behave under these circumstances?' Thus, the implementation of authority does not necessarily require that a command be uttered; rather, the 'order' may be implicit.

About as close as the OTA experiments ever got to Orne and Holland's (1968) demand characteristics, was when Williams anticipated what his employer desired: maximisation of the completion rate. ${ }^{142}$ Cognizant from the start of the ultimate goal, Williams frequently displayed great feats of bottom-up innovation in the invention of progressively more coercive (stressful?) prods in trying to bring about what he sensed his boss desired. For example, in one of the experimenter/teacher exchanges presented in Chapter Seven, a rather sceptical subject suspected that his friend/learner in the Relationship condition was not actually being shocked. Although on this occasion his attempts to ensure that this subject completed the experiment failed, Williams' response is an excellent illustration of just how shrewd he could be in parrying a subject's attempt to break free:

Teacher: "I don't believe you were giving him the shock ..."

Experimenter: "Well if you don't believe that he's getting the shocks, why don't you just continue with the test and we'll finish it?" (SMP, Box 153, Audiotape \#2439).

The regularity with which Williams strayed from his script suggests that Milgram never attempted to correct him, and therefore probably approved of Williams' actions. In any case, if Williams had kept faithfully to Milgram's seven prescribed prods, it would have been impossible during the experiments to convincingly answer the subjects' wide variety of unpredictable questions.

\footnotetext{
${ }^{142}$ As Darley (1995, pp. 130-131) has argued: “The experimenter's answers to the teacher's queries reveal that the experimenter had defined his role as doing whatever was necessary to get the teacher to continue giving the shocks [italics original]."
} 
Williams' tenacity in precluding the subjects' escape was probably due to him trying to secure his employer's desire (while both knowing he could act with impunity and that he would be rewarded for doing so). Had anyone been harmed, it would no longer have been in Williams' interests to mention to investigators his creative yet highly stressful innovations. ${ }^{143}$ Although it would have been far from the truth, Williams too may have found comfort in the rationalisation that he was "just following orders".

If Milgram knew from the first official condition (at least) that subjects might be harmed, but remained determined to complete the experimental programme, how throughout the data-collection stage was he able to continue with a clear conscience? It could be argued that he did so by traveling a similar road to that taken by his obedient subjects, under the influence of certain BFs, while using various SRMs.

\section{4 “An Experimenter's Dilemma"}

According to Blass (2004, p. 117), Milgram's private memos and diary notes "reveal that, at least early on, he was doing some painful soul-searching" and that "These notes provide a window into the workings of Milgram's mind, sometimes revealing inner conflicts that are not visible in his published writings or public statements [italics added]." 144 The intensity of these conflicts would have been strengthened by the fact that not only did he continue with the potentially harmful experiments, but he was also well aware of his central manipulative role in manufacturing his "obedient" subjects' immoral actions. In an undated document titled “An Experimenter's Dilemma” Milgram (as cited in Blass, 2004, pp. 117, 320) conceded: "it is not nice to lure people into the laboratory and ensnare them into a situation that is stressful and unpleasant to them." He knew this was indisputably his "experiment that forces the subject into a moral choice and marshals powerful forces against his making the right choice" (Blass, 2004, p. 118). Closing down

\footnotetext{
${ }^{143}$ Even had Williams argued that Milgram had pressured him into remaining in the research programme it would probably have failed to impress investigators because one of the other actors hired had managed to quit, for ethical reasons. G. Perry (personal communication, August 21, 2008) stated that during her phone interview with the son of Robert J. Tracy (the learner in the Change of Personnel condition), his father apparently withdrew from the experimental programme "after one of his mates from the army fronted as a volunteer and BT couldn't do it to someone who'd been through the war." Tracy's son was "kind of proud of" his father's recalcitrance (G. Perry, personal communication, August 25, 2008). Although the rest of the research team (including Tracy's co-actor Emil Elges) is mentioned in the acknowledgements in Milgram's (1974, pp. Xv-Xvi) book, Tracy's name is conspicuously absent.

${ }^{144}$ It is also important to point out that Milgram's inner conflict did not revolve solely around his awareness that subjects might be harmed. Another dilemma he faced was that his research might be used for malevolent purposes (see SMP, Box 46, Folder 173, Titled: “Notes: Ethics 1962-1966”).
} 
the research programme would not have been an easy decision. It would seem the further the curious Milgram ventured, the more he got entangled within his own "web of forces" (Milgram, 1974, p. 30).

Much like the BF of the foot-in-the-door phenomenon, the more incremental steps he made in making the official experimental programme a reality—running the first pilot, obtaining surprising results, capturing the intrigue of his academic peers at Yale, obtaining funding - the harder it became to pull out. Enhancing such feelings of entrapment was, for example, Milgram's acceptance of the NSF research grant, because any sudden decision to prematurely end the programme would require that he renege on his contractual obligation to complete the project (which may have precluded him from winning any future grants) (BF). On top of all this, should the experiments have turned out to be as significant as he suspected, in the "publish or perish" environment of the American tertiary education system (BF), for the sake of his academic career could he afford not to run them? Whatever the answer, and again reminiscent of the foot-in-the-door phenomenon, the further Milgram ventured the more daring his experimental variations became. For example, Milgram's relatively benign first official Remote condition (where the learner banged on the wall a few times), became the fifth Baseline condition (learner with a heart condition eventually faints), which in turn became the indisputably unethical twenty-fourth Relationship condition (subject brought an acquaintance who eventually faints). ${ }^{145}$ How did Milgram reconcile the likelihood that as his experiments became more daring (unethical?), so did the possibility of subjects being harmed?

As Milgram's experimental programme became both more daring and, for subjects, more dangerous, he drew upon a wide variety of SRMs in seeking to resolve his intensifying moral dilemma. For example, in January 1962 Milgram wondered if participation may have been beneficial: "Can the subject derive some benefit --moral benefit from his participation? Does it have some educative value[?]” (SRM) (SMP, Box 46, Folder 165, Titled: “Notes general, 1961-1962”; see also Schuler, 1982, p. 61). Another potential SRM that Milgram seems to have relied upon was that of blaming the victim - the so-called Just World Phenomenon (Lerner, 1980). In Chapter Five of this thesis a quote from a letter to Elms regarding his role as "Solicitor General" was presented in which Milgram stated that his (Elms') position somewhat resembled that of Eichmann's:

\footnotetext{
${ }^{145}$ Furthermore, if Milgram had decided to close the research programme down at any stage he would have had to concede that all his earlier trials had also been unethical, and that he was personally responsible for going as far as he had. However, by preferring to believe that the experiments were harmless (and that he could therefore act with virtual impunity) he was able to continue them.
} 
"but you at least should have no misconceptions of what we do with our daily quota. We give them a chance to resist the commands of malevolent authority and assert their alliance with morality" (SMP, Box 43, Folder 127, Titled: “Correspondence 1961”). Therefore, subjects were given the chance to ease their self-imposed discomfort by extricating themselves from the experiment. Milgram's conscience probably found comfort by the fact that those who subjected themselves to a prolonged state of near nervous collapse had only themselves to blame. Although Milgram never really explored, but was aware of, the potentially strain-resolving power of "Euphemistic Labeling" (Bandura, 1999, p. 195), it did not preclude his own use of this SRM:

In writings both published and unpublished, he objected to the use of the word 'deception' to refer to experiments that used cover stories or other kinds of misinformation, because he felt it was a value-laden term whose use prevented an objective discussion of the ethics of that type of method. He preferred instead terms such as 'staging' or 'technical illusion' (Blass, 2004, p. 128).

Another example was his description of extreme stress as "momentary excitement" (Milgram, 1964a, p. 849). Relative to the wording of Milgram's (1963, p. 377) first article, where within 20 minutes an initially confident businessman was described as having been "reduced to a twitching, stuttering wreck . . . rapidly approaching . . . nervous collapse", this was "a most astonishing about-face" (Patten, 1977b, p. 356).

There were points during the data-collection stage where, despite Milgram's unwavering public statements defending the ethical status of the experiment, he privately conceded they were unethical. In a document titled "OBEDIENCE ETHICS OF EXPERIMENTATION” dated January 1962:

Several of these experiments, it seems to me, are just about on the borderline of what ethically can and cannot be done with human subjects. Some critics may feel that at times they go beyond acceptable limits. These are matters that only the community can decide on, and if a ballot were held I am not altogether certain which way I would cast my vote. An important distinction is to be drawn between the situation as the subject sees it, and the situation as it actually is. It does, indeed, seem horrible when a man with a heart condition pleads to be let out of an electric chair, and the experimenter refuses. This would surely be unethical and, to my way of seeing it immoral (SMP, Box 46, Folder 165, Titled: "Notes general, 1961$1962 ") .{ }^{46}$

So Milgram conceded that the experiments were unethical, yet by completing them he had in fact cast his own "vote". After he had collected all his data, however, Milgram seems to have had regrets:

\footnotetext{
${ }^{146}$ Also see Footnote 37.
} 
Moreover, considered as a personal motive of the author --the possible benefits that might redound to humanity --withered to insignificance alonisde [sic] the strident demands of intellectual curiosity. When an investigator keeps his eyes open throughout a [scientific] study, he learns things about himself as well as about his subjects, and the observations do not always flatter (SMP, Box 46, Folder 173, Titled: "Notes: Ethics 1962-1966").

Despite Milgram's frequently disparaging and prejudicial remarks about his obedient subjects (Bartov, 2003, pp. 182-191), he himself had acted wrongly and had sensed that he had more in common with them than he might originally have wanted to believe.

Ironically, Milgram's conscience was probably appeased by his belief that he was discovering things about the Holocaust and the apparent "disease" of "destructive obedience" (SRM). So he perhaps felt that he had little choice in inflicting potentially harmful levels of stress because, as argued by Miller (2004, p. 211): "the apparent infliction of pain in the obedience research . . . added to the validity of the Holocaust analogy, in terms of the pain (and, of course, far worse fates) experienced by Holocaust victims."

With time his personal doubts progressively receded, and like Elinor Rosenblum, who seemed to soothe her guilty conscience by pushing the switch down very lightly (i.e. doing something to "help" the learner that actually did nothing other than act as a balm to her own guilty conscience), the most Milgram was willing to do was to vow never again to engage in similar research. As he stated: "while what has been done cannot be undone, one can at least resolve not to repeat the performance. There and then I decide, as a purely personal matter, not to do another experiment that requires illusion, or ensnarement" (SRM) (Blass, 2004, pp. 117-118). Soon after the publication of his first and most (in)famous OTA article in 1963, Milgram left Yale to take up a position at Harvard University. ${ }^{147}$ Before long, "Milgram's self-doubts evaporated-no more angst-filled selfdirected notes appear" just "statements and writings contain[ing] uniformly self-confident affirmations and strong arguments defending the ethics of the experiments" (Blass, 2004, p. 118). As Milgram (1964a, p. 852) said at this time: "Some people may feel it should not have been done. I disagree and accept the burden of their judgment.” It could be argued

\footnotetext{
${ }^{147}$ Even those outside the OTA's organisational structure sensed opportunities minus the responsibility. As Harvard University's Gordon Allport noted at the time, there was a risk that concerns about the ethics of the OTA experiments could result in the sullying of Yale University's good name. With Yale responsible for having allowed Milgram to pursue his idea, Allport also sensed an opportunity: "WHILE MILGRAM WAS at Yale, Allport had told his colleague Roger Brown, in a slightly conspirational manner: 'I'm rather glad he's doing these experiments in New Haven [Yale], but we'll hire him as soon as he finishes' "' (Blass, 2004, p. 131).
} 
that this response was akin to that of his obedient subjects: “ 'No one,' says Milgram, 'who got within five shocks of the end ever broke off. By that point, he had resolved the conflict'” (Meyer, 1970, p. 132).

\subsection{Conclusion}

In converting his inchoate research idea into reality, Milgram had to draw upon the sponsorship, labour and expertise of many others. He provided them with a sometimes different rationale/ideology to that supplied to subjects. Via moral inversion, this condoned the infliction of harm and/or tempted them into participating by appealing to their different needs and/or desires. However, as Milgram drew people into performing their specialist roles/tasks, he also unwittingly constructed a powerful organisational tool: the potentially destructive bureaucratic process. The bureaucratic process is a forceful tool in the achievement of malevolent goals, largely because the process leading to such ends is divided amongst specialists who need only engage in smaller parts of the whole process. Because other "probably" more responsible links in the bureaucratic chain were involved, all came to sense they could not be held responsible for making their necessary contributions. As each link in the chain made their small but important contributions, responsibility for both the actual and the seeming infliction of harm was displaced to and eventually diffused across all participants.

Consequently, no one person felt and/or appeared to others present fully responsible for the actual/seemingly harmful outcome/s. Thus, all came to suspect that they could continue to reap whatever personal benefits were associated with participation, and that they could do so with virtual if not full impunity. Indeed, it could be argued that because of the bureaucratic process, the person ultimately responsible had disappeared. Arendt (1970, p. 38) termed this the "rule by Nobody" where bureaucracy makes it "impossible to localize responsibility and to identify the enemy." 148 Or, as Bandura (1999,

\footnotetext{
${ }^{148}$ In his classic novel, The Grapes of Wrath, John Steinbeck (1993, pp. 47-48) captures the essence of diffuse responsibility in an exchange between the dispossessed tenant farmer and the tractor driver who had been ordered to destroy the farm buildings: " 'You even come too close and I'll pot you like a rabbit.' 'It's not me. . . . There's nothing I can do. I'll lose my job if I don't do it. . . . You're not killing the right guy.' 'That's so,' the tenant said. 'Who gave you orders? I'll go after him. He's the one to kill.' 'You're wrong. He got his orders from the bank. .. 'Well, there's a president of the bank. There's a board of directors. I'll fill up the magazine of the rifle and go into the bank.' The driver said: 'Fellow was telling me the bank gets orders from the east. The orders were: 'Make the land show profit or we'll close you up.' ' 'But where does it stop? Who can we shoot? I don't aim to starve to death before I kill the man that's starving me.' 'I don't know. Maybe there's nobody to shoot. ... Anyway I told you my orders.',
} 
p. 206) put it: "The triumph of evil requires a lot of good people doing a bit of it in a morally disengaged way with indifference to the human suffering they collectively cause." The eventual diffusion of responsibility, in conjunction with a means of inflicting harm inherently low in perceptual stimulation (itself capable of reducing feelings/the appearance of being responsible), were essential in generating the high completion rates. As many subjects later pointed out, they would not have engaged in such actions on their own accord because doing so in the absence of the others would have rendered them solely responsible. They therefore allowed the strain-resolving diffusion of responsibility, and the role of the shock generator, to determine their actions.

On a small scale-a microcosm - Milgram's unwitting construction, then use, of the goal-orientated bureaucratic process strongly aided the displacement and diffusion of each participant's personal feelings and/or their appearance of responsibility-the NSF, Yale, Milgram, his employees, and even the subjects of the experiment. ${ }^{149}$ This blanket perception of not feeling and/or appearing responsible saw their thought processes merge. None personally believed that they were responsible for the end result. They individually continued to participate, thereby contributing to the "organizational" goal of maximising the completion rate.

The following quote, although originally directed mostly at subjects, is equally applicable to all those involved in making the experiments work:

Carrying out the evil may even have been something they disliked doing while they did it. For all these reasons, it was easy ... to feel so innocent, so lacking in responsibility for the evil they performed. But feelings aside, they were responsible . . . because in these cases the question of intent is irrelevant to the question of responsibility. No matter how much the evil . . felt accidental, it was not .... We may feel responsible only for what we intend; we are responsible for all that we do. And we know it. Because our feelings of responsibility are grounded in our intentions, and bureaucracies arrange that everyone need only intend to follow the rules, the result is that bureaucracies have a genius for organizing evil (Sabini \& Silver, 1982, pp. 65-66).

The potentially destructive bureaucratic process has a genius for organising evil because those deploying such means are able to get operatives to act as if they were in the $S A D$

\footnotetext{
${ }^{149}$ For example, the fact that other more prominent figures such as Milgram and Yale University had earlier agreed to undertake this experiment may have encouraged subjects at the end of the bureaucratic chain to continue inflicting shocks, because they believed that if blame were apportioned, it would be laid at the feet of those further up the hierarchy. The experimenter probably suspected that Milgram was actually responsible for the infliction of intense stress on the subject. As pointed out, Milgram arguably did "blame the victim", by holding the obedient subjects (his focal point) responsible for their own stressful experience, because they did not stop the experiment.
} 
(where, for self-interested reasons, people conceal their awareness of harm-infliction internally, via self-deception, and/or externally, via attempts to deceive others present).

Milgram (and perhaps other central figures) were effectively able to play mind-games with themselves and others around them, which involved inner conflicts, coercive BFs, and the use of supplied and self-invented SRMs, while continuing to contribute to the goalorientated bureaucratic process.

There are a number of elements of bureaucracy which collectively tend to enhance individual "psychopathology" (Gregory, 1995, p. 17), and are reflected in the OTA experiments:

1. Moral inversion: the conversion of something evil into something good (Adams \& Balfour, 1998, p. xx): a scientific experiment exploring the effects of punishment on learning (not the infliction of torture).

2. Division of labour: small cogs in a "machine" following seemingly disjointed operational procedures (Arendt, 1963; Gerth \& Mills, 1974; Hilberg, 1961).

3. Separation from the consequences of one's actions (Milgram, 1974, pp. 32-39), made possible by technology — the shock generator (Russell \& Gregory, 2005, pp. 333-334).

4. Impersonality-the subject was referred to as the "Teacher" and Mr Wallace as the "Learner" (Gregory, 1995).

5. Reification of roles: "The experiment requires that you continue [italics added]" (Milgram, 1974, p. 21).

6. Use of euphemistic language (Bandura, 1999, p. 195): the experiments did not involve "deception", it was a "technical illusion".

7. Careerism where to get along one must go along (Friedlander, 1998, p. 246, as cited in Waller, 2002, p. 254; Gregory, 1995).

8. Organisational culture, mind-sets, and ideology—the so-called value of "science".

The arguments presented in the previous chapters suggest the following strategy may be fruitful in shedding new light on the fifth and final question of this thesis: how during the Holocaust were ordinary and mostly moderately anti-Semitic Germans so quickly converted into willing executioners? First, delineate the Nazi regime's construction and promulgation of the rationale/ideology that enabled so many ordinary Germans to condone (morally invert) the infliction of harm on Jews and others. Secondly, pay particular attention to the application of intuition, previous experience and the ad hoc trial and error process in the evolution of the most powerful SRM-the means of 
inflicting harm —in conjunction with some of the other particularly powerful SRMs and BFs accompanying it (like those inherent in the bureaucratic process, such as the displacement/diffusion of responsibility). The means of inflicting harm when extremely low in perceptual stimulation could allow seemingly trivial/self-centered concerns to dominate the centre of a subject's emotional universe—such as fear of a confrontation, peer-pressure, and perhaps even the fear of potentially having to return their $\$ 4.50$. Perhaps similar processes were at work in Nazi Germany? With a central focus on the most powerful SRM of the means of inflicting harm, Chapters Ten and Eleven will briefly outline the Nazi regime's journey of discovery to achieve their admittedly tentatively comparable end to ensure most ordinary people at the end of their destructive bureaucratic process killed other human beings. 


\section{Chapter Ten: The "Twisted Road" to Babi Yar}

What they were being asked to accomplish was at the time totally unprecedented. At this stage every step was uncharted, every policy an experiment, every action a trial run-Browning (1995, p. $113)$.

The preceding chapters have outlined how Milgram developed and implemented his initial quest to maximise ordinary people's participation in his experiment to inflict potentially lethal shocks on another human being. The aim of the following two chapters is to show that in their attempts to maximise the participation of ordinary Germans in the extermination of the Jews, the Nazis traveled a somewhat similar journey. Two case studies will be presented involving different techniques used by the Nazi regime in its attempt to exterminate the European Jews. The first, in this chapter, will address the evolving mass-shooting technique deployed during Operation Barbarossa-the Nazi regime's 1941 invasion of the Soviet Union. The second case study, explored in Chapter Eleven, is also from 1941, and explores the invention, evolution and implementation of the mass-gassing technique used during Operation Reinhard-the extermination of the Polish and other Jews. The mutual overlap in journeys between Milgram and the Nazis in making the seemingly undoable doable includes the following:

1. The central importance of the means of inflicting harm chosen to hurt others (whereby the less perceptual stimulation, experienced by the ordinary inflictors of harm, the easier it became to convince and/or tempt them into using these devices).

2. The presence of intuition and/or previous experience in the selection or invention of the means of inflicting harm, and dependence upon the ad hoc trial and error "exploratory" method of discovery in the gradual refinement of its use (also applicable to the harming process in general).

3. The increasing bureaucratisation of the initially rudimentary/experimental harming process.

This chapter pays only brief attention to the significant events in German history preceding 1941. What is of particular interest is the question of how, upon agreeing with or feeling indifferent toward the Nazi regime's intention to exterminate the Jews, over time moderately anti-Semitic Germans became willing executioners of Jews. 


\subsection{The Nazi's "Jewish Problem": An Overview of Events Leading up to 1941}

In 1933 the National Socialist—Nazi—party, led by Adolf Hitler was voted into office by the German electorate. The Nazi regime:

claimed that there is a biological basis for the diversity of Mankind. What makes a Jew a Jew, a Gypsy a Gypsy, an asocial individual asocial, and the mentally abnormal mentally abnormal is in their blood, that is to say in their genes. All ... are inferior. There can be no question of equal rights for inferior and superior individuals, so, as it is possible that inferior individuals breed more quickly than the superior, the inferior must be isolated, sterilized, rejected, and removed, a euphemism for killed. If we do not do this, we make ourselves responsible for the ruin of our culture (Müller-Hill, 1988, p. 22).

With total control over state finances, the Nazi regime rapidly came to fund and/or employ academics and scientists who were themselves willing to become National Socialists (Friedlander, 1995, p. 126). This contractual arrangement inadvertently increased the chances of "scientific" research confirming the regime's preconceived racist and prejudicial stereotypes. Future employment opportunities dwindled for those academics and scientists unwilling to make such an ideological commitment (or who went further and challenged the regime's beliefs), were forced to take their dissenting voices elsewhere (see Glass, 1997, p. 65; Glover, 1999, pp. 366, 384; Sereny, 1974, p. 62; Westermann, 2005, p. 36). The 1934 law against political libel and slander — the "Heimtückegesetz"—further suppressed anti-Nazi criticism (Johnson \& Reuband, 2005, p. 347). The result of such policies and laws was a progressive concentration of consenting and the diminishing existence of dissenting expert voices. This process saw, throughout the mid to late 1930s, the heightened production of pseudo-scientific research that further reinforced the regime's prejudicial stereotypes. The Nazi propaganda machine channeled this (mis)information into the national educational curriculum (Schleunes, 1970, pp. 107-108), newspaper media, various Nazi youth movements, and films, the last of which included frequently subsidised screenings with titles such as Jud Süss (Jew Suess) and Der Ewige Jude (The Eternal Jew). The relentless deluge of propaganda, in the near absence of any conflicting information, over time persuaded many Germans that a society without Jews and other "inferiors" would be good for Germany. ${ }^{150}$ Such propaganda sought to dehumanise the Jews and, at

\footnotetext{
${ }^{150}$ As Oskar Groening, an office worker at Auschwitz put it: "We were convinced by our worldview that there was a great conspiracy of Jewishness against us" (Rees, 2005, pp. 132-133). Rees (2005, pp. 133-134) argues that it was due to this worldview that Groening "carried on working at Auschwitz not just because he was ordered to but because, having weighed the evidence put before him, he thought that the extermination program was right."
} 
the very least, secured the indifference of the wider German public to their (the Jews') eventual fate (Heim, 2000, p. 320; Kulka, 2000, p. 277). ${ }^{151}$

Another side to these exclusionary measures was that if the so-called German race were to thrive and eventually replace those deemed inferior, then the ten million or so ethnic Germans living abroad needed to be repatriated, with the "superior" racial stock in the homeland. However, the return of this "German blood" would mean less living space, and therefore more land would be needed-so-called "Lebensraum (living space)" (Rossino, 2003, p. 2). As far as Hitler's [1925] (1943) Mein Kampf (My Battle or My Struggle) was concerned, this land would have to come from that attached to the Reich's Eastern national borders. This living space could be gained only by going to war (Wistrich, 2001, pp. 2, 44-45).

There was an obvious substantive difference between "excluding" (via, say, forced emigration) and "killing" the Jews, and before 1941 the preferred approach caused much debate between two main factions within Nazi circles. There were those termed the "realists" (Schleunes, 1970, p. 216), who favoured the policy of forced emigration, on the one hand, and the party radicals who were termed "strong believers", on the other (Wilhelm, 1997, p. 118). The latter:

were convinced that sterilization and euthanasia were the only adequate means of healing a badly infected 'people's body.' Emigration would not work and would be endangered if so-called parasites and deadly foes of the German people were allowed to survive, and reproduce, just outside the borders of the Reich (Wilhelm, 1997, pp. 118-119).

Between 1933 and 1941 the Nazi leadership tended to favour the policy of forced emigration, probably because it initially showed itself to be more "realistic". The two following events, both of which occurred in 1938, strongly reinforced this initial preference.

On 7 November 1938, a desperate Jewish teenager shot a German embassy official in Paris because of frustrations over a Nazi-initiated German/Polish border dispute

\footnotetext{
151 "There is general agreement that . . . in concrete, everyday matters during the 1930s, a kind of depersonalized attitude towards ... [the Jews] . . evolved during the war period .... The major area of disagreement concerns two interpretations .... One interpretation holds that the silence ... was the result of indifference, of not knowing or not wishing to know, or, alternatively, of a repression of such knowledge. The second interpretation views the absence of a pronounced reaction and the general passivity toward the physical annihilation of the Jews as the expression of a broad consensus on the government's policy, a kind of tacit agreement that there was no need to take an active stand on the subject" (Kulka, 2000, p. 277).
} 
involving his parents. In an attempt to accelerate the forced emigration of the Jews, on 9 November Hitler decided to capitalise on the assassination as an opportunity to promote anti-Semitic sentiment within Germany and instigate a nationwide pogrom against Germany's Jews. ${ }^{152}$ This pogrom became known as Kristallnacht (night of crystal, or the "Night of Broken Glass"). Largely at the hands of the Nazi stormtroopers, nearly 300 synagogues were burned down, hundreds of Jewish-owned department stores/shops were vandalised and looted, and thousands of Jews were rounded up and sent to concentration camps. There were about 100 Jewish fatalities. Because there had not been any pogromtype violence on this scale in any modern industrialised Western nations for some time, this was a watershed event in German/Jewish relations. Although Kristallnacht accelerated forced emigration, the violent approach had its drawbacks. Hitler failed to foresee that the pogrom threatened the jobs of non-Jewish Germans working in the stores, would lead to the destruction of Jewish property insured by German and international insurance firms, and sent shockwaves of fear through the German stock exchange. Also, to the regime's surprise, the disorder actually disgusted significant sectors of German society (Kershaw, 1983, pp. 264-65). With the pogrom having inadvertently raised the concerns of big business and therefore the majority of the parliamentary cabinet, the Streicher-led committee's plans for similar such initiatives in the near future were immediately and permanently shelved (Schleunes, 1970, pp. 62-91).

Simultaneously, there was a major breakthrough that reinforced the political acceptability of emigration as the "solution" to Germany's "Jewish problem". An "assembly-line technique" was applied to the process of Jewish emigration (Browning, 1978, p. 5), and within six months a relatively lowly ranked Adolf Eichmann of the SS became responsible for the deportation of one-quarter of all the Jews living in the recently annexed Austrian territory. Eichmann's superiors were able to boast in November 1938 of his emigration of 50,000 Jews, in contrast to the politically problematic Kristallnacht pogrom. Consequently, there occurred a pivotal power shift within the upper echelons of the Nazi hierarchy:

The year 1938 is marked . . by a trend towards centralization of control over Jewish policy. In part this trend reflected the newly found powers of Goering, Heydrich, and Eichmann; in part it reflected the final failure of the emotional antiSemitic wing of the Nazi movement to produce a solution to the Jewish problem through pogroms. The failure of the November pogrom finally discredited the

\footnotetext{
152 “. . . Goebbels was seen discussing this [the assignation] urgently with Hitler. Hitler apparently gave the order, or his approval, to the course suggested to him .... It was Hitler himself, therefore, who gave the party and Goebbels the green light for the pogrom ..." (Bauer, 1991, p. 132). With respect to Kristallnacht, Bankier (1988, p. 4) argued: "Hitler did not swim with the tide, he turned it."
} 
impulsive radicals and strengthened the hand of the realists whose work in 1938 promised a more effective solution through bureaucratic means (Schleunes, 1970, p. 216).

Although obviously Hitler saw, at least initially, merit in a combination of both approaches (see Bankier, 1988; Bauer, 1991; Dean, 2008), as Schleunes (1970, p. 216) added: "Most important of all, Hitler finally made a choice between these two approaches to the Jewish issue."

Clearly the "Göring-Himmler-Heydrich alliance" (Browning, 1978, p. 5), along with their subordinate's (Eichmann's) effective deployment of an assembly-line bureaucratic processes cemented all their roles in the future direction of anti-Jewish policy-whatever it might entail. Once Hermann Goering had been placed in charge of the Jewish question, he soon delegated its resolution to SS-Obergruppenführer Reinhard Heydrich, who on 24 January 1939 authorised the opening of the Reich Central Office for Jewish Emigration (Browning, 1978, pp. 6, 19). Heydrich demanded that Eichmann's efficient approach to mass emigration be applied to all the larger German cities, so as to bring " 'the Jewish question . . . to as favorable a solution as present circumstances permit' "(Fleming, 1984, p. 43). But the "realists" soon encountered a number of obstacles.

After having already annexed the Sudetenland (and soon after, in March of 1939, the remainder of Czechoslovakia), in September of the same year the Nazis invaded Poland instigating World War Two. The Wehrmacht (the German Army) attacked from the west and, by prior arrangement, the Nazi regime's then ally, the Soviet Union, invaded from the east. After defeating Poland the Germans annexed the western half and, based on the soon to be negotiated demarcation line, the Soviet Union appropriated the eastern half. But this rapid expansion of Germany's borders exposed a flaw in Eichmann's emigration model. The more nations the Wehrmacht invaded, the more Jews Germany inherited. This expansion left fewer places within Europe to which they could be expelled (Browning, 2004, p. 37). For these reasons, irrespective of the efforts of Eichmann and Heydrich, the "realists" were soon failing miserably to resolve the Nazi regime's rapidly expanding "Jewish problem".

Soon after Poland's defeat, the Germans divided their new territory into two: the western section which they called the Incorporated Territory, and that in the east, which they called the General Government. As the Soviet border of their new Polish territory tightened, the Germans could no longer push any unwanted peoples in the Soviet's 
direction. In relation to the massive numbers of so-called "inferiors", it was decided to expel the non-Jewish Poles from the Incorporated Territory and force them into the General Government. After initial chaos, it was decided to transfer the Jews to a reservation in the eastern corner of the General Government: the district of Lublin. However, the mass deportations proved to be a more difficult exercise than the Nazi regime had anticipated. Contributing to these difficulties was the higher priority placed on repatriating and housing ethnic Germans living abroad, various economic concerns, and particularly major logistical issues (Browning, 2004, pp. 36-72; Cesarani, 2004, pp. 8283). The regime soon realised that its aim to remove the Jews would take some time to implement. According to Heydrich (as cited in Browning, 2004, p. 26), as an interim solution it was decided that, " "in order to have a better possibility of control and later deportation" " the particularly unwanted and numerous Polish Jews were to be concentrated in designated ghettos within the major cities. Many of these ghettos were completed during 1940. But to where were they eventually to be deported? The realist Nazi bureaucrats identified a few potential locations, the most popular of which emerged from the Nazis' successful spring 1940 conquest of Denmark, Norway, Holland, Belgium, Luxemburg and, of particular interest, France. This idea became know as the Madagascar Plan.

The Madagascar Plan involved shipping Jews to the island of Madagascar, a French colony off the southeastern coast of Africa (Browning, 2004, pp. 81-82). According to Himmler, Hitler's response to the plan was that " 'The Führer read the six pages through and found them very good and correct' " (Browning, 2000, p. 14). Browning (2004, p. 70) has observed:

This episode is of singular importance in that it is the only firsthand account by a high-ranking participant-Himmler-of just how a Hitler decision was reached and a Führerbefehl, or Hitler order, was given in respect to Nazi racial policy during this period. The initiative came from Himmler. However, he did not present Hitler with a precise plan; it was rather a statement of intent, a set of policy objectives. The details of implementation would be left to Himmler. Hitler indicated both his enthusiastic agreement and the men with whom the information could be shared .... . He simply allowed it to be known what he wanted or approved. Presumably business was often conducted in such a way in the Third Reich. 
As Himmler had long known, Hitler rewarded with power those who could both anticipate then convert his desires into a reality. ${ }^{153}$ However, access to Madagascar required naval victory over Britain, an outcome which never occurred. Consequently, the plan was shelved pending a victory that never arrived.

With the intention of encouraging the English to concede defeat (with the additional bonus of enabling access to Madagascar), as early as 31 July 1940 Hitler began contemplating attacking Germany's then allies in the Soviet Union (Browning, 2004, p. 215). But tainting such a victory was that about five million Jews lived within the Soviet Union's post-August 1939 borders (Hilberg, 1992, p. 250). Soon after Hitler set his designs on the Soviet Union, potential sites to which Jews could be "migrated" were identified by the Nazis, including the marshes of the Ukraine and even the Siberian wastelands (Aly \& Heim, 2002, p. 179; Cesarani, 2004, p. 92).

During this period (between the start of World War Two nearing the end of 1939 and up until half way through 1941), other events contributed to the subsequent attempt to exterminate the European Jews. Germans within the "machinery of destruction"-who Hilberg (1961, p. 1011) believes were a "remarkable cross-section of the German population"- -started demonstrating an ability to kill fairly large numbers of defenseless Jewish and non-Jewish civilians. As the following will demonstrate, they used what by the end of the war became the three most common killing methods: shooting, starvation, and gassing.

\subsection{Shooting}

\footnotetext{
${ }^{153}$ An excellent example of "seizing the initiative from below in response to vague signals emanating from above" (Browning, 2004, p. 37), was Martin Luther and his meteoric rise in the German Foreign Office. This "had been due in no small part to his ability to anticipate which tasks Ribbentrop would need performed, to fill vacuums before others even realized they existed. When Luther sensed a turn in Judenpolitik in the late summer of 1941, he quickly aligned himself with the direction events were taking" (Browning, 1978, p. 82). As the Führer said himself: " 'Where would I be . . . if I would not find people to whom I can entrust work which I myself cannot direct, tough people of whom I know they take the steps I would take myself. The best man is for me the one who bothers me least by taking upon himself 95 out of 100 decisions" (Browning $\&$ Matthäus, 2004, p. 243). The result of this management style was a fiercely competitive bureaucratic environment: "composed of factions centered around the Nazi chieftains, who were in perpetual competition to outperform one another. Like a feudal monarch, Hitler stood above his squabbling vassals. He allotted 'fiefs' to build up the domains of his competing vassals as they demonstrated their ability to accomplish the tasks most appreciated by the Führer" (Browning, 1978, p. 2).
} 
On 3 September 1939, during the invasion of Poland, Himmler released a shoot-tokill authorisation, to discourage any civilian resistance (Rossino, 2003, p. 65).

Consequently, during a period of six weeks the German armed forces shot approximately 16,000 civilians - about 5,000 of whom were Jewish (Roseman, 2002, p. 24). On top of this, in the last few months of 1939 up to 50,000 of the Polish intelligentsia, and other civilian resisters (7,000 of whom were Jewish), were shot by SS forces and ethnic German auxiliaries (Musial, 1999, p. 106, as cited in Browning, 2004, p. 35; Rossino, 2003, p. 234). Possibly because of the Poles' frequently "Germanic"-looking facial features, some of the execution squads started to experience what Lieutenant General Max Bock described as " "vast agitation and powerful emotional stress" " (Browning, 2004, p. 74). ${ }^{154}$ The stress was exacerbated by the fact that shooting defenseless civilians meant that the killers necessarily experienced quite high levels of visual and auditory perceptual stimulation.

\section{$\underline{10.3 \quad \text { Starvation }}$}

Independent of the Nazi officials in Berlin, the local German authorities at the two largest Polish ghettos at Lodz and Warsaw-which between them contained about one third of all Polish Jews under Nazi control (Browning, 2004, p. 124)—decided at different times and for different reasons to seal off their ghettos from the adjacent non-Jewish communities. ${ }^{155}$ Cut off from those outside the ghetto boundaries, initially the poorest Jews began to perish from starvation and diseases.

The effects of these locally initiated policies were first observed in the Lodz ghetto, which was sealed in April 1940. By the summer of 1940 Arthur Greiser (the Governor of the Wartheland) stated, from the " 'point of view of nutrition and the control of epidemics" " life in the Lodz ghetto had already become " "untenable" " (Mommsen, 1997, p. 30). Between June 1940 and the end of January 1941 more than 7,000 Jews died (Corni, 2002, p. 205).

\footnotetext{
${ }^{154}$ See also Buchheim (1968, p. 317).

${ }^{155}$ The Lodz ghetto was sealed in April 1940 to enable the extraction of Jewish wealth in exchange for food, whereas the Warsaw ghetto was sealed in mid-November 1940 because of fears surrounding the possible spreading of disease and epidemics (Browning, 1995, pp. 32-34).
} 
Alexander Palfinger, a German ghetto administration official, seized upon this emerging catastrophe as a partial solution to the escalating "Jewish problem", arguing: "A rapid dying out of the Jews is for us a matter of total indifference, if not to say desirable". According to his interpretation of Nazi ideology, such an outcome was consistent with what he anticipated would be the regime's eventually " 'radical course' " (Browning, 2004, p. 128), because in relation to the " 'Jewish question the National Socialist idea . . permits no compromises' " (Browning, 1995, p. 36). Palfinger's initiative is an example of what regional functionaries in the East referred to as " 'anticipatory obedience' " (Lower, 2002, p. 14) — that is, anticipating their superiors' desires and converting them into reality.

Browning (1995) labels "attritionists" as the local German bureaucrats who, like Palfinger, believed the Jews should be starved. However, a more powerful group of German administrators were termed the "productionists". These people believed that sources of labour should not be wasted, and that making the Jews work would enable them to obtain food at no cost to the Reich and would avert the rapidly encroaching catastrophe. This policy could be carried through until Berlin decided where the Jews would be sent. At Lodz, Palfinger's immediate superior, Hans Biebow (the chief of the ghetto administration), on 18 October 1940 argued: “ "everything must be done to make the ghetto self-sustaining' " (Browning, 1995, p. 36). Biebow, and his superior, Dr. Karl Marder (the deputy mayor of Lodz), set up a ghetto economy in Lodz, ${ }^{156}$ indicating that at least in that city the "productionists" were in control (Browning, 1995, p. 36).

The discontented Palfinger soon transferred to the Warsaw ghetto. With the help of some like-minded local authority "attritionists" (including Waldemar Schön and Karl Naumann), he was able to generate what Schön euphemistically referred to as " 'premature impoverishment' " (Browning, 2004, p. 125). But again Palfinger's intentions were subordinated to the "productionists" in Warsaw, who also dominated the local German authorities. At a meeting held on 3 April 1941 Dr. Walter Emmerich argued: “ 'The starting point for all economic measures had to be the idea of maintaining the capacity of the Jews to live [italics original]' " (Browning, 1995, p. 39). Despite protestations from the "attritionists", the view of Hans Frank (the leading official in the General Government) was final: " "The responsibility that the government took on with the creation of a Jewish district of 500,000 human beings [Menschen!'] is very great, and a failure would always be

\footnotetext{
${ }^{156}$ By the summer of 1941 approximately 40,000 Jews were working in the Lodz ghetto (Browning, 2004, p. 154).
} 
blamed on the authorities of the General Government" " (Browning, 1995, p. 39). Frank was certainly not philo-Semitic: he had made statements a few months earlier to the effect that he saw great merit in killing the Jews. ${ }^{157}$ But his enthusiasm for killing Jews diminished out of a personal concern that, if Germany lost the war, he could later be held responsible for what during this period of the conflict was a radical policy. Thus, on 19 April 1941 a new "productionist"-based policy was introduced in Warsaw. Schön was replaced with Max Bischof (who was also told that if Palfinger caused any further problems he could have him removed). Palfinger stopped anticipating the direction of Nazi Jewish policy and, having narrowly avoided dismissal, by early May 1941 was to be found informing Adam Czerniakow (the Judenrat chairman): " that he will do everything to improve the food supply" " (Browning, 1995, pp. 40-41).

Soon after the war began the Nazi regime was struggling to meet the minimum food ration standards they had earlier set for the German civilian population (Aly \& Heim, 2002, pp. 243-244). If the regime was sometimes unable to accommodate the needs of those at the top of the racial hierarchy, irrespective of how hard the Jews at the bottom were willing to work, extremely hard times most certainly laid ahead. In the end, promises of more food were made but, as Biebow had pointed out in January 1941, little arrived because it was continually "withdrawn for allegedly more urgent needs" (Browning, 2004, p. 156).

Although there were later periods of stabilisation, in the Warsaw ghetto during April then May of 1941, 2,000 then 4,000 Jews died, respectively. It must have appeared that a famine of endemic proportions had taken hold (Browning, 1995, p. 47). The German administrators ("productionists" and "attritionists" alike) followed directives from Berlin during late 1940 and early 1941 that the Jews were not to leave the ghettos in search of food. ${ }^{158}$ Consequently, they imposed conditions that killed growing numbers of defenseless civilians. They could do so with relative ease because nobody involved-from those who rounded up and delivered the victims to the ghettos, to the administrators, or to the guards preventing their escape- - had to touch, see or hear the victims in their death throes. None was required to personally deliver any specific, unambiguous, death blow.

\footnotetext{
${ }^{157}$ See Browning (2000, p. 8).

${ }^{158}$ At a meeting on 19 April 1941, Frank argued: “ 'That one cannot dissolve the ghetto and leave the Jews in freedom, over that there is still full agreement' " (Browning, 2004, p. 129). Having said that, with so little food entering the Warsaw ghetto, Browning (2004, p. 130) has pointed out that, although there were some periods of lethal violence instigated by the ghetto administrators, it was "necessary to tolerate gaps in the ghetto cordon."
} 
Instead, they were able to pass responsibility on to a reified "Berlin" for imposing such deadly conditions. In the absence of any reflective thinking, what they might have seen for themselves within the ghettos could be construed as reinforcing the Nazi stereotypes of Ostjuden (Eastern Jew). Because starvation as a method of killing was generally low in perceptual stimulation, it could suppress within German officials feelings of strain, trauma, and/or repugnance. ${ }^{159}$

\subsection{Gassing}

During October 1939 Hitler produced a document that authorised the Kanzlei des Führers (KdF) to engage in “ 'domestic purification' ”, or the extermination of Germany's physically and mentally disabled (Friedlander, 1995, p. 67). Consequently, the KdF formed an organisation called Tiergartenstraße 4 (T4), which was charged with this killing operation. Different killing techniques were contemplated, such as lethal injections, but eventually Viktor Brack, in conjunction with chemist Albert Widmann, developed the idea of diverting pure bottled carbon monoxide gas into a hermetically sealed room (Friedlander, 1995, pp. 86-87). In December 1939 or January 1940 a T4 team tested the viability of Brack and Widmann's idea on some disabled men locked in a cell disguised as a shower room. From the perspective of the perpetrators—at least 17 people including Brack, Widmann and others who would become central figures in the extermination of the Jews, including Philipp Bouhler, Karl Brandt, Christian Wirth, Irmfried Ebel, and August Becker (Friedlander, 1995, p. 87) — the pilot test was deemed so "successful" that the Euthanasia gassing programme was initiated. Before long five other permanent gas chambers were set up at various institutions throughout Germany.

Soon afterwards, the Criminal Technology Institute invented mobile gas vans, which were used by a Sonderkommando, headed by Herbert Lange, to kill patients in the recently acquired Eastern territories (Friedlander, 1995, p. 139). Canisters of pure carbon monoxide were attached to the driver's compartment and released from valves located inside the van. The roaming Lange Commando became highly proficient at killing “defectives". For example, during two weeks in May 1940 Lange and his small team gassed 1,558 patients from an East Prussian hospital (Browning, 1985, p. 59).

\footnotetext{
${ }^{159}$ Photos and film footage of conditions in the ghettos were taken and sent back to Germany, but this was only used for propaganda purposes to reinforce Jewish stereotypes.
} 
Between the end of 1939 and the summer of 1941 at least 70,000 to 80,000 disabled people in Germany were killed, most of them in the recently invented permanent gas chambers (Friedlander, 1995, pp. 109-110). ${ }^{160}$ None of those involved in the killings had to touch, see or hear the victims as they died: this gassing technique offered the perpetrators the option of total perceptual avoidance and generated little strain, trauma, and/or repugnance.

Therefore, in relation to the three killing methods of shooting, starvation, and gassing: "The distressing fact is that mass killing as state policy had already become fairly widespread by 1941" (Browning, 1985, pp. 4-5). Approaching the end of this late 1939 to mid-1941 period, during which ordinary Germans were demonstrating an ability to kill fairly large numbers of defenseless civilians, another pivotal change took place. With the failure of the apparently more realistic emigration policy (such as the Madagascar Plan), the "realist" bureaucrats discerned potential in the previously rejected ideas of the "strong believers". Between late 1940 and mid 1941 the most powerful pro-emigration bureaucrats started contemplating or actually applying "strong believer"-type solutions to various local problems they were facing. For example, some time after October or November of 1940, the Chief SS physician, Ernst Grawitz, claimed that the "realist" Heydrich asked him to trigger an epidemic in the Warsaw ghetto, to boost the death rate (Breitman, 1991, p. 139). A few months later, Himmler started thinking about the application of the Euthanasia gassing method to his over-crowded concentration camps. In discussions with KdF chief Philipp Bouhler (concerning prisoners who were too weak to be productive), in early 1941 Himmler drew on his intuition and previous experience in wondering "whether and how the personnel and the facilities of T4 can be utilized for the concentration camps" (Friedlander, 1995, p. 142). According to Lifton (1986. p. 135):

Early in 1941, T4 leader Bouhler agreed to let Himmler use T4 personnel and facilities to rid the camps of 'excess' prisoners - notably those 'most seriously ill,' physically and mentally. Sometimes called 'prisoner euthanasia' or (by prisoners) 'Operation Invalid,' the resultant program was officially 'Operation [or Special Treatment] 14f13.'

By the spring of 1941, Lange and his T4 Sonderkommando, who had been seconded to Himmler's concentration camps in Germany, embarked on this experimental killing

\footnotetext{
${ }^{160}$ Bloxham and Kushner (2005, p. 84) point out that this figure does not include the tens of thousands of physically and mentally disabled adults and children killed in Poland and later in the Soviet territories.
} 
operation. Exactly as they had done with the mentally ill in the annexed Eastern territories, Lange and his men loaded the selected concentration camp prisoners into their hermetically sealed vans, turned on the valves to the externally attached pure carbon monoxide gas cylinders, and then drove their vehicle while the victims perished inside. The vans were driven to a previously specified burial site, where other prisoners were forced to unload and then dispose of the victims' bodies.

Soon the 14f13 killing programme was extended into the recently built concentration camps in the East. For example, by the end of May 1941 ex-T4 personnel working in the $14 \mathrm{f} 13$ programme had arrived in the back-blocks of Poland, in places like Auschwitz. ${ }^{161}$ According to Klodzinski (1987, p. 136ff, as cited in Dwork and van Pelt, 1996, pp. 280-281) 575 men who “ "were all worn out" "162 were selected, then transported by a train to the T4 gas chamber hundreds of miles away at Sonnenstein in Germany. The men could not be killed at Auschwitz "without causing great commotion" (Dwork \& van Pelt, 1996, p. 280). According to Browning (2004, p. 192), by the end of the war nearly 20,000 people had been killed during Operation $14 f 13$ (Lifton, 1986, p. 142).

The key Nazi "realists" like Heydrich and Himmler were only "realists" because the "strong believer" solutions to the Jewish problem (such as sterilisation or extermination) had previously appeared unrealistic (which may explain Himmler's then Hitler's initial preference for the Madagascar Plan). Confirming his "realist" status, Himmler had said in the summer of 1940, that “ 'out of inner conviction,' he still rejected 'the physical extermination of a race through Bolshevik methods . . . [because they were] un-Germanic and impracticable' " (Fleming, 1984, p. 44). In other words, it was beneath Germans dignity to engage in such acts. ${ }^{163}$ In any case, because they were considered "impracticable" such ideas were consequently ruled out from further discussion. In the last part of his statement Himmler implied that if extermination suddenly became possible he might be willing to reconsider it. Even for "realists" such as Himmler, Heydrich (even Hitler), the desire to exterminate "inferior" peoples had always been present. ${ }^{164}$ However,

\footnotetext{
${ }^{161}$ Rees (2005, p. 43) provides a slightly later date where " $14 \mathrm{f} 13$. . . reached Auschwitz on July 28 ”.

162 This is according to a political prisoner, Kazimierz Smoleń (Rees, 2005, pp. 43-44).

${ }^{163}$ Also during the summer of 1940 Heydrich was arguing: “ "The Jews are considered hostile to us because of our standpoint on race. For this reason they are of no use to us in the Reich. We must eliminate them. Biological extermination, however, is undignified for the German people as a civilized nation. Thus after the victory we will impose the condition on the enemy powers that the holds of their ships be used to transport the Jews along with their belongings to Madagascar or elsewhere'”(Aly, 1999, p. 3).
} 
before 1941 a means of achieving this end did not seem to exist. This may help explain why, as Bauer (2001, p. 30) has pointed out: "there certainly was no actual planning of the genocide before 1941." "165 Increasingly between late 1939 and mid 1941, as the Nazi regime's "Jewish problem" expanded, all the apparently more realistic "solutions" like emigration or expulsion were failing. During the military-style executions, within the ghettos, and inside the gas chambers, the ideas of the "strong believers" increasingly showed signs of potential. Before long the most perceptive within the Nazi regime came to believe that the undoable might actually be doable, after all. For example, on 16 July 1941 in the Lodz ghetto the lowly ranked SS-Sturmbannführer Rolf-Heinz Höppner stated in a letter to Eichmann: "This winter there is a danger that it will not be possible to feed all the Jews. It should therefore seriously be considered whether the most humane solution would not be to eliminate those Jews unfit for work by some fast-working method" (Krakowski, 1993, p. 74). He concluded: " "These things sound somewhat fantastic but are in my opinion definitely feasible' " (Browning, 1985, p. 4). Browning (2004, p. 354) believes Höppner had the Euthanasia gassing technology in mind. But only those in direct control of the machinery of destruction-Himmler and Heydrich-were in any position to do something about converting such ideas into a reality. There is merit in Browning's (2004) observation that, within influential Nazi circles just before the Soviet invasion: "Murder was in the air" (p. 320).

\subsection{Operation Barbarossa}

Since early in 1939 Heydrich had been placed in control of the machinery that was charged with resolving Germany's "Jewish problem". The prospect of eventual failure in

\footnotetext{
${ }^{164}$ In the November 1938 publication of Das Schwarze Korps Heydrich mentioned his desire surrounding the “ 'absolute annihilation' ” of German Jewry: " "The German people are not in the least inclined to tolerate in their country hundreds of thousands of criminals, who not only secure their existence through crime, but also want to exact revenge ... . These hundreds of thousands of impoverished Jews [would create] a breeding ground for Bolshevism and a collection of the politically criminal subhuman elements .... In such a situation we would be faced with the hard necessity of exterminating the Jewish underworld in the same way as, under our government of law and order, we are accustomed to exterminating any other criminals - that is, by fire and sword. The result would be the actual and final end of Jewry in Germany, its absolute annihilation" " (Breitman, 1991, p. 58). Not long into the war, after Heydrich's execution squads were experiencing "vast agitation and powerful emotional stress" while shooting mostly the gentile Polish intelligentsia, his earlier "strong believer" logic was relegated in favour of other apparently more realistic solutions. By 24 June 1940 Heydrich was arguing: “" The very size of the problem - and we have to consider that there are about three and a quarter million Jews in the territories now under German control means that it can no longer be solved by emigration; some territorial solution will have to be found [italics original]' " (Krausnick, 1968, p. 55).

${ }^{165}$ Since the early 1920s Hitler may have wished to exterminate the Jews. Between 1939 and 1940 this seemed impossible to achieve, so Hitler probably accepted that mass emigration was the only realistic option.
} 
this task would not only reflect poorly on Heydrich, but also on his superior officer, Himmler (who was equally concerned). ${ }^{166}$ With no obvious place to resettle the Polish Jews, and with about four million Soviet Jews at hand (Schleunes, 1970, p. 256), perhaps it might be "easier to murder than resettle" (Browning, 2004, p. 35). But how might the Jews be killed? T4 personnel had readily become proficient killers, so the most "obvious" method would predictably have been to gas the unwanted Soviet Jews. In Friedlander's (1995, p. 284) words:

The success of the euthanasia policy convinced the Nazi leadership that mass murder was technically feasible, that ordinary men and women were willing to kill large numbers of innocent human beings, and that the bureaucracy would cooperate in such an unprecedented enterprise.

However, Himmler had in May 1941 sent, at considerable financial cost, 575 incapacitated Auschwitz inmates all the way back to Germany by train to be gassed. Unlike Höppner in Lodz, he was well aware that such an idea was impracticable because the T4 gassing technique used cylinders of pure carbon monoxide, which were too expensive to produce, very difficult to transport out of Germany, and/or did not exist in the quantities required to kill such large numbers of civilians (Breitman, 1991, p. 197; Browning, 1985, p. 59; Fleming, 1984, p. 48; Friedlander, 1995, p. 286; Spektor, 1993, p. 52).

Perhaps the Soviet Jews could be rounded up and forced into secure ghettos and gradually starved to death? Just prior to the Soviet invasion some Nazi bureaucrats were thinking along these lines:

By the beginning of March 1941 the rationalization expert Rudolf Gater was already looking at ghettoization as a possible option for the 'liquidation of the Jewish population'. To avoid having to support the totally dispossessed Jewish minority out of public funds, he proposed a possible alternative . . 'Conditions of undernourishment could be allowed to develop without regard for the consequences' (Aly \& Heim, 2002, p. 180). ${ }^{167}$

However, as Heydrich discovered earlier in the Warsaw ghetto, starvation was a very slow method of killing large numbers of people, and repeatedly gave the most resourceful and/or wealthy enough time to evade death. (This may also explain Heydrich's apparent desire to

\footnotetext{
${ }^{166}$ As Cesarani (2004, p. 92) pointed out: “As early as January 1941, Himmler applied to Heydrich for a way out of the dead end into which the SS had galloped when promising to resettle hundreds of thousands of ethnic Germans on land to be cleared of Jews and Poles for whom the SS could not find room elsewhere."

${ }^{167}$ From February 1941 Paul Körner (Goering's immediate subordinate on the Four-Year Plan Authority) started "devising a military and economic strategy that deliberately envisaged the death by starvation of millions of people in the Soviet Union" (Aly \& Heim, 2002, p. 33).
} 
artificially introduce an epidemic to the Warsaw ghetto.) Thus, starvation was not a viable option. $^{168}$

Because the German armed forces had shot 50,000 Polish nationals in the last few months of 1939, it was apparent that the only cheap, mobile, readily available, and rapid method was shooting. The likelihood of men from such a modern and civilised Western nation like Germany - the home of Kant and Beethoven — being both willing and capable of shooting all Jews-not just men but also women, young children, and babies-might have sounded fantastical to Himmler and Heydrich. Breitman (2000, p. 48) has argued that the SS-Reichsführer "was keenly aware that the execution of civilians might have damaging psychological effects on the police executioners-even in 1940 [during the invasion of Poland] he said he had been warned about this." That shooting children was a distasteful task for most perpetrators can be discerned from the Polish invasion (Westermann, 2005, p. 144). If some men during the invasion had struggled to shoot men, how were they going to fare slaughtering women and children?

In fact, the logic behind some of Himmler's earlier decisions indicates that (putting the killing of women and children aside) even he was sceptical about the willingness of ordinary Germans to shoot defenseless men (let alone women and children). For example, back in June 1940 Himmler went to great lengths to employ and promote the brutal World War One veteran Oscar Dirlewanger (also a convicted pedophile). He supplied Dirlewanger with a battalion of previously imprisoned poachers for the kinds of human shooting assignments that he (Himmler) believed ordinary Germans would shy away from (Breitman, 1991, pp. 129-130). But Himmler could no longer rely upon the scarce specialists for the massive Soviet invasion. He would have to depend upon the more numerous ordinary Germans. It should be kept in mind, however, that although not all, some - perhaps even many_ of those from the execution squads in Poland had shown themselves to be capable of regularly shooting defenseless men (Roseman, 2002, p. 24; Rossino, 2003, p. 234). ${ }^{169}$ Also, now the victims would not be the somewhat similar looking Poles, but Soviet Jews, who would be ethnically, culturally, and socioeconomically very different from the Germans filling Himmler's ranks. As Breitman

\footnotetext{
168 Then again, two million Soviet POWs perished within one year of being imprisoned by the Wehrmacht. Thus, when totally isolated from the resources provided by big cities, and without any assets with which to trade for their lives, starvation could account for a huge number of deaths. See Browning (1985, p. 6).

${ }^{169}$ During the invasion of Poland shooting predominantly civilian men was an unsettling experience for many German executioners, but it was also seen by some as a measure of manliness (Rossino, 2003, p. 70). But could the same be said of shooting women and children?
} 
(2000, pp. 44-45) argued:

Himmler, Heydrich, and, Daluege ... [of the Order Police] did not yet know how smoothly the killing process would work, which leaders and units would prove effective, and whether there would be significant resistance, including resistance from the policemen themselves.

If at the time Himmler and Heydrich knew that neither gassing nor starvation would work, at least attempting to shoot all the Jews offered a potential "solution".

The Soviet invasion, only months away, offered the perfect experimental opportunity to test the viability of this possible method of killing victims who in themselves embodied two of the most despised Nazi enemies (Jews and communists), in the form of "Jewish Bolshevism". Furthermore, if some ordinary moderately anti-Semitic and supposedly civilised Germans were able to murder at least some civilians in the East, it was not hard for Himmler and Heydrich to anticipate the violent capabilities of the more fiercely anti-Semitic non-Jewish Eastern Europeans.

Therefore, before Operation Barbarossa, Himmler and Heydrich had to choose between two very different strategies in dealing with what had become their "Jewish problem". They could continue to pursue their failing strategy of expulsion; or they could try out a much more radical method: encouraging their men to shoot men, women, and children, and/or encourage the local non-Jewish Eastern Europeans to engage in lethal pogrom-type murder. ${ }^{170}$ With the outcome of any attempt to exterminate Soviet Jewry so uncertain, ${ }^{171}$ it made sense for leading figures like Himmler to start out small before

\footnotetext{
${ }^{170}$ Known as the Krausnick versus Streim debate: "There is a substantial dispute among experts over whether the initial instructions (before the war) included the killing of all the Jews - men, woman, and children - or whether a subsequent order, sometime between early August and September, added women and children to the targets" (Breitman, 1991, p. 290). Because Himmler and Heydrich were not sure if their men and/or nonJewish locals would be willing and/or capable of killing all Jews, before Operation Barbarossa the author suspects they did not disclose their desired goal of total extermination. This argument finds support in Longerich's (2005, p. 214) comments: "While Krausnick's assumption of an early, universal annihilation order can clearly be disproved, we should, on the other hand, go further than Streim in emphasizing that the task allotted to the Einsatzgruppen, prior to 22 June, involved a mass murder whose limits were unclear. This order already contained within it the tendency towards total annihilation, and it was deliberately left up to the death squads themselves to decide what limits to place on the killings. Here we see a form of issuing of orders which relied upon interaction, fully in keeping with Nazi tradition." It was deliberately left up to the men in the field because Himmler and Heydrich were not confident that their men could kill all Jews (see also Matthäus, 2004, p. 267). This is why Franz Stahlecker (commander of Einsatzgruppen A) stated in one of his reports on 15 October 1941 (that is, during the extermination campaign): " it was expected from the start ... that the Jewish problem would not be solved solely through pogroms' and 'the security police cleansing work had according to basic orders ... the goal of the most complete removal possible of the Jews [italics added]' "' (Browning, 1994, p. 139).

${ }^{171}$ As Browning (1995, p. 113) said: "they did not know - indeed could not have known - if the plans they had been formulating would even work."
} 
deciding whether or not to invest more manpower in this " "feasibility study" " within the Soviet interior (Browning, 1995, p. 114; also see Mommsen, 1997, p. 32).

Several weeks before Operation Barbarossa, during May of 1941, about 3,000 men were somewhat haphazardly recruited for training (originating from the SS, SD, the Gestapo, Sipo, Waffen SS, State Police, Reserve Police Battalion 9, and also some civilian draftees) (Browning, 2004, p. 225; Büchler, 1986, p. 12). The men were divided into four groups called Einsatzgruppe $A, B, C$ and $D$, and were to be led by carefully selected ideologically-minded Nazis (Wildt, 2003, pp. 546-553, as cited in Bloxham \& Kushner, 2005, p. 137). These four groups were subdivided further into smaller units called Einsatzkommandos and Sonderkommandos. As was the case for the police battalions, the first part of their training involved exposure to a deluge of anti-Semitic propaganda. ${ }^{172}$ Perhaps it was expected that if the men were subjected to enough propaganda, they might come to see the "necessity" of killing all of the Jews (thus the provision of a legitimising rationale/ideology) and eventually associate the second part of their training scheduleshooting practice — as the means of achieving this end. ${ }^{173}$ During May of 1941 Himmler also organised a much larger group of disparate SS units (a total of 25,000 men), to be placed under his direct command. These men were collectively known as his Kommandostab Reichsführer-SS (Browning, 2004, p. 233).

Several days before the launching of Operation Barbarossa, Heydrich began to express his doubts about the willingness and/or capability of these men to shoot civilians. With the intention of passing such dirty work off onto the locals, in a meeting on 17 June in Berlin with the Einsatzgruppen commanders, Heydrich stressed: "No obstacle was to be placed in the way of the 'self-cleansing efforts' (Selbstreinigungsbestrebungen) of anticommunist and anti-Jewish circles" (Browning, 2004, p. 228). On the eve of the attack, the German armed forces received the ambiguous "commissar order", which made specific mention of the Jews and their " 'sub-human nature' " (Matthäus, 2004, p. 250). In its words: “"This struggle demands ruthless and energetic measures against bolshevist agitators, guerrillas, saboteurs, Jews, and complete elimination of any active or passive resistance'” (Browning, 2004, pp. 222-223). As Matthäus (2004, p. 267) stated:

\footnotetext{
${ }^{172}$ Browning (2004, p. 232) has pointed out that before the invasion of Soviet Union: "Numerous materials were circulated among the police to provide the basis for these ideological training sessions." It increased as the campaign progressed (Westermann, 2005, pp. 8; 103-114; 118).

${ }^{173}$ Units in the Order Police, like Battalion 322, for example, underwent similar military training and ideological indoctrination (Breitman, 2000, p. 45).
} 
At the time, the Nazi leadership might have shared the doubts expressed at the periphery that mass shootings of Soviet Jews were, as a report by the Kommandostab on the killings in the Baltics put it, the way in which 'the Jewish problem can be fundamentally solved' .... Nevertheless, Hitler and the top leadership refrained from addressing the issue and left it to their men in the field to decide how to proceed. ${ }^{174}$

Operation Barbarossa was launched on 22 June 1941. The invading Wehrmacht was soon after followed by the 3,000 or so members of the Einsatzgruppen, and at least nine thousand Order Police-about 18 battalions in all (Breitman, 2000, p. 41). ${ }^{175}$

In line with Heydrich's orders, upon entering the Lithuanian city of Kaunas (also called Kovno), Franz Stahlecker, the leader of Einsatzgruppe A, assessed the intensity of local anti-Semitic fervor by releasing violent convicts from a prison and instigating possibly the first pogrom of the campaign. The released prisoners immediately began beating Jews with iron bars or wooden clubs in the city square. All of the victims were men (Rhodes, 2002, p. 41). On 29 June, Heydrich issued a written order to " "remind' " the Einsatzgruppen commanders of his earlier verbal instruction to encourage " "selfdefense circles" " (Browning, 2004, p. 228). By 30 June the Lithuanian partisans in Kaunas had killed several thousand Jews (Arad, 1989, p. 1, as cited in Rhodes, 2002, p. 43). Jewish woman and children were not targeted, which might have confirmed in Stahlecker's mind that even where the locals were willing to engage in pogroms, their selective choice of targets meant that they alone could not be relied upon to resolve the "Jewish problem" in the Soviet Union. In other locations there was even less or no interest in killing all the Jews (Corni, 2002, p. 34; Gerlach, 1997, p. 56, as cited in Matthäus, 2004, p. 273; Longerich, 2005, p. 209). ${ }^{176}$ At this early stage of the invasion, it appeared that the only people who might have both the intention and the logistical, organisational, and technical capability to kill all the Jews were the German armed forces themselves. The following explores how they fared.

Between 22 June and mid-August 1941 the numbers of Jews shot by the Einsatzgruppen varied. Jewish victims numbered in the thousands. Unusually high was

\footnotetext{
${ }^{174}$ See also Lower (2002, p. 6).

${ }^{175}$ In conflict with this, Browning (1995, p. 105) has stated that at "least eleven battalions of Order Police (each of approximately $500 \mathrm{men}$ ) were part of the invasion force."

${ }^{176}$ Having said this, there were a few places were there was a greater eagerness to kill all Jews (Matthäus, 2004, pp. 260-261).
} 
Karl Jäger's relatively small Einsatzkommando 3, which had shot 9,188 civilians (10 percent of whom were women, with children spared) (Streit, 1994, p. 108). However, at the other end of the continuum was the much larger Einsatzgruppe $D$ who shot 4,425 Jews during the same period (Streit, 1994, p. 108). Headland (1989, pp. 401-412, as cited in Browning, 1995, p. 100) has calculated that by the end of July, collectively the Einsatzgruppen had killed a total of about 62,805 civilians, most of whom (about 90 percent) were Jews (Gerlach, 1998, p. 58, as cited in Matthäus, 2004, p. 260). Excluding Jäger's small group, the initial progress reports leading up to mid-August indicated that arming far greater numbers of ordinary German men with firearms was unlikely to succeed as a strategy to murder all Jews in the Soviet interior.

After mid-August the death toll escalated. For example, in the two-week period after mid-August Einsatzkommando 3 killed a further 33,000 civilians (with the proportion of female victims increasing, and the statistics now including children). The same pattern applied to the much larger Einsatzgruppe D. Its death toll before the end of September had risen to 36,000 (Streit, 1994, p. 108). What factors explain this change from a tentative reluctance to kill, to large-scale slaughter? With reference to the Milgram-Holocaust linkage (M-H linkage), at least five major factors seem to have been central. First, leading figures like Himmler used various Binding Factors (BFs) and supplied Strain Resolving Mechanisms (SRMs) to those below them. Secondly, and particularly effective in increasing the probability of obtaining higher participation rates was, via the ad hoc trial and error "exploratory" method of discovery, a movement within the executions squads to reduce the stressful perceptual stimulation associated with the shootings (thus bottom-up innovation). Thirdly, the mass-shooting executions were increasingly bureaucratised, whereby the shootings were broken down into a compartmentalised process (division of labour) with participants performing subsidiary specialist roles (aiding greatly the SRM of the displacement/diffusion of responsibility). Finally, "hardier" Eastern Europeans-most prominently from Latvia, Ukraine, and Lithuania (Matthäus, 2004, p. 268)—were increasingly deployed as the killers.

\subsubsection{The Application of Top-Down Binding Factors and Strain Resolving Mechanisms}

Although just before the invasion Himmler's men were issued with the vague “commissar order”, by 2 July 1941 Heydrich had issued the restricted order to shoot " 'all 
Jews in state and party positions" " (Streit, 1994, p. 105). On 17 July the broadest killing order conceivable was committed to writing for the first time_- " 'all Jews" " from this date onwards were to be shot (Streit, 1994, pp. 108-109). This may have been an attempt by Himmler and/or Heydrich to apply the BF of the foot-in-the-door phenomenon. As Breitman (2000, p. 48) argued:

Himmler believed that, in addition to orders, the police needed a reason to kill, and they needed social gatherings in the evening to reduce the strain. Once they had carried out mass murder in response to an alleged crime or provocation, it would be easier to get them to follow broader killing orders later.

According to Matthäus (2004), Heydrich too knew the men would struggle. He is also believed to have held a "fear of going too far too quickly" and:

instead of providing explicit orders for the rapid expansion of the killing process, the SS and police leadership in Berlin seems to have followed a course that can be described as controlled escalation (p. 263).

Einsatzgruppe B commander, Artur Nebe, suggested about a month into the invasion, in mid-July, that with so few men, what was being asked of them was simply unachievable (Browning, 2004, p. 313). However, Himmler had already anticipated the manpower issue when several weeks earlier, on 27 June 1941, he commandeered off the army his Kommandostab SS brigades, arguing: “ 'I need these units for other tasks' ” (Büchler, 1986, p. 14). Although consisting of 25,000 men, only SS Brigade One (about 7,000 men), commanded by Higher SS/Police Leader Friedrich Jeckeln, and the SS Cavalry Brigade (4,000 men) commanded by Higher SS/Police Leader Erich von dem Bach-Zelewski were to be used by Himmler to kill civilians en masse (Büchler, 1986, pp. 15-18). As Breitman (2000, p. 41) said:

In spite of the gaps in the picture, it is clear that the Order Police battalions were a less politicized force than the Einsatzgruppen. They may not have represented the average German-policeman in a police state share some characteristics and behavior that set them apart from the mass of the population. Still, what we know of their numbers and their institution suggests that they were not part of a politicalideological elite.

By 10 July Himmler had decided to use the SS Cavalry Brigade to comb the Pripet marshes in the east of Lublin, and about a week later these men received their orders to kill all Jews. Soon after their arrival, however, they struggled to carry out their orders. As Himmler and Heydrich had suspected all along, the order to shoot defenseless civilians en masse was generating what the German's themselves referred to as Seelenbelastung or " 'burdening of the soul" " (Hilberg, 1980, p. 91). It is tempting to argue that this is a phrase that scholars 
such as Milgram (1974) and Grossman (1995) might describe using their own terminology, with words like strain, trauma, and repugnance. The main source of this "burdening of the soul" seems to have been, when killing, the unavoidable and disturbing visual (and, to a lesser extent, auditory) spectacle associated with the killing of people at close range by firearms. The stress was exacerbated when shooting women and children (Lifton, 1986, p. 15). ${ }^{177}$

Himmler's suggestion as to how these men could overcome their initial reluctance to kill women and children shows how desperate the SS-Reichsführer had become. At the end of July Himmler issued the following command: " 'Express order of the FFSS [Himmler]. All [male] Jews must be shot. Drive Jewish females into the swamps" ", (Breitman, 2000, p. 60). Himmler was trying to find a way of sparing his men from having to directly murder women and children and thus experience the accompanying mental anguish. In early August SS Sturmbannführer Franz Magill informed Himmler that his idea had failed:

The driving of women and children into the marshes did not have the expected success, because the marshes were not so deep that one could sink. After a depth of about a meter there was in most cases solid ground (probably sand) preventing complete sinking (Arad, Gutman \& Margaliot, 1999, p. 415).

On a daily basis the cavalry and some local militias continued to shoot at least 3,000 Jewish males over the age of five. But despite their orders that "the Pinsk action must be completed", the men refused to follow their orders. By the evening of 8 August the action was abandoned (Büchler, 1986, p. 16-17). The remaining women and children survived for another year before being killed during the liquidation of the Pinsk ghetto on 27 October 1942 (Buna, 1966, p. 350, as cited in Büchler, 1986, p. 17). Between the end of July and mid-August 1941, a frustrated Himmler was regularly observed criticising his men for their " "soft' " behaviour. He demanded that they shoot more Jews (Büchler, 1986, p. 16). ${ }^{178}$

Himmler, incensed by the inability of his men to carry out his orders, and constantly reminded of their emotional difficulties, on 15 August 1941 asked Einsatzgruppe B commander Artur Nebe to organise an execution when he was in Minsk (Padfield, 1990, p. 342). He wanted to "see what one of these 'liquidations' really looked

\footnotetext{
${ }^{177}$ See Browning (1992, pp. 72-73) for an exception to this general rule.

${ }^{178}$ Also see Browning (1992, p. 11, 2004, p. 312), Lower (2002, p. 5), and Pohl (2000, p 143, as cited in Bloxham \& Kushner, 2005, p. 136).
} 
like” (Hilberg, 1961, p. 218). The SS Reichsführer's Chief of Personal Staff, Karl Wolff, later stated that "he knew 'from his [Himmler's] own mouth'" that Himmler had never seen people killed before (Padfield, 1990, p. 342). Nebe organised for about a hundred people to be executed - two of whom were women. Before the mass-shooting, Himmler conveyed an air of casual indifference as he asked the Jews some questions. However, the SS Reichsführer's easy attitude disintegrated as the first shots were fired, and his lack of experience of direct killing was exposed:

Both Wolff and Bach-Zelewski remembered that Himmler was shaken by the murders. 'Himmler was extremely nervous,' Bach-Zelewski testified. 'He couldn't stand still. His face was white as cheese, his eyes went wild and with each burst of gunfire he always looked at the ground' (Rhodes, 2002, p. 152).

Like subjects in the OTA experiments who engaged in avoidance-type behaviours, Himmler looked away from what was in front of him, unlike those pulling the triggers, who could not do so. ${ }^{179}$ When the two women lay down to be shot members of the squad lost their nerve, and fired badly, injuring, rather then killing them. At that point Himmler “panicked [and] ... . jumped up and screamed at the squad commander: 'Don't torture these women! Fire! Hurry up and kill them!' " (Rhodes, 2002, p. 152). This event probably showed Himmler that his concept of shooting the Soviet Jews was not commensurate with the task's disturbing perceptual reality. " 'Almost fainting, pale, [and with] limbs quivering' " Himmler had come to understand personally the problem his men were facing (Adams, 1989, p. 139, as cited in Berger, 2002, p. 62). Bach-Zelewski then said to Himmler:

Reichsführer, those were only a hundred .... Look at the eyes of the men in this Kommando, how deeply shaken they are! These men are finished [fertig] for the rest of their lives. What kind of followers are we training here? Either neurotics or savages! (Hilberg, 1961, p. 218).

According to Nebe, immediately after this execution Himmler asked him to search for a less stressful method of killing. Until its discovery the men in the field were expected to continue the mass shootings.

As the leading figure present at this execution, Himmler felt compelled to try to resolve the men's stressful experience by providing them with a variety of strain-resolving rationalisations:

\footnotetext{
${ }^{179}$ S.S.-Brigadier General Erwin Schulz behaved similarly when he organised several shooters to aim at each civilian and then "With a keen sense of delicacy, General Schulz would avert his head as the rifles were aimed. Then, after the volley had been fired, he would turn around and see that 'all persons were lying on the ground" "(Musmanno, 1961, p. 177).
} 
He pointed out that the Einsatzgruppen were called upon to fulfil a repulsive (widerliche) duty. He would not like it if Germans did such a thing gladly. But their conscience was in no way impaired, for they were soldiers who had to carry out every order unconditionally. He alone had responsibility before God and Hitler for everything that was happening. They had undoubtedly noticed that he hated this blood business ... and that he had been aroused to the depth of his soul. But he too was obeying the highest law by doing his duty, and he was acting from a deep understanding of the necessity for this operation. Himmler told the men to look at nature. There was combat everywhere, not only among men but also in the world of animals and plants ... . Didn't bedbugs and rats have a life purpose also? Yes, but this has never meant that man could not defend himself against vermin (Hilberg, 1961, pp. 218-219).

In other words, the men had no choice but to continue: it was absolutely necessary (BF), and anyway, they were in no way responsible for their actions; instead he, Himmler, was (SRM). They were not murderers; their actions were morally inverted into those of defenders against insidious vermin (SRM). For those who had already shot Jewish men, but were unconvinced by Himmler's logic that it was essential that they also had to kill women and children, they would find themselves in a foot-in-the-door trap. The men were told that if they did not kill all Jews, thereby allowing seemingly harmless victims to survive, future generations of Germans would later be targeted for revenge (BF). It was now too late to turn back. Having shot the men the bridges behind them had been burned-foot-in-the-door-like - they had to go on (BF) (Sereny, 2000, p. 281). If Himmler and the shooting squad leaders who echoed his arguments failed in appealing to their men's rationality that all Jews had to be killed, they could and did draw upon other coercive techniques. One such "evil trick" was identified by an insightful staff officer in Einsatzgruppe A (BF):

Himmler issued an order stating that any man who no longer felt able to take the psychological stresses should report to his superior officer. These men were to be released from their current duties and would be detailed for other work back home ... . In my view this whole order was an evil trick; I do not think I would be wrong to say it bordered on the malicious - for after all, which officer or SS Mann would have shown himself up in such a way? Any officer who had declared that he was too weak to do such things would have been considered unfit to be an officer (Klee et al., 1988, p. 82). ${ }^{180}$

Just as in the OTA experiments, where the experimenter attempted to cajole the subject with a barrage of BFs and/or provide them with a variety of strain-resolving rationalisations, Himmler also hoped that his BFs and SRMs might encourage the men to continue to participate in the killings. This is reminiscent of Staub's (1989, pp. 79-88)

\footnotetext{
180 "In cases where a final determination was made by the Reichsführer against a policeman, the remark 'unsuited for duties in the East' was added to his personnel file, precluding the opportunity for further promotion” (Westermann, 2005, p. 208).
} 
“continuum of destructiveness" or Darley’s (1992, pp. 207-208) “conversion process".

It is important to note that some shooting squad leaders expressed an interest in saving the Jews, not because of the psychological difficulty associated with the killings, but because (like the Nazi "productionists" in the ghettos) they believed that by killing the Jews they were wasting a valuable source of labour (Longerich, 2005, p. 211). Certain influential members of the Wehrmacht, and later the Ministry for the Occupied Eastern Territories, expressed similar concerns (Breitman, 1991, pp. 216-217; Breitman, 2000, pp. 81, 85; Lower, 2002, pp. 8-9).

However, for the shooting squad commanders, the most common concern was the detrimental impact the killing was having on their men's psychological well-being. Just as Bach-Zelewski had done, other leaders-for example, Police Lieutenant Colonel Max Montua (Breitman, 2000, p. 75) —also confronted Himmler about the impact the "burdening of the soul" was having on the rank and file. In 1942, Heinz Jost, the new commander of Einsatzgruppe A, had became so concerned about the mental state of some of his men that he also felt it necessary to directly confront Himmler. Jost got no further than Bach-Zelewski and Montua: " 'I was asked [by Himmler], 'Are you a philosopher? What is the meaning of this? What do you mean, problems? All that is concerned are our orders', " (Rhodes, 2002, p. 227). Himmler's response may have been strategic: by refusing to sympathise with his subordinates' concerns, he ensured that most of them would return to their troops and just say "orders are orders". They would then keep pushing their men until they grew accustomed to their grisly tasks, or else broke down. When some did break down, Himmler simply advised that they be sent home and replaced with another shooter. Thus, Gustave Fix of Sonderkommando 6 said: "I would also like to mention that as a result of the considerable psychological pressures, there were numerous men who were no longer capable of conducting executions and who thus had to be replaced by other men" (Klee, et al., 1988, p. 60). And as Rhodes (2002, p. 154) has noted: "Hitler's executioners may have been willing, but they were not always able."

Himmler's attrition and replacement policy was likely to have had another, unanticipated, impact on the killing toll. Those carrying out the slaughter may have been, as Browning (1992) and Goldhagen (1996) agree, “ordinary”. But as Hannah Arendt (as cited in Naumann, 1966, p. xxvii) noted, time saw the attrition and replacement policy eventually produce a concentration of ordinary men who differed from those who dropped out, in that they could more regularly handle the intense strain associated with their bloody 
tasks. Therefore, the ordinary German men who remained differed significantly from those who dropped out, in that the former were not just willing, they were also able. As implied in the infamous Jäger Report, written for the "realist" bureaucrats in Berlin, for the bigger jobs some Germans were certainly more able than others. For example, before presenting a ledger-style list of over 130,000 victims killed between 7 July and 25 November 1941 by the highly destructive Einsatzkommando 3, Jäger stated: "Following the formation of a raiding squad under the command of SS-Obersturmführer Hamann and 8-10 reliable men from the Einsatzkommando the following actions were conducted in cooperation with Lithuanian partisans [italics added]" (Klee et al. 1988, p. 46).

Somewhat like Milgram's subjects, many of the German shooters seem to have felt that, short of total disobedience, they were stuck with Himmler's seemingly relentless orders. With Himmler's rationalisations-mere words—proving incapable of relieving them of the anguish generated by the perceptually intense spectacle of the shootings, it became obvious to most that if they wanted to avoid breaking down and/or keep up the appearances of being "hard", they would have to find their own ways of relieving their "burdening of the soul".

\subsubsection{Application of Bottom-Up Strain Resolving Mechanisms}

Many perpetrators relied on alcohol to reduce the emotional stress generated by shooting their victims. As Hilberg (1961, p. 249) argued: "Most of them were drunk most of the time-only the 'idealists' refrained from the use of alcohol." As one such nondrinker from Reserve Police Battalion 101 stated: “" Most of the other comrades drank so much solely because of the many shootings of Jews, for such a life was quite intolerable sober' " (Browning, 1992, p. 82). Karl Kretschmer (from Sonderkommando 4a) explained in a letter to his family the effect of abstinence: "We have to eat and drink well because of the nature of our work, as I have described to you in detail. Otherwise we would crack up [italics original]" (Klee et al., 1988, p. 168). For some, alcohol was rationed and became a central part of the exterminatory process before, during, and/or after the mass-shootings. For example: "due to a deterioration of morale among his own men" Alfred Filbert's of Einsatzkommando 9 "had to be issued with increasing rations of vodka to carry out their killing orders" (as cited in Dicks, 1972, p. 207). And in relation to Police Battalion 322: 
In Gargzdai, Kretinga and Palanga, coveted schnapps rations were distributed following each Judenaktion ... . Within the framework of seelische Betreuung (pastoral care), social get-togethers in the evenings ... took place in order to wipe out the impressions of the day (Kwiet, 1998, p. 20, as cited in Rhodes, 2002, p. 168).

Some shooters seemed to rely on alcohol's ability to induce memory loss—-wipe out the impressions of the day"-something normally described as a negative side effect (Jung, 2001, p. 323). Other than lowering perpetrators' inhibitions, alcohol acted as a pharmacological drug, dulling the senses, and reducing their ability to accurately receive and then respond to perceptual information (Jung, 2001, p. 322).

The fact that in the early stages of the mass shootings many (although certainly not all) Jews went to their deaths without offering much resistance may also have reduced the perceptual intensity of what would otherwise have been for the executioners a much more emotionally disturbing task. Consider the following quotation by a Wehrmacht cadet officer based in the Ukraine in August 1941:

What struck me particularly was the calmness and discipline of these [Jewish] people .... The marksmen were members of the SS. On the orders of a superior they fired shots at the heads of these people with their carbines .... Sometimes the tops of their skulls flew up into the air .... The people who were to be shot walked towards this grave as though they were taking part in a procession. They walked in a line, each person with their hands on the shoulders of the person in front. They went composed and quietly to their deaths. I saw only two women weep the whole time I observed such executions. I found it simply inexplicable (Klee et al. 1988, p. 140).

This description may have been an attempt to "blame the victims", but it was not an uncommon one. Hermann Friedrich Graebe witnessed a similar event on 5 October 1943:

Without screaming or weeping these [Jewish] people undressed, stood around in family groups, kissed each other, said farewells and waited for a sign from another S.S.-man, who stood near the pit, also with a whip in his hand. During the 15 minutes that I stood near the pit I heard no complaint or plea for mercy (Musmanno, 1961, p. 91; see also Gitelman, 1997, pp. 282-283; Johnson \& Reuband, 2005, pp. 239-240).

Other witnesses, like Alfred Metzner, suggested that some Jews went to the trouble of reducing the stressful nature of the executioners' task by going to their deaths in a very orderly_-some might say considerate—manner: “ "It was amazing . . how the Jews stepped into the graves, with only mutual condolences in order to strengthen their spirits 
and in order to ease the work of the execution commandos" " (Hilberg, 1961, p. 249). ${ }^{181}$

The Gypsies (Roma) frequently caused greater difficulties for the German shooting squads. As Lieutenant Colonel Walther stated on 1 November 1941:

Shooting the Jews is easier than shooting the gypsies [sic]. I have to admit that the Jews are very composed as they go to their death - they stand very calmly—while the gypsies wail and scream and move about constantly when they are already standing at the execution site (Benz, 1999, p. 86).

However, the mentally ill put up most resistance. After shooting 748 mentally ill Lithuanians in October 1941 because they were "a 'danger' to security", Einsatzgruppe A were asked by the Wehrmacht to repeat the exercise in a similar institution (Hilberg, 1961, p. 218). Stahlecker refused, pointing out that if the Wehrmacht deemed the task so necessary then they should do it themselves (Hilberg, 1961, pp. 217-218). What Stahlecker and his men had discovered was that these institutionalised people refused to follow instructions, and became hysterical. Consequently, they were often difficult to kill instantly with one shot (thus heightening and prolonging the perpetrators' stress). Like Stahlecker, other commanders encountered similar difficulties (Arad, Krakowski \& Spector, 1989, p. 228; Headland, 1992, p. 64). The mentally ill were suddenly no longer a "danger" to security, and their execution by firing squad was no longer deemed so "necessary" after all. The prospective victim pool contracted, and attention shifted to those categories of victims who, like the Jews, generated less "burdening of the soul".

The irony in the resistance of the mentally ill and the passivity of the "sane" Jews has been highlighted in the literature. For example, after Einsatzkommando 5 had shot a group of mentally ill patients in Kiev, the men then experienced the accompanying “ 'heavy mental burden' ". Headland (1992, p. 64) has drawn attention to the apparently "twisted thinking of these men". It was "much easier to kill people who were sane" (Headland, 1992, p. 64).

However, it was the way the German executioners used their firearms that proved most effective in reducing the perceptual intensity generated by mass-shootings. The shooting techniques evolved over time. The pattern no doubt differed among

\footnotetext{
${ }^{181}$ Hilberg (1961) has also emphasised this issue: "The entire Jewish community, and particularly the Jewish leadership, now concentrated all its efforts in one direction - to make the ordeal bearable, to make death easy" (p. 668). However, as the Warsaw ghetto uprising and prisoner revolts at Auschwitz and Treblinka (to be discussed later) showed, Jewish resistance was hardly insignificant.
} 
independently operating killing squads. But the more stressful and inefficient techniques were everywhere eventually replaced by less stressful and more efficient techniques that emerged over time through a process of trail and error and word of mouth.

10.5.3 Strain Resolving Mechanism of the ad hoc Trial and Error "Exploratory" Shooting Technique

When starting out on their shooting campaigns, many squad commanders employed the only method of killing they knew-the military execution. That is, from a reasonably short distance, the executioners were assigned to shoot at one victim each (facing them in a line up).

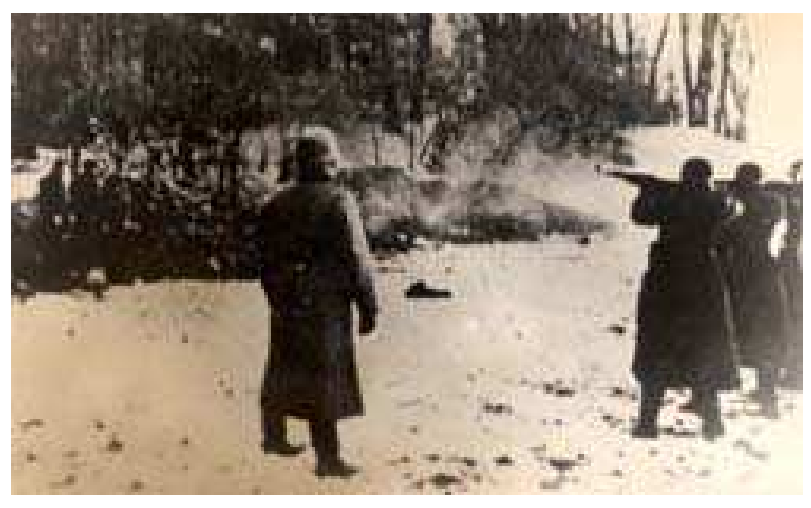

Figure 18: "Einsatzgruppen mass shooting-1941". ${ }^{182}$

As a member of Einsatzgruppe $C$ described: "In Rovno I had to participate in the first shooting .... Each member of the firing-squad had to shoot one person. We were instructed to aim at the head from a distance of about ten metres" (Klee, et al., 1988, p. 62). After firing at five civilians, this German pulled out due to "nervous strain" (Klee, et al., 1988, p. 62). In an attempt to alleviate this strain a different style of military execution evolved, whereby several shooters were required to fire at each victim. Soon after the start of the campaign, on 12 July 1941 Einsatzkommando member Felix Landau described such an execution in his diary:

${ }^{182}$ Retrieved October, 2008, from: http://www1.yadvashem.org/about_yad/magazine/data6/Browning.html 
Six of us had to shoot them. The job was assigned thus: three at the heart, three at the head. I took the heart. The shots were fired and the brains whizzed through the air. Two in the head is too much. They almost tear it off. Almost all of them fell to the ground without a sound (Klee, et al., 1988, p. 97).

Milgram's Peer Administers Shock condition was later reminiscent of this particular style of military execution. It dispersed the nervous strain among multiple subjects (and firing squad members), thus diminishing any sense of individual responsibility for each person's contributions. As the commander of Einsatzgruppe D, Otto Ohlendorf, said: "I always gave orders for several people to shoot simultaneously, in order to avoid any individual having to take direct, personal responsibility" (Klee, et al., 1988, p. 60). ${ }^{183}$

The earlier executions produced other problems. Because the victims collapsed where they were shot, the shooting squad members had to dig graves to hide all evidence of the killings. However, this meant that the perpetrators had to confront directly the horrific human consequences of their actions. According to Grossman (1995, p. 112), confronting a person one has just killed can significantly accentuate the initial trauma "since some of the psychological buffer created by a midrange kill disappears upon seeing the victim at close range." The executioners learnt early in the campaign that it was both physically and psychologically less burdensome if some of the victims were forced to dig the graves before they were shot. Then all those about to be shot were required to stand on an edge of the grave, from which upon being shot they would fall into the grave, and quickly disappear from view (Musmanno, 1961, p. 76). The graves were then rapidly covered over, before the killing squads moved on.

\footnotetext{
${ }^{183}$ In the early stages, other squads went through a similar step-by-step learning process. Consider the experiences in early August 1941 of Sonderkommando 4a, where according to August Häfner: "A group of Jews was lined up by the edge of the grave. There were about ten to twelve of them. They were standing facing the marksmen. There was one marksman for each Jew. Then the platoon-leader of the Waffen-SS platoon gave the order to fire. The victims fell backwards into the grave. When it became apparent that many of the victims did not die immediately the method of execution was changed. Then a discussion was held .... The outcome of this discussion was an order to the Waffen-SS platoon to aim at the head for the rest of the execution. The result of this was that if the marksmen hit their target the tops of the victims' skulls flew into the air and bits of their brains were spattered in the faces of the firing-squad. KompanieFührer [company commander] Grafhorst, who felt responsible for his men, was strongly opposed to this type of execution. And so once again the method of shooting was changed [presumably to shoot at the heart which also proved inadequate] . . . During this discussion it was said that this type of shooting was intolerable for both the victim and firing-squad members. This was because when the firing squad aimed at the heart, in my view, about twenty-five per cent were off the mark and when the victims were shot in the head, not only did the victims have to look at the firing-squad but in addition five per cent were not killed outright" (Klee, et. al., 1988, p. 114). Reserve Police Battalion 101 went through a similar learning process during their first few mass shootings (see Browning, 1992, pp. 55-87).
} 


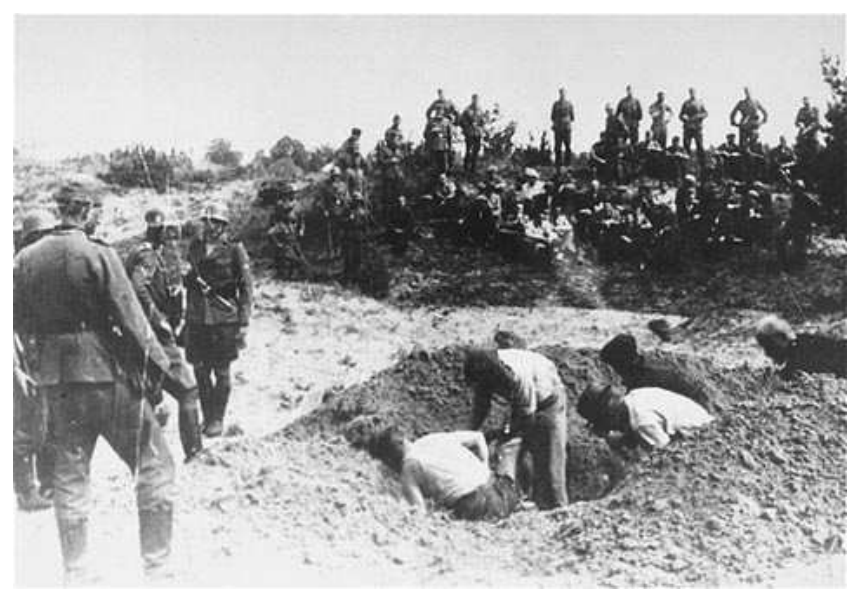

Figure 19: "Jewish men are forced to dig their own graves before being executed". ${ }^{184}$

Although victims quickly disappeared into the graves, the perpetrators could not shoot them without having to look at them relatively close-up, just before and during the executions. Bauman (1989, p. 26) has pointed out that consequently the executioners were inclined to distance themselves as far as possible from their victims. This strategy, however, only created another problem: less accurate shooting, with some victims falling into the graves unharmed or, more often, seriously wounded rather than dead. After they had been buried alive, some would try to claw themselves out of the grave to escape.

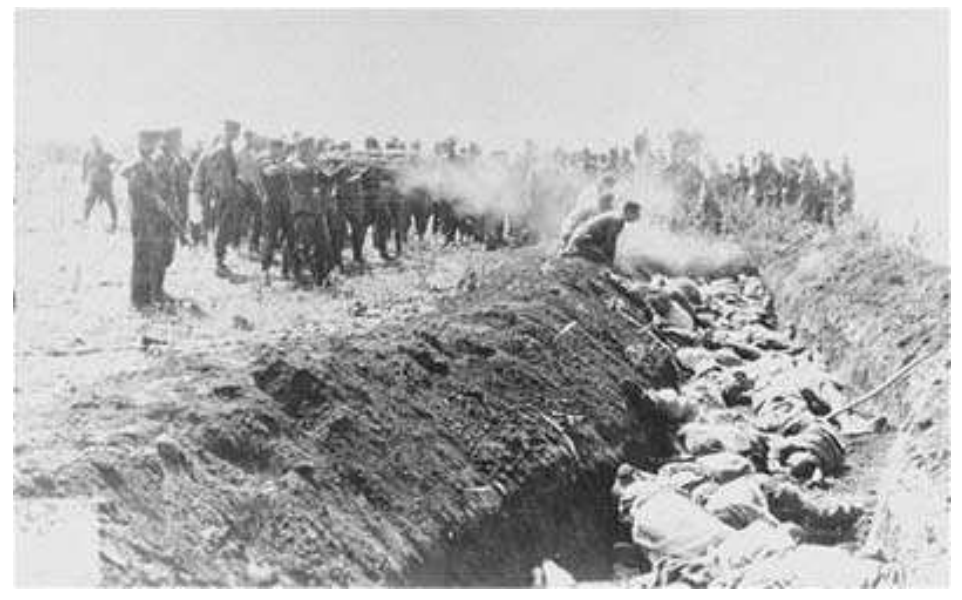

Figure 20: "An Einsatzgruppe during the execution of Soviet civilians in Kraigonev, USSR. Summer 1941." 185

\footnotetext{
${ }^{184}$ Retrieved September, 2008, from: http://www.historyplace.com/worldwar2/holocaust/h-einz-42.htm

${ }^{185}$ Retrieved October, 2008, from: http://www.nachfolgeprozesse.nuernberg.de/english/trials/trials10.html
} 
Nazi commanders soon demanded changes to this shooting technique, which they found abhorrent. For example, an S.S.-Commissioner-General complained in a letter to the Reich Minister:

Peace and order cannot be maintained in White Ruthenia with methods of that sort. To bury seriously wounded people alive who worked their way out of their graves again, is such a base and filthy act that this incident as such should be reported to the Führer and Reichsmarschal (Musmanno, 1961, p. 82). ${ }^{186}$

As with Himmler at the execution in Minsk, it was not the killing of innocent people that concerned the S.S.-Commissioner-General. Rather, it was the method of killing that he found reprehensible.

The firing squads' accuracy had to be improved. To do so the perpetrators had to move closer to their victims. Of course, the closer they got, the more they could see and hear, intensifying their psychological burden. It was a dilemma. Many years later, a Vietnam Special Forces veteran related his own similar experiences to Grossman (1995): “ 'When you get up close and personal,' he drawled with a cud of chewing tobacco in his cheek, 'where you can hear 'em scream and see 'em die,' and here he spit[s] tobacco for emphasis, 'it's a bitch'" (p. 117). Because they were defenseless and often acquiescent civilians, the Germans had opportunities to manipulate their victims in ways that the Vietnam veteran could not. To maximise accuracy, the executioners had to see exactly where they were shooting. As they moved closer to their victims one of the ad hoc techniques commonly used to alleviate the psychological strain was to have the victims turn their backs to the shooters. This enabled the shooters to avoid any eye contact with their victims. Nor could the perpetrators then see the fearful expressions on the faces of their imminent victims. In Grossman's (1995, p. 128) words:

The eyes are the window of the soul, and if one does not have to look into the eyes when killing, it is much easier to deny the humanity of the victim. The eyes bulging out 'like prawns' and blood shooting out of the mouth are not seen. The victim remains faceless, and one never needs to know one's victim as a person. And the price most killers have to pay for a close-range kill- the memory of the 'face terrible, twisted in pain and hate, yes such hate' - this price need never be paid if we can simply avoid looking at our victim's face.

\footnotetext{
${ }^{186}$ For other examples of victims digging themselves out of graves see Regional Commissioner Slutsk's 30 October 1941 report to the General Commissioner in Minsk (Browning, 1992, p. 22). See also Klee et al. (1988, p. 176) and, from a survivor's perspective, see Gitelman (1997, pp. 275-278).
} 
Also, because the victims faced away from their executioners the latter were not so directly forced to hear any crying or screaming.

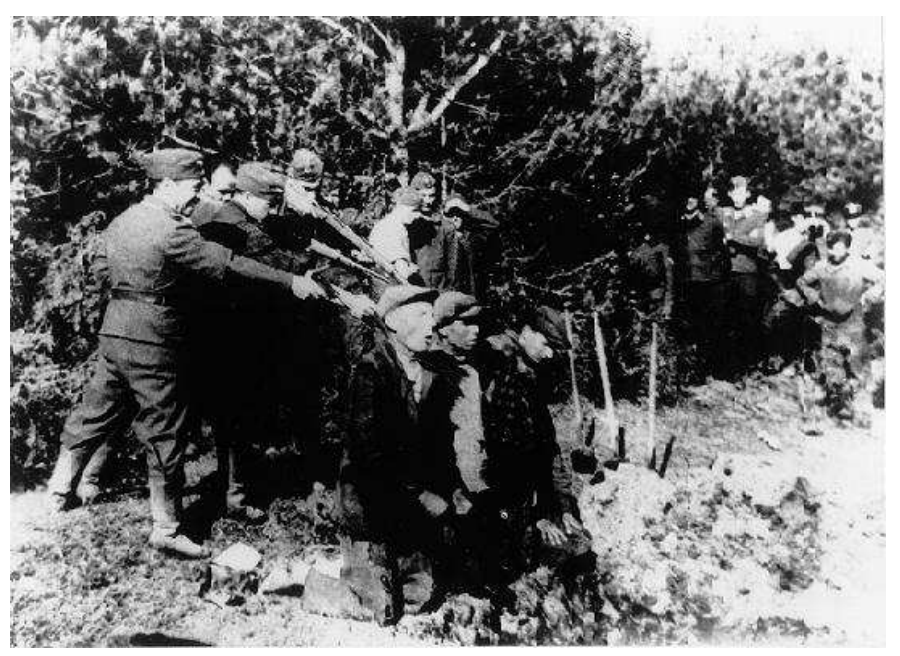

Figure 21: Execution of Jews by the Einsatzkommando in Kovno (Berenbaum, 1997, p. $115)$.

This method, however, was also not without its problems. For example, sometimes victims' heads exploded when hit by a bullet, a sight the shooter could not avoid seeing. Such images haunted some of the shooters. After some experimentation the Genickschuss, or neck-shot, method became what Goldhagen (1996, p. 217) has termed the "recommended shooting technique". This technique required the victim face away from the executioner, or lie face-down on the ground. Then, from point-blank range, the shooter would fire a single shot into the nape of the neck (just above the shoulders). The bullet would enter the back of the neck, producing only a small entrance wound and severing the victim's spinal cord, thus causing instant death. If the victim was lying face down the shooter could not see the larger exit wound. Compared to some of the earlier shooting techniques, the Genickschuss method was un-survivable, relatively clean, and because it resulted in instant death, was perceived by many Nazis as being more "humane". 


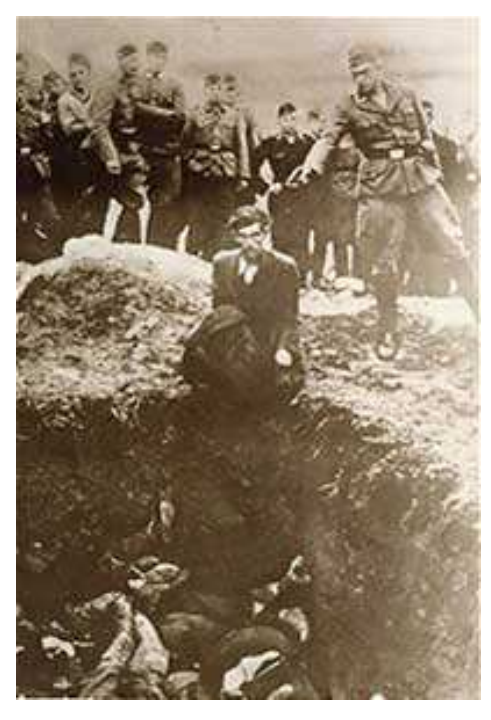

Figure 22: A member of Einsatzgruppe D shooting a man sitting by a mass grave in Vinnitsa, Ukraine, in 1942. The back of the photograph is inscribed "The last Jew in Vinnitsa" (Berenbaum, 2006, p. 93).

Perpetrators came to find mass killing more easily doable, by using such techniques. As Hilberg (1961, p. 218) has argued: "For many, undoubtedly, the task became just another job, to be done correctly and mechanically, i.e., the men made some sort of 'adjustment' to the situation".

With fewer psychologically fragile perpetrators, and more increasingly "harder" ordinary Germans involved in the killings, ambitious leaders in the field continued to come up with innovative changes to the shooting technique. Probably the most significant development was Higher SS/Police Leader, Friedrich Jeckeln's, “Sardinenpackung” shooting method, introduced at the end of July 1941 (Rhodes, 2002, p. 114). A minor bureaucrat, August Meier, has described how this technique evolved and what it entailed:

I still particularly recall an Aktion in Schepetovka which stands out in my mind as extraordinarily gruesome. It involved about a hundred people. Women and children were among those shot. Jeckeln said: 'Today we'll stack them like sardines.' The Jews had to lie layer upon layer in an open grave and were then killed with neck shots from machine pistols, pistols and rifles. That meant they had to lie face down on those previously shot [whereas] in other executions they were shot standing up and fell into the grave or were dragged in .... I don't know if Jeckeln did any shooting, but I don't believe so (Wilhelm, 1991, p. 231, as cited in Rhodes, 2002, p. 114). 
This method of mass execution proved to be very effective. According to Hilberg (1961, p. 196), by the end of August 1941, Jeckeln's 7,000 strong Kommandostab SS Brigade One, which Breitman (2000, p. 41) believes "were not part of a political-ideological elite" had shot 44,125 civilians in the Western Ukraine-a figure which Büchler (1986, p. 17) believes exceeded those of any other units that month. Other shooting squads soon adopted this technique.

\subsubsection{Bureaucratisation of the Mass-Shootings}

By late September 1941, Jeckeln's highly efficient "Sardinenpackung" method was used at the front end of an assembly-line process of mass murder. During the Babi Yar massacre in the Ukraine, Jeckeln's execution team showed they could kill more people more quickly than any other unit (see Rhodes, 2002, p. 175). A truck driver named Höfer described what he saw:

The Ukrainians led them past a number of different places where one after the other they had to remove their luggage, then their coats, shoes and overgarments and also underwear. They also had to leave their valuables in a designated place. There was a special pile for each article of clothing. It all happened very quickly and anyone who hesitated was kicked or pushed by the Ukrainians to keep them moving . . . . Once undressed, the Jews were led into a ravine which was about 150 metres long, 30 metres wide and a good 15 metres deep. Two or three narrow entrances led to this ravine through which the Jews were channeled. When they reached the bottom of the ravine ... . there was a 'packer' at either entrance to the ravine. These 'packers' were Schutzpolizisten, whose job it was to lay the victim on top of the other corpses so that all the marksman had to do as he passed was fire a shot (Klee et al. 1988, pp. 63-66).

In just two days 33,771 Jews were killed in the way. Specialists removed clothing and valuables, men on cordon duty channeled the victims towards the sardine "packers" who prepared them for the arrival of the hardened "marksmen" who, as they passed by, could casually yet rapidly carry out the killing. Such a precise division of labour in an assemblyline of death was instrumental in generating what was, at this stage of the Holocaust, a staggering statistic of mass murder.

However, even some of the "ordinary" shooters who had been hardened by several months of killing were struggling. For example, Kurt Werner, one of the German marksmen at Babi Yar, admitted: "It's almost impossible to imagine what nerves of steel it took to carry out that dirty work down there. It was horrible" (Klee, et al., 1988, p. 67). 
With a seemingly endless supply of victims to be killed, the question was: how long could men like Werner keep this up?

The reports submitted to Berlin by the shooting squad leaders rarely mention the existence of any psychological problems among the perpetrators. But as Headland (1992) pointed out: "there is much proof that this was often a serious problem with these men and that this problem demanded constant attention" (p. 211). ${ }^{187}$ Consider Lifton's (1986, p. 15) interview with a former Wehrmacht neuropsychiatrist who, after having treated many of those affected, believed that about 20 percent of the men suffered from psychological disorders associated with the shootings. In November 1941, international lawyer Helmuth von Moltke (as cited in Streit, 1994) wrote in a letter to his wife that at least one hospital existed " "where SS men are cared for who have broken down while executing woman and children" " (p. 116). SS-Obersturmführer Albert Hartl has delved further into the concerns of another doctor:

SS-Gruppenführer Thomas was . . . very preoccupied with the psychological repercussions of the Einsatz on his people. From my conversations with him I know that these effects took many different forms. There were people whose participation awakened in them the most evil sadistic impulses ... . The Einsätze also had the reverse effect on some of the SS men detailed to the firing-squads. These men were overcome with uncontrollable fits of crying and suffered health breakdowns. Thomas once told me that a very common manifestation in members of these firing-squads was temporary impotence. It also happened that one member of the Einsatzgruppe who had participated in mass shootings one night suddenly succumbed to a type of mental derangement and began to shoot wildly about him, killing and wounding several men (Klee et al. 1988, pp. 83-84).

Some of the commanders of these execution squads, who themselves never had to kill anybody, were susceptible to "burdening of the soul". SS-Obersturmführer August Häfner has described the mental breakdown of Paul Blobel (leader of Sonderkommando $4 a$ ), in July 1941, and his desperate calls for a less stressful and more efficient killing method:

I found my unit, they were all running around like lost sheep. I realized that something must have happened and asked what was wrong. Someone told me that [Standartenführer] Blobel had had a nervous breakdown and was in bed in his room .... He was talking confusedly. He was saying that it was not possible to shoot so

\footnotetext{
${ }^{187}$ In support of this, Sereny (2000) has said: “As we know from many soldiers' letters found over the last years, and hundreds of statements by German witnesses in the Einsatzgruppen trials in West Germany, the killings put an intolerable strain on personnel—despite liberal supplies of alcohol and sex — and provoked protests from the Wehrmacht" (p. 141).
} 
many Jews and that what was needed was a plough to plough them into the ground. He had completely lost his mind (Klee et al. 1988, p. 111). ${ }^{188}$

Other commanders, including Einsatzkommando 3's Karl Jäger (Fleming, 1984, p. 98), and Higher SS/Police Leader Bach-Zelewski (Rhodes, 2002, p. 226), suffered similar breakdowns. The shootings appear to have affected the mental well-being even of Einsatzgruppe B commander, Artur Nebe (Rhodes, 2002, p. 225; Rubenstein \& Roth, 1987, p. 134). The most popular and effective means of reducing or even eliminating the "burdening of the soul" was to ensure that Eastern European German collaborators were increasingly deployed at the killing end of this bureaucratised process of mass murder.

\subsubsection{The Insertion of "End Special Units"}

It was obvious to Himmler that even though they did not have guns, some of the anti-Semitic Eastern Europeans appeared much more eager than his own men to attack Jews. So he would have seen the prospective "gains" to be had from arming them. This possibility seems to have been raised at a 16 July 1941 meeting in Berlin, but Hitler was adamant that the Eastern Europeans should never be armed (Matthäus, 2004, p. 273). However, in late July 1941, as his Kommandostab SS Cavalry Brigade was desperately herding Jewish women and children into the quicksand, in total disobedience to Hitler's emphatic order Himmler "authorized the creation of auxiliary police forces from the reliable non-Communist elements among Ukrainians, Estonians, Latvians, Lithuanians and Byelorussians" (Breitman, 2000, p. 52). He apparently did so "because "the task of the police in the occupied eastern territories can not be accomplished with the manpower of the police and SS now deployed or yet to be deployed" " (Browning, 2004, p. 310). But as Breitman (2000, p. 53) has observed:

The creation of Schutzmannschaften and their future use as executioners reflected more than just a shortage of German policeman. Whereas Himmler, Daluege, Bach-Zelewski, and some other high officials had some concerns for the morale of German police, they did not much care what happened psychologically to the nonGermans as long as there were enough of them to carry out their appointed tasks [italics added].

Simply increasing the manpower was unlikely to work, but it seems Himmler suspected that augmenting a certain type of manpower might. This may explain Himmler's disobedience. By the end of 1941, 33,000 native collaborators had been added to the

\footnotetext{
${ }^{188}$ Also see Browning (1992, p. 69).
} 
German extermination squads (Browning, 1994, p. 140). Six months later the number had risen to 165,000, and by January 1943 it had almost doubled to 300,000 (Browning, 1995, p. 106).

However, simply arming large numbers of Eastern Europeans was, by itself, inadequate. The task at hand demanded meticulous logistical and organisational preparation. ${ }^{189}$ Under the careful management of the German authorities, their Eastern European collaborators were slotted into the end of the shooting assembly line where they could efficiently perform their specialist type of labour.

A mass shooting undertaken during August 1941 in the Ukrainian village of Byelaya Tserkov illustrates the way in which the collaborators were used. Immediately after the initial shooting of the Jewish men, women, and two boys the Germans involved chose not to shoot the children who remained. Instead, they were held in a house without food or water. Most of the children were later shot by some Ukrainian auxiliaries. However, the Ukrainians left behind the 90 or so children under the age of seven-who were mainly toddlers and babies. Having recovered from his mental breakdown, Paul Blobel discussed the situation with his subordinate Häfner:

Then Blobel ordered me to have the children executed. I asked him, 'By whom should the shooting be carried out?' He answered, 'By the Waffen-SS.' I raised an objection and said, 'They are all young men. How are we going to answer to them if we make them shoot small children?' To this he said, 'Then use your men.' I then said, 'How can they do that? They have small children as well.' This tug-ofwar lasted about ten minutes ... . I suggested that the Ukrainian militia of the Feldkommandant should shoot the children. There were no objections from either side to this suggestion (Klee et al., 1988, p. 153).

Regarding the proposed execution site, Häfner continued:

The Wehrmacht had already dug a grave. The children were brought along in a tractor .... The Ukrainians were standing round trembling. The children were taken down from the tractor. They were lined up along the top of the grave and shot so that they fell into it. The Ukrainians did not aim at any particular part of the body. They fell into the grave. The wailing was indescribable. I shall never forget

\footnotetext{
${ }^{189}$ According to one Einsatzgruppen report: “"The Romanians proceed against the Jews without any plans. There would be nothing to complain about the very numerous shootings of Jews if the technical preparations and implementation were not so inadequate" " (Browning, 2004, p. 400). Dicks (1972) has also pointed out that at one SS officer's trial the prosecutor reported the former "stopped the wild shooting of the Lithuanian auxiliary police, but he substituted for it the routine mechanical slaughter of the Chicago stockyards at the rate of 500 [Jews] a day' " (p. 206).
} 
the scene throughout my life .... Many children were hit four or five times before they died (Klee, et al., 1988, p. 154).

The rejuvenated Blobel clearly held no qualms in ordering the Ukrainians to undertake this mass execution. Perhaps unsurprisingly, he chose not to attend.

The Eastern Europeans were increasingly given the killing tasks, like the shooting of women and children, that the Germans often shied away from (see Matthäus, 2004, p. 275). As a member of Einsatzgruppe A stated:

The orders for the third or fourth Einsatz were particularly important because they gave instructions for members of the local population to be used to carry out the actual dirty work, to which end special units should be set up. The purpose of this measure was to preserve the psychological equilibrium of our own people [italics added] (Klee, et al., 1988, p. 81).

Although the German supervisors and executioners may not have liked to admit it, the locals in these "end special units" (that is, the last and most stressful link in the bureaucratic killing chain) were responsible for producing some of the bleakest statistics. For example, it will be recalled that the Jäger report (which listed the deaths of over 130,000 civilians killed in less than five months) stated the massacres were undertaken by only eight to 10 "reliable" Germans in "cooperation with Lithuanian partisans" (Klee et al. 1988, p. 46). As Matthäus (2004) said of the Lithuanians under Jäger's control: "these men contributed massively towards the staggering figure" (p. 273). ${ }^{190}$

The most common strategy that was used to prevent members of the German execution squads becoming, as Bach-Zelewski stated, "neurotics or savages" was one that (unlike alcohol, and the evolving shooting technique) made it possible for the German perpetrators to engage in total perceptual avoidance. As a security-police interpreter in Liepaja stated: "It was only in the early days that members of our section had to man the firing-squad. Later we had a Kommando of Latvians who made up the firing-squad" (Klee et al., 1988, p. 126). The reason this strategy proved so popular among the Germans-as Milgram's Peer Administers Shocks experiment later demonstrated, when an actor was placed at the "sharp" end of the process—was that it enabled all the non-shooters to make

\footnotetext{
${ }^{190}$ As MacQueen (1997, p. 100) concluded: "Jager's 'achievement' has to be considered largely as a triumph of managing the Lithuanian Schutzmannschaft forces (some 8,000 men by the end of 1941) and the Lithuanian Police, without whom this deadly work would not have been remotely possible."
} 
their own essential contributions to the killing process (victim capture, round up, cordon duty, and so on) without feeling personally responsible for the deadly outcome. With the help of the non-Germans as shooters, "Even at the lowest level of the Nazi hierarchy, one could play one's part in the 'final solution' without dirtying one's hands" (Lower, 2005, pp. 251-252).

The use of Ukrainians, Latvians, Lithuanians, and others at the killing-end of the extermination assembly line (the most destructive of whom were, for obvious reasons, often deployed as specialists outside their homelands), ${ }^{191}$ raises another question. If the psychological strain generated by shooting civilians was as debilitating as many Germans attested after the war, why did the Eastern Europeans not seem to experience comparable levels of strain and trauma? One possible reason may be that in the wake of Operation Barbarossa, many of the Eastern Europeans in the armed forces automatically became prisoners of war. Therefore, it was only after they agreed to do the Germans' dirty work that their status changed and, as a result, they became less likely to die from starvation (Arad, 1987, pp. 20-21; Browning, 1992, p. 52). ${ }^{192}$ Therefore, they too may have struggled with the shootings, but continued to participate in an effort to secure their own survival. Another reason maybe that, as Bauer (2001, p. 103) pointed out earlier, the Germans who were involved in killing all of the Jews came from a mildly anti-Semitic society. To ensure that the orders of those in Berlin were met, the Germans frequently required the help of those who more likely actually hated the Jews and, as a result, might be more willing to act on such feelings. ${ }^{193}$ In this regard, Breitman (1991, p. 204) has recorded:

After the war Erich von dem Bach-Zelewski explained that the extermination camps arose because Germans and Central Europeans were not suited to be mass executioners. Stalin, he said, always had people to employ for this purpose-for example, the Latvians. Although the Nazis found some individuals to serve as killers, there was no collective eagerness to do so. The extermination camp . . . was something that the Russians could not accomplish: it reflected the German gift for organization. Bureaucrats created it, he concluded.

\footnotetext{
${ }^{191}$ For example, in Belorussia the locals were not keen to collaborate in the extermination process. The Germans frequently imported shooters from Latvia and Lithuania to undertake this work (Matthäus, 2004, p. 268).

192 The only non-Germans who were to be fed during the Soviet invasion were, as Goering himself said, those " "performing important tasks for Germany" " (Herbert, 2000, p. 257, as cited in Rees, 2005, p. 44).

${ }^{193}$ Arad (1987, p. 20) has encapsulated all of the above and other factors likely to have motivated the Eastern European into undertaking the shootings.
} 


\section{$\underline{10.6 \text { Conclusion }}$}

A variety of top-down and bottom-up techniques were used to try and ease the psychological burden associated with engaging in the mass shootings. Himmler and other leading figures offered a variety of BFs and SR-rationalisations. And there were the trial and error discoveries within the German execution squads of methods to reduce the perceptual intensity of the mass-shootings. These included the heavy consumption of alcohol, taking advantage of the more docile victims, the evolving shooting technique and - after the bureaucratisation of the shooting process (Lower, 2002, p. 7) - the almost exponential dependence on Eastern European collaborators to carry out the shootings. As Lower (2005, p. 251) argued:

The Nazi implementation of the "final solution" was an ongoing invention of central and peripheral leaders. Hitler, Himmler, and Heydrich defined the aim . . . . Yet, [once legitimised] in its implementation, the 'process' of mass murder developed from the ground up .... the most remarkable administrative pattern was one of ad hoc collaboration.

In the end, although the use of guns required a large number of executioners, complex logistics, and was hard to keep hidden from public view, it nonetheless proved capable of killing people on a horrendous scale. Despite the initially slow start to the shooting campaign and perhaps even to the surprise of the leading Nazis themselves, by the end of the war the use of this killing method ended about 1,400,000 Jewish lives (Hilberg, 2003, p. 1320). About 25 percent of all the Jewish victims killed during the Holocaust perished in these open air shootings

Nonetheless, as far as the Nazis were concerned, the major limitation with this means of killing was that although (like starvation) it enabled the executioners to avoid having to experience tactile perceptual stimulation, guns (unlike starvation) required them to see the connection between themselves, their act of killing, and the effects on their victims. While throughout the war the Nazi regime never completely abandoned this killing method, as 1941 came to an end they had concluded that, despite having become highly efficient, the use of firearms alone could not provide any long-term "solution" to their European-perhaps worldwide?_- "Jewish problem" (Lower, 2005, p. 245). The main shortcoming with the use of guns was that they made many of the executioners feel directly responsible for their actions, thereby stimulating intense feelings of strain, guilt, trauma and, perhaps most commonly, repugnance. What was needed instead was a more 
impersonal (less perceptually perceivable and strain-inducing), more private, and less

labour intensive, and even more industrially organised, method of mass extermination. 


\title{
Chapter Eleven: Further Along the "Twisted Road" to Treblinka
}

\begin{abstract}
[I]t was exceedingly difficult for the shooters to overlook the connection between shooting and killing .... Other murder techniques were therefore sought—such as would optically separate the killers from their victims-Bauman (1989, p. 26).
\end{abstract}

When in December 1941 I was transferred to Rauff's department he explained the situation to me, saying that the psychological and moral stress on the firing squads was no longer bearable and that therefore the gassing programme had been started-August Becker (as cited in Klee et al., 1988, p. 69).

It will be recalled that after Himmler had personally observed a mass-shooting, he requested that Nebe search for a new method of killing. The intention of this chapter is to present the results of Himmler's directive and the influence it had on what is referred to as Operation Reinhard: the extermination of all the Jews in the General Government. The discussion reaffirms the importance of intuition, previous experience, and the ad hoc trial and error "exploratory" method of discovery in the invention and gradual refinement of the means of mass killing. It also confirms the increasing bureaucratisation of the killing processes.

\section{$11.1 \quad$ Nebe's Experiments}

After the mid-August 1941 mass-shooting in Minsk, Himmler, Wolff, BachZelewski, and Nebe visited a recently formed ghetto which had a large institution housing the mentally ill. Relying on strain-resolving euphemistic language, Himmler casually suggested that Nebe “"release" " (meaning "kill”) these people (Rhodes, 2002, p. 154). But shooting such people was extremely stressful, so Nebe informed Himmler that he (Nebe) " "could not ask his troops to shoot these incurably insane people" " (Friedlander, 1995, p. 141). Nebe then inquired as to how he might carry out this task. " 'Himmler said that today's event had brought him to the conclusion that death by shooting was certainly not the most humane'" (Rhodes, 2002, p. 154). Then, "Himmler asked Nebe 'to turn over in his mind' various other killing methods more humane than shooting" (Hilberg, 1961, p. 219).

Himmler knew that Nebe had overcome similar killing problems during the latter's involvement in the Euthanasia programme (de Mildt, 1996, p. 56; Friedlander, 1995, pp. 
54-55, 86-87). Subsequent events reveal that this conversation came to powerfully influence the fate of the Jews and Gypsies who in the Polish ghettos had managed to avoid starvation and its related illnesses.

Following Himmler's request, Nebe soon consulted with Dr. Heess and acquired the help of a former colleague from the Euthanasia programme - the chemist, Albert Widmann (one of the inventors of the bottled (pure) carbon monoxide gassing technique). Both Heess and Widmann were from the Criminal Technology Unit in Berlin. During the middle of September 1941 they engaged in their first ad hoc experiment. Milgram's Proximity Series would suggest that if Nebe's and Widmann's experiments were to diminish the "burdening of the soul", they would have to reduce the perceptual intensity generated by the shootings. Or, optimally, as in the Truly Remote Pilot, they would have to find a way for the perpetrators to avoid experiencing all sources of such stressful stimulation. The duo's first experiment, using explosives, was inadvertently a step in this direction. According to Arad (1987, p. 10):

Twenty-five mentally ill people were locked into two bunkers in a forest outside Minsk. The first explosion killed only some of them, and it took much time and trouble until the second explosion killed the rest. Explosives therefore were unsatisfactory.

It did not help that, along with the victims, explosives also tended to destroy the bunkers. Moreover, the victims' body parts had to be retrieved (some of which were hanging from the branches of nearby trees) (Breitman, 1991, p. 201; Browning, 1985, p. 60; Friedlander, 1995, p. 141).

A group of men under Odilo Globocnik (the commander of the SS and Police in the districts of Lublin and Triest) were also struggling with the strain generated by the massshootings. A month later, during October 1941, they were independently experimenting with a similar method of killing. Their experiment produced a killing technique, whereby victims were forced to lie in a ditch head-to-toe in batches of ten; and then the killers, while seeking cover, lobbed hand-grenades on top of them. Again, body parts filled the air, and if anybody survived the perpetrators would then administer what they euphemistically referred to as "mercy shots". Globocnik's men are believed to have murdered about 75,000 civilians with this killing technique (Breitman, 1991, p. 201). Although in the absence of these so-called "mercy shots", this method often enabled the perpetrators to automatically avoid the horrific visual spectacle while killing. Eventually, this method was also abandoned. Like Nebe and Widmann before them, Globocnik's men 
continued to search for a less strain-inducing means of killing large numbers of victims. One of their experiments was even more of a failure, and for obvious reasons, was immediately abandoned. ${ }^{194}$

The day after the failure of Nebe and Widmann's explosives experiment, they moved to an asylum in Mogilev, where they embarked on a second experiment that, as it happened, enabled the perpetrators to avoid any disturbing visual spectacle while killing. Drawing on both an intuitive feeling for what Germans might willingly use, and also previous experiences, Nebe (with Widmann's help) connected one end of a hose to the exhaust pipe of a running motor vehicle and the other end to a hermetically sealed room containing 20 to 30 mentally ill patients. ${ }^{195}$ A cheap, abundant, and mobile alternative gas to that used by the Tiergartenstraße 4 (T4) killers had been found. Around this time, too, a similar experiment that led to the discovery of a second alternative gas was undertaken by Karl Fritzsch at the Auschwitz concentration camp. ${ }^{196}$ Also motivated by the desire for an alternative to the mass shootings, around this time period there were a variety of killing experiments being undertaken by Nazi officials, usually independently of one another. ${ }^{197}$

\footnotetext{
${ }^{194}$ A month later during November 1941, a number of Gestapo men, who Rhodes (2002, pp. 201-203) has assumed were some of Globocnik's subordinates, poured slaked lime over a large group of Jews they had squeezed into a deep pit. The victims were slowly burned to death by the chemicals. Rhodes believes the men were trying to combine the killing and decomposition of corpses into a single and therefore more efficient operation. The experiment was deemed a failure "because the suffering of the victims was so extraordinary that it disturbed even perpetrators hardened by months of participation in mass shootings" (Rhodes, 2002, p. 203). This method of killing increased both visual and auditory perceptual stimulation and extended it over a longer period.
}

${ }^{195}$ Many years earlier Nebe, after having driven home drunk one evening, nearly killed himself when he parked his vehicle in his garage, failed to turn the motor off, and fell asleep (Browning, 2004, p. 355).

${ }^{196}$ Soon after the start of Operation Barbarossa there was a sudden influx of Soviet POWs into the Auschwitz concentration camp in Poland. Commandant Rudolf Hoess had been ordered to immediately execute the leaders (Breitman, 1991, p. 202; Hoess, 2001, pp. 124, 146, 185). Hoess had them shot in small groups, but like other Germans elsewhere, it eventually got to the point where Hoess and his men 'had had enough of ... the mass killings by firing squad ordered by Himmler and Heydrich' (Berenbaum, 1997, p. 184). One day when Hoess was away, his deputy, Hauptsturmführer Karl Fritzsch, experimented with an extremely poisonous pesticide called Zyclon-B. Zyclon-B consisted of small pellets which turned into gas when exposed to oxygen at a temperature of 25.7 degrees Celsius (Wellers, 1993, p. 206). Fritzsch then came to the view that if Zyclon-B could easily kill vermin it probably could kill humans as well. On 3 September 1941 (less than two weeks before Nebe's experiments) a large group of Soviet POWs and some Polish prisoners where placed in a sealed detention cell. Pellets of the pesticide were then dropped into a small number of re-sealable vents in the roof. The victims died soon afterwards (Hoess, 2001, pp. 146-147). Upon Hoess's return, Fritzsch replicated his experiment, and Hoess later admitting being surprised by the fact that Zyclon B killed the victims quickly: "A short, almost smothered cry, and it was all over" (Hoess, 2001, p. 146). Hoess was also "relieved to think that we were to be spared all those blood-baths" (Hoess, 2001, p. 147).

${ }^{197}$ At the Mauthausen concentration camp similar less "successful" killing experiments had taken place: "Construction of this basement labyrinth began in October 1941. In the dark corridors and rooms inmates under sentence of death—'special treatment' was the euphemism—were hung after climbing onto an automatically operated, collapsible stool. Others were lined up and shot from behind. Deceived into believing they were to be measured or photographed (a device draped with a black cloth made to resemble a 
Most failed or proved unviable, but the trial and error experiments by Nebe and Fritzsch gained prominence.

Widmann's trial after the war revealed that "Nebe discussed the technical aspects of the idea with Dr. Heess and together they brought the proposal before Heydrich who adopted it" (Arad, 1987, p. 11). ${ }^{198}$ There is a similarity between Nebe's invention of the exhaust gas chamber, and Milgram's shock generator: both drew upon previous experiences and upon an intuitive hunch in the invention/selection of a means of inflicting harm they thought many people might use on others. Before the end of September 1941, Nebe's innovation was incorporated into one of the original gas vans. Tests using this prototype were then undertaken on a group of Soviet POWs in Sachsenhausen concentration camp. From the perspective of the actual killers the results were deemed so "satisfactory", that it was decided to produce more killing vans than had originally been planned (Breitman, 1991, pp. 201-202; Browning, 2004, pp. 355-356). A month or so after the tests the first vans off the production line were sent to the East, to be used on those victims who produced the greatest "burdening of the soul" - that is, the mentally ill, and women and children. By 23 June 1942, twenty to thirty gas vans had been built, under the supervision of Walter Rauff in the RSHA Criminal Technical Institute (Arad, 1987, p. 11; Spektor, 1993, p. 54).

\subsection{Arrival of the Einsatzgruppen Gas Vans}

The first batch of gas vans invented by Nebe arrived in the Soviet interior and were immediately put to use. A recipient of one of the vans was the leader of Einsatzkommando $4 a$, Paul Blobel, who_-as shown earlier-had suffered acute "burdening of the soul". During his trial in 1947, Blobel stated: “ 'In September or October 1941, I received a gas

camera stood nearby) the inmates pressed against a wall into which holes had been bored. Through these openings an SS man, armed with a sub-caliber gun, fired into the victim's neck. After each execution, from behind the door of the adjoining mortuary an inmate swiftly emerged to wipe up the traces of the killing and drag away the body; he then closed the door just before the next victim arrived. In this manner the inmates could be killed individually at a rate of 2 per minute, or up to 30 per hour [sic]" (Horwitz, 1990, p. 17). As part of Himmler's 14f13, many of the Mauthausen concentration camp members no longer capable of working were later sent then killed at the euthanasia gassing facility at Hartheim (de Mildt, 1996, p. 90).

198 "The Minsk-Mogilev experiments in killing with exhaust gas did not remain a local experiment for local purposes. In Berlin, Reinhard Heydrich immediately turned to the head of his office for technical affairs within the RSHA (Amt II D), Walter Rauff . . . The chief of this motor pool was Friedrich Pradel .... Sometime in September Rauff summoned Pradel to his office and instructed him to ask his chief mechanic if exhaust gas could be directed into a closed truck to kill the passengers" (Browning, 2004, p. 355). 
van from Einsatzgruppe C (under Dr. Rasch's command), and an execution was carried out using this van" " (Spektor, 1993, p. 60). A member of Einsatzkommando $4 a$ by the name of Lauer described the following action in Poltava in November:

Two gas vans were in service. I saw them myself. They drove into the prison yard, and the Jews - men, women, and children - had to get straight into the vans from their cells. I also know what the interior of the vans looked like. It was covered with sheet metal and fitted with a wooden grid. The exhaust fumes were piped into the interior of the vans. I can still hear the hammering and the screaming of the Jews-'Dear Germans, let us out!' (Spektor, 1993, pp. 60-61).

The gas vans enabled the perpetrators to avoid the stressful visual spectacle produced by guns but, as the above quotation shows, they could not shield the killers from the sounds made by those dying inside. A witness, Eugenia Ostrovec, described an action that is reminiscent of Milgram's subjects talking over the learner's screams to avoid this remaining source of perceptual stimulation:

When it was quite full, the doors were firmly locked. The driver started the engine and left it running at full revs, but he couldn't drown the cries of the prisoners and the trampling of feet inside the van (Spektor, 1993, p. 70).

Because the Euthanasia gassing programme used canisters of pure carbon monoxide, which is both odourless and colourless (Rhodes, 2002, p. 155), those carrying it out were more likely to be spared from having to hear the sounds of the dying victims. By the time the victims realised what was happening to them it was generally too late. On the other hand, the malodorous and visible diesel fumes used by the Einsatzgruppen had a different effect. The victims were immediately alerted to the danger they were in, and reacted desperately to their plight (producing frightful sounds that were difficult to ignore and/or avoid).

After the victims of the gas van operation in Poltava had been killed, Blobel's chauffeur described the consequent visual spectacle:

The back doors of the van were opened, and the bodies that had not fallen out when the doors were opened were unloaded by Jews who were still alive. The bodies were covered with vomit and excrement. It was a terrible sight (Spektor, 1993, p. $61)$.

With this, Blobel used a strain-resolving technique frequently relied upon by the shooting squads. As his chauffeur said: “ 'Blobel looked, then looked away, and we drove off. On such occasions Blobel always drank schnapps, sometimes even in the car' " (Spektor, 1993, p. 61). Blobel's avoidance behaviour is reflected in a report (sent to Rauff on 5 June 
1942) on how "improvements" might be made to the vans: " "Technical adjustments on the basis of previous experience .... The observation windows that have been installed up to now could be eliminated, as they are hardly ever used" "(Spektor, 1993, p. 55). The German executioners needed to know when the victims were dead, which is why these windows were installed. But few executioners seemed eager to use them.

Although Einsatzgruppe $C$ came to depend on their gas vans, other squads made little or no use of them, preferring to continue shooting their victims. The reason for this is implied in August Becker's report to Berlin, dated 16 May 1942:

I would like to take this opportunity to draw your attention to the following: some of the Kommandos are using their own men to unload the vans after the gassing. I have made commanders of the Sonderkommandos in question aware of the enormous psychological and physical damage this work can do to the men, if not immediately then at a later stage (Klee et al., 1988, p. 70).

Unlike Blobel's men who from the start used Jews to unload the vans, other Einsatzgruppen decided, for security reasons, to deploy their own men to do this (Browning, 1985, p. 64).

Becker also pointed out in his May 1942 report that the tendency for some gas van operators to accelerate their vans' motors induced painful death:

In order to get the Aktion finished as quickly as possible the driver presses down on the accelerator as far as it will go. As a result the persons to be executed die of suffocation and do not doze off as was planned. It has proved that if my instructions are followed and the levers are properly adjusted death comes faster and the prisoners fall asleep peacefully. Distorted faces and excretions, such as were observed before, no longer occur (Arad et al., 1999, p. 420).

For many perpetrators, it was important to kill the victims as quickly as possible. In this respect, the gas vans were clearly inferior to a bullet in the back of the neck. Although the gas vans enabled the Germans to avoid having to see the victims dying, the sound of screams and the visual spectacle upon the door opening made it difficult to deny the reality that their victims had died slow and agonising deaths. Consequently, some of the Einsatzgruppen commanders, and their men formed the opinion that, compared with the neck shot, use of the gas vans caused even more emotional stress for the perpetrators. As stated in a 1972 Munich State Court verdict: 
The defendant Schuchart declared to a member of the commando that personally he would have preferred to be shot rather than gone into the truck. When the doors were opened the bodies were all entangled and covered with excrement. As a result of complaints from members of the commando, the defendant Schuchart later refused to use the gas vans again, on the grounds that it was impossible to persuade his men to carry out such a task (Spektor, 1993, p. 69).

The reason the inventors of the gas van cared little about the cruel manner in which their device killed the victims was because their search for a more "humane" method centred on alleviating the psychological burden experienced by the executioners, not the victims. For some German executioners, this was not good enough. In the end: "the vans remained unpopular with the men and commanders alike [and] . . . may therefore be regarded as a late and not very successful development in the course of the mobile killing operations" (Hilberg, 1961, p. 219; see also Chrostowski, 2004, p. 8). Nebe's innovation was not the "panacea" that many in the shooting squads had been hoping for. They turned back to the mass shooting method, but in so doing they exacerbated the initial psychological problems, with some eventually cracking under the pressure. However, in the hands of those involved in the Euthanasia extermination programme-the gassing professionals-Nebe's innovation had devastating consequences on all those who had thus far survived deprivation in the Polish ghettos.

\subsection{The Emergence of the First Extermination Camp: Chełmno and the Gas Vans}

As part of Himmler's 14f13 killing programme, the ex-T4 Lange Commando had, since the spring of 1941, been gassing "worn out" concentration camp prisoners. After a trip to Berlin near the end of 1941, Lange returned to his team in Posen with instructions that they were to set up a new and permanent base close to the Lodz ghetto (Browning, 1985, pp. 30, 63). In late October or early November 1941, Lange selected a castle located in the small township of Chełmno-about 60 kilometres northwest of the ghetto. According to Browning (1985, p. 30):

Thereafter a team of SS men was assembled from Posen and Lodz, followed by a guard detachment of Order Police. A work force of Polish prisoners from Lodz together with local inhabitants was put to work renovating and fencing the old villa or Schloss, where the Jews would be undressed and loaded into the waiting vans.

Wilhelm Koppe, a chief of police and SS leader based in the Warthegau, was informed by Lange that he had been instructed to undertake the "evacuation" of Jews in the area (Browning, 2004, p. 416). As far as Koppe knew, Lange was to: 
be employed only on an experimental basis to begin with. This idea was based on the fact that a certain Dr. Brack, of Hitler's private chancellery, had already done some preparatory work with poison gases, and that these were to be tried out by the Sonderkommando Lange .... . Dr. Brandt told me that Dr. Brack had already carried out experiments with gas in Berlin, that these experiments had almost been completed, and that it was planned that he, Dr. Brack, would be put in charge of testing these gases in the Warthegau. Sonderkommando Lange was the obvious choice for carrying out the gassings [italics added] (Krakowski, 1993, pp. 74-75).

The Lange Commando was, as Koppe put it, the "obvious choice" in this Nazi killing experiment, for several reasons. First, unlike some of the Einsatzgruppen units, Lange's men had learnt a few years earlier not to unload the vans themselves. Secondly, any members of Lange's Commando who found use of the vans to be disgusting, too stressful, cowardly and/or inhumane, had long since left the ranks of the T4 staff. ${ }^{199}$ They had been replaced by others until all positions were filled by perpetrators whose actions were unimpeded by such beliefs, concerns, and/or feelings. Thirdly, the men remaining in the Lange Commando had accumulated extensive experience and were emotionally inured to the killing of defenseless civilians. The only difference was that over time the type of "inferior" humans to be eliminated had gradually changed. The Commando had started out killing the disabled, then moved onto other so-called "useless [frequently Jewish] mouths" worn out in Himmler's concentration camps, to finally eradicating almost exclusively "useless mouths" in the Lodz ghetto. The bureaucrats in Berlin knew that when it came to killing defenseless civilians, irrespective of their type, Lange and his men were indisputably the "obvious choice". This progressive killing was analogous to the foot-inthe-door technique inherent within the OTA experiments.

From 8 December 1941, the Lange Commando started killing the Lodz ghetto's predominantly Jewish, but also Gypsy, inhabitants. ${ }^{200}$ The Commando initially made do with Lange's fleet of vans which used canisters of pure carbon monoxide. But soon after, probably in January 1942, gas vans with Nebe's innovation arrived (Browning, 2004, p. 418). With access to a much cheaper, more abundant and highly mobile source of gas, the end result was to become, as Hilberg (1961, p. 84) put it, the first and most "primitive" of the several Nazi extermination centres. The following section will describe the actual

\footnotetext{
${ }^{199}$ One physician wrote in a 1940 letter of resignation from the Euthanasia programme: "despite my intellectual understanding and good will, I cannot help stating that I am temperamentally not fitted for this ... . I prefer to see clearly and to recognize that I am too gentle for this work than to disappoint you later" (Noakes \& Pridham, 1988, pp. 1014-1015, as cited in Glover, 1999, p. 347).
}

${ }^{200}$ Although the great majority of the victims were Jews, among the first victims at Chełmno were 5,000 Gypsies, who were killed during January 1942 (Krakowski, 1993, p. 91). 
gassing process established by the Lange Commando, once they were equipped with the gas vans with Nebe's innovation.

A guard at Chełmno, Kurt Möbius, described what happened after the victims had been transported there by trains then trucks:

they waited some time in the courtyard. Then Plate or I addressed them. We told them that they were to be sent to Austria to a large assembly camp, where they would have to work. But, it was explained to them, they would first have to take a bath and have their clothes deloused. We told the Jews this so that they would not know what fate awaited them, and to encourage them to obey calmly the instructions that they were given. After this the Jews-men, women, and children-were taken to the ground floor of the castle (as cited in Krakowski, 1993, p. 83).

SS-Hauptscharführer Walter Burmeister (as cited in Krakowski, 1993, p. 84) described the next part of the process:

New arrivals undressed in the hall .... Their valuables and money were collected by Poles from the work detail .... When the Jews had undressed, they were ordered to go down the stairs and into the cellar .... signs hung bearing the words: 'To the Baths.'. ... . From the cellar, the naked people continued straight on, leaving the building by a rear door and going up onto a wooden ramp. One of the gas vans ... was backed up to the end of the ramp with the doors open .... The people who came out of the cellar by the rear door did not have any choice but to climb into the van. As soon as the interior was full, with 35 to 40 people inside, the door was closed.

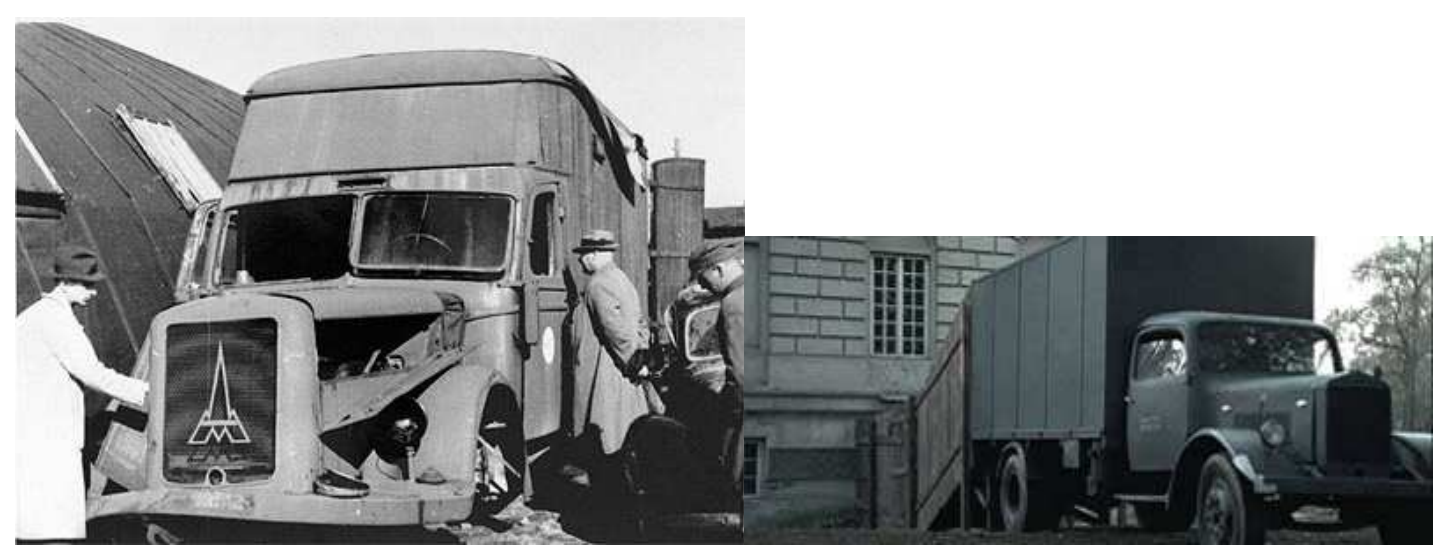

Figure 23: Type of gas van used at Chełmno (Fleming, 1984) and a "recreation" of the van attached, via a ramp, to the castle. ${ }^{201}$

${ }^{201}$ Retrieved September, 2008, from: http://www.pbs.org/auschwitz/40-45/killing/ 
According to Kurt Möbius (as cited in Krakowski, 1993, p. 84):

Most of the Jews got into the gas van calmly and obediently, trusting in the promises made to them. The Polish workers accompanied them. They carried leather whips with which they struck obstinate Jews who had become mistrustful and who hesitated to go further.

Another guard, Theodor Malzmüller, provided more detail about this part of the process:

The Jews were made to get inside the van. The job was done by three Poles, who I believe were sentenced to death. The Poles hit the Jews with whips if they did not get into the gas-van fast enough. When all the Jews were inside the door was bolted. The driver then switched on the engine, crawled under the van and connected a pipe from the exhaust to the inside of the van (Klee et al. 1988, p. 218).

Just as in the mass-shootings, the most stressful jobs were assigned to non-Germans, who- - sentenced to death-felt they had little choice but to participate. According to another member of the Commando, Wilhelm Heukelbach: " 'Soon screams and groans could be heard coming from the interior. Those inside were hammering on the sides of the van'" (Krakowski, 1993, p. 86). Burmeister (as cited in Krakowski, 1993, p. 84) continued:

From the time the people got out of the transport trucks in front of the castle courtyard to the time they were loaded into the gas vans, a little less than an hour, at the most one and a half hours, had passed.

The van would then remain in a stationary position until the perpetrators were confident that the victims were dead. Then the vehicle was driven from the castle to a burial site in the Maiden forest several kilometres away.

Hauptscharführer Gustav Laabs (as cited in Krakowski, 1993, p. 87) described what happened on his first driving mission:

After about three kilometers we arrived in a clearing in the wooded area that runs alongside the road to Warthbrücken. In the clearing the officer told me to stop in front of a mass grave, where a work detail of Jews was working under the supervision of a police officer. There were also several policemen spread out in a circle, who were obviously on sentry duty. The police officer supervising the work detail ordered me to back the van up to the mass grave. 
According to Jacob W., a non-commissioned police officer, the clearing contained several mass graves, shaped like very large swimming pools, each about 3 meters deep

(Krakowski, 1993, p. 77). Gustav Laabs (as cited in Krakowski, 1993, p. 87) continued:

Then the policeman who had driven in the cab with me undid the padlock that fastened the doors. A few members of the work detail were ordered to open the double doors. Eight or ten corpses fell to the ground, and the rest were thrown out of the back by the members of the work detail.

The bodies were then buried.

It has been estimated that between about 35 and 150 victims (depending on the size of the vans) could be killed during one cycle of this process of mass extermination (Arad, 1987, p. 11; Krakowski, 1993, p. 84). Information from the 1962 and 1963 trial at Bonn has shown that between December 1941 and March 1943 at least 145,500 people were killed in the gas vans at Chełmno (Krakowski, 1993, p. 101). As the Berlin-based Nazi bureaucrats would almost certainly have noticed, Chełmno saw the alignment of a number of factors that foreshadowed mass killing on an even larger scale: a cheap/mobile gas, an industrialised process, and a hardened/professional pool of executioners.

\subsection{The Origins of Operation Reinhard}

As Lange began killing those Lodz ghetto Jews who could no longer work, the onset of winter in 1941-42 saw the advancing Nazi war machine grind to a halt in the Soviet interior. More bad news for the Nazi regime came with the 7 December 1941 Japanese attack on Pearl Habour, which saw the United States enter the war against Germany. With Germany waging war on both eastern and western fronts, the sudden change in military fortunes clearly signalled that from 1942 onwards, the Nazis were going to need all the help they could muster to win the war. Even if the Nazi regime had wanted to exterminate all the Jews as rapidly as possible, their rapidly growing need for slave labour meant they could no longer afford to do so.

On 20 January 1942 the Wannsee conference was held in Berlin. It was here that Reinhard Heydrich revealed how the Nazi regime intended to simultaneously win a war on 
two fronts and, in particular, to resolve the "Jewish problem". In the presence of representatives of the German civil service agencies, whose help Heydrich anticipated would be needed, it was explained that all the Jews within the German sphere of influence_-basically all of continental Europe-were to be concentrated in a small number of locations. Upon their arrival on trains from all over Europe, the Jews would then undergo a selection process to identify those capable of productive work. Those selected would provide labour that would help to strengthen the Nazi war machine and/or the German economy. They would also receive an inadequate diet. Heydrich euphemistically called the consequent starvation "natural diminution" (Browning $(1978$, p. 78). When victims were no longer capable of productive labour they were simply to be killed. Those who died would then be replaced with new intakes of slaves. This plan-referred to by some historians as “ 'extermination through work' " (Marcuse, 2001, p. 41)—would not only overcome criticism by the "productionists" (regarding the wasteful extermination of potentially useful slave labour), it would also appease the "strong believers/attritionists", by eventually bringing about the total extermination of the European Jews. ${ }^{202}$

Questions were soon raised about what was to be done with those not selected to work. All these so-called "useless mouths"- the very young and old-were to be killed immediately. But how? Anticipating this question, Heydrich probably let Dr. Rudolf R. Lange (not to be confused Herbert Lange at Chełmno), take the floor. Lange, the commander of a shooting squad, probably explained first-hand that, although there had been problems, since June 1941 hundreds of thousands of Jews had simply been shot. ${ }^{203}$ And even if this method started to falter, Heydrich—probably referring to the gassing facilities at Auschwitz (see Footnote 196) and/or the experimental Chełmno (which by this time had been killing people for about five and two months, respectively)—said: “ 'even now practical experience is being gathered that is of major significance in view of the coming Final Solution of the Jewish Question" (Dawidowicz, 1990, p. 176).

\footnotetext{
202 The Nazi regime's eventual arrival at "extermination through work" as the preferred final solution to the "Jew Problem" is reminiscent of Lindblom's (1959, p. 79) branch method of "Muddling Through" the public policymaking process.

203 "Lange was ... . doubtless invited by Heydrich to the conference . . . to describe his practical experiences with the Final Solution to the other participants gathered . . . at . . Wannsee" (Fleming, 1984, p. 93). Padfield (1990) has also concluded: "it is difficult to understand why Lange was there or why the conference had to be postponed for him unless he was to explain the practicalities of liquidation" (p. 357). Further, as Fleming (1984) said: "When Heydrich postponed the conference from 9 December 1941 to 20 January 1942, it was not simply the Japanese attack on Pearl Harbor on 7 December and Germany's subsequent declaration of war on the United States on 11 December that weighed in the balance. On 8 December 1941, [Ensatzkommando 2 C Special Duties leader] Lange's services as supervisor at the execution pits in the Rumbuli Forest outside Riga, and later in the Bikerniek Forest, could not be spared" (p. 94).
} 
As stated in the conference protocol, then "productionist" Hans Frank's representative at the meeting:

Staatssekretär Dr. Bühler announced that the General Government would welcome it if the final solution of this problem would begin in the General Government, as, on the one hand, the question of transport there played no major role and consideration of labor supply would not hinder the course of Aktionen .... [because] of the approximately two and a half million Jews under consideration, the majority were in any case unfit for work (Arad, 1987, pp. 12-13).

Bühler's request that the starving and unproductive Jews in the General Government should be killed was accepted-a task later termed Operation Reinhard (in fitting memory of Heydrich, who was assassinated a few months later). Now that Frank would no longer be directly held responsible for the actual killing of the Jews in the General Government, he suddenly favoured their extermination. ${ }^{204}$ This decision may officially have been endorsed in January 1942, but earlier, in October 1941 (about the same time as the Lange Commando received their instructions to kill the Jews in the Incorporated Territory), Odilo Globocnik suggested to Himmler that the General Government should be "Germanized" by killing all the local Jews (Musial, 2000, p.115 cited in Lower, 2002, p. 2). Himmler then apparently consulted Hitler. As shown, Globocnik's own men had failed to find a more "humane" method of killing (with grenades and corrosive slaked lime-see Footnote 194). This failure would explain why he was sent specialist in killing civilians, specialists who, after being "employed only on an experimental basis" might have more success in achieving the ambitious goal now before them. ${ }^{205}$

\footnotetext{
${ }^{204}$ About a month before this meeting Hans Frank had heard rumours about the forthcoming Wannsee Conference (Hilberg, 1961, p. 308). His knowledge of the destruction of the European Jews was further confirmed by Hitler's anti-Semitic speech on 12 December 1941. Four days later "productionist" Frank was now arguing: "We must destroy the Jews wherever we meet them . . . . we can take measures that will, one way or another [so oder so], lead to extermination, in conjunction with the large-scale measures under discussion in the Reich" (Gerlach, 1997, pp. 29-30, cited in Wistrich, 2001, pp. 108-109). Frank then must have realised that the "attritionist" Palfinger had correctly anticipated the Nazi inner circle's exterminationist policy.

205 As Friedlander (1994) has argued: "When Himmler commissioned the Lublin SS and Police Leader Odilo Globocnik to kill the Polish Jews, Globocnik needed the experienced staff of T4 to carry out this assignment. In September of 1941 Philipp Bouhler and Viktor Brack visited Globocnik in Lublin. Although at Nuremberg Brack denied that this visit had anything to do with the Final Solution, it seems likely that they discussed their future collaboration" (p. 54).
} 


\subsection{Operation Reinhard}

The German public became aware of the Nazi regime's furtive T4 Euthanasia project, which since 1939 had been gassing physically and intellectually disabled Germans. Consequently, the Nazi regime began attracting heated public criticism (see Lifton, 1986, p. 89). On or about 24 August 1941 and under the rising tide of public pressure, Hitler at least officially put an end to the Euthanasia programme (Fleming, 1984, p. 23; Friedlander, 1995, p. 111; Lifton, 1986, p. 95). Breitman (1991, p. 198) has argued:

Because of Hitler's decision, the gassing specialists were now available for other duties, and no one recognized this fact quicker than Himmler, who had just [over a week earlier] left the scene of the unsatisfactory police execution at Minsk.

This conclusion is largely correct, except that at the time a potentially viable gas had not yet been discovered, so it probably took Himmler a little longer (at least until September) to make this connection.

As 1941 came to an end (and after a viable gas had been discovered), ninety-two ex-T4 personnel were sent to the East by the Führer's Chancellery (Krausnick, 1968, p. 97). One of them was to become Globocnik's top aide: Christian Wirth. Wirth had not only been present at the first-ever Euthanasia gassing pilot two years earlier, he had also recently been killing people at a permanent gas chamber located in Brandenburg in Germany.

Although Wirth had, at least, personally observed the killing process used at Chełmno, ${ }^{206}$ he never contemplated using mobile gas vans. With there being about two and a-half million Jews living in the General Government, his mind was focused on the kind of system he had relied upon in Germany: permanent gas chambers, which wouldunlike the vans-be capable of handling the large numbers of victims. Also, he intended for the bodies to be disposed of on-site, which would be more efficient and-with reference to the surrounding local populations-more discrete (Browning, 1985, p. 65). Thus, with the numbers of victims having moved into the millions, Wirth's Operation Reinhard plan was to build several industrialised extermination centres within the General Government. These large facilities would each aim to kill then dispose of hundreds of

\footnotetext{
206 "Before coming to Belzec, Wirth became acquainted with the gas vans in operation in Chełmno and in the eastern occupied territories of the Soviet Union and learned their advantages and disadvantages" (Arad, 1987, p. 24). Benz (1999, p. 144) has suggested Wirth worked at Chełmno; and Chrostowski (2004, pp. 6-7) and Padfield (1990, p. 372) claim that he co-designed and helped build the centre.
} 
thousands of victims. The first one was at Belzec, was to serve as the experimental prototype from which the subsequent extermination centres would learn then advance upon. $^{207}$

The construction of the Belzec extermination centre had started almost three months before the Wannsee Conference, on 1 November 1941 (Arad, 1993, p. 107). However, the gassing apparatus for this centre came from one of Germany's recently abandoned Euthanasia facilities (Dawidowicz, 1990, p. 175). ${ }^{208}$ According to Stanislaw Kozak, a Polish construction worker, the gas chambers at Belzec initially had wooden walls:

we built a third barrack, which was $12 \mathrm{~m}$. long and $8 \mathrm{~m}$. wide. This barrack was divided by wooden walls into three sections, so that each section was $4 \mathrm{~m}$. wide and $8 \mathrm{~m}$. long. These sections were $2 \mathrm{~m}$. high. The interior walls of these barracks were built such that we nailed the boards to them, filling in the empty space with sand. Inside the barrack the walls were covered with cardboard; in addition, the floors and the walls were covered with sheet zinc to a height of $1.1 \mathrm{~m}$. (as cited in Arad, 1993, pp. 107-108).

When the installation had been completed at the end of February 1942, Wirth undertook a number of pilot studies_experimental gassings— to test and refine the killing process. According to SS Unterscharführer Franz Suchomel (and much like Milgram during the OTA pilot studies): "Belzec was the laboratory. Wirth was camp commandant. He tried everything imaginable there" (as cited in Lanzmann, 1995, p. 53). Like Lange at Chełmno before him, Wirth initially used pure bottled carbon monoxide (Arad, 1987, p. 26). These pilots were undertaken over a period of several days and involved several convoys, each consisting of about four to six freight cars of Jewish victims (Arad, 1993, p. 109). Soon afterwards (again like Chełmno) Wirth replaced the canisters with the exhaust fumes generated by a 250 horsepower engine (Arad, 1987, p. 26). At the conclusion of these experiments the Belzec extermination centre came into use on 17 March 1942, thus beginning the implementation of what was soon to become known as Operation Reinhard.

According to SS-Untersturmführer Josef Oberhauser, who was Wirth's liaison officer with Globocnik, for the first few months of operation: "the gassings were not yet

\footnotetext{
207 "Belzec was to be the camp where these experiments would be initiated, and additional camps would be planned and constructed according to the results obtained there" (Arad, 1987, p. 23).

${ }^{208}$ Treblinka also obtained some of its gassing apparatus from the recently abandoned Euthanasia gassing programme.
} 
part of a systematic eradication action but were carried out to test and study closely the camp's capacity and the technical problems involved in carrying out a gassing" (Klee et al. 1988, p. 228). Belzec soon proved to be capable of the efficient killing of large numbers of people. The biggest technical concern for Wirth was that the wooden gas chambers might not be able to contain the internal pressures generated by large numbers of panicking victims (Arad, 1993, p. 122). Since Belzec was the model from which further death camps could be developed, it was decided from the start to construct the next such facilitySobibor-using bricks rather than wood. Managed by ex-T4 employee, Franz Stangl, the Sobibor extermination centre opened during May 1942. The initial chambers at Belzec and Sobibor were capable of killing about $1,000^{209}$ and 600 people per gassing - a task that could readily be performed several times a day (Arad, 1987, p. 123).

In mid-June 1942 Wirth suspended operations at Belzec, deciding to replace the original wooden structure with a structurally much stronger facility (Arad, 1993, p. 122). This suspension signalled the end of the first stage of exterminations at Belzec. In its first three months of operations, between mid-March and mid-June 1942, it had killed nearly 100,000 Jews (Arad, 1993, p. 122), showing itself to be clearly more effective than Chełmno. One month later, Himmler visited Globocnik at the coordination headquarters of Operation Reinhard, presumably to receive a progress report. Globocnik was armed with information about the killing capacity of both Belzec and the equally destructive Sobibor. ${ }^{210}$ A few days later, on 19 July 1942 Himmler (after having had some meetings with Hitler $)^{211}$ issued to the staff of Operation Reinhard an end of year deadline:

I herewith order that the resettlement of the entire Jewish population of the General Government be carried out and completed by December 31, 1942. From December 31, 1942, no persons of Jewish origin may remain within the General Government, unless they are in the collection camps in Warsaw, Cracow, Czestochowa, Radom, and Lublin. All other work on which Jewish labor is employed must be finished by that date, or, in the event that this is not possible, it must be transferred to one of the collection camps (Arad, 1987, p 47).

A week or so later, at the end of July 1942 and, again with the accumulation of knowledge gained from previous experience, the third and what was to be the most

\footnotetext{
${ }^{209}$ This is according to a specialist on the Belzec extermination camp, R. O’Neal (personal communication, March 15, 2009).

${ }^{210}$ Like Belzec, the Sobibor centre killed 90,000 to 100,000 Jews in its first three months (Arad, 1987, p. 80).

${ }^{211}$ See Bloxham and Kushner (2005, p. 136).
} 
“ 'perfect' " of the Operation Reinhard extermination centers-Treblinka-was completed (Arad, 1993, p. 115). This centre was to be managed by another ex-T4 employee, Dr. Irmfried Eberl (also present at the winter 1939/40 Euthanasia pilot gassing). Sharing much in common with some of the more ambitious leaders of the Einsatzgruppen units, Treblinka employee Unterscharführer August Hingst later testified: “Dr. Eberl's ambition was to reach the highest possible numbers and exceed all the other camps" (Arad, 1987, p. 87). Eberl's strategy in seeking to achieve this goal seems to have been to accept and/or solicit far greater numbers of potential victims than either Wirth or Stangl, to have the gas chambers running almost continuously, and to dump the bodies in mass graves dug mechanically by a large industrial scoop shovel, and, finally, to just hope that the centre's staff and facilities were able to sustain the high killing rate. Soon after, Eberl accepted 312,500 potential victims during Treblinka's first five weeks in operation (Arad, 1987, p. 87). However, as he soon discovered, although Treblinka was the most "perfect" of the three Operation Reinhard facilities, it was not per se "perfect". The commandant's ambitions exceeded the extermination centre's ability to absorb the deluge of victims and a backlog of freight cars crammed with prospective victims accumulated outside the camp gates. With no access to water, many started to perish in the intense summer heat.

Simultaneously, Sobibor started experiencing body disposal/burial problems. The high summer temperatures caused the victims' recently buried bodies to bloat, thus exposing the graves. Stangl's immediate solution to this problem was to start cremating the victims' bodies (Arad, 1987, p. 172). However, this was time-consuming, and slowed down the killing rate. And it was soon to become a problem in the other extermination camps as well: the maximum killing capacity exceeded their on-site ability to adequately dispose of the victims' bodies.

With Eberl at Treblinka (unlike Stangl at Sobibor) unwilling to slow down, chaos soon reined throughout the camp. Before long, the centre's tight security measures began deteriorating. This progressive decline in security resulted in many escapes (Arad, 1987, p. 87; 1993, p. 127). These quickly attracted the attention of Globocnik and Wirth who, upon seeing that the camp was almost out of control, dismissed the ambitious Eberl and replaced him with the more competent Stangl (with Franz Rechsleitner taking over at the smaller Sobibor centre). However, because Treblinka had consumed almost a third of a million lives in just its first five weeks of operation, Eberl's ambitious behaviour had demonstrated the latest extermination centre's phenomenal killing capacity (Arad, 1993, p. 
127). Eberl had not been exaggerating when he had written in a letter to his wife: " "The pace in Treblinka is truly breathtaking" "(Friedlander, 1995, p. 299). By now the mass slaughter had taken on a more explicitly industrialised form. As one survivor-Abraham Kszepicki-noted, Treblinka was "A factory of horror whose sole product was bodies" (Arad, 1987, p. 94).

Himmler's grandiose deadline presented over a month earlier was now clearly in jeopardy. Globocnik and Wirth were aware that, just like Belzec, the killing capacity of the initial gas chambers at both Sobibor and Treblinka had to be increased. Consequently, additional or completely new and much larger gas chambers had to be built.

Such expansion, however, produced new problems that also threatened the achievement of Himmler's goal. For example, as the dimensions of the new chambers increased, so did the space that had to be filed with sufficiently lethal quantities of exhaust fumes. This would not only mean increased fuel costs, but it also meant that it would take longer to kill the victims. Finally, because a much greater volume of exhaust fumes was now required, the chances of survival were likely to increase for those people who happened to be lying on the chamber floor. Collectively, the much larger gas chambers might generate financial, temporal, and killing-related inefficiencies.

To varying degrees, these problems were encountered at the second, and larger, gas chambers at Belzec and Sobibor. But they were eliminated at Treblinka with one single innovation. That is, at the most "perfect" of the Operation Reinhard extermination centres, it was decided to lower the ceiling height of their second set of gas chambers by $60 \mathrm{~cm}$. This increased efficiency because with the reduction in cubic meter volume, less exhaust fumes were required, reducing fuel costs. Secondly, with less space to fill with sufficiently lethal concentrations of exhaust fumes, this change "shortened the asphyxiation time" (Arad, 1993, p. 132). Finally, because the reduced space was more likely to have higher concentrations of exhaust fumes, the survival chances were reduced.

Nonetheless, the larger gas chambers installed at the three camps produced massive increases in killing efficiency, with the number of victims per gassing doubling at Belzec 
and Sobibor, and quadrupling at Treblinka. ${ }^{212}$ Operation Reinhard not only went on to meet Himmler's end-of-year deadline by exterminating all the Jews in the General Government (Arad, 1987, p. 130), but it was expanded to include the Jews of Bialystok and the Ostland (Arad, 1987, pp. 131, 165). By the end of Operation Reinhard, in late October 1943, it had resulted in the following rates of mass murder: about 1,500,000 (Arad, 1993, p. 137) or 1,700,000 Jews (Arad, 1987, p. 165) —approximately 600,000 at Belzec, ${ }^{213} 250,000$ at Sobibor, ${ }^{214}$ and between 700,000 and 800,000 at Treblinka (Hilberg, 1980, p. 93). Unlike the labour-intensive mass-shootings:

Astounding as it may be, these three huge extermination factories [Belzec, Sobibor, and Treblinka] in which approximately one-third of all Nazi genocide victims were murdered, were never operated by more than little over 100 German camp officials (de Mildt, 1996, p. 16).

On 19 August 1942, hygienist professor Wilhelm Pfannenstiel of the Waffen-SS, visited and observed the highly bureaucratised killing process at Belzec, after the installation of the new gas chambers. In great detail he described the arrival of the victims, the means used to deceive them, and the stripping of their valuables and hair:

After they had undressed, the whole procedure went fairly quickly. They ran naked from the hut through a hedge into the actual extermination centre. The whole extermination centre looked just like a normal delousing institution. In front of the building there were pots of geraniums and a sign saying 'Hackenhold Foundation', above which there was a Star of David. The building was brightly and pleasantly painted so as not to suggest that people would be killed here. From what I saw, I do not believe that the people who had just arrived had any idea of what would happen to them. Inside the building, the Jews had to enter chambers into which was channeled the exhaust of a [100(?)]-HP engine, located in the same building (Klee, et al. 1988, p. 241).

In Pfannenstiel's view, once locked in:

\footnotetext{
${ }^{212}$ The initial killing capacity of Belzec, Sobibor, and Treblinka per gassing was about 1,000, 600, and 600 respectively (R. O’Neal, personal communication, March 15, 2009; Arad, 1987, pp. 123, 120). However, after undergoing expansion, the killing capacity of Belzec and Sobibor had risen to about 2,000 and 1,300, respectively (Arad, 1987, pp. 73-74, 123). After renovations Treblinka's killing capacity was either about 2,300 or 3,800 per gassing (Arad, 1987, pp. 119-120). At his trial Franz Stangl admitted, "the optimum amount of people gassed in one day, I can state: according to my estimation a transport of thirty freight cars with 3,000 people was liquidated in three hours. When the work lasted for about fourteen hours, 12,000 to 15,000 people were annihilated" (Arad, 1987, pp. 120-121).

${ }^{213}$ Hilberg (2003, p. 1320) provides a lower figure at Belzec: 434,508.

${ }^{214}$ Sobibor had fewer victims than Belzec and Treblinka because it was the first extermination centre to be closed down and it was also the first to introduce cremation facilities.
} 
it was only then that the people sensed something else was in store for them. It seemed to me that behind the thick walls and door they were praying and shouting for help. After about twelve minutes it became silent in the chambers (Klee et al. 1988, pp. 242, 244).

Whether by accident or design, the new "thick" concrete walls obviously reduced the intensity of the victims' screams. After removing gold teeth and checking bodily orifices for hidden valuables, the Jewish work detail removed the bodies and burned them in mass graves using flammable liquid. The personnel at Belzec, like Wirth, used some of the previously employed T4 techniques of deception to encourage the victims to enter the gas chambers on their own accord. Fake showerheads (as used during the Euthanasia programme) were installed, and victims were promised work on condition that they undergo delousing (as at Chełmno). With its pleasantly painted buildings and strategically placed pots of geraniums, so as to suggest that this could not be a killing site, Belzec had developed its own techniques of deception. ${ }^{215}$ Similar ones were used at both Sobibor and Treblinka. As Ada Lichtmann, a survivor of Sobibor has said:

We heard word for word how SS-Oberscharführer Michel, standing on a small table, convincingly calmed the people; he promised them that after the bath they would get back all their possessions, and he said that the time had come for Jews to become productive members of society. They would presently all be sent to the Ukraine, where they would be able to live and work. The speech inspired confidence and enthusiasm among the people. They applauded spontaneously, and occasionally they even danced and sang (Arad, 1993, p. 122).

Some of those Jews lucky enough to escape returned to the ghettos to warn the others of the impending danger. Word soon spread and for those Jews being forcibly transferred to unknown destinations on Nazi trains, increasingly names like "Belzec", "Sobibor", and especially_considering its comparatively high number of escapees"Treblinka", became signals of imminent death. More and more Jews arriving at the extermination centres were no longer as easily duped by the apparent purpose of the "showers", and by promises of work. Growing numbers of those targeted for

\footnotetext{
${ }^{215}$ Alice Lok Cahana, who was imprisoned in Auschwitz, has provided one of the few accounts on the deceptive effects of flowers at the gas chambers. On 7 October in 1944, Cahana and her sister were selected to go to a new barrack and, on the way, have a shower. They found themselves at " 'a nice building with flowers at the windows' " (Rees, 2005, p. 254). " 'I see flowers in a window-reminding you of home. Reminding you that mother went out when the Germans came into Hungary, and instead of being scared or crying or hysterical she went to the market and bought violets. And it made me so calm. If Mother buys flowers it can't be so bad. They will not hurt us' " (Rees, 2005, pp. 255-256). Consequently: “" 'we went in and an SS woman said, 'Everyone put their shoes nicely together, your clothes on the floor.' And we were taken into a room-naked" " (Rees, 2005, p. 254). Quickly the door to the cold and pitch-black room was closed behind them and before they could work out what was going on, the door swung open and they were quickly ushered out of the so-called showers. They were not gassed because just as the door had closed the Sonderkommando (the Jewish work detail), staged a revolt.
} 
extermination not only refused to comply with their executioners' requests, but also began to mount spontaneous acts of resistance.

Probably the earliest significant and verified act of resistance to Operation Reinhard occurred, perhaps unsurprisingly, at Treblinka. In the second week of December 1942 a group of youths from the Kelbasin camp, near Grodno, refused to enter the gas chambers. With fists, knives, and even a grenade, they resisted. A riot ensued. With superior firepower, the guards rapidly quelled the resisters, resulting in massive carnage (Arad, 1987, pp. 254-256).

Wirth and Stangl feared the unpredictable presence of resistance because it removed a key ingredient that enabled them to create death on such a massive scale: victim docility. From start-to-finish, the gassing operations required that the victims remain compliant, because any resistance would create bottlenecks in the process, which would threaten the system's ability to meet Himmler's very tight exterminationist deadlines.

Thus, Franz Stangl attempted to introduce even more cunning techniques of deception which, he hoped, might ensure total docility. ${ }^{216}$ For example, just a few weeks after the revolt at Treblinka, the new commandant went to great lengths to have a façade built:

AT CHRISTMAS 1942 Stangl ordered the construction of the fake railway station. A clock (with painted numerals and hands which never moved, but no one was thought likely to notice this), ticket-windows, various timetables and arrows indicating train connections 'To Warsaw,' 'To Wolwonoce,' and 'To Bialystock' were painted on to the façade of the 'sorting barracks'; all for the purpose of lulling the arriving transports - an increasing number of whom were to be from the West into a belief that they had arrived in a genuine transit camp (Sereny, 1974, p. 200). ${ }^{217}$

Orchestras had earlier been used as deception devices. As Abraham Kszepicki stated:

\footnotetext{
${ }^{216}$ Auschwitz survivor Rudolf Vrba highlighted the centrality of deception: " 'The whole murder machinery could work on one principle: that the people came to Auschwitz and didn't know where they were going and for what purpose. The new arrivals were supposed to be kept orderly and without panic marching into the gas chambers .... The Nazis were concentrating on one thing: it should go in an orderly fashion so that it goes unimpeded. One doesn't lose time' "(Lanzmann, 1995, p. 113).

${ }^{217}$ Also see Arad (1987, pp. 122-123).
} 
Forty meters from the gas chambers, near the path where the Jews were led to the 'showers,' a small musical ensemble stood under a tree. Three Jews with yellow patches, three musicians from Stock, stood and played there on their instruments .... They played enthusiastically. It was difficult to make out their repertoire . . . these were apparently the latest hit songs favored by the Germans and Ukrainians (Arad, 1987, p. 86).

With the victims becoming increasingly alert to any evidence that might signal their arrival at a death camp, the primary purpose of the orchestra was: "To drown out the victims' screams on their way to the gas chambers - so that they would not be heard throughout the camp" (Arad, 1987, p. 86). An orchestra was also used at Sobibor. ${ }^{218}$

It could also be argued that the speeches, the carefully positioned flowers, Stangl's fake train station, and the jubilant orchestras were all strain-resolving avoidance mechanisms that ensured the perpetrators did not have to personally confront victims who might otherwise realise their lives were abruptly about to end. The tools of deception-

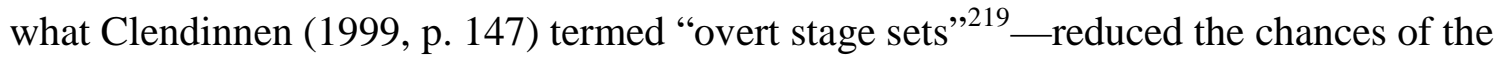
Germans having to hear their victims" cries for mercy as they ran along "the tube" or what little sounds that could be heard while being asphyxiated within the concrete chambers. It can also be argued that another reason for the lowered ceiling in Treblinka's second set of gas chambers was to further reduce the span of the victims' now increasingly muffled screams. Being able to kill the victims as quickly as possible was certainly of great concern to many in the Einsatzgruppen shooting squads and gas van operators.

Were the above innovations introduced to reduce the intensity and/or span of the remaining sources of perceptual stimulation (reducing further perpetrator strain, trauma, guilt, and/or repugnance)? Or were the innovations introduced solely with efficiency in mind? The probable answer is that both factors played an important, even inter-related, role. Whether introduced by accident or design, the more direct perpetrators were likely to be drawn towards those innovations that not only enhanced or maintained the required rates of killing efficiency, but also ensured they saw and heard much less of their victims (particularly when distressed). It is therefore suggested that any efficiency-promoting

\footnotetext{
${ }^{218}$ See Dov Freiberg's quotation (as cited in Arad, 1987, p. 75).

${ }^{219}$ In regard to the deception relied upon at Auschwitz-and somewhat reminiscent of the OTA experiments "staging"-Clendinnen (1999) stated: "the 'changing rooms', the anterooms to the gas chambers [were] ... overt stage sets, with their numbered pegs for clothing ('Remember your number!') and the signs in various languages advertising the benefits of hygiene. When the episode was over and the rooms emptied, there would be a frantic rush to remove all traces of the last audience and to reset the scene for the next intake and the next performance" (p. 147).
} 
innovations that happened to increase the intensity and/or duration of the only remaining sources of perceptual stimulation (or even introduced completely new sources) would not at all have been welcomed by the frontline perpetrators. These developments were a "oneway street" that headed continuously, with only rare and short-lived interruptions, in the direction of diminishing (not increasing) the levels of perpetrator strain, trauma, guilt, and/or repugnance. ${ }^{220}$ Compared to the shooting methods, all these technical developments helped the perpetrators to kill their victims more calmly, quietly, and less offensively than before. The following example lends weight to this argument that the "overt stage sets" were not solely about maintaining or advancing killing efficiency.

According to a German court investigation of events occurring at the Stutthof camp between August and November 1944, commandant Paul Werner Hoppe instructed his subordinates: " 'All the Jews who were old, sick, or unable to work had to be killed' " (Pingel, 1993, p. 192). To deal with similar such requests in the past, a railway car had been converted into a sealed gas chamber that used a gas called Zyclon B, as an alternative to exhaust fumes (discovered earlier at Auschwitz, see Footnote 196). During the above period, a group of Jewish women fitting this description were to be murdered. They were told that they had been granted work at a stocking and darning shop and therefore had to be transported elsewhere by train:

One of the SS men put on a railroad employee's uniform and whistled, as is usually done in marshaling yards. To make the subterfuge complete, an ordinary car was placed next to the gassing car ... . The SS staff of the camp urged the twenty or

\footnotetext{
${ }^{220}$ For an example of an experimental killing technique that increased the levels and duration of perceptual stimulation, and then was rapidly abandoned, see Footnote 194. One possible counterfactual is that lethal injections, during which victims were touched, seen and heard, were quite common. Between September 1941 until March 1942 a score of physicians and SD disguised as medics at the Kiev Pathological Institute killed about 100,000 people using this method (Freidlander, 1995, p. 142). Also, at Auschwitz tens of thousands perished from lethal phenol injections. They were given as "inoculations" or " "an anti-typhus injection" " (Naumann, 1966, p. 295) and victims were required to place their left arm across their eyes, exposing the rib area. According to Dr. Klodziński (as cited in Lifton, 1986, p. 258) the next part of the procedure involved " 'driving the long needle into the fifth [rib] space.' " Apparently this was

" 'inexpensive, easy to use, and absolutely effective when introduced into the heart ventricle' ", killing victims in about 15 seconds (Lifton, 1986, p. 258). According to one survivor of Auschwitz: "As a rule, not even a moan could be heard." (International Auschwitz Committee, 1986, pp. 104-105, as cited in Glass, 1997, p. 92). Although a Dr. Entress refined the technique, he preferred that others administer the injections. According to a prisoner, Dr. Glowacki, (as cited in Naumann, 1966, p. 138), Josef Klehr, a " 'sadistic' " German medical orderly, stood apart in the application of this technique (Lifton, 1986, p. 259). In relation to the question "Who did the killing", another prisoner, Professor Dr. Fejkiel, testified: " "At first Dr. Entress himself, then Klehr, and then-in this order-Scherpe and Hantl. Hantl did it rarely" " (Naumann, 1966, p. 154). Klehr's ability to kill using this method was exposed when, in his absence, about 120 youths were to be killed. Halfway through Scherpe paused and said, "I can't any more" (Lifton, 1986, p. 267). According to Glowacki: “ "He left, and we never saw him again after that' " (Naumann, 1966, p. 138). Glowacki adds:

" 'Hantl took over. Hantl finished the murder of the children'" (Naumann, 1966, p. 138). Hantl emerged:

" 'in a state of total collapse' and 'completely went to pieces, cursed the war,' and lost his SS demeanor" (Lifton, 1986, p. 267).
} 
thirty victims to hurry: it was time to leave; they had to go clear to Danzig. As soon as everybody was in the car, the doors were closed. Then the gas was thrown [in its pellet form] through the opening in the roof (Pingel, 1993, pp. 192-193).

The killing of these old, sick, and/or probably emaciated women begs the question: why did the perpetrators go to such inefficient lengths to deceive these powerless victims into entering the train carriage of their own accord? An explanation is that these front-line perpetrators wanted to avoid having to experience the guilt-inducing emotions that might be evoked by the behaviour of victims who were aware of their fate. Having to physically force these prostrate women into the gas chamber would have made the perpetrators actually feel like the ruthless killers they had become. It was psychologically easier for them to keep the women totally oblivious of their fate, to deceive them into going to their deaths then-to avoid hearing their screams-make sure that once the pellets hit the floor they got as far away from the train carriage as quickly as possible. Killing became much easier on the conscience when, having been deceived, the victims went along willingly and quietly. Even better, if — as survivor Ada Lichtmann—said (above) they "danced", "sang", and "applauded" their way to their graves. The perpetrators were, of course conceptually aware what they were doing, but were at pains—literally— to avoid the perceptual realities of their actions. The deception helped to ensure that their consciences were less burdened than they otherwise would have been. Indeed, such killing may not have felt that bad at all. In short, the strong reliance on deception was not only about reducing the risk of victim resistance in order to maintain or increase killing efficiency.

It could be argued that this thesis overstates the importance of deception during the Holocaust. Such an objection is not supported by evidence from some of the principal perpetrators. For example Rudolf Hoess (2001, pp. 149-150), the commandant of Auschwitz, who after World War Two recalled some "shattering" events that he believed he would "never forget":

One woman approached me as she walked past and, pointing to her four children who were manfully helping the smallest ones over the rough ground, whispered: 'How can you bring yourself to kill such beautiful, darling children? Have you no heart at all?' . . . . I remember, too, a woman who tried to throw her children out of the gas-chamber, just as the door was closing. Weeping she called out: 'At least let my precious children live.' There were many such shattering scenes, which affected all who witnessed them. 
It would seem that the words of those victims who saw through the "overt stage sets" had an impact on the guilty consciences of some of the most destructive Nazis. This was not, for Hoess, an isolated event:

On one occasion two small children were so absorbed in some game that they quite refused to let their mother tear them away from it. Even the Jews of the Special Detachment were reluctant to pick the children up. The imploring look in the eyes of the mother, who certainly knew what was happening, is something I shall never forget. The people were already in the gas-chamber and becoming restive, and I had to act. Everyone was looking at me. I nodded to the junior non-commissioned officer on duty and he picked up the screaming, struggling children in his arms and carried them into the gas-chamber, accompanied by their mother who was weeping in the most heart-rendering fashion. My pity was so great that I longed to vanish from the scene: yet I might not show the slightest trace of emotion (Hoess, 2001, p. 154).

Bureaucrats like Hoess convey a tone of officiousness and stoicism, just as Milgram's subjects did, like the pseudonymous Morris Braverman, when communicating with the learner: " 'Mr. Wallace, your silence has to be considered as a wrong answer' " (Milgram, 1974, p. 53). But behind the façade of the bureaucrat, and as Hoess noted, the situation confronting them "affected all who witnessed them". Behind the scenes the subject would frequently drop their façade enquiring, as Braverman did: “ 'Do I have to follow these instructions literally?" " (Milgram, 1974, p. 53). But the bureaucratic momentum at least implicitly, often explicitly, urges all functionaries to continue fulfilling their role. Hoess (2001) added: "If I was deeply affected by some incident, I found it impossible to go back to my home and my family. I would mount my horse and ride, until I had chased the terrible picture away" (p. 155).

When the commandant of Sobibor and Treblinka, Franz Stangl, was asked several decades after World War Two where the worst place in the extermination camps were for him, his response suggests he went to great lengths to insulate his conscience from the realities around him:

'The undressing barracks,' he said at once. 'I avoided it from my innermost being; I couldn't confront them; I couldn't lie to them; I avoided at any price talking to those who were about to die: I couldn't stand it [italics added]' (Sereny, 1974, p. 203). ${ }^{221}$

\footnotetext{
${ }^{221}$ Stangl's (and Hoess') choice of words are similar to those of Mrs. Rosenblum in the Milgram experiments, who later pleaded: "You don't know what I went through here" (Milgram, 1974, p. 82). Stangl glosses over the victims' experience, arguing instead that he could not stand it.
} 
Yet, it was this continual avoidance of personal encounters with his approximately one million victims that ensured that until Stangl was released of his duties, he was indeed able to "stand it". ${ }^{222}$ Such distance allowed him to later argue: “ 'Of course, I wasn't 'involved' in that sense,' he said quickly. 'Not in the operational sense' " (Sereny, 1974, p. 57). As far as Stangl was concerned, not having personally killed anyone, he was not responsible for the massive death toll that took place under his command. This explains why, when he was accused of being more directly involved and having shot into a crowd of prisoners, he:

appeared to be more indignant about this accusation than about anything else, and to find irrelevant the fact that, whether he shot into the group or not, these very same people died anyway, less than two hours later, through actions ultimately under his control (Sereny, 1974, p. 124).

A similar response might have been expected from Milgram's Peer Administers Shocks experiment (subject just asked questions: actor inflicted shocks-92.5 percent completion rate) if, say, obedient subjects were later accused by the learner of having been the person who inflicted the shocks.

It would seem that for Stangl and most of his German staff, if they never received any cues, they could simply avoid thinking about the implications of their actions. It was as if the mass killing of human beings was not even happening. The option of perceptual avoidance seemed to perpetuate Stangl's and his German subordinates' “intentional ignorance" (Seibel, 2005, p. 351). Or as the Dutch Protestant theologian, Willem A. Visser't Hooft, put it, they could very conveniently " 'live in a twilight between knowing and not knowing" " (as cited in Sereny, 1995, p. 335).

\subsection{Conclusion}

There are many major differences between the perpetration of the Holocaust and Milgram's OTA experiments. But the implementation of Operations Barbarossa and Reinhard shows that there are certain similarities that link them closer together-thus the M-H linkage. Like Milgram's, Nebe's experiments and selection of a means of inflicting harm also drew on his past experiences and an intuitive feel for what he suspected might

\footnotetext{
${ }^{222}$ Similarly, Hoess (2001) conceded: "My inner scruples about remaining in the concentration camp, despite my unsuitability for such work, receded into the background now that I no longer came into such direct contact with the prisoners as I had done in Dachau" (p. 82).
} 
"work". To make it all a reality, again like Milgram, Nebe drew on the expertise of others-Heess and Widmann-and the more specialists he drew in, inadvertently, the more bureaucratic the process became. Globocnik and Wirth then took up the baton and with the help of the T4 personnel in conjunction with the ad hoc trial and error exploratory method of discovery, a seemingly monolithic bureaucratised and industrialised factory of death emerged (see Bartov, 1996, pp. 3-4). As the machine grew and others were implicated, overall responsibility for the end result was easily displaced and eventually dissipated.

This general pattern of incremental "advances" and refinements continued with further time and experience. Those managing the Auschwitz-Birkenau work and extermination camp learnt from this ad hoc trial and error, which led to Operation Reinhard's most "perfect" system. ${ }^{223}$ The use of the faster-acting Zyclon-B (crystals which turned into gas when exposed to oxygen at a temperature of at least 25.7 degrees Celsius) was the bureaucratic "zenith"—but moral "nadir"—of the Nazis' system of industrialised killing (see below):

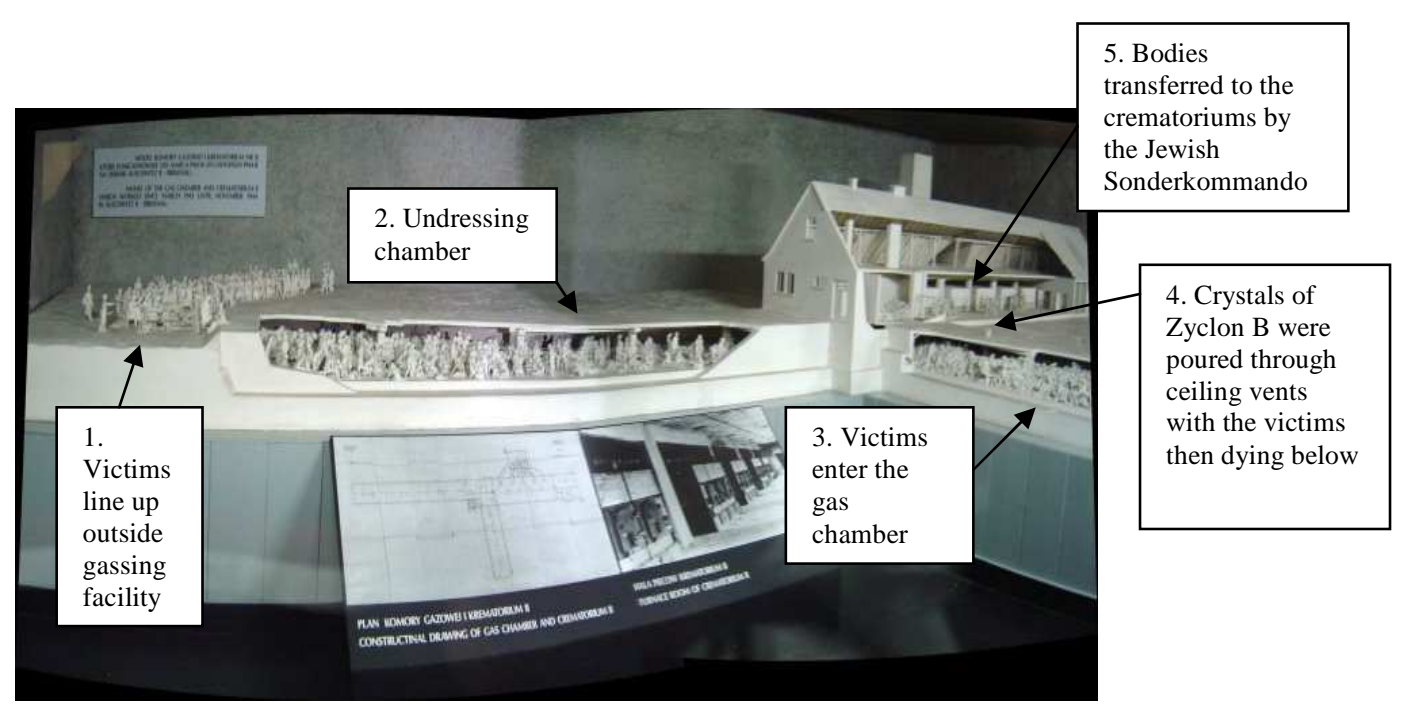

Figure 24: Model of the most advanced industrialised gas chamber at AuschwitzBirkenau-Crematorium II (see Berenbaum, 2006, pp. 140-141).

\footnotetext{
${ }^{223}$ For example, see Footnote 196. It is interesting to note that before Wirth was killed in an ambush in Italy near the end of the war, he spoke of Rudolf Hoess (who had no T4 Euthanasia experience) as his

“ 'untalented pupil'” (Hilberg, 1961, p. 572).
} 
The last link in this humanly destructive bureaucratic process required "merely" the pouring of Zyclon-B crystals into the ceiling vents, which then only required sealing (see below):

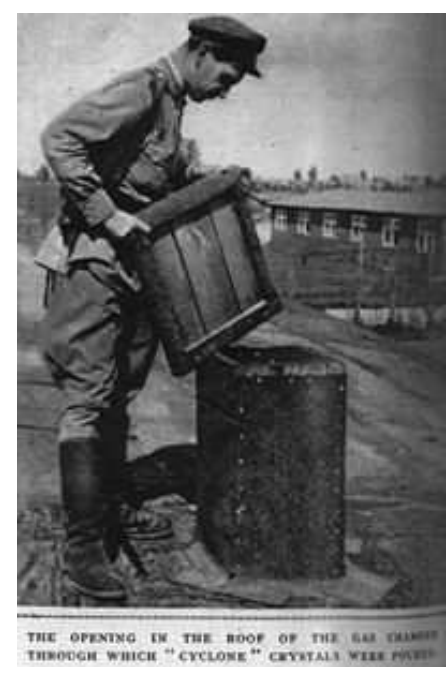

Figure 25: The opening in the roof through which Zyclon-B crystals were poured into the gas chamber below (this photo is actually of the Majdanek concentration camp, which used the same technology and technique).

It would seem the so-called success of the more advanced gassing enterprises lay in their ability to render the highly destructive outcome a "purely theoretical notion" (Bauman, 1989, p. 25) — that is, killing which is almost devoid of any perceptual reality. And it was the gas chamber, as the most powerful of all SRMs that made this possible. Like the shock generator, as set up in Milgram's Truly Remote Pilot condition-it, not the perpetrators-inflicted the forceful blow and it, not them, did so remotely. For the Germans in the camps it became possible to engage in Truly Remote-like total perceptual avoidance, to the point that their lethal contributions closely resembled the seemingly benign contributions of all the paper-shuffling "desk murderers" further up the bureaucratic chain. $^{224}$

The majority of moderately anti-Semitic Germans posted to this most "advanced" of camps were unlikely to demur from participating in the Nazi regime's exterminatory goals. After searching long and hard, the Nazi regime had finally found a method of killing that,

${ }^{224}$ See Schwan (2001, pp. 68-71) for a variety of avoidance-type behaviours relied upon by perpetrators at all levels of the Nazi hierarchy. 
as far as possible, removed the necessity for the Germans involved to feel, see, and hear the impact of their actions on their fellow human beings.

The push to continue killing would come from above, but the most powerful innovations-which were introduced with the egocentric intention of easing the more front-line perpetrators' stressful experiences-came from those below. ${ }^{225}$ What those further down the ranks failed to realise was that the more bottom-up innovation they engaged in (their invention and use of new SRMs), the more bearable for them became the destructive desires of their masters in Berlin. The easier it all became, the more likely those at the front-line would - and could — continue participating (and the longer they participated, the greater the numbers of people killed). However, the bigger the death toll, the more grandiose the desires of their leaders became and the more undesirables they found (like, for example, ugly people) for whom death was deemed necessary. ${ }^{226}$

For a variety of reasons, all involved wanted the last link in the destructive bureaucratic chain to feel completely benign. In this way, evil—as Arendt (1963) would later argue—had indeed been rendered banal.

\footnotetext{
${ }^{225}$ Thad Allen (2005, p. 266) has argued: "The primary question concerning the Holocaust as a crime based on the division of labour" is "What interrelationship existed between centralized authority and spontaneous initiative at the local level?" It is believed hat this thesis may shed some light on answering this question.

${ }^{226}$ By 1944 even those considered to be ugly were being considered for extermination. According to Hilberg (1961): "In consequence of an agreement between Himmler and Justice Minister Thierack, so-called asocials were transferred from prisons to concentration camps. On November 16, 1944, after the transfer of the 'asocials' had largely been completed, the judiciary met to discuss a weird subject: ugliness. The phrase on the agenda was 'gallery of outwardly asocial prisoners [Museum äusserlich asozialer Gerfangener].' The summary of that conference states: 'During various visits to the penitentiaries, prisoners have always been observed who - because of their bodily characteristics - hardly deserve the designation human [Mensch]; they look like miscarriages of hell [Missgeburten der Hölle]. Such prisoners should be photographed. It is planned that they too shall be eliminated [auszuschalten]. Crime and sentence are irrelevant. Only such photographs should be submitted which clearly show the deformity" (pp. 642-643).
} 


\section{Chapter Twelve: Overview and Conclusion}

... when I first heard of the Milgram experiments .... I knew I could do such a thing .... The impetus lay within me, like a little hot spot .... How often had I, have you, heard a racial slur and said nothing in order to keep the peace? How often have I, have you, seen something wrong at work, maybe a mistreated colleague, and done nothing so your own job stays steady? The little hot spot travels inside us. Certain situations may make it glow brighter, and others dimmer ... [it is] ... the moral failing that lies at the heart of so many humans ...-Slater (2004, p. 63).

This thesis began with an overview of the literature that led to Bauer's (2001) "real question" (p. 103): how did a mostly moderately anti-Semitic society like Germany in the 1930s become, by the early 1940s, "a reservoir of willing murderers of Jews?" A commonality that Milgram shares with the Nazi regime is that both rapidly transformed large proportions of "ordinary" people into willing inflictors of harm. A central aim of this thesis has been to delineate Milgram's (research) journey of discovery with the intention that it might shed some insights into Bauer's question of how the Nazi regime so rapidly converted ordinary onlookers into willing executioners. Also, since Milgram's own explanation for his results was ultimately unsatisfactory, another central aim of the thesis was to provide a new theoretical interpretation of the OTA experiments.

To achieve these aims the thesis addressed five questions. First, how did Milgram transform a large proportion of ordinary people into willing torturers of other human beings? As outlined in Chapters Four and Five, Milgram's results can be traced back to the cumulative inclusion within his experimental procedure of a variety of what he termed Binding Factors (BFs) and Strain Resolving Mechanisms (SRMs). BFs are coercive bonds that aid in the entrapment of individuals into participating in otherwise distasteful behaviour. SRMs are mechanisms that help reduce the feelings of tension a person normally experiences when engaging in distasteful behaviour. For Milgram there were three main sources of BFs and SRMs. In the first instance, he drew on past experiences, like the inclusion of the BF of group forces-peer pressure. Having previously worked under Solomon Asch, Milgram knew before the pilot stage that such pressure would probably result in some subjects (ostensibly) torturing the learner. Secondly, Milgram relied upon his intuition, drawing upon ideas that he thought might encourage subjects to complete the experiment: for example, his invention/selection of a means of inflicting harm — the shock generator (SRM) — that he suspected subjects might use on another person. The third factor promoting high completion rates was Milgram's use of the ad hoc trial and error exploratory method of discovery. The application of this method of discovery throughout the pilot studies led to a refined experimental procedure along with 
the addition of even more BFs and SRMs. One example was increasing the coercive power of Milgram's intuitive idea to incrementally escalate the shock intensity-the footin-the-door technique (BF) - by increasing the number of shock switches from 12 in the first pilot to 30 in the official experiments.

It has been argued in this thesis that Milgram's results were largely (but not exclusively) due to the cumulative inclusion of the following BFs and SRMs:

- the provision of a plausible rationale/ideology (exploring the potential of punishment on learning) that, via moral inversion, encouraged subjects to at least initially condone the infliction of harm (SRM),

- the ability of the shock generator to enable subjects to avoid having to experience most of the perceptual consequences surrounding their decision to inflict harm (SRM),

- the shock generator's piecemeal foot-in-the-door-like escalation in shock intensity (BF),

- the experimenter's response that the shocks apparently caused no permanent injury (SRM) and his implied but especially explicit offer to accept all responsibility for the subjects' actions (SRM),

- the shock generator's ambiguously labelled last switch—XXX—adding uncertainty to the shocks likely effect (SRM),

- a proximate and coercive experimenter who obviously condoned the infliction of harm (BF), and a seemingly harmless and defenceless learner (SRM).

From the inception of Milgram's first inchoate ideas, through to the last pilot study, the gradual accumulation, refinement and incorporation of these and other BFs/SRMs progressively increased the probability of any one subject completing the experiment. In fact, by the time of his last test run-the Truly Remote Pilot-Milgram had introduced so many patently powerful BFs and SRMs that he went too far, ensuring "virtually all" completed the experiment. 
The second question the thesis addressed was: how did Milgram explain his results? As discussed in Chapter Six, Milgram argued that, due to the survival value of organisation over disorganisation, humans have increasingly come to rely upon hierarchical structures, resulting in them developing significant advantages over their competitors in the natural environment. He was careful to argue that obedience to those higher in the chain of command is not innate but that people are born with a potential for obedience which interacts with wider situational forces to promote potentially destructive obedience. These potentially destructive impulses are kept in check by the consciences of autonomously acting individuals. The problem emerges when a person is introduced into a hierarchical chain of command, where apparently a homeostatic-type change can occur which supplants local conscience-driven control in favour of the demands of a malevolent authority. The individual then enters into the agentic state: a condition where "the individual no longer views himself as responsible for his own actions but defines himself as an instrument for carrying out the wishes of others" (Milgram, 1974, p. 134). Accelerating entry into the agentic state are potentially numerous BFs. However, Milgram believed that submergence into the authority system is rarely total and, upon inflicting harm, subjects often experienced strain (like sweating or trembling). Numerous SRMs are capable of mitigating this strain. In sum, Milgram explained obedience as the outcome when BFs exceeded the ability of the SRMs to reduce strain. And disobedience was the outcome when the BFs failed to exceed the capacity of the SRMs to reduce strain.

Chapter Seven addressed the third question: with particular regard to the Holocaust, what was the scholarly reaction to the Obedience to Authority (OTA) research and Milgram's explanation of it? Although most scholars believed the experiments to be methodologically sound, the initial reaction centered on what most regarded as the highly unethical nature of the study. With respect to Milgram's findings and their purported connection to the Holocaust, scholars have largely remained unconvinced by the centerpiece of his theory - the agentic state. Across the many experimental conditions, this explanation failed to explain the variance in completion rates, or why some subjects/Germans who completed the experiments/participated in the Holocaust, respectively, later held themselves to be primarily responsible for their own actions. The agentic state also tended to exonerate obedient subjects and the Holocaust perpetrators, by suggesting that they believed themselves to be mere instruments of higher authority and were being honest when later arguing, as so many did, that they were "just following orders". 
In light of the failure of Milgram's own theory, the fourth question of the thesis was: does a more convincing explanation of his results exist? It was argued that the main (although not exclusive) reason subjects completed the Baseline experiment was that most assessed it to have been easier for themselves to continue inflicting the shocks than to help the learner, which would have necessitated they shoulder the burden of engaging in an uncomfortable confrontation with the experimenter. Confronted by a moral dilemma to do what independent audiences assessed to be the wrong course of action, those who completed chose to prioritise their desire to avoid a confrontation over the learner's obviously more important need to escape what appeared to be potentially lethal shocks. The reason so many subjects were willing to repeatedly make the choice they did was that they were led to believe that they could probably do so with impunity. The experimental procedure therefore encouraged subjects to suspect that, although the learner would suffer, they could probably get away with it—actions without consequences. The claim of OTA—“I had to do it. You said so"—was just one of many strain-resolving rationalisations that allowed many subjects to do what they were tempted to do: avoid a confrontation. ${ }^{227}$ Over and above Milgram's Holocaust-inspired obsession with the power of "obedience", his research is much more about how ordinary people resolve moral dilemmas, and about the influence of situational factors-BFs and SRMs-on their decision-making processes. This alternative interpretation fits well within some of the broader literature, bolstering the argument that the OTA experiments were actually about the resolution of a moral dilemma. It is, for example, concordant with Bandura's (1999, p. 194) concept of moral disengagement in the perpetration of inhumanities where, much like Milgram's BFs and SRMs: "there are many social and psychological maneuvers by which moral self-sanctions can be disengaged from inhumane conduct." The experiments were really about the top-down provision and/or bottom-up invention of opportunities that provided subjects with an easy, albeit immoral, means of resolving a moral dilemma (with the likelihood of evading responsibility for having done so). To reiterate, the OTA experiments paradoxically have less to do with "obedience" to authority per se, and much more to do with the availability of opportunities that enabled subjects to evade responsibility for the harmful actions they in fact chose to undertake.

${ }^{227}$ C P Snow (1961, p. 258) captured it well: “. . . I am saying that loyalty can easily turn into conformity, and that conformity can often be a cloak for the timid and self-seeking. So can obedience, carried to the limit." 
In Milgram's agentic state, subjects were mere instruments who did not believe themselves to be responsible for their own actions. The alternative explanation presented in this thesis suggests, however, that most of those who completed the experiments were probably in much greater control of their actions than they were willing to concede. Consequently, this thesis has posited the State of Autonomous Denial (SAD) in place of Milgram's agentic state. The $S A D$ is where subjects were aware that they were responsible for their own actions. However, due to their fear of having to pay some personal cost in order to help the learner (that is, engage in a confrontation with the experimenter) they attempted to conceal this awareness of responsibility internally (via self-deception) and/or externally (via the deception of others). Having denied to themselves that they were responsible for their own actions, they could then pursue what for them was the easiest available option in resolving the moral dilemma: continue inflicting the shocks on the learner. A variety of factors promoted access to the $S A D$, thus reducing the subjects' feelings of responsibility. Among these were BFs (foot-in-the-door phenomena, financial remuneration) and supplied and/or self-invented SRMs (strain-resolving rationalisations, avoidance behaviour, positive self-image). However, this thesis has argued that the most powerful mechanism, in conjunction with an ideology/rationale that legitimised the infliction of harm, was the SRM of the shock generator used by Milgram as a vital component of his methodology.

The central importance of the shock generator can be traced back to two key characteristics that, when used simultaneously, rendered this device the single most powerful mechanism in the entire research programme. The first characteristic was that the shock generator, not the subject, inflicted blows seemingly strong enough to render another human being at least unconscious (engendering a loss of agency). The second one was the shock generator's capacity to inflict these (seemingly) intense blows in a situation in which the subject was physically separated from the recipient of the shocks. The shock generator made possible the "physical separation of the act [flick switches] and its effects [seemingly rendering the victim unconscious]" (Milgram, 1974, p. 39). Therefore, the maximum utility of these two characteristics ensured the victim's apparent suffering came to possess "an abstract, remote quality for the subject. He is aware, but only in a conceptual sense, that his actions cause pain to another person; the fact is apprehended but not felt" (Milgram, 1974, p. 36). Because subjects did not have to feel, see, and hardly hear the seemingly destructive implications stemming from their actions they were only ambiguously responsible: there was ambiguity as to who- the subject, experimenter, or even the learner-was most responsible for the latter's treatment. The fact that the act was 
separated from its effect meant that subjects did not personally feel and/or sensed they might not appear as responsible as they were for the seemingly painful outcome. Ambiguous responsibility gave subjects the opportunity to deceive themselves and/or others in the concealment of their actual awareness of personal responsibility for their own actions. And, if they did not feel and/or appear most responsible for the implications stemming from their actions then, very conveniently, perhaps they believed they were not? The shock generator was a necessary but not a sufficient cause of the experimental effect"Obviously some acceptable rationale [for inflicting shocks] must be provided." Nonetheless, without the shock generator a 65 percent completion rate in the Baseline experiment would have been extremely unlikely.

However, there are limitations with this or any other subject-centric explanation of the results of the OTA experiments. That is, subjects later often pointed out that they would not have completed such an experiment of their own accord, and added that their decision to do so was strongly influenced by the fact that other, clearly more prominent figures_-such as the experimenter and Yale University—had been instrumental in developing and running this experiment. Chapter Eight's subject-centric explanation may therefore shift attention away from the intra-group forces that also played a significant role in the subjects' individual decision-making processes. This point is bolstered when the experiments are interpreted as a Weberian-like goal-orientated bureaucratic process.

To illustrate the validity of this interpretation, it was shown that Milgram's conversion of his experimental idea into a reality saw him draw upon the help and expertise of a wide variety of specialist groups/individuals, including, for example, the National Science Foundation (NSF), Yale University, John Williams, James McDonough, and even himself. Since harm in the form of intense stress was to be inflicted on the subject, it was shown how Milgram overcame any concerns they may have expressed regarding the experiments' unethical nature. As was the case with subjects, it was argued that Milgram provided each individual/group with a sufficiently convincing rationale/ideology that also legitimated the infliction of harm (highlighting the probable significance of the research). It appears that this rationalisation was greatly bolstered by Milgram anticipating, then appealing to each individual's/group's often different needs and/or desires. Thus, to get all on board and secure their eventually harmful contributions, Milgram applied to each individual/group what he suspected would be the most successful motivational formula. In one case, an employee developed reservations and refused to 
perform his role. He was simply replaced with someone else who would. ${ }^{228}$ Milgram's anticipation of the most likely successful motivational formula also applied to the subjects. They were given a rationale/ideology that condoned the infliction of harm - that is, the exploration of the effects of punishment on learning. Then Milgram appealed to their needs and/or desires (in the form of opportunities which would enable them to avoid a confrontation with the experimenter). But as all these people, in their various roles, contributed to the infliction of intense stress on the subjects (and to the subject's infliction of apparently intense shocks on the learner), a powerful force was brought into effect, one essential to the production of the requisite experimental results. That is, as each party agreed to participate and make their necessary contributions, Milgram had unwittingly constructed a coercive and strain-resolving structural tool of organisation-a goalorientated bureaucratic process.

Inherent in the bureaucratic process are a variety of BFs and SRMs. There is the top-down chain of command-OTA-whereby less powerful links in the chain are to do as they are told by more powerful links. Less obvious is bureaucratic momentum (BF), whereby individuals feel pressured by other members of the bureaucratic chain into performing their specialist tasks (the "in-tray" continues to fill, and upon completion of the work other functionaries further down the chain await the transfer of this work to their own "in-tray"). Finally, the displacement/diffusion of responsibility (SRM), where responsibility for the malign outcomes is passed on to other, or spread across, all links in the chain so that no one single person feels and/or appears to be fully responsible for what occurs (Arendt's (1970, p. 38) "rule by Nobody"). The top-down chain of command appears most relevant to the OTA experiments, but displacement/diffusion of responsibility - that others were involved-was much more important in generating the high completion rates. All participants-from the subject through to the NSF and perhaps even Milgram - appear to have sensed that even if blame were later apportioned, it could easily be diverted elsewhere. For example, subjects probably suspected they could blame clearly more prominent links in the chain, like Milgram and Yale University, for undertaking such unethical experiments. Similarly, it is likely that Williams the experimenter thought that Milgram was actually responsible for the former's infliction of intense stress on the subject. Finally, with so many subjects having chosen to continue to inflict the shocks, Milgram could (and arguably did) blame them for their own stressful experiences. Because there were so many links in the organisational chain, each participant's feeling of responsibility for the destructive end result eventually dissipated as 
all came to sense blame could be shifted elsewhere-thus occurred the displacement and eventual diffusion of responsibility.

Although not addressed in the academic literature, as shown in Chapter Nine, Milgram's construction and use of the bureaucratic process played a central coercive and strain-resolving role in the generation of his experimental results. The presence of a bureaucratic process ensures that others are involved, which then makes the diffusion of ultimate responsibility possible. Any explanation that does not consider this structural (and sociological) feature-as do more subject-centric/individual explanations-will fail to achieve a more nuanced and comprehensive understanding of the OTA experiments.

Milgram's development of his theoretical model would seem to have been impeded by the fact that, as was also the case with his doctoral research, he originally founded the OTA idea on what soon after World War Two was a commonly held stereotype. As he said: " 'I came across many statements which implied that Germans tended to obey orders more conscientious[ly] than Americans" " (as cited in Fermaglich, 2006, p. 88). The results he obtained in the rudimentary pilot study seemed to reinforce part of this stereotype: there indeed appeared to be an inclination in ordinary people to obey authority figures. Although there were some counterfactual "gaps" that detracted from the so-called "compelling tendency to obey", with the concept of "obedience" firmly in his mind, Milgram failed to contemplate that an explanation for the experiments might, as this thesis has argued, have much less to do with OTA, per se, than he was inclined to believe.

What does the above information reveal about the fifth and final question of the thesis? That is, how during the Holocaust a mostly "moderately anti-Jewish" society like Germany in the 1930s become, by the early 1940s, "a reservoir of willing murderers of Jews?" (Bauer, 2001, p. 103). The first nine chapters of this thesis suggested that a fruitful starting place in understanding how ordinary moderately anti-Semitic people could so quickly be converted into willing executioners of Jews might be to first explore the construction of the ideological/rationale that resulted in a moral inversion that legitimated the deliberate infliction of harm on some people by others. Secondly, the thesis suggested that taking a close look at the potential influence of intuition, previous experience and the ad hoc trial and error process in the evolution of the most powerful SRM of all-the means of inflicting harm-in conjunction with some of the other powerful SRMs and BFs. Milgram's OTA experiments illustrated that when the means of inflicting harm was 
extremely low in perceptual stimulation, it was possible for clearly trivial/self-centered concerns to dominate a subject's emotional universe-like fear of a confrontation, peerpressure, and even the prospect of being deprived of \$4.50. Can it be at all possible that similar trivial/self-centered concerns were at work during the extermination of the Jews and others?

Chapter Ten argued that upon coming to power in 1933 the Nazi regime worked assiduously to promulgate an ideology/rationale promoting the need to remove or eliminate the Jews and some other groups (Dawidowicz, 1990, p. 195). Most ordinary Germans came to accept this ideology, or at least felt indifferently towards its malevolent pursuit and implications, especially after the regime crushed the expression of any dissenting views. The end result was that many people in Germany came to condone, or feel indifference towards, the infliction of harm against so-called enemies of the state. Using a variety of methods, by 1941 many ordinary Germans were already demonstrating an ability to kill fairly large numbers of civilians. As the German empire (and its corollary of the putative Jewish problem) expanded, on the eve of the invasion of the Soviet Union the idea of killing the "inferior" populations was being considered within influential Nazi circles.

The thesis then explored how leading Nazi bureaucrats, like Himmler and Heydrich, used a combination of Milgram-like intuition and past experience in coming to the view that arming local Eastern Europeans and/or ordinary Germans with firearms (as a means of inflicting harm) might prove effective in achieving their goal of killing the Soviet Jews and others. Because so many of the Germans who manned these shooting squads initially experienced what they termed "burdening of the soul", Himmler attempted, from the top-down, to ensure his men's continuing participation in the shootings by supplying them with a variety of BFs (such as the gradual foot-in-the-door-like expansion of enemy targets) and SRMs (such as his accepting responsibility for their actions). The shooters came to realise that the Reichführer's strain-resolving ideas were largely ineffective in easing their psychologically stressful tasks. As they felt that they were stuck with this work, from the bottom-up they began inventing their own, far more effective, SRMs. There was, for example, the wide use and abuse of alcohol, as well as a tendency to avoid the types of victim most difficult to shoot, such as the mentally ill. Particularly popular among the shooters was the movement over time towards a less disturbing (perceptually benign) shooting technique. That is, the campaign started out with the distressful militarystyle execution which then moved on to the eventually most relied upon clean, quick, 
lethal, and relatively less stressful genickschuss or "neck shot" technique. The increasing bureaucratisation of the shooting process (increasing specialisation and division of labour) was also observable during this process. This rapidly incorporated the least stressful shooting techniques, in conjunction with the most efficient means of implementation (Jeckeln's "Sardinenpackung" technique). The progressive incorporation of most of these BFs and SRMs were arguably all present three months into Operation Barbarossa, at the time of the Babi Yar massacre. However, in the end, the only SRM capable of enabling the ordinary Germans to totally avoid the otherwise unavoidable repugnant visual spectacle generated by firearms was the increasingly popular strategy of inserting Eastern Europeans_-"special end units"—as SRMs at the immediate killing end of the exterminatory bureaucratic process.

After Himmler had observed an execution near the start of the campaign, he asked Artur Nebe to devise a more "humane" method of killing. Chapter Eleven examined how Nebe and his colleagues' search and discovery of a new method of extermination involved (again) a combination of Milgram-like intuition, past experience, and the ad hoc trial-anderror method of discovery. Following a number of pilot studies they invented the visually more benign exhaust-fume gas chamber technique. Then came more ad hoc trial and error experimentation by other bureaucrats, until a more refined and efficient killing process emerged - from the mobile gas vans using carbon monoxide fumes, to the semi-permanent extermination camp at Chełmno, to the hugely destructive Operation Reinhard and its increasingly more refined industrialised factories of death at Belzec, Sobibor and then Treblinka). ${ }^{229}$ Eastern Europeans were frequently given the job of pushing the victims into the gas chambers, and then the Sonderkommandos (Jewish work groups) were required to remove and burn the victims" bodies. The more "advanced" gassing processes ensured that, if they so desired, most ordinary Germans within the camps had only to perform the less stressful tasks (devoid of most, or any, perceptual reality).

This pattern of ad hoc developments, revolving mostly around the means of inflicting harm, continued at what became the largest killing centre the Nazi regime had time to devise-Auschwitz-Birkenau (with its faster-killing gas, greater efficiency, and even more industrialised killing/body disposal processes).

\footnotetext{
${ }^{229}$ Milgram did not notice that his path of experimental discovery had similarly been traversed 20 years earlier by the most "successful" Nazi bureaucrats.
} 
In the end, most of the key bureaucrats_- “desk murderers" like Himmler, Heydrich, Eichmann, Stangl and Hoess_-probably did not feel responsible for the colossal death toll. They could convince themselves that they had not directly, themselves, actually killed anyone. $^{230}$ Eichmann repeatedly argued: " 'I never killed a single one . . . I never killed anyone and I never gave the order to kill anyone" " (Todorov, 1999, p. 152, as cited in Wistrich, 2001, p. 236). Irrespective of such self-deception-knowing without knowingEichmann knew the truth: "I created a situation for myself in which I could find a spark of inner calm. The main medicament was: I have nothing to do with it all personally. They are not my people. But my nervousness got worse" (Kulcsar, Kulcsar \& Szondi, 1966, p. 39, as cited in Rhodes, 2002, p. 247). For those ordinary Germans most directly involved-shooting squad members and those operating the gas chambers-the majority knew they would never have engaged in such behaviours of their own accord-that others of higher rank, status or expertise desired or had approved guaranteed that those lower down the hierarchical chain could act with impunity. They knew that should anyone later ask, they could always argue that they were "just following orders". As de Mildt (1996, p. 311) wrote of those involved in the Euthanasia programme and in Operation Reinhard:

Instead of . . the paranoiac ideological warriors so often invoked when describing the fieldworkers of Nazi genocide, their background profile far more closely matches that of rather ordinary citizens with a well-developed calculating instinct for their private interests . . . . The key word which springs to mind ... is not 'idealism' but 'opportunism'.

The bureaucratic process, with its division of labour, helped reduce the perpetrators' feeling of personal responsibility. Just as in Milgram's OTA experiments, each link in the chain could blame someone else for the destructive outcome. Whether or not they agreed with what they were doing, the key was that nobody felt ultimately responsible. And the bureaucratic chain, embodying a perceptually benign method of killing at its final link, helped all involved to diffuse their feelings of personal responsibility. They could then prioritise their lesser needs and/or desires (mild antiSemitism, peer pressure, desire for world domination, careerism, financial reward, fear of a confrontation and probably many other relatively trivial motivations). ${ }^{231}$ Insulated from

\footnotetext{
${ }^{230}$ However, in 1923 Hoess had been convicted and imprisoned for his involvement in a politically-related murder.

${ }^{231}$ Concordant with this conclusion, Mann's $(2000 ; 2005)$ study of Nazi perpetrators has yielded a similar typology of motivations for participating in the killings. More specifically: "The entire group of perpetrators is driven by the many motives that are normally found among ordinary people participating in more mundane social movements. Ordinary people are brought by normal social processes behind the ethnic barricades and then into committing murderous ethnic cleansing ... Radicals at all levels are helped to kill by their sense of righteousness. But even you or I could do it, for reasons of career, comradeship, patriotism, work routines,
} 
the perceptual realities of their seemingly benign actions enabled such trivial motivations to more forcefully dominate their emotional and moral universe. Thus, in the overall development of this process one is able to find an answer to Bauer's (2001, p. 103) "real question" of how it was that so many moderately anti-Semitic Germans could be converted into willing executioners.

It is important to point out, of course, that there are huge differences between Milgram's laboratory experiments, on the one hand, and the Holocaust, on the other (Waller, 2002, pp. 111-112). Perhaps the most important is that most of Milgram's subjects who refused to complete the experiments did so on ethical grounds: "I don't think it's right" (SMP, Box 153, Audiotape \#2305). However, as Browning (1992, pp. 74-75) said of the ordinary men in Reserve Police Battalion 101:

Even twenty or twenty-five years later those who did quit shooting along the way overwhelmingly cited sheer physical revulsion against what they were doing as the prime motive but did not express any ethical or political principles behind this revulsion.

These ordinary Germans did not feel that they faced any sort of moral dilemma, as such. Rather, they were upset by the physical repulsiveness of having to kill. Most of Milgram's subjects at various stages of the procedures disagreed with what was being asked of them, whereas the ordinary Germans seemed to have agreed with, or at least felt indifferently about, the extermination of "inferior" human beings. ${ }^{232}$ The implication that these Germans faced a dilemma of revulsion was that upon the discovery of, what for the perpetrators was a less disturbing means of inflicting harm, there would be no dilemma (a conclusion borne out by subsequent events).

By way of some concluding reflections, it seems relevant to think of the present and future, as well as the past. The moral dilemma in the OTA experiments may not sit easily with the historical event that stimulated them, but it may be applicable to many other situations beyond Milgram's laboratory. Consider, for example, the moral dilemma surrounding global warming. Increased greenhouse gas emissions are indispensable for continued economic growth. But so much scientific data indicates that the effect of increasing average global temperatures will generate a world-wide environmental

and other mundane human motives. We are humans, capable of evil.” (Mann, 2005, p. 504). In relation to another point, see Katz's (1993, pp. 78-79) views on Hoess.

${ }^{232}$ Perhaps Milgram could have achieved this if he had had more than one hour with the subjects and had gone through with his plans to dehumanise (SRM) the learner as an arrogant petty-thug. 
catastrophe. Independent audiences (much like the ones Milgram approached), presented with this moral dilemma, would probably conclude that to increase instead of decrease greenhouse gas emissions would be the morally wrong course of action. So is it possible that if world-wide greenhouse gas emissions increase, people may find themselves caught in an insidiously regressive and seemingly inescapable Milgram-like trap? Despite much talk about the need to take effective action, the reality may more likely be few will actually be prepared to do so, because of what they perceive to be their more pressing, immediate, interests - ever higher standards of living, continued economic growth, and the prioritisation of convenience over sustainability. As we enter and pass through what many scientists believe to be this critical "irreversible harm" phase, perhaps we will soon reach that point on the metaphorical shock board where, having resolved the conflict, no one ever breaks off?

The moral dilemma inherent in the OTA experiments may resemble the moral dilemma embedded in global warming more closely than it did the Nazis' implementation of their "Final Solution". Nonetheless, the Milgram-Holocaust linkage is more apparent than many scholars would presently allow. For example, Lutsky (1995, p. 63) has argued that the lens Milgram viewed his experimental results and their purported relationship with the Holocaust was severely limited:

What an emphasis on obedience slights, however, are voluntary individual and group contributions to Nazi ideology, policy, bureaucracy, technology, and ultimately, inhumanity. Historical scholarship recognizes this problem in the controversy between intentionalists, who view the Holocaust as the product of Hitler's plans and orders, and functionalists, who see the Holocaust as evolving from bureaucratic developments and rivalries, improvisation, individual and group initiatives, and other external conditions and forces (see Marrus, 1987, chap. 3. for a review). The top-down orientation of the intentionalist perspective melds well with social psychology's emphasis on obedience to authority; the functionalist perspective, which is prominent in historical scholarship, does not.

However, as this thesis has demonstrated, the OTA experiments have much to say about "individual" and "group" contributions to the development of a rationale or ideology that condones the deliberate infliction of harm on people. They also have plenty to say about top-down and bottom-up "improvisation" and "initiatives" within a destructive "bureaucracy", as well as shedding further insights into the relationship between "technology" and "inhumanity".

Finally, in regard to the potentially destructive tripartite nexus between bureaucracy, technology, and inhumanity, it is worth noting that just before the Cuban 
missile crisis of October 1962, ${ }^{233}$ Hilberg (1961, p. 760) ominously observed:

Before the emergence of the twentieth century and its technology, a destructive mind could not play in fantasy with the thoughts that the Nazis were to translate into action. The administrator of earlier centuries did not have the tools. He did not possess the network of communications; he did not dispose over rapid small arms fire and quick-working poison gases. The bureaucrat of tomorrow would not have these problems; already, he is better equipped than the German Nazis were. Killing is not as difficult as it used to be. The modern administrative apparatus has facilities for rapid, concerted movements and for efficient massive killings. These devices not only trap a larger number of victims; they also require a greater degree of specialization, and with that division of labor the moral burden too is fragmented among the participants. The perpetrator can now kill his victims without touching them, without hearing them, without seeing them.

It is certain that at the height of the Cuban missile crisis, neither the American nor the Soviet leadership would have had any difficulty in finding bureaucratic compliance with commands to push the buttons that would have released a nuclear Armageddon.

Therefore, it is not difficult to understand Milgram's (1974, p. 188) concern over the phenomenon he demonstrated in his laboratory-a strong propensity for people to prioritise relatively trivial personal interests over the need to act in response to their sense of more urgent moral propriety. His words of warning may prove to be prophetic:

The behavior revealed in the experiments reported here is normal human behavior but revealed under conditions that show with particular clarity the danger to human survival inherent in our makeup .... This is a fatal flaw nature has designed into us, and which in the long run gives our species only a modest chance of survival. 


\section{References}

Abse, D. (1973). The dogs of Pavlov. London: Vallentine, Mitchell.

Adams, G. B., \& Balfour, D. L. (1998). Unmasking bureaucratic evil. Thousand Oaks, CA: Sage Publications.

Adorno, T. W., Frenkel-Brunswik, E., Levinson, D. J., \& Sanford, R. N. (1950). The Authoritarian Personality. New York: Harper.

Allison, G. T., \& Zelikow, P. (1999). Essence of decision: explaining the Cuban Missile Crisis ( $2^{\text {nd }}$ Ed.). New York: Longman.

Aly, G. (1999). Final solution: Nazi population policy and the murder of the European Jews. London: Arnold.

Aly, G., \& Heim, S. (2002). Architects of annihilation: Auschwitz and the logic of destruction. London: Weidenfeld \& Nicolson.

Anderson, T. B. (2007). Amazing alphabetical adventures. Auckland, New Zealand: Random House.

Ancona, L., \& Pareyson, R. (1968). Contributo allo studio della aggressione: La dinamica della obbedienza distruttiva [Contribution to the study of aggression: The dynamics of destructive obedience]. Archivio di Psicologiu. Neurologia. $e$ Psichiatria, 29(4), 340-372.

Arad, Y. B. (1987). Belzec, Sobibor, Treblinka: the Operation Reinhard death camps. Bloomington, IN: Indiana University Press.

Arad, Y. B. (1993). Operation Reinhard: gas chambers in Eastern Poland. In E. Kogon, H. Langbein, \& A. Rückerl (Eds.), Nazi mass murder: a documentary history of the use of poison gas (pp. 102-138). New Haven, CT: Yale University Press.

Arad, Y., Gutman, I., \& Margaliot, A. (1999). Documents on the Holocaust: selected sources on the destruction of the Jews of Germany and Austria, Poland, and the Soviet Union ( $8^{\text {th }}$ Ed.). Lincoln, NE: University of Nebraska Press.

Arad, Y., Krakowski, S., \& Spector, S. (1989). The Einsatzgruppen Reports: selections from the dispatches of the Nazi death squads' campaign against the Jews in occupied territories of the Soviet Union July 1941-January 1943. New York: Holocaust Library.

Arendt, H. (1963). Eichmann in Jerusalem: a report on the banality of evil. London: Faber and Faber.

Arendt, H. (1970). On violence. London: Allen Lane the Penguin Press. 
Asch, S. E. (1958). Effects of group pressure upon modification and distortion of judgments. In E. E. Maccoby, T. M. Newcomb, \& E. L. Hartley (Eds.), Readings in social psychology ( $3^{\text {rd }}$ Ed.) (pp. 174-183). New York: Holt, Rinehart and Winston.

Aschheim, S. E. (1996). Reconceiving the Holocaust? Tikkun, 11(4), 62-65.

Askenasy, H. (1978). Are we all Nazis? Secaucus, NJ: Lyle Stuart Inc.

Bandura, A. (1973). Aggression: a social learning analysis. Englewood Cliffs, NJ: Prentice Hall INC.

Bandura, A. (1999). Moral disengagement in the perpetration of inhumanities. Personality and Social Psychology Review, 3(3), 193-209.

Bankier, D. (1992). The Germans and the final solution: public opinion under Nazism. Oxford, United Kingdom: Blackwell.

Barnard, C. I. (1968). The functions of the executive. Cambridge, MA: Harvard University Press.

Bartov, O. (1996). Murder in our midst: the Holocaust, industrial killing, and representation. New York: Oxford University Press.

Bartov, O. (1996b). Ordinary monsters. The New Republic, 214(18), 32-38.

Bartov, O. (2001). The Eastern Front, 1941-45, German troops and the barbarisation of warfare ( $2^{\text {nd }}$ Ed.). New York: Palgrave.

Bartov, O. (2003). Germany's war and the Holocaust: disputed histories. Ithaca, NY: Cornell University Press.

Bauer, Y. (1991). Who was responsible and when? Some well-known documents revisited. Holocaust and Genocide Studies, 6(2), 129-149.

Bauer, Y. (2001). Rethinking the Holocaust. New Haven, CT: Yale University Press.

Bauman, Z. (1989). Modernity and the Holocaust. Ithaca, NY: Cornell University Press.

Baumeister, R. F. (1997). Evil: inside human cruelty and violence. New York: W. H. Freeman and Company.

Baumrind, D. (1964). Some thoughts on ethics of research: after reading Milgram's 'behavioral study of obedience.' American Psychologist, 19(6), 421-423.

Benz, W. (1999). The Holocaust: a German historian examines the genocide. New York: Columbia University Press.

Berenbaum, M. (Ed.). (1997). Witness to the Holocaust. New York: Harper Collins Publishers. 
Berenbaum, M. (2006). The world must know: the history of the Holocaust as told in the United States Holocaust Memorial Museum ( $2^{\text {nd }}$ Ed.). Washington, DC: Johns Hopkins University Press.

Berger, R. J. (2002). Fathoming the Holocaust: a social problems approach. New York: Aldine de Gruyter.

Berkowitz, L. (1999). Evil is more than banal: situationism and the concept of evil. Personality and Social Psychology Review, 3(3), 246-253.

Birn, R. B. (1997). Historiographical review, revising the Holocaust. The Historical Journal, 40(1), 193-215.

Blass, T. (1991). Understanding behavior in the Milgram obedience experiment: the role of personality, situations, and their interactions. Journal of Personality and Social Psychology, 60(3), 398-413.

Blass, T. (1993). Psychological perspectives on the perpetrators of the Holocaust: the role of situational pressures, personal dispositions, and their interactions. Holocaust and Genocide Studies, 7(1), 30-50.

Blass, T. (1998). The roots of Stanley Milgram's obedience experiments and their relevance to the Holocaust. Analyse \& Kritik, 20(1), 46-53.

Blass, T. (2002). The man who shocked the world. Psychology Today, 35(2), 68-75.

Blass, T. (2004). The man who shocked the World: the life and legacy of Stanley Milgram. New York: Basic Books.

Bloxham, D., \& Kushner, T. (2005). The Holocaust: critical historical approaches. Manchester, United Kingdom: Manchester University Press.

Bourke, J. (1999). An intimate history of killing: face-to-face killing in twentiethcentury warfare. London: Basic Books.

Brandt, L. W. (1978). Don't sweep the ethical problems under the rug! Totalitarian versus equalitarian ethics. Canadian Psychological Review, 19(1), 6366.

Breitman, R. (1991). The architect of genocide: Himmler and the final solution. New York: Alfred A. Knopf.

Breitman, R. (2000). Official secrets: what the Nazis planned, what the British and Americans knew. London: Penguin Books.

Breton, A., \& Wintrobe, R. (1986). The bureaucracy of murder revisited. The Journal of Political Economy, 94(5), 905-926.

Brief, A. P., Buttram, R. T., Elliott, J. D., Reizenstein, R. M., \& McCline, R. L. (1995). Releasing the beast: a study of compliance with orders to use race as a selection criterion. Journal of Social Issues, 51(3), 177-193.

Browning, C. R. (1978). The final solution and the German Foreign Office: A study of Referat D III of Abteilung Deutschland 1940-43. New York: Holmes and Meier. 
Browning, C. R. (1985). Fateful months: essays on the emergence of the final solution. New York: Holmes and Meier.

Browning, C. R. (1992). Ordinary men: Reserve Police Battalion 101 and the final solution in Poland. New York: Harper Collins.

Browning, C. R. (1994). Hitler and the euphoria of victory: the path to the final solution. In D. Cesarani (Ed.), The final solution: origins and implementation (pp. 137-147). New York: Routledge.

Browning, C. R. (1995). The path to genocide: essays on launching the final solution. New York: Cambridge University Press.

Browning, C. R. (1998). Ordinary men: Reserve Police Battalion 101 and the final solution in Poland. New York: Harper Perennial.

Browning, C. R. (2000). Nazi policy, Jewish workers, German killers. New York: Cambridge University Press.

Browning, C. R. (2004). The origins of the final solution: the evolution of Nazi Jewish policy, September 1939 - March 1942. Lincoln, NE: University of Nebraska Press.

Buchheim, H. (1968). Command and compliance. In H. Krausnick, H. Buchheim, M. Broszat, \& H. A. Jacobsen (Eds.), Anatomy of the SS state (pp. 303-396). London: Collins.

Büchler, Y. (1986). Kommandostab Reichsführer-SS: Himmler's personal murder brigades in 1941. Holocaust and Genocide Studies, 1(1), 11-25.

Burley, P. M., \& McGuinness, J. (1977). Effects of social intelligence on the Milgram paradigm. Psychological Reports, 40, 767-770.

Cesarani, D. (2004). Eichmann: his life and crimes. London: William Heinemann.

Charny, I. W. (1982). How can we commit the unthinkable? Genocide, the human cancer. Boulder, CO: Westview Press.

Chrostowski, W. (2004). Extermination camp Treblinka. London: Vallentine Mitchell.

Clendinnen, I. (1999). Reading the Holocaust. New York: Cambridge University Press.

Collins, B. E., \& Brief, D. E. (1995). Using person-perception vignette methodologies to uncover the symbolic meanings of teacher behaviors in the Milgram paradigm. Journal of Social Issues, 51(3), 89-106.

Corni, G. (2002). Hitler's ghettos: voices from a beleaguered society 1939-1944. London: Arnold. 
Costanzo, E. M. (1976). The effect of probable retaliation and sex related variables obedience. Unpublished doctoral dissertation, University of Wyoming (UM 773253), Laramie, WY.

Damico, A. J. (1982). The sociology of justice: Kohlberg and Milgram. Political Theory, 10(3), 409-433.

Darley, J. M. (1992). Social organization for the production of evil. Psychological Inquiry, 3(2), 199-218.

Darley, J. M. (1995). Constructive and destructive obedience: a taxonomy of principal-agent relationships. Journal of Social Issues, 51(3), 125-154.

Dawidowicz, L. S. (1990). The war against the Jews 1933-1945 (10 ${ }^{\text {th }}$ Ed.). Harmondsworth, United Kingdom: Penguin.

Dean, M. (2008). Robbing the Jews: the confiscation of Jewish property in the Holocaust, 1933-1945. Cambridge, United Kingdom: Cambridge University Press.

De Mildt, D. (1996). In the name of the people: perpetrators of genocide in the reflection of their post-war prosecution in West Germany - the 'Euthanasia' and 'Aktion Reinhard' trial cases. London, United Kingdom: Martinus Nijhoff Publishers.

Dicks, H. V. (1950). Personality traits and National Socialist ideology: a war-time study of German prisoners of war. Human Relations, 3(2), 111-154.

Dicks, H. V. (1972). Licensed mass murder: a socio-psychological study of some SS killers. London: Heinemman Educational for Sussex University.

Dwork, D., \& van Pelt, R. J. (1996). Auschwitz: 1270 to the present. New York: W. W. Norton \& Company.

Eckman, B. K. (1977). Stanley Milgram's 'obedience' studies. Et cetera, 34(1), 8899.

Elias, N. (1987). The retreat of sociologist into the present. Theory, Culture \& Society, 4(2), 223-247.

Elias, N. (1991). The symbol theory. London: Sage Publications.

Elms, A. C. (1995). Obedience in retrospect. Journal of Social Issues, 51(3), 21-31.

Elms, A. C., \& Milgram, S. (1966). Personality characteristics associated with obedience and defiance towards authoritative command. Journal of Experimental Research in Personality, 1(4), 282-289.

Etzioni, A. (1968). A model of significant research. International Journal of Psychiatry, 6(4), 279-280.

Evans, R. I. (1980). The making of social psychology: discussions with creative contributors. New York: Gardener Press. 
Fenigstein, A. (1998a). Reconceptualizing the obedience of the perpetrators. In D. G. Shilling (Ed.), Lessons and legacies, volume II: teaching the Holocaust in a changing world (pp. 55-84). Evanston, IL: Northwestern University Press.

Fenigstein, A. (1998b). Were obedience pressures a factor in the Holocaust? Analyse \& Kritik, 20(1), 54-73.

Fermaglich, K. (2006). American dreams and Nazi nightmares: early Holocaust consciousness and liberal America, 1957-1965. Waltham, MA: Brandeis University Press.

Festinger, L. (1957). A theory of Cognitive Dissonance. New York: Harper \& Row.

Finkelstein, N. G. (1997). Daniel Goldhagen's crazy thesis, a critique of Hitler's Willing Executioners. New Left Review, 224(1), 39-88.

Finkelstein, N.G., \& Birn, R.B. (1998). A nation on trial: the Goldhagen thesis and historical truth. New York: Henry Holt and Co.

Fleming, G. (1984). Hitler and the final solution. Berkeley, CA: University of California Press.

Foddy, W. H. (1971). Compliance to rational-legal authority (Monograph Series of Experimental Sociology Laboratory No. 3). Vancouver, Canada: University of British Columbia, Department of Anthropology and Sociology.

Freedman, J. L., \& Fraser, C. C. (1966). Compliance without pressure: the foot-in-thedoor technique. Journal of Personality and Social Psychology, 4(2), 195-202.

Friedlander, H. (1994). Euthanasia and the final solution. In D. Cesarani (Ed.), The final solution: origins and implementation (pp. 51-61). New York: Routledge.

Friedlander, H. (1995). The origins of Nazi genocide: from euthanasia to the final solution. Chapel Hill, NC: University of North Carolina Press.

Friedrich, C. J. (1946). Constitutional government and democracy: theory and practice in Europe and America. Boston: Ginn and Company.

Fromm, E. (1973). The anatomy of human destructiveness. London: Jonathan Cape.

Fussell, P. (1989). Wartime: understanding and behavior in the Second World War. New York: Oxford University Press.

Gerth, H. H., \& Mills, C. W. (1974). From Max Weber: essays in sociology. New York: Oxford University Press.

Gilbert, S. J. (1981). Another look at the Milgram obedience studies: the role of the gradated series of shocks. Personality and Social Psychology Bulletin, 7(4), 690695. 
Gitelman, Z. (1997). Eyewitness accounts. In Z. Gitelman (Ed.), Bitter legacy: confronting the Holocaust in the USSR (pp. 275-285). Bloomington, IN: Indiana University Press.

Glass, J. M. (1997). Life unworthy of life: racial phobia and mass murder in Hitler's Germany. New York: Basic Books.

Glover, J. (1999). Humanity: A moral history of the twentieth century. London: Pimlico.

Goldhagen, D. J. (1996). Hitler's willing executioners: ordinary Germans and the Holocaust. London: Alfred A. Knopf.

Goldhagen, D. J. (1996b). Motives, causes, and alibis: a reply to my critics. The New Republic, 215(26), 37-45.

Gonen, J. Y. (2000). The roots of Nazi psychology: Hitler's utopian barbarism. Lexington, KY: The University of Kentucky.

Gregory, R. J. (1995). Bureaucratic 'psychopathology' and technocratic governance: whither responsibility? Hong Kong Public Administration, 4(1), 17-36.

Grossman, D. (1995). On killing: the psychological cost of learning to kill in war and society. Boston: Little Brown.

Hamilton, V. L., \& Sanders, J. (1995). Crimes of obedience and conformity in the workplace: surveys of Americans, Russians, and Japanese. Journal of Social Issues, 51(3), 67-88.

Hamilton, V. L., \& Sanders, J. (1999). The second face of evil: wrongdoing in and by the corporation. Personality and Social Psychology Review, 3(3), 222-233.

Harré, R. (1979). Social being: a theory for social psychology. Oxford, United Kingdom: Basil Blackwell.

Harré, R., \& Second, P. F. (1972). The explanation of social behaviour. Oxford, United Kingdom: Basil Blackwell.

Headland, R. (1992). Messages of murder: a study of the reports of the Einsatzgruppen of the Security Police and the Security Service, 1941-1943. London: Associated University Press.

Heaton, J. (2004). Reworking qualitative data. London: Sage Publications.

Heim, S. (2000). The German-Jewish relationship in the diaries of Victor Klemperer. In D. Bankier (Ed.), Probing the depths of German Antisemitism: German society and the persecution of the Jews, 1933-1941 (pp. 312-325). New York: Berghahn Books.

Helm, C., \& Morelli, M. (1979). Stanley Milgram and the obedience experiment: authority, legitimacy, and human action. Political Theory, 7(3), 321-345.

Helm, C., \& Morelli, M. (1985). Obedience to authority in a laboratory setting: generalizability and context dependency. Political Studies, 33(4), 610-627. 
Hilberg, R. (1961). The destruction of the European Jews (Vols. 1-3). New York: Holmes \& Meier.

Hilberg, R. (1980). The anatomy of the Holocaust. In H. Friedlander, \& S. Milton (Eds.), The Holocaust: ideology, bureaucracy, and genocide (the San José Papers) (pp. 85-94). Millwood, NY: Kraus International Publications.

Hilberg, R. (1997). The Goldhagen phenomenon. Critical Inquiry, 23(4), 721-728.

Hilberg, R. (2003). The destruction of the European Jews ( ${ }^{\text {rd }}$ Ed.) (Vols. 1-3). London: Yale University Press.

Hitler, A. (1943). Mein kampf. Boston, Houghton Mifflin Company.

Hoess, R. (2001). Commandant of Auschwitz: the autobiography of Rudolf Hoess. London: Phoenix Press.

Hofling, C. K., Brotzman, E., Dalrymple, S., Graves, N., \& Pierce, C. (1966). An experimental study of nurse-physician relations. Journal of Nervous and Mental Disease, 143(2), 171-180.

Holmes, R. (1985). Acts of war: the behaviour of men in battle. New York: The Free Press.

Horwitz, G. J. (1990). In the shadow of death: living outside the gates of Mauthausen. New York: The Free Press.

Humphreys, L. (1970). Tearoom trade: impersonal sex in public places. Chicago: Aldine Publishing Co.

Johnson, E. A., \& Reuband, K. H. (2005). What we knew: terror, mass murder and everyday life in Nazi Germany, an oral history. London: John Murray.

Jung, J. (2001). Psychology of alcohol and other drugs: a research perspective. London: Sage Publications.

Katz, F. E. (1993). Ordinary people and extraordinary evil: a report on the beguilings of evil. New York: State University of New York Press.

Kaufmann, H. (1967). The price of obedience and the price of knowledge. American Psychologist, 22(4), 321-322.

Kelman, H. C. (1972). Human use of human subjects: the problem of deception in social psychological experiments. In A. G. Miller (Ed.), The social psychology of psychological research (pp. 163-178). New York: Free Press.

Kelman, H. C., \& Hamilton, V. L. (1989). Crimes of obedience: toward a social psychology of authority and responsibility. New Haven, CT: Yale University Press.

Kershaw, I. (1983). Popular opinion and political dissent in the Third Reich: Bavaria 1933-1945. Oxford, United Kingdom: Oxford University Press. 
Klee, E., Dressen, W., \& Riess, V. (Ed.). (1988). "The good old days": the Holocaust as seen by its perpetrators and bystanders. New York: Free Press.

Koenigsberg, R. A. (2009). Nations have the right to kill: Hitler, the Holocaust, and war. New York: Library of Social Science.

Krakowski, S. (1993). The stationary gas vans at Kulmhof. In E. Kogon, H. Langbein, \& A. Rückerl (Eds.), Nazi mass murder: a documentary history of the use of poison gas (pp. 73-101). New Haven, CT: Yale University Press.

Krausnick, H. (1968). The persecution of the Jews. In H. Krausnick, H. Buchheim, M. Broszat, \& H. A. Jacobsen (Eds.), Anatomy of the SS state (pp. 1-124). London: Collins.

Kühl, S. (2005). Ganz normale organisationen: organisationssoziologische interpretationen simulierter brutalitäten/ordinary organizations: Sociological reinterpretations of simulated brutalities. Zeitschrift für Soziologie, 34(2), 90-111.

Kulka, O. D. (2000). The German population and the Jews: state of research and new perspectives. In D. Bankier (Ed.), Probing the depths of German Antisemitism: German society and the persecution of the Jews, 1933-1941 (pp. 271-281). New York: Berghahn Books.

Lanzmann, C. (1995). Shoah: the complete text of the acclaimed Holocaust film. New York: Da Capo Press.

Lee, S. J. (1996). Weimar and Nazi Germany. Oxford, United Kingdom: Heinemann Educational.

Lerner, M. J. (1980). The belief in a just world: a fundamental delusion. New York: Plenum.

Levin, J., \& Fox, J. A. (1985). Mass murder: America's growing menace. New York: Plenum Press.

Lifton, R. J. (1986). The Nazi doctors: medical killing and the psychology of genocide. New York: Basic Books.

Lindblom, C. E. (1959). The science of "muddling through". Public Administration Review, 19(2), 79-88.

Longerich, P. (2005). From mass murder to the "final solution": the shooting of Jewish civilians during the first months of the Eastern campaign within the context of the Nazi Jewish genocide. In S. Gigliotti, \& B. Lang (Eds.), The Holocaust: a reader (pp. 198-219). Oxford, United Kingdom: Blackwell Publishing.

Lower, W. (2002). "Anticipatory obedience" and the Nazi implementation of the Holocaust in the Ukraine: a case study of the central and peripheral forces in the Generalbezirk Zhytomyr, 1941-1944. Holocaust and Genocide Studies, 16(1), 1-22. 
Lower, W. (2005). The "Reibungslose" Holocaust? The German military and civilian implementation of the "final solution" in Ukraine, 1941-1944. In G. D. Feldman, \& W. Seibel (Eds.), Networks of Nazi persecution: bureaucracy, business, and the organization of the Holocaust (pp. 340-360). New York: Berghahn Books.

Luban, D., Strudler, A., \& Wasserman, D. (1992). Moral responsibility in the age of bureaucracy. Michigan Law Review, 90(8), 2348-2392.

Lutsky, N. (1995). When is 'obedience' obedience? Conceptual and historical commentary. Journal of Social Issues, 51(3), 55-65.

MacQueen, M. (1997). Nazi policy towards the Jews in Reichskommissariat Ostland, June-December 1941: from white terror to Holocaust in Lithuania. In Z. Gitelman (Ed.), Bitter legacy: confronting the Holocaust in the USSR (pp. 91-103). Indianapolis, IN: Indiana University Press.

Mandel, D. R. (1998). The obedience alibi: Milgram's account of the Holocaust reconsidered. Analyse \& Kritik, 20(1), 74-94.

Mann, M. (2000). Were the perpetrators of genocide "ordinary men" or "real Nazis"? Results from fifteen hundred biographies. Holocaust and Genocide Studies, 14(3), 331-366.

Mann, M. (2005). The dark side of democracy: explaining ethnic cleansing. New York: Cambridge University Press.

Mantell, D. M. (1971). The potential for violence in Germany. Journal of Social Issues, 27(4), 101-112.

Mantell, D. M., \& Panzarella, R. (1976). Obedience and responsibility. British Journal of Social and Clinical Psychology, 15(3), 239-245.

Marcus, S. (1974). Book review of 'Obedience to Authority' by Stanley Milgram. The New York Times Book Review, 79(2), 1-3.

Marcuse, H. (2001). Legacies of Dachau: the uses and abuses of a concentration Camp, 1933-2001. New York: Cambridge University Press.

Marrus, M. R. (1988). The Holocaust in history. London: Weidenfeld \& Nicolson.

Marrus, M. R. (1997). The Nuremberg war crimes trial 1945-46. New York: Bedford/St. Martin's.

Marshall, S. L. A. (2000). Men against fire: the problem of battle command. Norman, OK: University of Oklahoma Press.

Martin, J., Lobb, B., Chapman, G. C., \& Spillane, R. (1976). Obedience under conditions demanding self-immolation. Human Relations, 29(4), 345-356.

Mastroianni, G. R. (2002). Milgram and the Holocaust: a reexamination. Journal of Theoretical and Philosophical Psychology, 22(2), 158-173. 
Matthäus, J. (2004). Operation Barbarossa and the onset of the Holocaust, JuneDecember 1941. In C. R. Browning (Ed.), The origins of the final solution: the evolution of Nazi Jewish policy, September 1939-March 1942 (pp. 248-308). Lincoln, NE: University of Nebraska Press.

McGranahan, D. V. (1946). A comparison of social attitudes among American and German youth. Journal of Abnormal and Social Psychology, 41(3), 245-257.

McGranahan, D. V., \& Janowitz, M. (1946). Studies of German youth. Journal of Abnormal and Social Psychology, 41(1), 3-14.

Meeus, W. H. J., \& Raaijmakers, Q. A. W. (1986). Administrative obedience: carrying out orders to use psychological-administrative violence. European Journal of Social Psychology, 16, 311-324.

Meeus, W. H. J., \& Raaijmakers, Q. A. W. (1995). Obedience in modern society: the Utrecht studies. Journal of Social Issues, 51(3), 155-175.

Meyer, P. (1970, February). If Hitler asked you to electrocute a stranger, would you? Probably. Esquire, 73, 128, 130, 132.

Miale, F. R., \& Selzer, M. (1975). The Nuremberg mind: the psychology of the Nazi leaders. New York: Quadrangle.

Milgram, S. (1961). Nationality and conformity. Scientific American, 205(6), 45-51.

Milgram, S. (1963). Behavioral study of obedience. Journal of Abnormal and Social Psychology, 67(4), 371-378.

Milgram, S. (1964a). Issues in the study of obedience: a reply to Baumrind. American Psychologist, 19(11), 848-852.

Milgram, S. (1964b). Group pressure and action against a person. Journal of Abnormal and Social Psychology, 69(2), 137-143.

Milgram, S. (1964c). Technique and first findings of a laboratory study of obedience to authority. Yale Science Magazine, 39, 9-11, 14.

Milgram, S. (1965a). Some conditions of obedience and disobedience to authority. Human Relations, 18(1), 57-76.

Milgram, S. (1965b). Liberating effects of group pressure. Journal of Personality and Social Psychology, 1(2), 127-134.

Milgram, S. (1965c). Obedience (a filmed experiment). Distributed by New York University Film Library.

Milgram, S. (1972). Interpreting obedience: error and evidence. A reply to Orne and Holland. In A. G. Miller (Ed.), The social psychology of psychological research (pp. 138-154). New York: Free Press.

Milgram, S. (1973, December). The perils of obedience. Harper's, 62-66, 75-77. 
Milgram, S. (1974). Obedience to authority: an experimental view. New York: Harper and Row.

Milgram, S. (1977). The individual in a social world. Reading, MA: Addison-Wesley Publishing Company.

Miller, A. G. (1986). The obedience experiments: a case study of controversy in social science. New York: Praeger.

Miller, A. G. (1995). Constructions of the obedience experiments: a focus upon domains of relevance. Journal of Social Issues, 51(3), 33-53.

Miller, A. G. (2004). What can the Milgram obedience experiments tell us about the Holocaust? Generalizing from the social psychology laboratory. In A. G. Miller (Ed.), The social psychology of good and evil (pp. 193-237). New York: Guilford Press.

Miller, A. G., Collins, B. E., \& Brief, D. E. (1995). Perspectives on obedience to authority: the legacy of the Milgram experiments. Journal of Social Issues, 51(3), $1-19$.

Mixon, D. (1972). Instead of deception. Journal of the Theory of Social Behavior, 2(2), 145-177.

Mixon, D. (1976). Studying feignable behavior. Representative Research in Social Psychology, 7, 89-104.

Mixon, D. (1989). Obedience and civilization: authorized crime and the normality of evil. London: Pluto Press.

Mommsen, H. (1997). There was no Führer order. In D. L. Niewyk (Ed.), The Holocaust: problems and perspectives of interpretation (pp. 27-38) $\left(2^{\text {nd }}\right.$ Ed.). Houghton Mifflin Company: New York.

Mooks, D. G. (1983). In defense of external invalidity. American Psychologist, 38(4), 379-387.

Mooks, D. G. (2004). Classic experiments in psychology. Westport, CN: Greenwood Press.

Morelli, M. F. (1983). Milgram's dilemma of obedience. Metaphilosophy, 14(3-4), 183-189.

Müller-Hill, B. (1988). Murderous science: elimination by scientific selection of Jews, Gypsies, and others, Germany 1933-1945. New York: Oxford University Press.

Musmanno, M. A. (1961). The Eichmann Kommandos. London: Peter Davies.

Naumann, B. (1966). Auschwitz. New York: Praeger.

Nissani, M. (1990). A cognitive reinterpretation of Stanley Milgram's observations to obedience to authority. American Psychologist, 45(12), 1384-1385. 
Nussbaum, M. (2007, October 17). Texts for torturers: From Stanford to Abu Ghraib -what turns ordinary people into oppressors? The Times Literary Supplement. Retrieved November 17, 2008, from http://entertainment.timesonline.co.uk/tol/arts_and_entertainment/the_tls/article267 7344.ece

Orne, M. T. (1962). On the social psychology of the psychology experiment: with particular reference to demand characteristics and their implications. American Psychologist, 17(11), 776-783.

Orne, M. T., \& Holland, C. C. (1968). On the ecological validity of laboratory deceptions. International Journal of Psychiatry, 6(4), 282-293.

Padfield, P. (1990). Himmler: Reichsführer-SS. London: Macmillan.

Parker, I. (2000). Obedience. Granta: The Magazine of New Writing, 71, 99-125.

Patten, S. C. (1977a). Milgram's shocking experiments. Philosophy, 52(202), 425-440.

Patten, S. C. (1977b). The case that Milgram makes. The Philosophical Review, 86(3), 350-364.

Penner, L. A., Hawkins, H. L., Dertke, M. C., Spector, P., \& Stone, A. (1973). Obedience as a function of experimenter competence. Memory and Cognition, 1(3), 241-245.

Pigden, C. R., \& Gillet, G. R. (1996). Milgram, method and morality. Journal of Applied Philosophy, 13(3), 233-250.

Pingel, F. (1993). Gassing in other concentration camps. In E. Kogon, H. Langbein, \& A. Rückerl (Eds.), Nazi mass murder: a documentary history of the use of poison gas (pp. 174-204). New Haven, CT: Yale University Press.

Raven, B. H., \& Rubin, J. Z. (1983). Social psychology. (2 ${ }^{\text {nd }}$ Ed.). New York: John Wiley and Sons.

Rees, L. (2005). Auschwitz: a new history. New York: BBC Books.

Rhodes, R. (2002). Masters of death: the SS-Einsatzgruppen and the invention of the Holocaust. New York: Alfred A. Knopf.

Rochat, F., \& Modigliani, A. (1997). Authority: obedience, defiance, and identification in experimental and historical contexts. In M. Gold (Ed.), A new outline of social psychology (pp. 235-246). Washington, DC: American Psychological Association.

Roseman, M. (2002). The villa, the lake, the meeting: Wannsee and the final solution. London: Penguin Press.

Rosenbaum, M. (1983). Compliance. In M. Rosenbaum (Ed.), Compliant behavior: beyond obedience to authority (pp. 25-49). New York: Human Sciences Press, Inc. 
Rosenhan, D. (1969). Some origins of concern for others. In P. Mussen, J. Langer, \& M. Covington (Eds.), Trends and issues in developmental psychology (pp. 134153). New York: Holt, Rinehart \& Winston.

Rossino, A. (2003). Hitler strikes Poland: blitzkrieg, ideology, and atrocity. Lawrence, KS: University Press of Kansas.

Rubenstein, R. (1978). The cunning of history: the Holocaust and the American future. New York: Harper Collins.

Rubenstein, R. L., \& Roth, J. K. (1987). Approaches to Auschwitz: The Holocaust and its legacy. Atlanta, GA: John Knox Press.

Russell, N. J. C. (2000). Firearms and homicide: the influence of the weapon substitution hypothesis on the American gun control debate. Unpublished masters dissertation, University of Victoria University of Wellington, Wellington, New Zealand.

Russell, N. J. C., \& Gregory, R. (2005). Making the undoable doable: Milgram, the Holocaust and modern government. American Review of Public Administration, 35(4), 327-349.

Sabini, J., Siepmann, M., \& Stein, J. (2001a). The really fundamental attribution error in social psychological research. Psychological Inquiry, 12(1), 1-15.

Sabini, J., Siepmann, M., \& Stein, J. (2001b). Authors' response to commentaries. Psychological Inquiry, 12(1), 41-48.

Sabini, J., \& Silver, M. (1982). Moralities of everyday life. New York: Oxford University Press.

Saltzman, A. L. (2000). The role of the obedience experiments in Holocaust studies: the case of renewed visibility. In T. Blass (Ed.), Obedience to authority: current perspectives on the Milgram paradigm (pp. 125-143). Mahwah, NJ: Lawrence Erlbaum Associates Publishers.

Schachter, S. (1959). The psychology of affiliation: experimental studies of the sources of gregariousness. London: Tavistock.

Schlenker, B. R., \& Forsyth, D. R. (1977). On the ethics of psychological research. Journal of Experimental Social Psychology, 13(4), 369-396.

Schleunes, K. A. (1970). The twisted road to Auschwitz: Nazi policy toward German Jews, 1933-1939. Chicago: University of Illinois Press.

Schwan, G. (2001). Politics and guilt: the destructive power of silence. London: University of Nebraska Press.

Scott, D. S. (1980). Pain endurance induced by a subtle social variable (demand) and the 'reverse Milgram effect'. British Journal of Social and Clinical Psychology, 19(2), 137-139.

Scott, J. (1990). A matter of record: documentary sources in social research.

Cambridge, United Kingdom: Polity Press. 
Shuler, H. (1982). Ethical problems in psychological research. New York: Academic Press.

Seibel, W. (2005). Restraining or radicalizing? Division of labor and persecution effectiveness. In G. D. Feldman, \& W. Seibel (Eds.), Networks of Nazi persecution: bureaucracy, business, and the organization of the Holocaust (pp. 340-360). New York: Berghahn Books.

Sereny, G. (1974). Into that darkness: from mercy killing to mass murder. London: Pimlico.

Sereny, G. (1995). Albert Speer: his battle with truth. New York: Alfred A. Knopf.

Sereny, G. (2000). The German trauma: experiences and reflections 1938-2000. London: Allen Lane.

Shalit, B. (1988). The psychology of conflict and combat. New York: Praeger.

Shanab, M. E., \& Yahya, K. A. (1977). A behavioural study of obedience in children. Journal of Personality and Social Psychology, 35(7), 530-536.

Shandler, J. (2001). The man in the glass box: watching the Eichmann trial on American television. In B. Zelizer (Ed.), Visual culture and the Holocaust (pp. 91110). New Brunswick, NJ: Rutgers University Press.

Sheridan, C. L., \& King, R. G. (1972). Obedience to authority with an authentic victim. Proceedings of the American Psychological Association $\left(80^{\text {th }}\right.$ Annual Convention), 7, 165-166.

Slater, L. (2004). Opening Skinner's box: great psychological experiments of the Twentieth Century. New York: W. W. Norton \& Company.

Snow, C. P. (1961). The moral un-neutrality of science. Science, 133(3448), 255-262.

Specktor, S. (1993). Killing in the gas vans behind the front. In E. Kogon, H. Langbein, \& A. Rückerl (Eds.), Nazi mass murder: a documentary history of the use of poison gas (pp. 52-72). New Haven, CT: Yale University Press.

Staub, E. (1989). The roots of evil: the origins of genocide and other group violence. Cambridge, United Kingdom: Cambridge University Press.

Steinbeck, J. (1993). The grapes of wrath. London: Everyman's Library.

Steiner, J. M. (1980). The SS yesterday and today: a sociopsychological view. In J. E. Dimsdale (Ed.), Survivors, victims, and perpetrators: essays on the Nazi Holocaust. New York: Hemisphere Publications.

Stern, F. (1996). The Goldhagen controversy: one nation, one people, one theory. Foreign Affairs, 75(6), 128-138. 
Streit, C. (1994). Wehrmacht, Einsatzgruppen, Soviet POWs and anti-Bolshevism in the emergence of the final solution. In D. Cesarani (Ed.), The final solution: origins and implementation (pp. 103-118). New York: Routledge.

Strudler, A., \& Warren, D. E. (2001). Authority, heuristics, and the structure of excuses. In J. M. Darley, D. M. Messick, \& T. R. Tyler (Ed.), Social influences on ethical behavior in organizations (pp. 155-173). Mahwah, NJ: Lawrence Erlbaum Associates Publishers.

Takooshian, H. (2000). How Stanley Milgram taught about obedience and social influence. In T. Blass (Ed.), Obedience to authority: current perspectives on the Milgram paradigm (pp. 9-24). Mahwah, NJ: Lawrence Erlbaum Associates Publishers.

Tarnow, E. (2000). Self-destructive obedience in the airplane cockpit and the concept of obedience optimization. In T. Blass (Ed.), Obedience to authority: current perspectives on the Milgram paradigm (pp. 111-123). Mahwah, NJ: Lawrence Erlbaum Associates Publishers.

Tavris, C. (1974a). The frozen world of the familiar stranger. Psychology Today, 8(1), 71-73, 76-79, 80.

Tavris, C. (1974b). A sketch of Stanley Milgram: a man of 1,000 ideas. Psychology Today, 8(1), 74-75.

Tavris, C. (1974c). The force of authority. Psychology Today, 8(1), 76-77.

Tedeschi, J. T., Lindskold, S., \& Rosenfeld, P. (1985). Introduction to social psychology. St. Paul, MN: West Publishing Company.

Thad Allen, M. (2005). Introduction: a bureaucratic Holocaust - toward a new consensus. In G. D. Feldman, \& W. Seibel (Eds.), Networks of Nazi persecution: bureaucracy, business, and the organization of the Holocaust (pp. 259-268). New York: Berghahn Books.

Thorne, S. E. (1998). Ethical and representational issues in qualitative secondary analysis. Qualitative Health Research, 8(4), 547-555.

Tilker, H. A. (1970). Socially responsible behavior as a function of observer responsibility and victim feedback. Journal of Personality and Social Psychology, 14(2), 95-100.

Traverso, E. (1999). Understanding the Nazi genocide: Marxism after Auschwitz. London: Pluto Press.

van Krieken, R. (1998). Norbert Elias. London: Routledge.

Waller, J. (2002). Becoming evil: how ordinary people commit genocide and mass killing ( $2^{\text {nd }}$ Ed.). New York: Oxford University Press.

Watson, P. (1978). War on the mind: the military uses and abuses of psychology. New York: Basic Books. 
Wellers, G. (1993). The two poison gases. In E. Kogon, H. Langbein, \& A. Rückerl

(Eds.), Nazi mass murder: a documentary history of the use of poison gas (pp. 205209). New Haven, CT: Yale University Press.

Westermann, E. B. (2005). Hitler's police battalions: enforcing racial war in the east. Lawrence, KS: University Press of Kansas.

Wheler, H. (1998). Like a thorn in the flesh. In R. R. Shandley (Ed.), Unwilling

Germans? The Goldhagen debate (pp. 93-104). Minneapolis, MN: University of Minnesota Press.

Wilhelm, H. (1997). "Inventing” the Holocaust for Latvia. In Z. Gitelman (Ed.), Bitter legacy: confronting the Holocaust in the USSR (pp. 104-122). Bloomington, IN: Indiana University Press.

Wilson, J. Q. (1993). The moral sense. New York: The Free Press.

Wistrich, R. S. (2001). Hitler and the Holocaust: how and why the Holocaust happened. London: Weidenfeld and Nicolson.

Zangwill, N. (2003). Perpetrator motivation: some reflections on the Browning/Goldhagen debate. In E. Garrard, \& G. Scarre (Eds.), Moral philosophy and the Holocaust (pp. 89-102). Burlington, VT: Ashgate Publishing Company.

Zimbardo, P., Haney, C., Banks, W.C., \& Jaffe, D. (1973, April 8). The mind is a formidable jailer: a pirandellian prison. The New York Times Magazine, p. 38.

Zimbardo, P.G. (1974). On 'obedience to authority'. American Psychologist, 29(7), 566567. 